\title{
ULTRASONIC INTERROGATION OF OIL SANDS TAILINGS DURING SEDIMENTATION
}

\author{
by
}

Hirlatu Yose Peruga

A thesis submitted to the Faculty of Graduate and Postdoctoral Affairs in partial fulfillment of the requirements for the degree of

Master of Applied Science

in

Environmental Engineering

Carleton University

Ottawa, Ontario

(C) 2021, Hirlatu Yose Peruga 


\section{Abstract}

The ultrasonic pulse velocity (UPV) method has been widely used as a nondestructive testing (NDT) in Civil Engineering to evaluate the quality of concrete, soils, and other materials. However, this method has never been used to evaluate the properties of the oil sands tailings. The oil sands tailings have slow consolidation, low density and stiffness, which often lead to the continuous accumulation of the FFT; leading to reclamation problem due to lack of strength to support the FFT . The main objective of this thesis is to assess whether the UPV method can be used as an on-site measurement application in the oil sand tailings in order to detect changes and trends in tailings' properties such as strength, density and structuration as a function of time. The ultrasonic equipment is calibrated, verified, and then used to capture P-waves and S-waves when the waves interact with the column filled with flocculated fluid fine tailings (fFFT). To increase the reliability of the UPV test, special "holders" were designed and fabricated to improve the stabilization of the piezoelectrical transducers. Inferred wave velocities and changes in wave attenuation determined from the p-wave data showed correlations with the expected changes in density in the column; data using s-wave or p-wave-s-wave combinations did not show useful trends. 


\section{Dedication}

To my parents, sister and brother

I cannot thank you enough for your countless supports, understanding and

believing in me. I am grateful for the sacrifices you made to get me where I am today.

Coming to Canada to further my education would have only been a dream without you.

To my grandma,

You will always be remembered. Thank you for watching over me and I hope I have made you proud. 


\section{Acknowledgements}

First and foremost, I would like to express my sincerest gratitude to Professor.

Paul Simms for giving me a chance to be his master's student. I would not have been able to get to where I am today without his support and encouragement. Thank you Professor Paul Simms for having so much patience with me while trying to explain things that I do not understand.

Next, I would also like to express my sincerest gratitude to Professor. Giovanni Cascante for giving me an opportunity to work under his guidance at the University of Waterloo. This thesis would not have been completed without his guidance and patience. His dedication towards this research has inspired me.

I would also like to express my appreciation to the staff members of the Department of Civil and Environmental Engineering at the University of Waterloo, especially Mark Merlau, for his assistance in equipment and material. Your hard work does not go unseen.

In addition, my gratitude is extended to all to my research group members in the NDT lab, in particular Hongwei Liu and Cristobal Lara. I am also thankful to them for making my time in Waterloo more enjoyable.

I would also like to express my appreciation to the Natural Science and Engineering Research Council of Canada (NSERC) and the Canada's Oil Sands Innovation Alliance (COSIA) for providing financial support throughout this project. 


\section{Table of Contents}

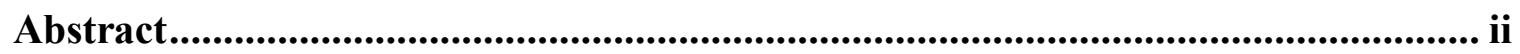

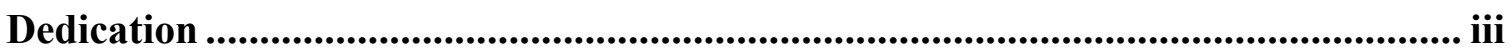

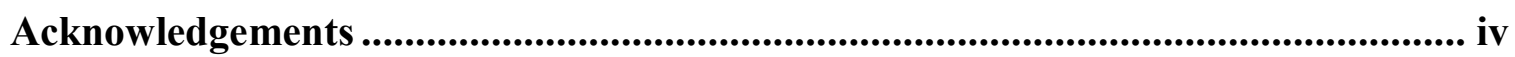

Table of Contents...................................................................................................................v

List of Tables ..................................................................................................................... ix

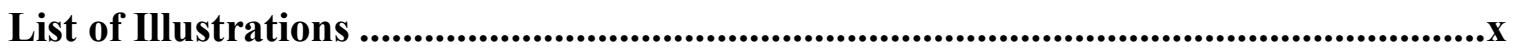

List of Appendices ............................................................................................................. xvii

Chapter 1: Introduction .............................................................................................................1

1.1 The Objective and Scope of the Research Work ..........................................5

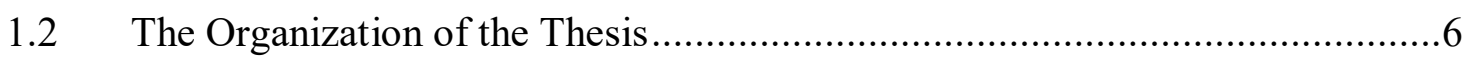

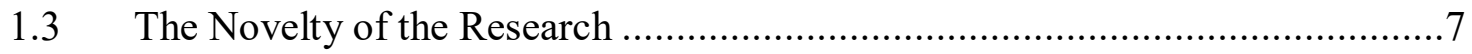

Chapter 2: Literature Review .............................................................................................8

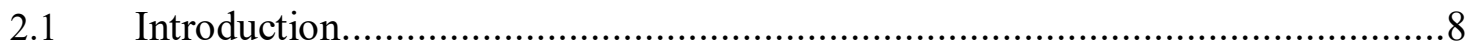

2.2 Ultrasonic Pulse Velocity (UPV) Method ..................................................

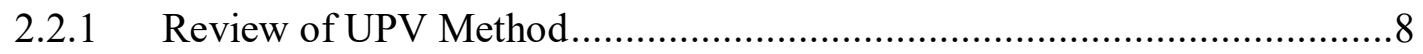

2.2.2 Amplitude, Frequency and Wavelength..................................................10

2.2.3 Test Equipment and Transducer Arrangement........................................11

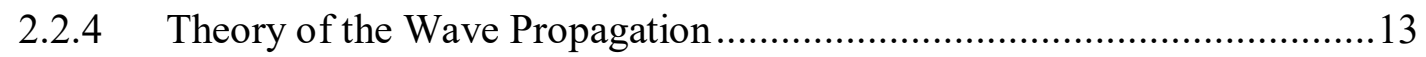

2.2.5 Relationship between Velocity and Elastic Moduli..................................17

2.2.6 Factor Affecting Modulus of Elasticity of Soil ......................................18

2.2.6.1 Soil Particles Density ................................................................18

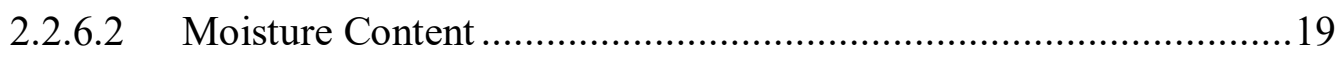


2.2.6.3 Temperature …................................................................... 19

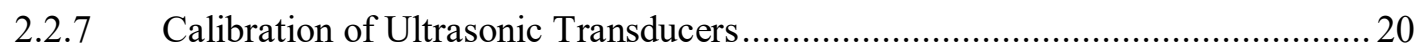

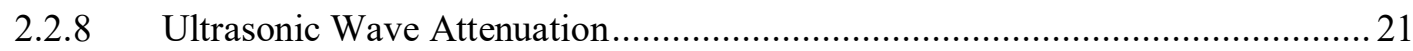

2.2.9 Application of the UPV Method on the Cemented Paste Backfill (CPB) ...........22

2.2.10 Advantanges and Disadavantages of the UPV Method ...................................24

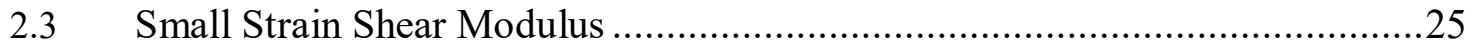

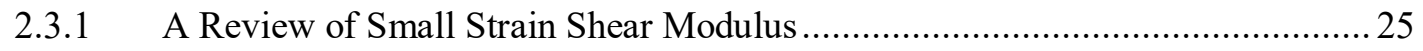

2.3.1.1 Influences of Effective Stress and Void Ratio on Gas...........................2 27

2.3.2 Seismic Test for Quality Control and Assurance ................................................ 31

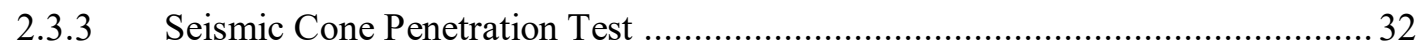

2.3.3.1 Seismic Cone Penetration Testing Procedure .......................................... 33

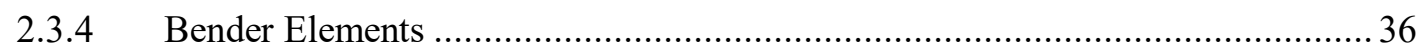

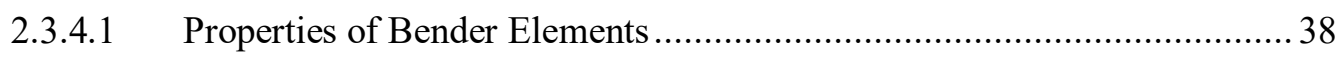

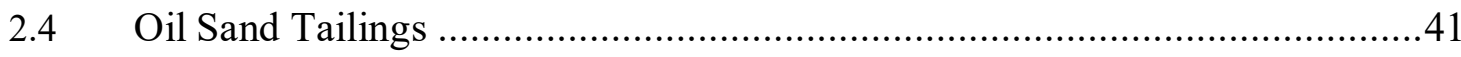

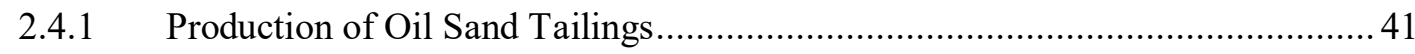

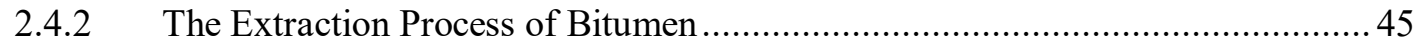

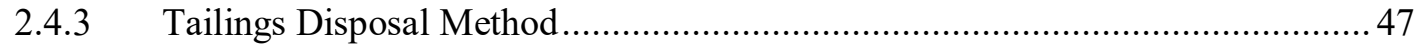

2.4.4 Technologies for the Treatment of Fluid Fine Tailings .................................. 48

2.4.4.1 Physical/Mechanical Processes ........................................................ 48

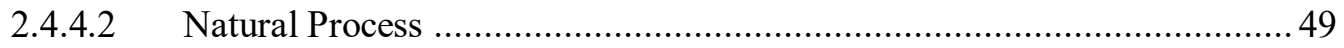

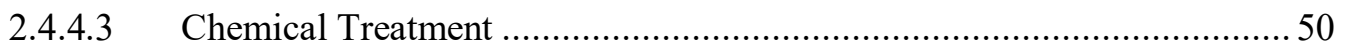

2.4.4.4 Mixture/Co-disposal ............................................................. 51

Chapter 3: Material Characterization and Experimental Procedures .......................52

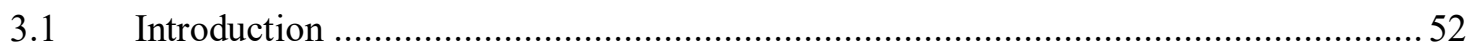




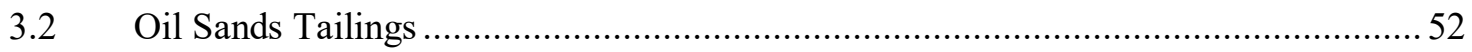

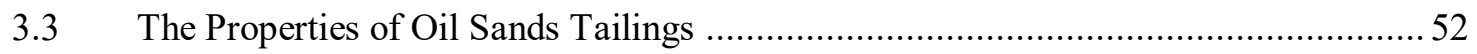

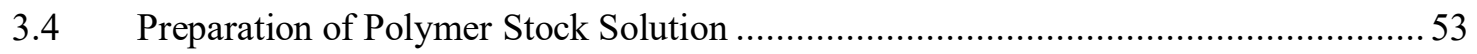

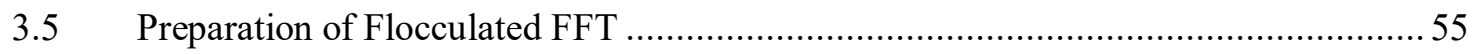

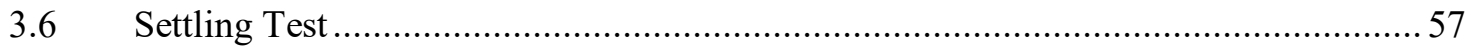

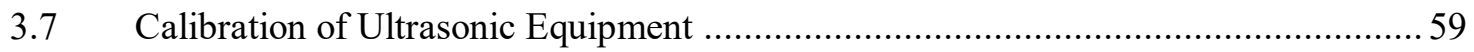

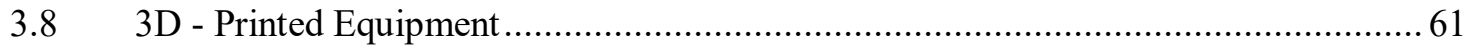

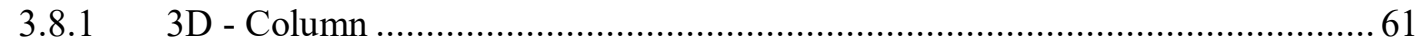

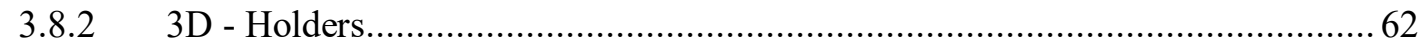

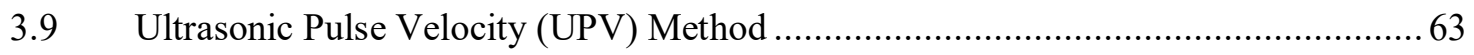

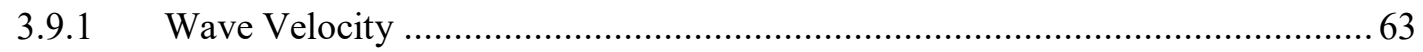

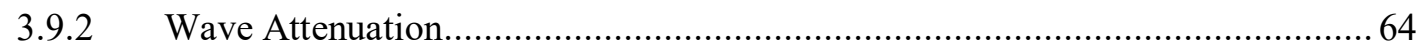

3.10 Ultrasonic Pulse Velocity (UPV) Method Experiment Setup ................................. 65

Chapter 4: Results and Discussion ....................................................................................68

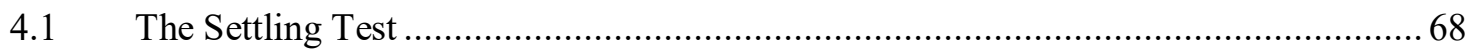

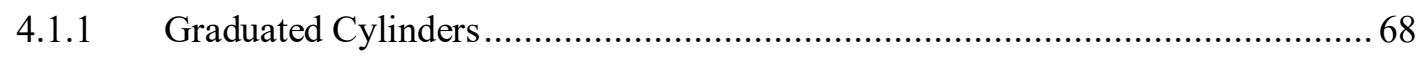

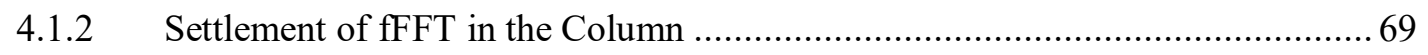

4.2 Gravimetric Water Content at Various Height of the Column ............................... 70

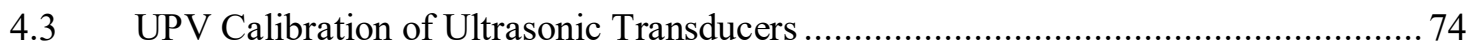

4.3.1 The calibration of ultrasonic transducer on reference standard bars .................. 74

4.3.2 The calibration of ultrasonic transducer in the empty column .......................... 76

4.3.3 The calibration of ultrasonic transducer in the column filled with water ............ 80

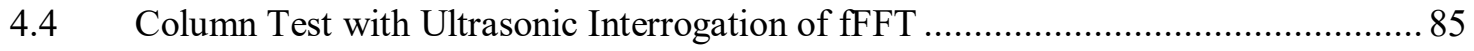

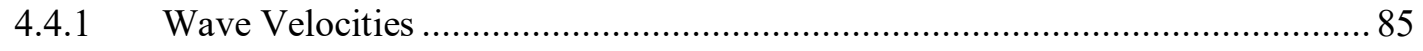

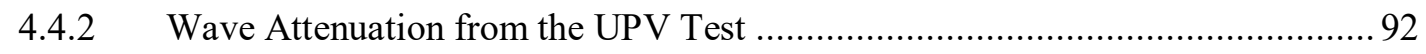

4.4.3 The Density Obtained from Velocity using a Constant Constrained Modulus .. 100 
Chapter 5: Conclusion and Recommendation ..............................................................105

Bibliography or References ............................................................................................108

Appendices.........................................................................................................................115

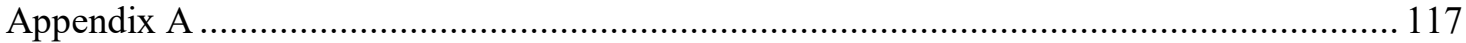

A.1 Geotechnical Characterization Test Resutls ………………………………....... 117

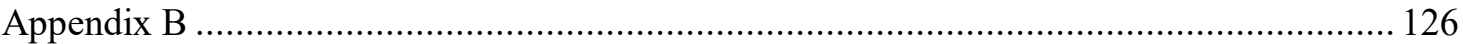

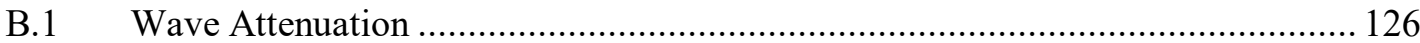

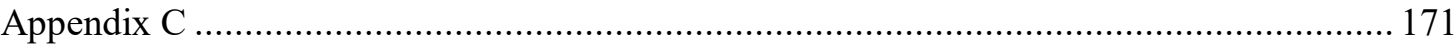

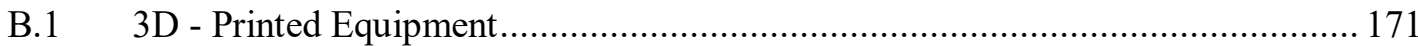




\section{List of Tables}

Table 1 Geotechnical properties of unamended FFT (compared with other FFTs)

(Salam, 2020) .53

Table 2 Velocity measurement obtained from the empty column using $\mathrm{p}$-wave transducers with diameter of the column of $110 \mathrm{~mm}$ .77

Table 3 Velocity measurement obtained from the empty column using s-wave transducers with length of the aluminum bar of $130 \mathrm{~mm}$ 80

Table 4 Velocity measurement obtained from the column filled with water using p-wave transducers with length of the aluminum bar of $130 \mathrm{~mm}$ 82

Table 5 Velocity measurement obtained from the column filled with water using swave transducers with length of the aluminum bar of $130 \mathrm{~mm}$ 84

Table 6 Pore water chemistry of untreated FFT, Day-7 fFFT, and Day 42 fFFT samples

(Salam, 2020)

Table 7 MBI test data and percentage of the clay-sized fraction of unamended FFT

(Salam, 2020)

Table 8 Non-Clay minerals in the FFT samples (from the XRD analysis) (Salam, 2020).

Table 9 Clay minerals in the FFT samples (from the XRD analysis) (Salam, 2020).....125 


\section{List of Figures}

Figure 1 Fluid tailings pond volume growth since 1968 (McNeil, 2017) .....................2

Figure 2 The distance and arrival time of the UPV method (Irfan, 2019) .....................9

Figure 3 Wave with (a) low amplitude and (b) high amplitude ............................... 10

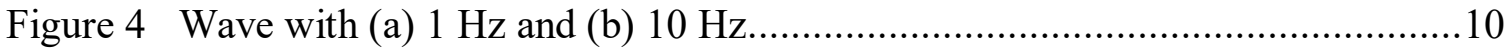

Figure 5 Schematic diagram of pulse velocity test circuit (Malhotra, 2003)................12

Figure 6 Arrangement of ultrasonic transducers: (a) Direct transmission (b) Semi-direct transmission (c) Indirect transmission (Ndagi et al., 2019) ........................................13

Figure 7 The movement of different types of wave

(http://www.geo.utep.edu/kidd/eqwave.html)................................................... 14

Figure 8 Wave propagation modes in a thin structure. (a) Symmetric mode (extension)

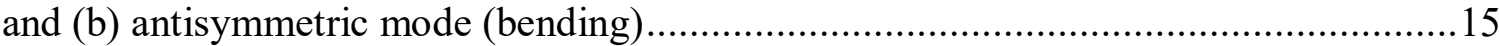

Figure 9 Dispersion curves of Lamb waves in a $2 \mathrm{~mm}$ thick aluminum plate: (a) phase

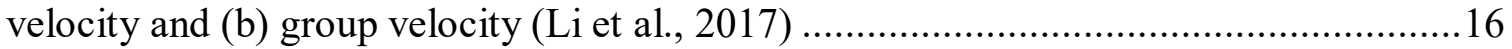

Figure 10 Variation of elastic modulus with moisture contents (Eun et al., 2012).........19

Figure 11 Elastic modulus vs temperature (Maier, 2020) ….................................20

Figure 12 Reference standard bars (https://www.nde-ed.org) ..................................21

Figure 13 UPV development of CPB specimens with cement to tailings ratio of (a) $1 / 10$

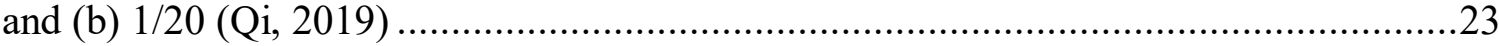

Figure 14 Relationship between UCS and UPV values of CPB specimen (Qi, 2019)....23

Figure 15 Shear strain versus shear stress response curve (Budhu, 1999) ...................25

Figure 16 The typical variation of different moduli with different strain for soils. $\mathrm{K}$ ' is the bulk modulus and E' is the elastic modulus (Budhu, 1999).....................................26 
Figure 17 In situ shear wave velocity, against vertical effective stress (L'Heureux et al., 2017) 30

Figure 18 Void ratio, against $\mathrm{G}_{\max }(\mathrm{L}$ 'Heureux et al., 2017).................................. 31

Figure 19 The schematic diagram of the SCPT (Lee et al, 2018) ..............................33

Figure 20 Schematic of SCPT and the shear-wave source is placed perpendicular to the cone (Robertson et al, 1986) .35

Figure 21 An example outcome of seismic test - a record of vibration in the $X$ direction

(Baginska, 2013).) 36

Figure 22 Schematic diagram of the BE system (Camacho-Tauta, 2011).....................37

Figure 23 Bender element probes for the unconfined test (Chan, 2006)......................38

Figure 24 Bender elements: a) parallel and b) series (Dyvik, 1985) .........................39

Figure 25 Transmitter and receiver time chart (Camacho-Tauta, 2011) ......................40

Figure 26 Alberta's three oil sands areas (AEUB, 2007) ......................................42

Figure 27 (a) The picture of Athabasca oil sands area in 1984 and (b) the picture of Athabasca oil sands area in 2016 (Nasa Earth Observatory, 2019). ............................42

Figure 28 Arrangement of oil sand particles (ARC Tailings, 1977) .........................43

Figure 29 Management of Tailings Ponds (www.oilsandsmagazime.com) .................44

Figure 30 The schematic of Clark Hot Water Extraction Process (Chalaturnyk, R.J. et

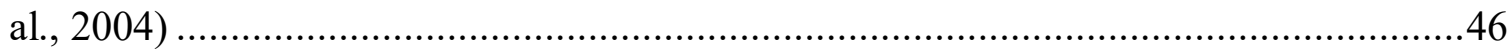

Figure 31 The effect of $\mathrm{NaOH}$ on release of surfactants and hydrolysis sands. a) Low $\mathrm{pH}$

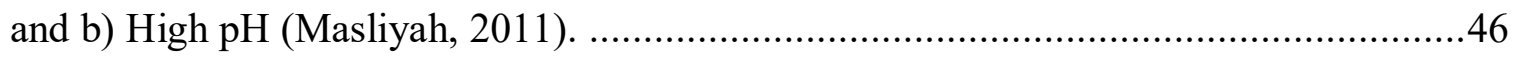

Figure 32 Oil sands tailings basin (Fine Tailings Fundamental Consortium, 1995)......47

Figure 33 Bridging formation of fine tailings of FFT (adapted from Kitchener, 1972)..51 
Figure 34 Preparation of the polymer stock solution using Jar tester .54

Figure 35 The mixing of the of the polymer stock solution with the FFT .56

Figure 36 The settling test performed on the graduated cylinder, each with a height of $16.8 \mathrm{~cm}$, with different polymer dosages. .58

Figure 37 Standard calibration reference steel and PVC bars .60

Figure 38 Calibration test setup: (a) face to face and (b) reference standard bar (Fartosy, 2018) .60

Figure 39 Column's plates. .62

Figure 40 The embedded aluminum bars of the column: (a) side view and (b) top view

Figure 41 The 3D - holders attached to the columns .63

Figure 42 Ultrasonic pulse velocity (UPV) set up .66

Figure 43 Ultrasonic transducers: (a) $54 \mathrm{kHz}$ P-wave transducers and (b) $50 \mathrm{kHz}$ S-wave transducers .66

Figure 44 The settlement rate vs time obtained from the fFFT conducted on the graduated cylinder for the 14-day period. .68

Figure 45 The settlement rate vs time obtained from the fFFT conducted on the 3D -

Column for the 46-day period (600-PPM polymer dosage)..

Figure 46 The elevation of the fFFT as function of time (600-PPM polymer dosage)...70

Figure 47 Gravimetric water content at various height of the column (testing conducted

2 month. .70

Figure 48 The settlement rate vs time at transducer estimated by modeling .................72

Figure 49 Modelled vs measured settlement......................................................72 
Figure 50 Actual final density distribution vs expected distribution from a fitted compressibility curve .73

Figure 51 Calibration results obtained from the steel and PVC (a) using compressional transducers and (b) shear transducers .75

Figure 52 Wave signal of empty column obtained by placing $\mathrm{p}$-wave transducers at different section of the cylinder's plate: (a) Bottom, (b) Middle and (c) Top. .76 Figure 53 Wave signal of empty column obtained by placing s-wave transducers at different section of the cylinder's plate: (a) Bottom, (b) Middle and (c) Top. .78 Figure 54 Wave signal of column filled with water obtained by placing p-wave transducers at different section of the aluminum bar: (a) Bottom, (b) Middle and (c) Top

Figure 55 Wave signal of column filled with water obtained by placing s-wave transducers at different section of the aluminum bar: (a) Bottom, (b) Middle and (c) Top

Figure 56 Waveforms at the specific times, showing the selection of arrival times used to calculate wave velocity (compressional transmitter/receiver). .86

Figure 57 The wave velocity as a function of time (compressional transmitter/receiver)

Figure 58 Waveforms at the specific times, showing the selection of arrival times used to calculate wave velocity (compressional transmitter/shear \#1 receiver)..

Figure 59 The wave velocity as a function of time (shear transmitter/compressional \#1 receiver) 
Figure 60 Waveforms at the specific times, showing the selection of arrival times used to calculate wave velocity (Compressional transmitter/shear \#2 receiver).. .88

Figure 61 The wave velocity as a function of time (shear transmitter/receiver)..... .88

Figure 62 Waveforms at the specific times, showing the selection of arrival times used to calculate wave velocity (shear transmitter/receiver).

Figure 63 The wave velocity as a function of time (shear transmitter/receiver)

Figure 64 Waveforms at the specific times, showing the selection of arrival times used to calculate wave velocity (shear transmitter/compressional \#1 receiver)...

Figure 65 The wave velocity as a function of time (shear transmitter/compressional \#1 receiver)

Figure 66 Waveforms at the specific times, showing the selection of arrival times used to calculate wave velocity (shear transmitter/compressional \#2 receiver).

Figure 67 The wave velocity in the function of time (shear transmitter/compressional \#2 receiver)

Figure 68 Without Window (compressional transmitter/receiver): (a) Time signal, (b) FFT, (c) Area under the curve in the function of time

Figure 69 Window 1 (compressional transmitter/receiver): (a) Time signal, (b) FFT, (c) Area under the curve in the function of time .96 Figure 70 Window 2 (compressional transmitter/receiver): (a) Time signal, (b) FFT, (c)

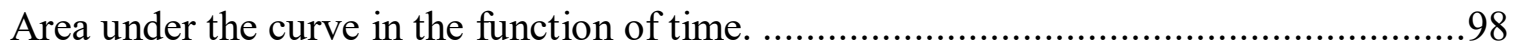

Figure 71 Fast Fourier transform of Water. .................................................. 100

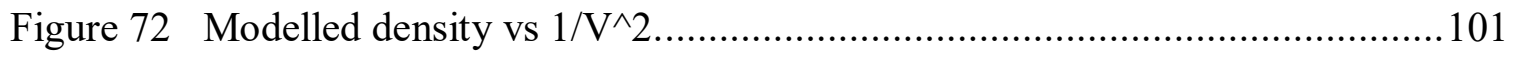

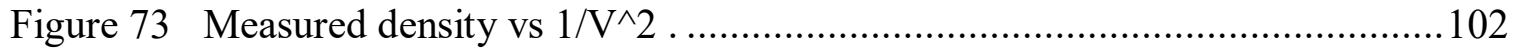




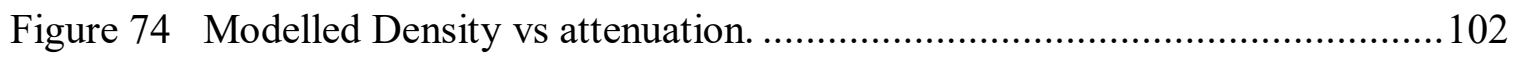

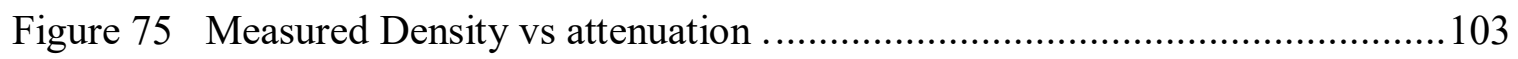

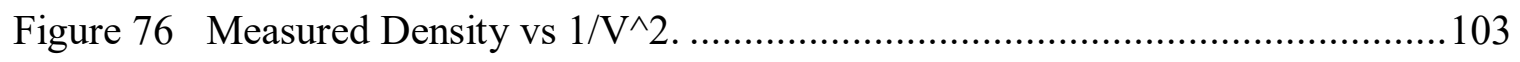

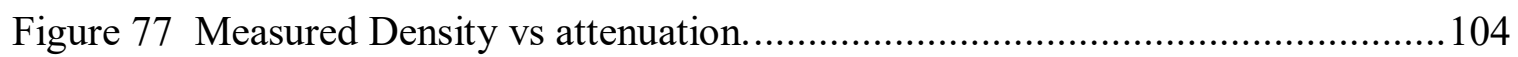

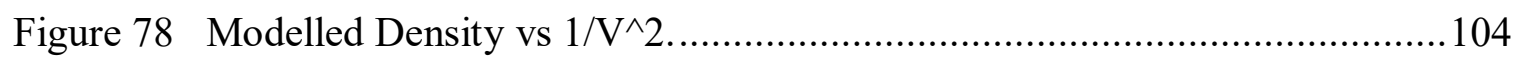

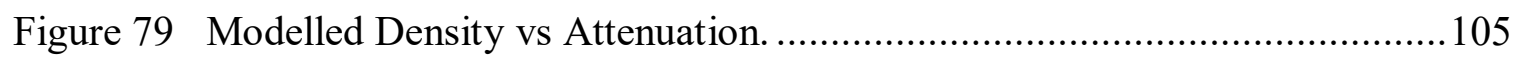

Figure 80 Particle size distribution of FFT from wet sieve and the hydrometer analyses

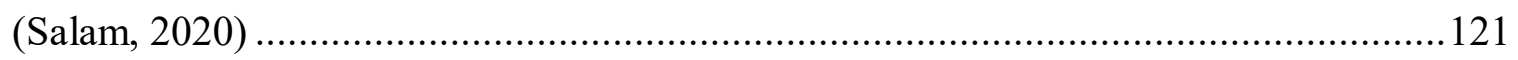

Figure 81 Without window (compressional transmitter/shear \#1 receiver): (a) Time signal, (b) FFT, (c) Area under the curve in the function of time ............................. 127

Figure 82 Window 1 (compressional transmitter/shear \#1 receiver): (a) Time signal, (b)

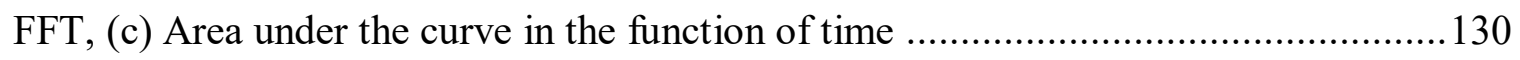

Figure 83 Window 2 (compressional transmitter/shear \#1 receiver): (a) Time signal, (b)

FFT, (c) Area under the curve in the function of time

Figure 84 Without window (compressional transmitter/shear \#2 receiver): (a) Time

signal, (b) FFT, (c) Area under the curve in the function of time ............................. 136

Figure 85 Window 1 (compressional transmitter/shear \#2 receiver): (a) Time signal, (b)

FFT, (c) Area under the curve in the function of time .......................................... 139

Figure 86 Window 2 (compressional transmitter/shear \#2 receiver): (a) Time signal, (b)

FFT, (c) Area under the curve in the function of time ........................................... 142

Figure 87 Without window (shear transmitter/compressional \#1 receiver): (a) Time

signal, (b) FFT, (c) Area under the curve in the function of time .............................. 145 
Figure 88 Window 1 (shear transmitter/compressioanl \#1 receiver): (a) Time signal, (b) FFT, (c) Area under the curve in the function of time 148

Figure 89 Window 2 (shear transmitter/compressional \#1 receiver): (a) Time signal, (b) FFT, (c) Area under the curve in the function of time 151

Figure 90 Without window (shear transmitter/compressional \#2 receiver): (a) Time signal, (b) FFT, (c) Area under the curve in the function of time 154

Figure 91 Window 1 (shear transmitter/compressioanl \#2 receiver): (a) Time signal, (b)

FFT, (c) Area under the curve in the function of time

Figure 92 Window 2 (shear transmitter/compressional \#2 receiver): (a) Time signal, (b)

FFT, (c) Area under the curve in the function of time

Figure 93 Without window (shear transmitter/ receiver): (a) Time signal, (b) FFT, (c) Area under the curve in the function of time

Figure 94 Window 1 (shear transmitter/shear receiver): (a) Time signal, (b) FFT, (c) Area under the curve in the function of time 166

Figure 95 Window 2 (shear transmitter/shear receiver): (a) Time signal, (b) FFT, (c) Area under the curve in the function of time 169

Figure 96 The 3D - holders attached at the bottom of the column 


\section{List of Abbreviations}

CPB - Cemented paste backfill

CPT - Cone penetration test

CT - Consolidate tailings

fFFT - Flocculated fluid fine tailings

FFT - Fluid fine tailings

CHWP - Clark hot water process

GWC - Gravimetric water content

MBI - Methylene blue index

NAIT - Northern Alberta Institute of Technology

NDT - Non-destructive testing

UPV - Ultrasonic pulse velocity

SCPT - Seismic cone penetration test

TSF - Tailings storage facility

XRD - X-ray diffraction analysis 


\section{Chapter 1: Introduction}

This thesis is concerned with measurement of oil sands tailings properties using ultrasonics. To appreciate the potential utility of this work, the reader must understand the problems posed by generation of tailings in the oil sands industry. The term "oil sands", refer to the stratigraphic units in Northern Alberta, which contain substantial quantities of bitumen. Some of these deposits are extractable by surface mining, the byproduct of which are fluid fine tailings.

Currently, the extraction process of bitumen in the oil sand industries is usually performed by using the Clark Hot Water Process (CHWP) method and this technique was initially developed by Karl Clark in 1920. This technique involves mixing hot water and $\mathrm{NaOH}$ with oil sands in order to liberate the bitumen (Shaw, 1996). The bitumen can be then extracted through floatation and the extracted bitumen is upgraded into synthetic crude oil (SCO). Once the bitumen is upgraded into $\mathrm{SCO}$, it can then be refined into products such as gasoline, fuel oil, ethylene as well as propylene (Institute for Oil Sands Innovation, 2016). In 2019, the oil sands accounted for $63 \%$ of Canada's oil production or 2.95 million barrels per day (NRC, 2020).

The biggest challenge faced by most oil sands industries in tailings management is that oil sands tailings require a long period of time in order to reach full consolidation. Poor consolidation properties, mainly the low hydraulic conductivity, is the main reasons that lead to the generation of massive volume of tailings. Figure 1 illustrates the continuous growth of volume of tailings ponds since oil sands mining operation started in 1967. 
The extraction process of bitumen generates a large volume of tailings, which is the combination of residual soil material from the original body (sand plus clay minerals), and the water and chemical used in the extraction process. The tailings generated from extracted are typically transported and stored in the large engineered dam and dykes facilities also known as tailings storage facility (TSF). The sand fraction settles out, but the silt size particles and clay minerals remain in suspension, slowly settling to achieve approximate $30 \%$ (weight of solid/weight total) solid content or about $230 \%$ gravimetric water content. This suspension of fines and water is also known as fluid fine tailings (FFT) during the deposition (Siddique et al., 2014; Thompson et al., 2017).

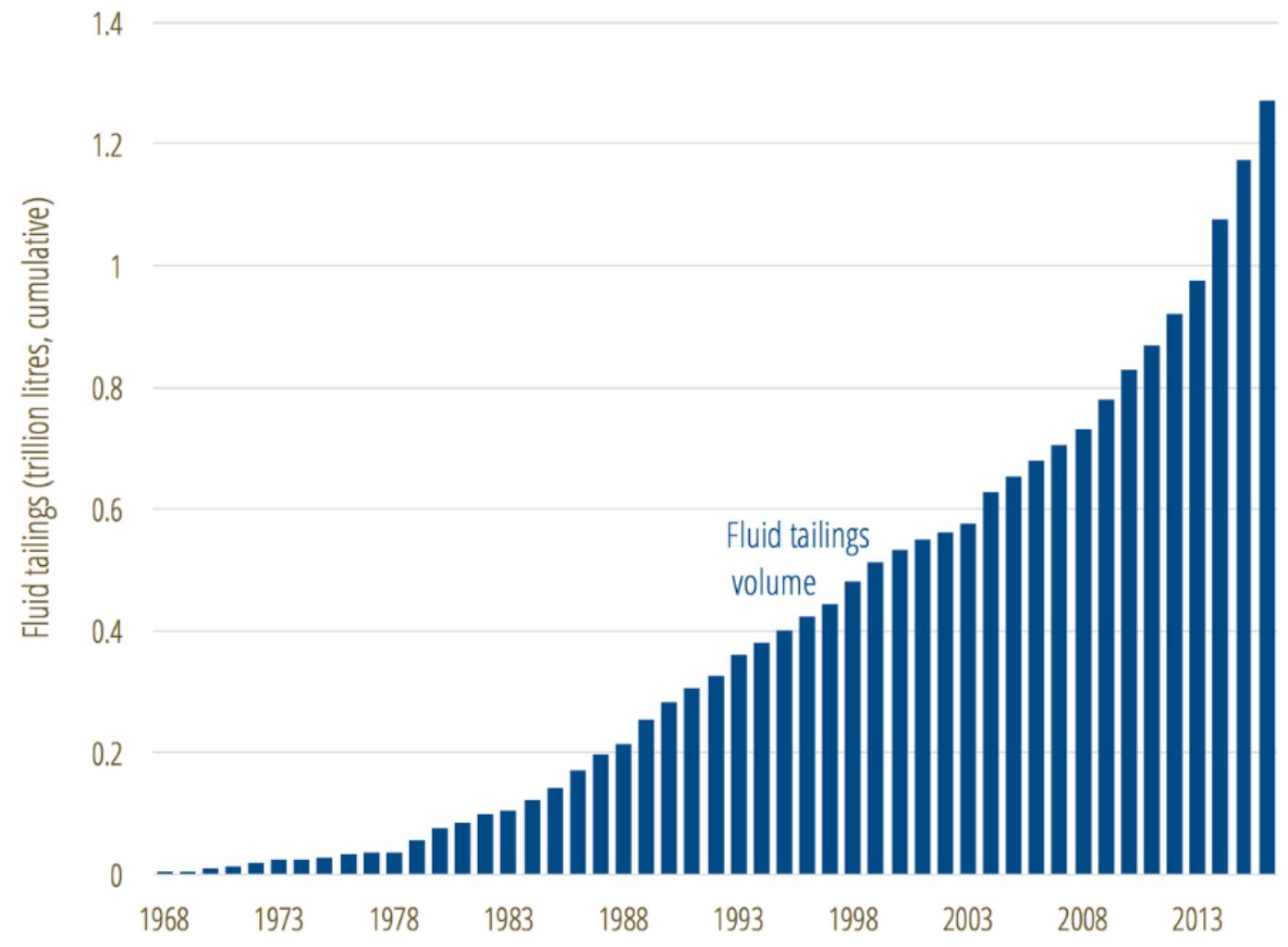

Figure 1: Fluid tailings pond volume growth since 1968 (McNeill, 2017). 
In response to the problem of poor consolidation of FFT and concern involving tailings dam failures, mine operators have implemented a range of technologies for dewatering the tailings prior to deposition such as filtered tailings, in-line flocculation, electrical and centrifuge tailings. However, these technologies do not dewater the tailings sufficiently to achieve enough strength to support reclamation goals, immediately after deposition. Operations relay on ongoing dewatering, primarily through consolidation, to achieve sufficiently dense and strong tailings deposits, to allow for reclamation into terrestrial and aquatic landforms. The consolidation process, however, takes considerable amount of time. Processes such as ageing may be important over such timescales, and render accurate predictions of dewatering somewhat complex. Therefore, on-site measurement of the stiffness of tailings deposits, is important both to check if deposits are on their expected trajectories towards reclamation, and to aid efficient laboratory studies on aging and related phenomena.

This thesis explores the potential uses of ultrasonic pulse velocity (UPV) and related ultrasonic methods to detect changes and trends in the properties of oil sands tailings during dewatering. The UPV method is one of the most popular non-destructive testing commonly used in civil engineering to evaluate the integrity of concrete or rock and to detect the internal cracking and presence of voids. The UPV method involves determining the travel time for the ultrasonic pulse to propagate through a material medium. The travel time of the ultrasonic pulses rely on the density and elastic properties of the sample. Knowing the travel time, the velocity can simply calculated by dividing the travel time with the distance between the transmitting and receiving transducers. Thus, the changes of geotechnical properties can be evaluated using known relationship 
between velocities and mechanical properties. The UPV method is well-known for its several advantages such as it uses mechanical waves resulting no damage to the sample during testing which allows the core samples to be tested repeated at the same spot and it can be also used to analyze the changes in internal structure over a long period of time without the need to destroy the sample. Thus, the number of samples required is very minimal.

This paper investigates the use of UPV method to generate ultrasonic waves such as wave velocity and wave attenuation to interrogate FFT samples in the laboratory on a different types of tailings, notably cemented paste backfill (CPB) for hard rock mines. Previous study has also found that the increase in sample length can lead to the increase in void ratio or micro cracks, resulting in a decrease in wave velocity (Karaman et al., 2010). FFT, however, even after the treatment, are considerably softer material than cemented tailings. Despite the use of UPV method in numerous studies to determine the geotechnical properties of $\mathrm{CPB}$, there is still no available data found on the use of wave velocity and wave attenuation to identify the properties change in FFT.

Understanding the changes in properties of tailings such as strength, density and structuration are important to the success of the optimization of tailings management. Therefore, the possibility exists of using the UPV method was explored in this study to monitor changes in low-strain properties of oil sands tailings during the sedimentation. 


\subsection{The Objective and Scope of the Research Work}

The general objective of this research is to investigate the potential of the UPV method as a non-destructive and potential on-site measurement application in the oil sand tailings in order to detect changes and trends in tailings' properties such as strength, density and structuration as a function of time. These measurements would also help in estimating settlement and studying the consolidation behavior of the tailings. Specifically, the scope of research in this thesis is:

- To design a specialized column test to perform the ultrasonic testing during sedimentation of FFT.

- To design specialized transducer holders in order to hold the transducers in place while conducting ultrasonic testing on the aluminum bars.

- To characterize the ultrasonic transducers using standard calibration reference bars made from steel ( 4 bars) and PVC ( 4 bars) with various dimension, face to face procedure and water in order to understand the actual signal response of these transducers.

- To monitor changes in low-strain properties of oil sands tailings during the settlement in the function of time.

- To examine the wave velocity and wave attenuation measurements in order to understand the behavior of the FFT. 


\subsection{The Organization of the Thesis}

The thesis is organized in six chapters:

Chapter 2: Literature Review - This chapter introduces the UPV method, provides a brief description of the generation and the properties of oil sands tailings, and includes a review of the small strain shear modulus and the technologies used to evaluate this parameter.

Chapter 3: Method and Materials - This chapter is focused on the material preparation of the oil sands tailings for the UPV method. The chapter also includes the setup and procedures used on this experiment as well as some of the analytical work behind the findings.

Chapter 4: Results and Discussion - This chapter presents all the results and detail description of all the findings.

Chapter 5: Conclusion and Recommendation - This chapter summarizes all findings of the project. It also provides recommendation for future work related to the evaluation of oil sands tailings using ultrasonic waves which was not covered in this project. 


\subsection{The Novelty of the Research}

Most of the existing studies conducted using UPV method on various materials, including cemented hard rock tailings. However, there are no information available in literature on the use of the UPV method on FFT to detect the changes or trends in tailings properties such as strength, stiffness and structuration. Therefore, this is the first public reported study on the use of UPV method in FFT. One focus of this research is to determine if UPV method can be used to interrogate the changes in properties of oil sands tailings during sedimentation. Proof of concept may provide significant opportunity for the use of ultrasonic measurements to detect changes in density and compressibility in treated FFT independently and in real time. 


\section{Chapter 2: Literature Review}

\section{$2.1 \quad$ Introduction}

Three distinct topics have been found to be relevant to this thesis project. The purpose of this chapter is to summarize the available information of these findings. The literature reviews are as followed: a brief background information on the UPV method (Section 2.2), a general introduction of a small strain shear modulus and technologies used to evaluate this parameter (Section 2.3) and background information on oil sands tailings (Section 2.4).

\subsection{Ultrasonic Pulse Velocity (UPV) Method}

\subsubsection{Review of UPV Method}

The UPV method is a non-destructive testing (NDT) method used widely in Civil Engineering. Example applications include the detection of cracks and large voids in rock, soil and concrete (Malhotra, 2003). The method uses low-amplitude non-destructive mechanical waves that allows specimens to be interrogated repeatedly over a long period of time, without damage or method induced changes in material behavior.

In ultrasonic testing, the quality of the sample is assessed by measuring the properties of an ultrasonic pulse propagating through the sample, which include the wave velocity and the attenuation of the signal by the sample medium. The wave velocity is determined from the arrival time for some receiving sensor, usually located on the other 
side of a specimen from a transmitting transducer. The pulse velocity $V_{p}$ is calculated as (ASTM C $597-16)$ :

$$
V_{p}=\frac{L}{T}=\sqrt{\frac{M}{\rho}}
$$

Where $L$ is the distance between the transmitting transducer and receiving transducer, $T$ is the arrival time when the receiving transducer receives the pulse, $M$ is the constrained modulus and $\rho$ is the density. Figure 2 illustrates the explicit way to obtain the $L$ and $T$ in equation 1.

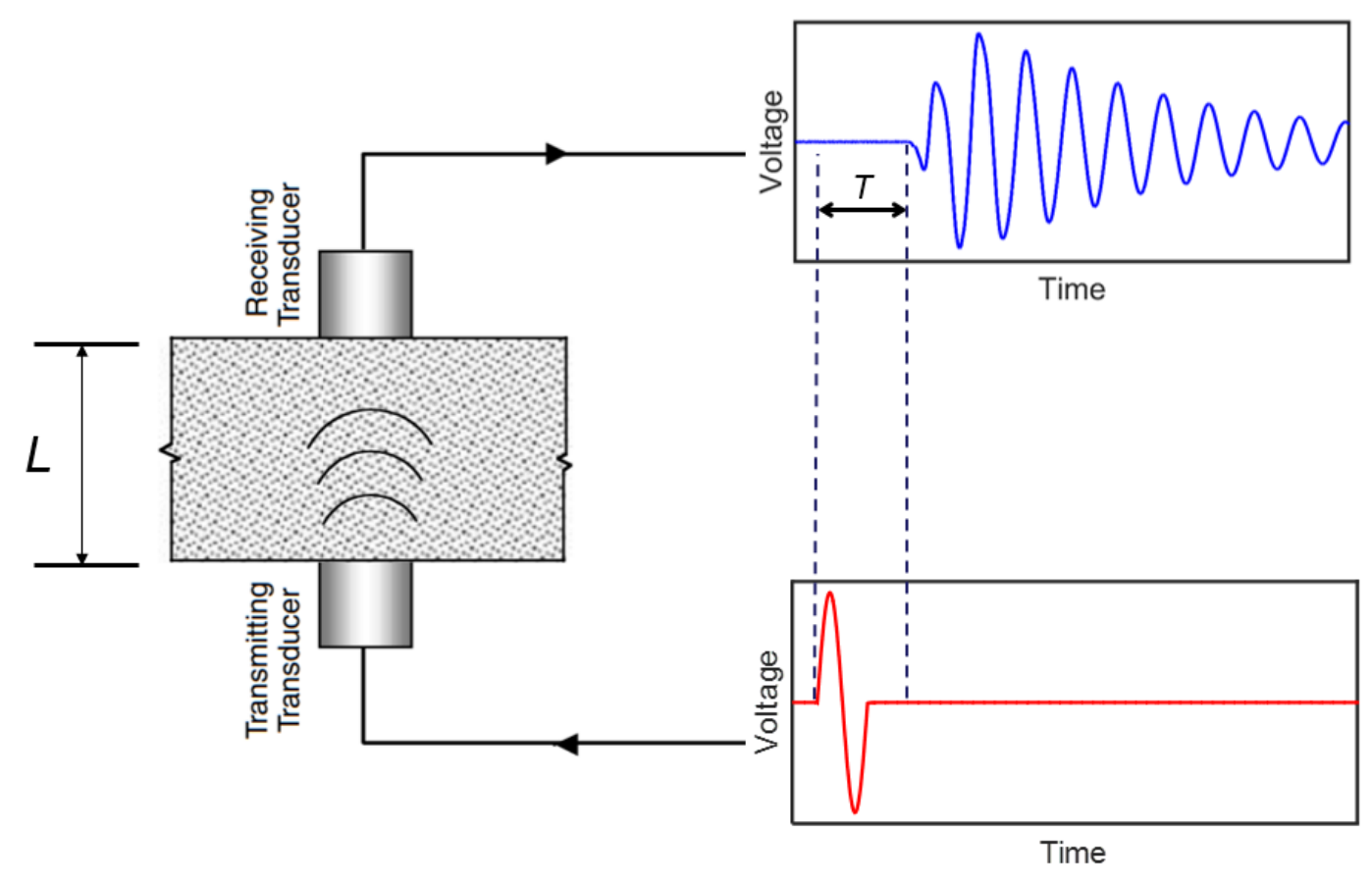

Figure 2: The distance and arrival time of the UPV method (Irfan, 2019). 


\subsubsection{Amplitude, Frequency and Wavelength}

The parameters of the ultrasonic waves passing through the specimen are amplitude, frequency, and wavelength. Amplitude is controlled by the magnitude of the vibration induced by the emitting transducer. For example, for audible signals, the amplitude of the sound wave correlates with the volume of the sound. The frequency of the wave is defined as the number of oscillations of a given cycle per second. Figure 3 shows two waves, one with low amplitude the other with high amplitude. Figure 4 illustrates waves with different frequencies.

Figure 3: Wave with (a) low amplitude and (b) high amplitude

(a)

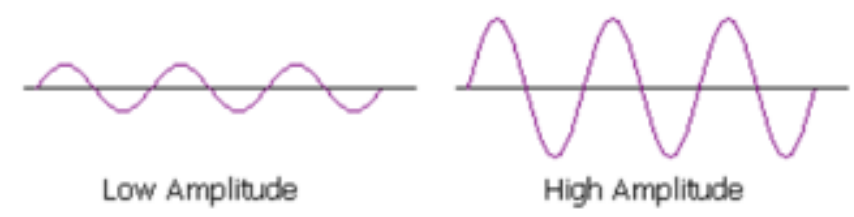

(a)

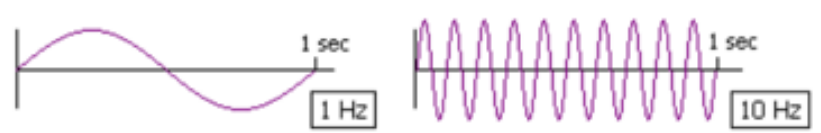

(b)

\section{(b)}

Figure 4: Wave with (a) $1 \mathrm{~Hz}$ and (b) $10 \mathrm{~Hz}$

Wavelength is defined as the distance between two successive crest or troughs of a wave. The wavelength is calculated using the following equation: 


$$
\text { Wavelength }(\lambda)=\frac{\operatorname{Velocity}(v)}{\text { Frequency }(f)}
$$

\subsubsection{Test Equipment and Transducer Arrangement}

The UPV method consists of generating and transmitting an ultrasonic pulse into the sample by using pulse generator and transmitting transducer. In addition, a receiving transducer is required to detect the arrival pulse and measure the arrival time accurately. The test equipment is also connected to the oscilloscope in order to observe the received pulse. Figure 5 illustrates the schematic diagram of conducting the pulse velocity measurement in a concrete specimen.

Understanding the placement of the transducers is also crucial in the UPV method. The following are the three possible arrangements for the transducers, as shown in Figure 6:

a. Direct transmission: this transmission can be achieved by placing the transmitting and receiving transducers directly opposite to one another. It is the most desirable and satisfactory among all the other transmissions as it provides the best results since maximum energy of the pulse is transmitted and received through this arrangement (Malhotra, 2003). Moreover, the distance between the transducers can be measured easily and accurately.

b. Semi-direct transmission: this transmission can be achieved by placing the transmitting and receiving transducers adjacent to one another. This arrangement is less sensitive compared to direct transmission and more sensitive than indirect transmission. The semi-direct transmission is best to use when the angle and the 
distance between transducer are not too great. Otherwise, attenuation of the transmitted pulse will occur if these requirements are not met (Bungey \& al, 2014).

c. Indirect transmission: the indirect transmission is achieved by placing both transmitting and receiving transducers on the same platform. This arrangement is the least desired since the received signal amplitude is quite low compared to direct transmission (Hong, 2012).

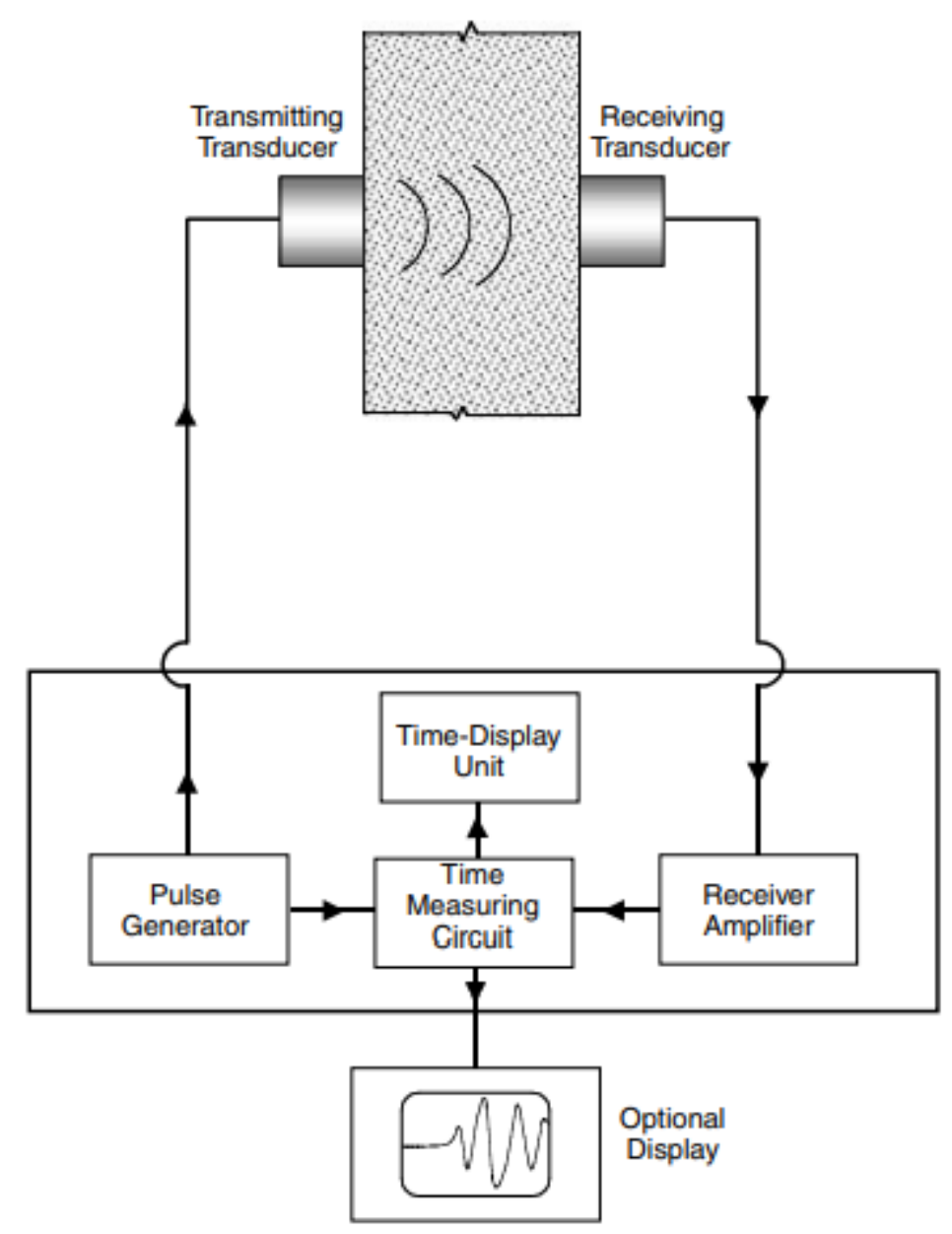

Figure 5: Schematic diagram of pulse velocity test circuit (Malhotra, 2003). 


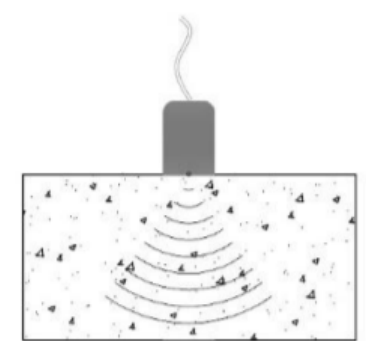

(a)

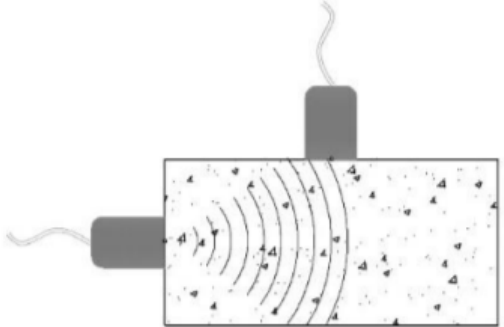

(b)

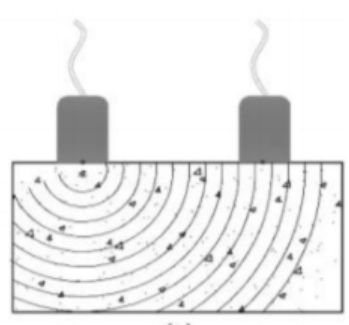

(c)

Figure 6: placement of ultrasonic transducers: (a) direct transmission (b) Semi - direct transmission (c) Indirect transmission (Ndagi et al., 2019).

Regardless of which transmission is used, it is still important to ensure that transducers are fully in contact with the sample in order to avoid air pockets between the specimen and the transducers. An ultrasonic couplant such as gel agent (Ultragel II) can be utilized to eliminate air pockets and to ensure good contact.

\subsubsection{Theory of the Wave Propagation}

In ultrasonic testing, there are three types of mechanical waves generated when the medium is disturbed by a vibratory load. These waves are primary waves (also known as longitudinal or compressional waves), secondary waves (also known as transverse or Shear waves) and Rayleigh waves (also known as surface waves) (Malhotra, 2013). However, primary and secondary waves are the two mode of propagation most widely used in ultrasonic testing. Figure 7 illustrates the movement of each type of wave. 


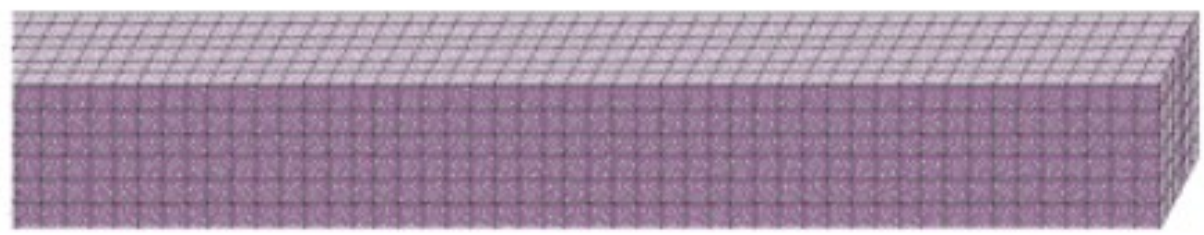

(a) Undisturbed material

Compression Compression Compression

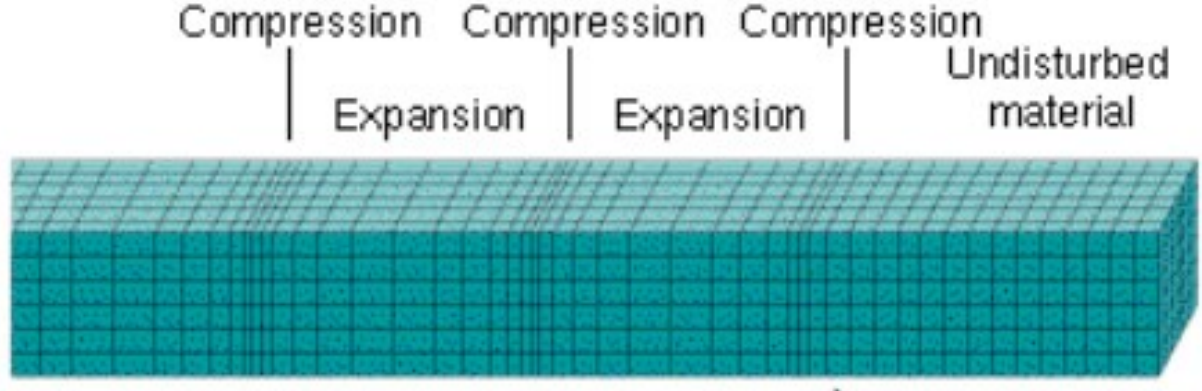

(b) Primary wave

Direction of w ave movemert

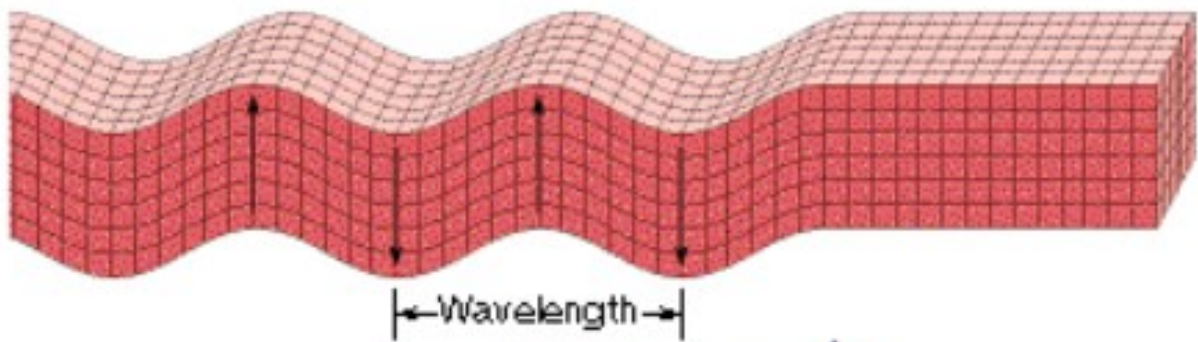

(c) Secondary wave

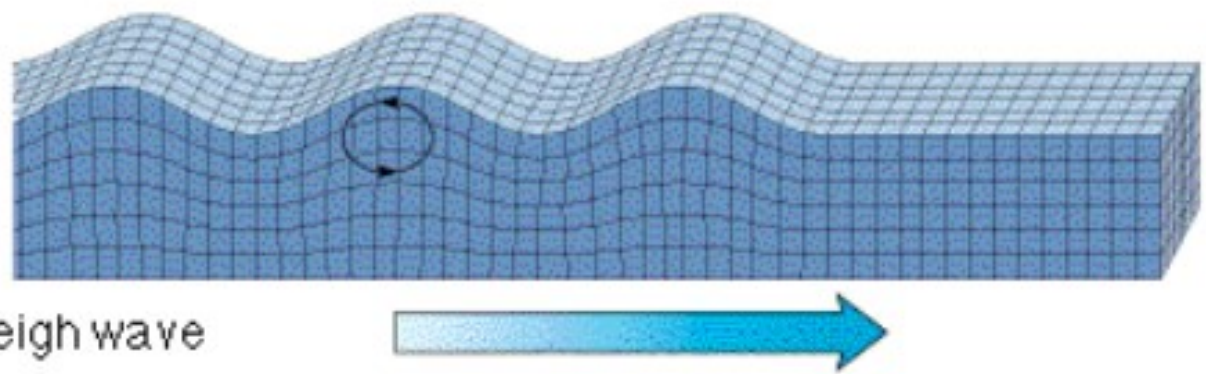

(d) Rayleigh wave

Figure 7: The movement of different types of wave

(http://www.geo.utep.edu/kidd/eqwave.html). 
In addition, Lamb waves (also known as plate waves) can be generated when there is an interaction of the surface waves with a plate with free boundaries and the thickness of the plate has the same magnitude as the wavelength. Lamb waves are normally used in the acoustic guided - wave for thin plates. Symmetric and antisymmetric are two modes of vibration for the propagation of surface waves, illustrated in Figure 8 (Wu, 2012).

(a)

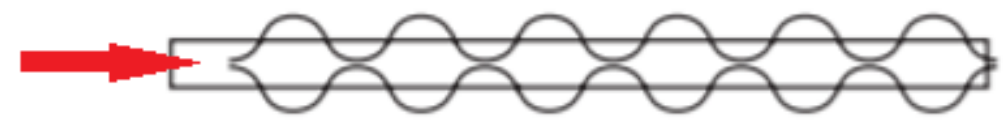

(b)

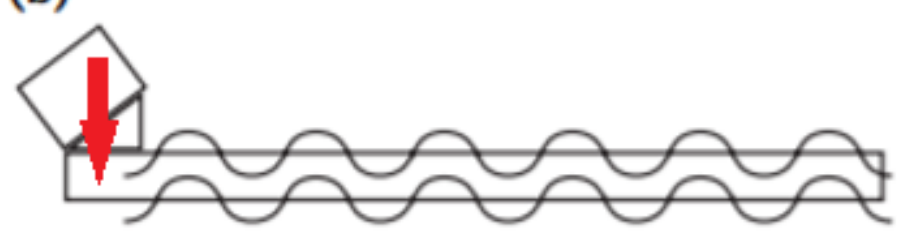

Figure 8: Wave propagation modes in a thin structure. (a) Symmetric mode (extension) and (b) antisymmetric mode (bending).

The dispersion curve of the lamb waves is the most important characteristics of the waves as elastic constants and density of the material are not the only aspects used to determine the velocity of lamb waves but also the frequency of the waves, illustrated in Figure 9 (Li et al., 2018). 
(a)

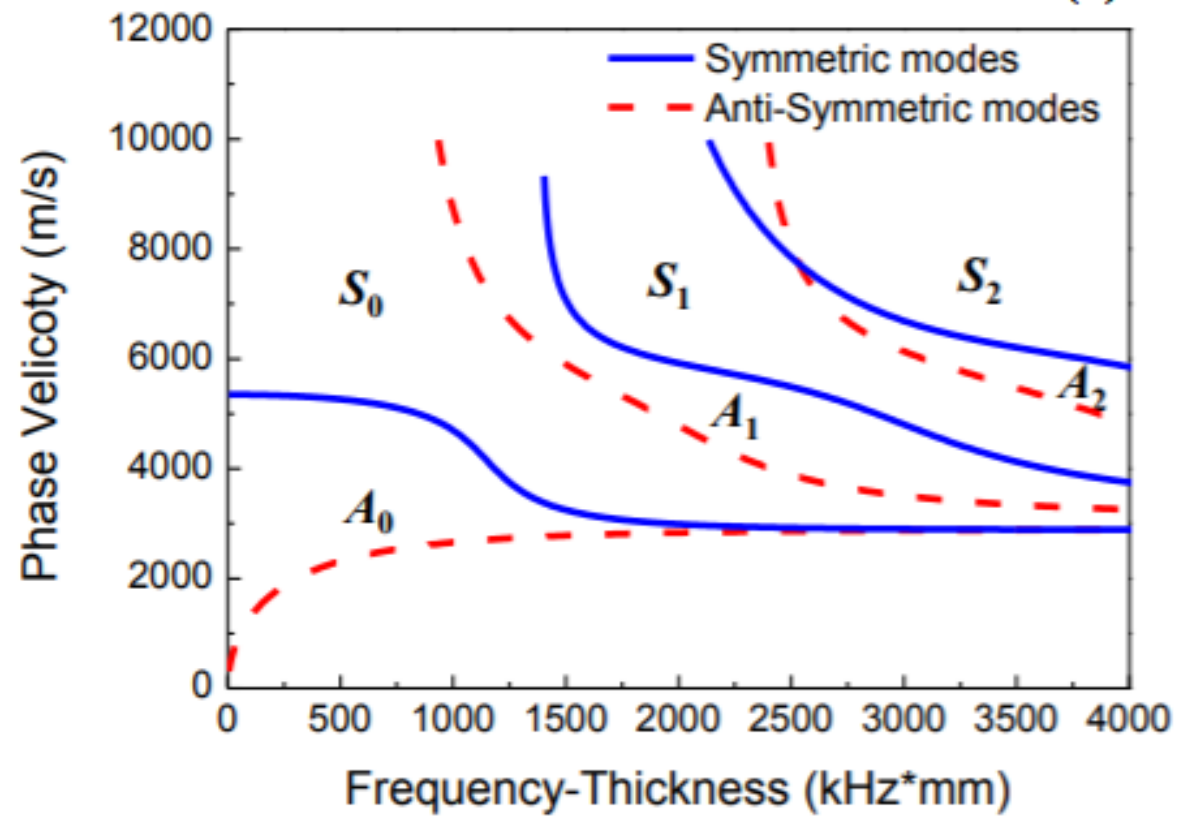

(b)

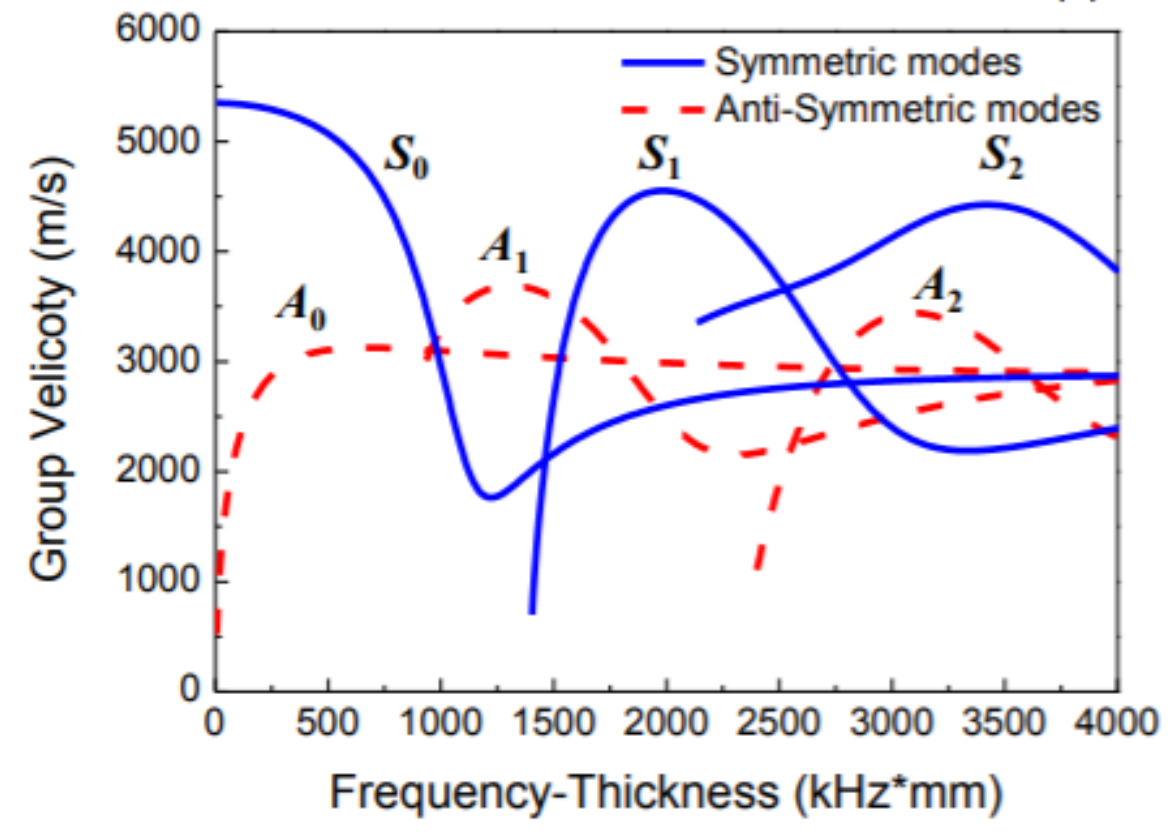

Figure 9: Dispersion curves of Lamb waves in a $2 \mathrm{~mm}$ thick aluminum plate: (a) phase velocity and (b) group velocity (Li et al., 2018). 
The interaction between the matter and the waves occur when the mechanical waves are generated and this interaction is an essential component of the UPV method. Reflection, refraction and diffraction are the three possible ways for waves to interact with matter in ultrasonic testing. The following are the main characteristics of each interaction of wave:

1. Reflection: this interaction occurs when waves are unable to pass through the surface and rebound back from the surface.

2. Refraction: this interaction occurs when waves enter a new medium at an angle causing them to bend and start propagating at a different speed.

3. Diffraction: this interaction occurs when waves disperse as they propagate around or through obstacles.

\subsubsection{Relationship between Velocity and Elastic Moduli}

An elastic modulus is defined as a measurement of the resistance of the material being deformed elastically when the stress is being applied to it. As mentioned previously, compressional wave and shear wave are the two modes of propagation most widely used in the UPV method. These waves are able to propagate through the elastic solids. The movement of each type of wave is presented and explained in Figure 7. Based on the elastic theory, many important parameters such as Poisson's ratio (v), Young's modulus and the small strain shear modulus $\left(G_{\max }\right)$ can be calculated, once the velocities (compressional and shear) are known, using the following equations (Ginzel and Turnbull, 2016): 
Poisson's ratio (v),

$$
v=\frac{1-2\left(\frac{V_{s}}{V_{l}}\right)^{2}}{2-2\left(\frac{V_{s}}{V_{l}}\right)^{2}}
$$

Young's Modulus (E),

$$
E=\frac{V_{l}^{2} \rho(1+v)(1-2 v)}{(1-v)}
$$

Small Strain Shear Modulus $\left(G_{\max }\right)$,

$$
G_{\max }=\rho V_{s}^{2}
$$

Where, $V_{l}$ is the compressional wave velocity, $V_{s}$ is the shear wave velocity and $\rho$ is the material density.

\subsubsection{Factors Affecting Modulus of Elasticity of Soil}

Several factors affecting modulus of elasticity of soil include the density of the soil particles, moisture content and temperature. Each factor will be discussed further in the section below.

\subsubsection{Soil Particles Density}

In soil, the void ratio (Volume of voids / volume of solids) is a quantification of soil density. The lower the void ratio, the greater the density. The closer the soil particles, the less likely to deform, the higher the modulus. 


\subsubsection{Moisture content}

The stiffness and strength of soil can be affected by the moisture content. From Figure 10, it is found that the elastic modulus of the soil decreases with increasing water content. The reduction of the modulus due to the increase of moisture content could be caused by partial mobilization of excess pore pressure and reduction of friction between particles (Eun et al., 2012).

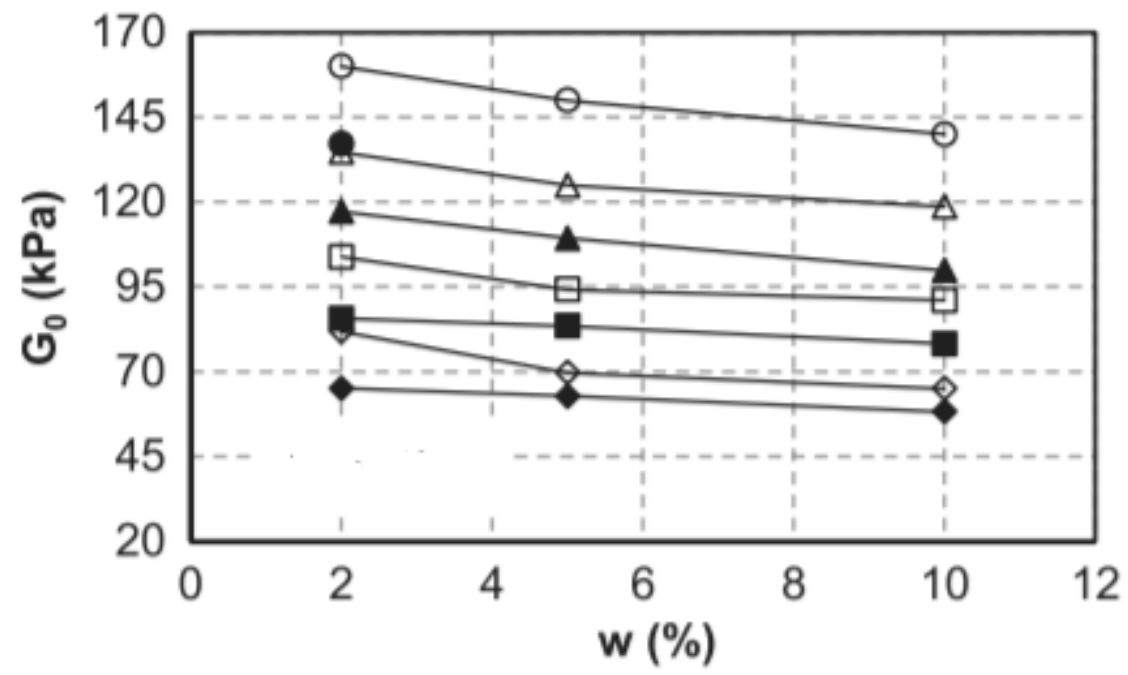

Figure 10: Variation of elastic modulus with moisture contents (Eun et al., 2012).

\subsubsection{Temperature}

Studies have found that an increase in temperature will cause a decrease in elastic modulus. The reduction of elastic modulus due to increasing temperature is likely caused by a decrease in yield stress of unsaturated soil with increase of temperature (Francois et al., 2008). Soil specimen would behave softer given a smaller yield stress and overconsolidation ratio (OCR) (Francois et al., 2008). Figure 11 illustrates the reduction of elastic modulus with increase temperature. 


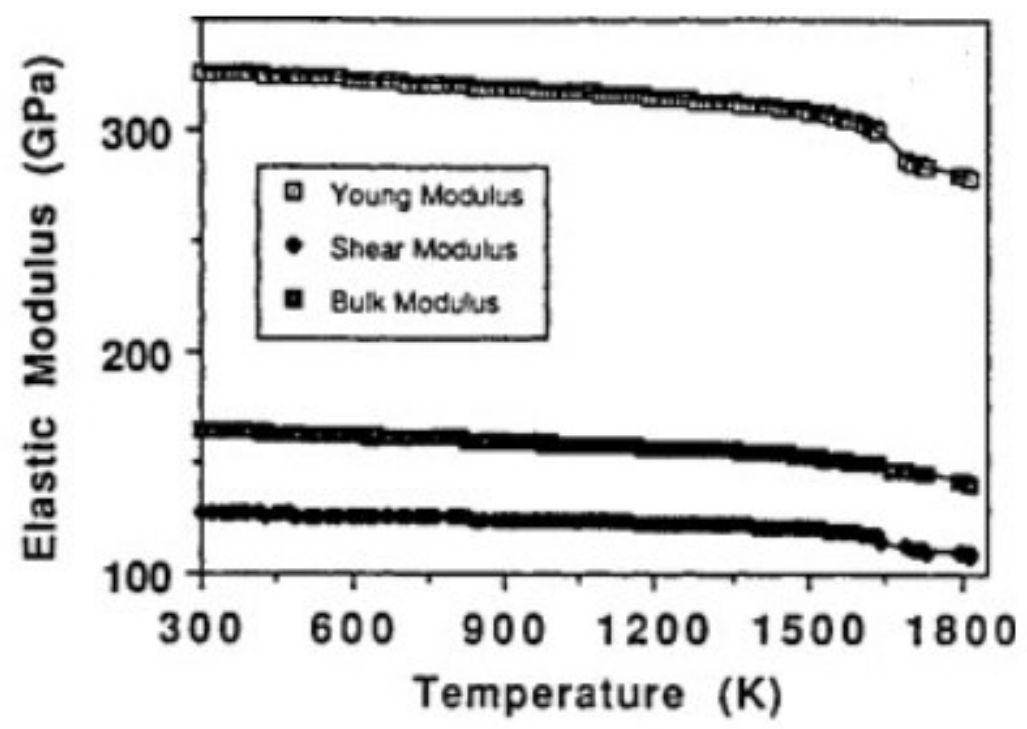

Figure 11: Elastic modulus vs temperature (Maier, 2020).

\subsubsection{Calibration of Ultrasonic Transducers}

In ultrasonic testing, the transducers themselves play an essential role in interacting with medium and therefore influence signal properties. Therefore, the calibration of the transducers prior to testing is crucial in NDT in order to ensure efficient results are obtained (ASTM-E1316-11b).

For the UPV method, the most common method used to calibrate the transducers is to measure the arrival time with the reference standard bar. This method is used to determine the time delay in the instrumentation and is then subtracted with the travel time for wave to travel through the specimen (Fartosy, 2018). According to ASTM E127 and ASTM E428, the common reference standards used in UPV method are made of aluminum and steel. Figure 12 illustrates the standard reference bars in various sizes. 


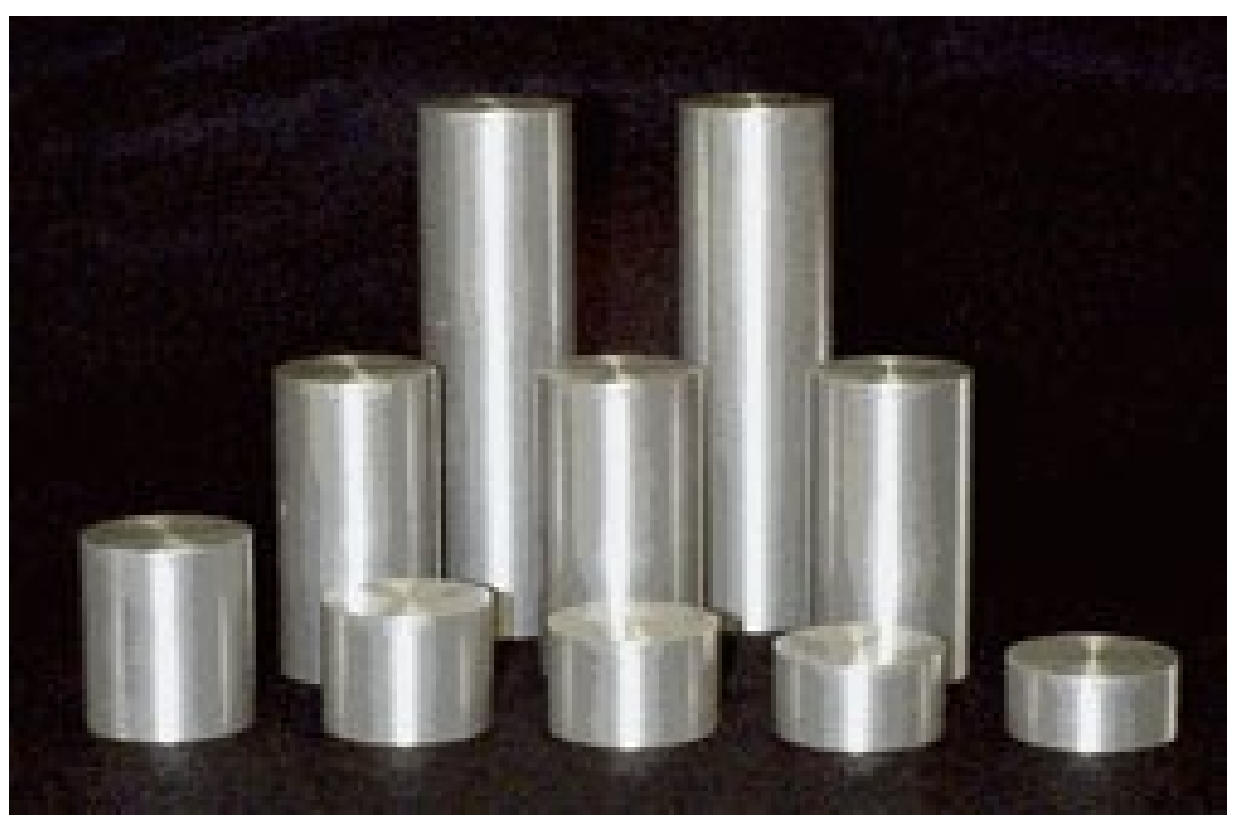

Figure 12: Reference standard bars (https://www.nde-ed.org).

Besides the reference standard bars, other procedures such as face to face, water and air are also used to calibrate the transducers and these procedures will be discussed, as it is the focus of the present work.

\subsubsection{Ultrasonic Wave Attenuation}

Wave attenuation in ultrasonic testing is defined as the loss of wave signal when sound propagates through the medium. The wave attenuation occurs due to absorption and scattering (Aki \& Richards, 1980). Absorption is mainly caused by the viscosity of the medium. Scattering occurs when the specimen is not strictly homogenous, resulting the amplitude and the intensity of ultrasonic waves reduce with distance.

Besides evaluating the damage of the specimen using wave velocity, wave attenuation is another reliable parameter in ultrasonic testing which can be used to analyze the quality of the sample. In fact, wave attenuation can be more sensitive to damage or changes than wave velocity and this method can be used to evaluate the 
degradation or loss of material strength through the reduction in the wave amplitude, commonly represented by an exponential decay (Ensminger \& Bond, 2011). The amplitude change of a decaying plane wave is expressed by following equation:

$$
A=A_{0} e^{-\alpha \gamma}
$$

Where $\mathrm{A}$ is the amplitude, $\mathrm{A}_{0}$ is the incident amplitude generated by transmitting transducer, $\gamma$ is the traveling distance, and $\alpha$ is the amplitude attenuation coefficient.

\subsubsection{Example Application of the UPV Method on the Cemented Paste Backfill (CPB)}

Since CPB is another type of tailings with some similar properties to oil sand tailings, the application of the UPV method to this specific material will be discussed in detail in this section. CPB are typically hard rock tailings (silt sized tailings generated from grinding or rock) combined with a small amount of cement, which have deposited in mine-out voids in underground mines, to maintain geomechanical stability of the mine works, and hence necessary to maximize ore recovery while maintaining safe working condition (Tariq et al. 2013; Wu et al. 2014, 2016).

$\mathrm{CPB}$ is an engineered mixture of mill tailings ( $75-85 \%$ solids by weight), a hydraulic binder (2-9\% by dry total paste weight) and mixing (Ercikdi, 2013). The UPV method has been applied to CPB to monitor the curing process as well as the correlation between UPV and unconfined compressional strength (UCS) of CPB specimens.

Studies have found that the UPV values increase with increasing curing temperature and age. This shows that during the curing process, the CPB specimen has 
become denser, resulting in improvement of internal structure of the CPB specimen. Figure 13 illustrates the UPV development of CPB specimen cured for 3, 7 and 28 days, respectively. In addition, Figure 14 shows the relationship between the UCS and UPV values of $\mathrm{CPB}$ specimens.
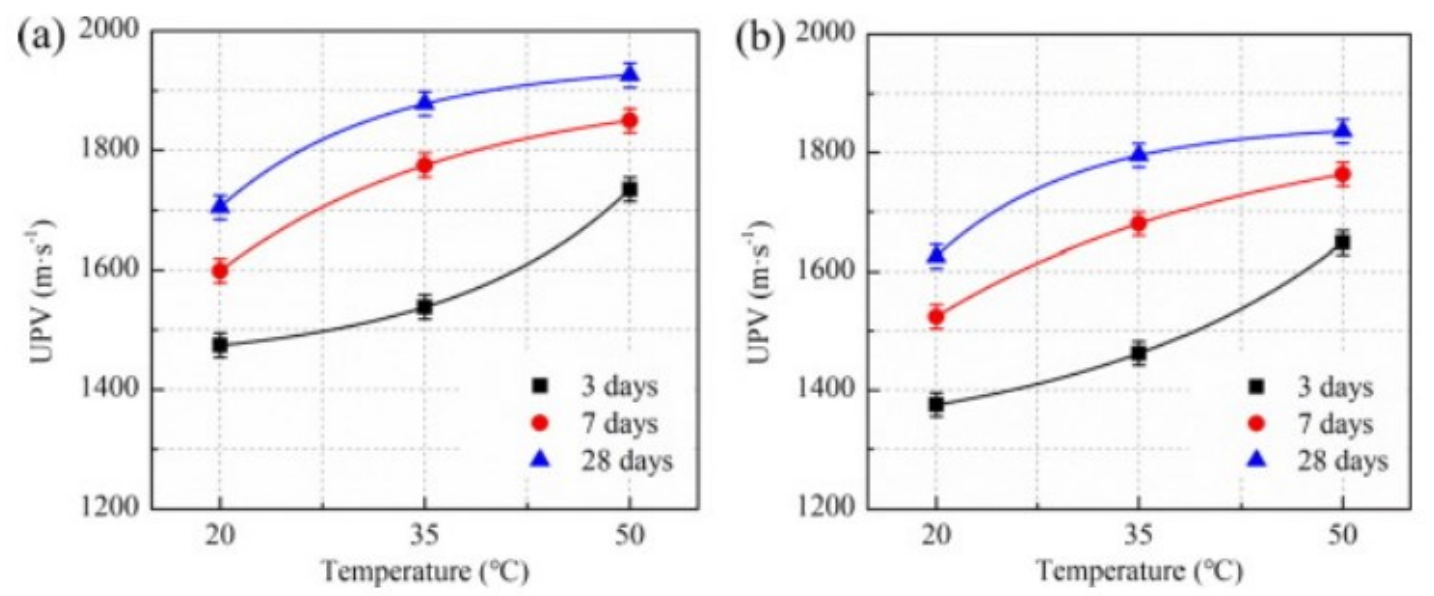

Figure 13: UPV development of CPB specimens with cement to tailings ratio of (a) $1 / 10$ and (b) $1 / 20$ (Qi, 2019).

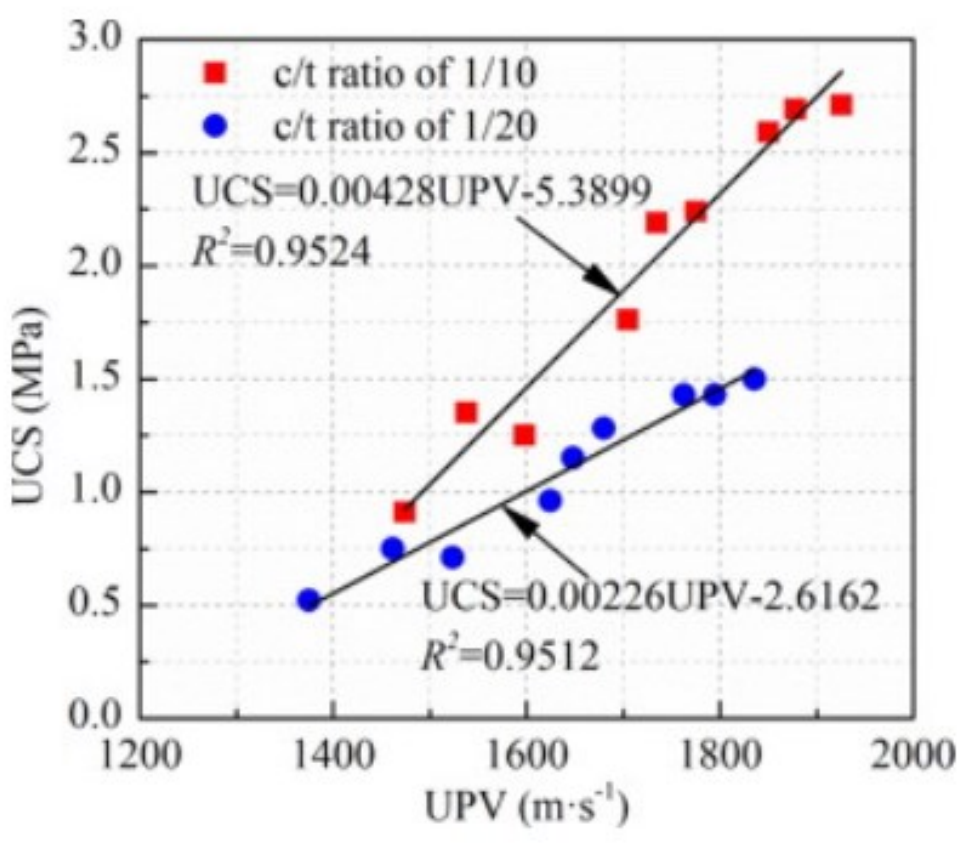

Figure 14: Relationship between UCS and UPV values of CPB specimens (Qi, 2019). 


\subsubsection{Advantages and Disadvantages of the UPV Method}

As with most non-destructive testing, there is always advantages and disadvantages. Several advantages and limitations of the UPV method will be discussed in detail in the following paragraphs.

The UPV method is a non-destructive testing commonly used to determine the quality of the specimen. This method is relatively simple and easy to use and it has a high sensitivity, therefore, it allows the detection of even minor flaws. In addition, the high penetrating power of the UPV method enables the wave to propagate deep into the tested sample. Another advantage of the UPV method is that the equipment is easily transportable. Thus, the operation of this method can be done either in the laboratory or in the field. Moreover, the UPV has the capability in estimating the size, shape, nature of the flaws (Malhotra, 2003).

However, UPV method has a several limitations such that the method is difficult to test on samples which are rough, shaped irregularly, very thin or not homogenous. In addition, ultrasonic couplants are always required in the ultrasonic testing in order to achieve efficient results by preventing air pocket between the test specimen and the transducers. Another disadvantage is that the test samples must be water resistant or a least water content changes in the sample must be known, as changes in water content affect the wave velocity. This is especially important for soil samples that go from a saturated to an unsaturated condition (or vice versa), as sound waves travel faster in water than in air filled pores of specimen (Godinho et al, 2019). 


\subsection{Small Strain Shear Modulus}

\subsubsection{A Review of Small Strain Shear Modulus}

The $G_{\max }$ can be defined as the ratio of shear stress to shear strain, shown in Equation 7, and it is also known as the modulus of rigidity (Helmenstine, 2019). In addition, Figure 15 illustrates the relationship between shear strain and shear stress response curve.

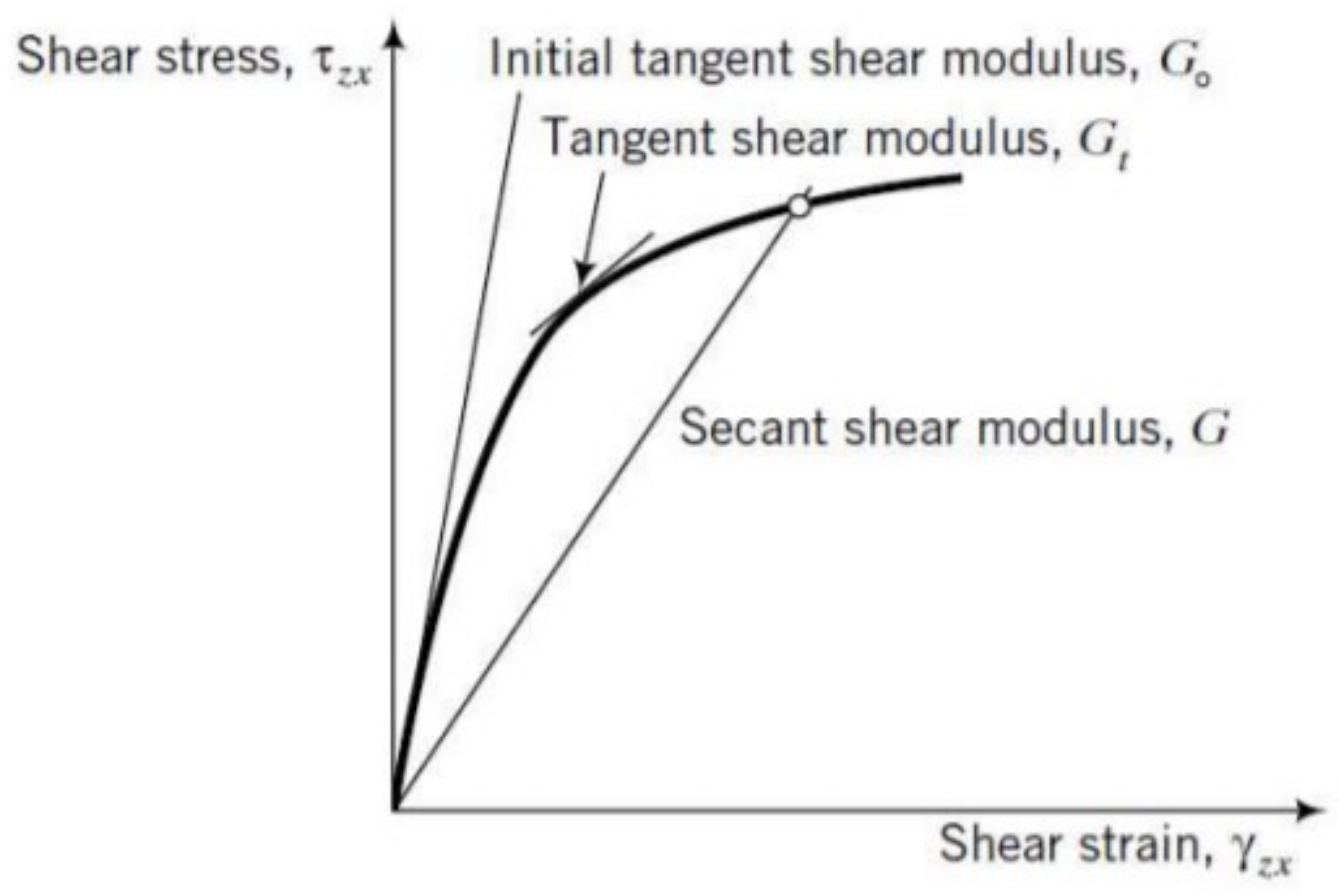

Figure 15: Shear strain versus shear stress response curve (Budhu, 1999).

$$
G_{\max }=\frac{\tau_{x y}}{\gamma_{x y}}
$$

Where, $\tau_{x y}$ is the shear stress and $\gamma_{x y}$ is the shear strain. 
In the elastic theory, for values of small strain below 0.001 , the soil behavior is usually considered linear and elastic. However, the values of small strain above 0.001 have a significant reduction in the modulus of elasticity. Figure 16 indicates the typical variation of different moduli with different strain for soils.

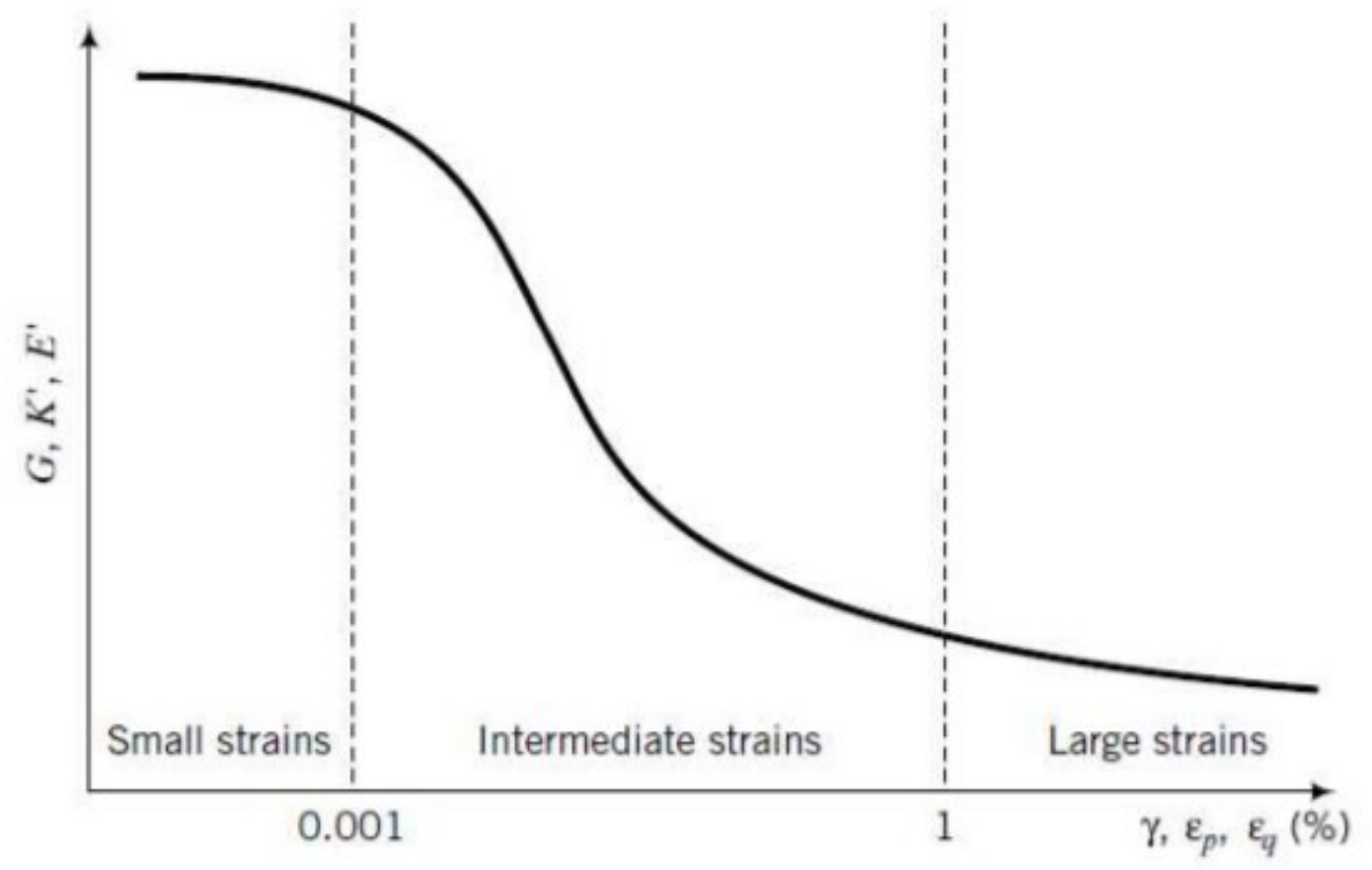

Figure 16: the typical variation of different moduli with different strain for soils. K' is the bulk modulus and E' is the elastic modulus (Budhu, 1999).

The $G_{\max }$ is an important key parameter in soils as this parameter is related to the small strain shear for predicting the response of the dynamic of soils during earthquakes, explosive detonations and vibration from machinery. This parameter also yields valuable soil properties information required in the analysis and design of foundations (Lee \& Santamarina, 2005). In addition, the significance of $G_{\max }$ has also been emphasized even in static deformational analyses of geotechnical problems (Burland et al, 1977). There are 
many ways to calculate $G_{\max }$ such as calculating by using equation 5 or measuring it directly using the resonant column test.

Therefore, comprehensive studies of the $G_{\max }$ have been conducted in the early 1970's, leading to the development of the resonant column apparatus (Hardin \& Richart, 1963). Past studies have found that the small $G_{\max }$ is mainly related to the effective stress and void ratio (Taukoor et al, 2019; Santamarine et al, 2001; Mitchell and Soga 2005). The effects due to effective stress and void ratio will be discussed in the following section.

\subsubsection{Influences of Effective Stress and Void Ratio on Gas}

In soil, the void ratio (Volume of voids / volume of solids) is a quantification of soil density. The lower the void ratio, the greater the density. The closer the soil particles, the less likely to deform, the higher the stiffness.

Richart (1963) performed resonant column experiments to measure the shear wave velocity of the rounded Ottawa sandy soil and angular crushed quartz sand, and showed that the $G_{\max }$ and shear wave velocity of the sands are mainly dependent on the effective stress and void ratio. Furthermore, it was observed that the shear wave velocity is liner with the void ratio but independent of particle size, gradation and specific gravity (Campbell, 2007). The shear wave velocity in term of confining pressure $\left(\sigma^{\prime}\right)$ of the rounded particles can be calculated with the proposed equations below:

$$
\begin{aligned}
& \text { For } \sigma^{\prime} \geq 95.80 \mathrm{kPa} \text {, } \\
& \qquad V_{s}=(19.70-9.07 e) \sigma^{\prime 0.25}
\end{aligned}
$$




$$
\begin{aligned}
& \text { For } \sigma^{\prime}<95.80 \mathrm{kPa} \\
& \qquad V_{s}=(11.36-5.35 e) \sigma^{\prime 0.30}
\end{aligned}
$$

In addition, the shear wave velocity of the sand having angular crushed quartz in terms of confining pressure can be calculated with the following equation:

$$
V_{s}=(18.43-6.20 e) \sigma^{\prime 0.25}
$$

Where $V_{s}$ and $\sigma^{\prime}$ are expressed in the unit of $\mathrm{m} / \mathrm{s}$ and $\mathrm{Pa}\left(\mathrm{N} / \mathrm{m}^{2}\right)$, respectively In term of $G_{\max }$, these are expressed as:

Rounded Ottawa Sand,

$$
G_{\max }=700\left[\frac{(2.17-e)^{2}}{1+e}\right] \sigma^{\prime 0.25}
$$

Angular Quartz Sand,

$$
G_{\max }=326\left[\frac{(2.97-e)^{2}}{1+e}\right] \sigma^{\prime 0.5}
$$

Based on the studies conducted by Hardin and Richart (1963), two void ratio functions were defined as follow: 


\section{Rounded Ottawa Sand,}

$$
F(e)=\frac{(2.17-e)^{2}}{1+e}
$$

\section{Angular Quartz Sand,}

$$
F(e)=\frac{(2.97-e)^{2}}{1+e}
$$

However, the two void ratio equations mentioned above are based on the shear wave velocity in sands which decrease linearly with void ratio, independent of grain size gradation and relative density (Hardin and Richart, 1963). Due to the linear fit to the data, problem at the high and low of stress occurs. Negative value of void ratio occurs at high stresses if these forms of void ratio functions are used (Pestana and Whittle, 1995). As a result, another void ratio function based on the critical state testing of ErKsak is proposed in term of $\mathrm{e}_{\min }{ }^{*}$ (Jefferies and Been 2000), in which $\mathrm{e}_{\min }{ }^{*}$ refers as changes of soils from particles to solid. Therefore, the new proposed void ratio function in term $\mathrm{e}_{\min } *$ is shown below:

$$
F(e)=\frac{1}{\left(e-e_{\min } *\right)}
$$

As mentioned previously, consolidation occurs due to the increase in effective stress, resulting in a decrease in volume as the excess of pore water pressure dissipate. Hardin (1978) suggested $G_{\max }$ depends on the effective stress $\left(\sigma^{\prime}\right)$ and void ratio (e). Studies have found that the shear wave velocity of clay increases with the increase of 
effective stress, illustrated in Figure 17. In addition, Figure 18 showed the $G_{\max }$ values decrease when the void ratio increases.

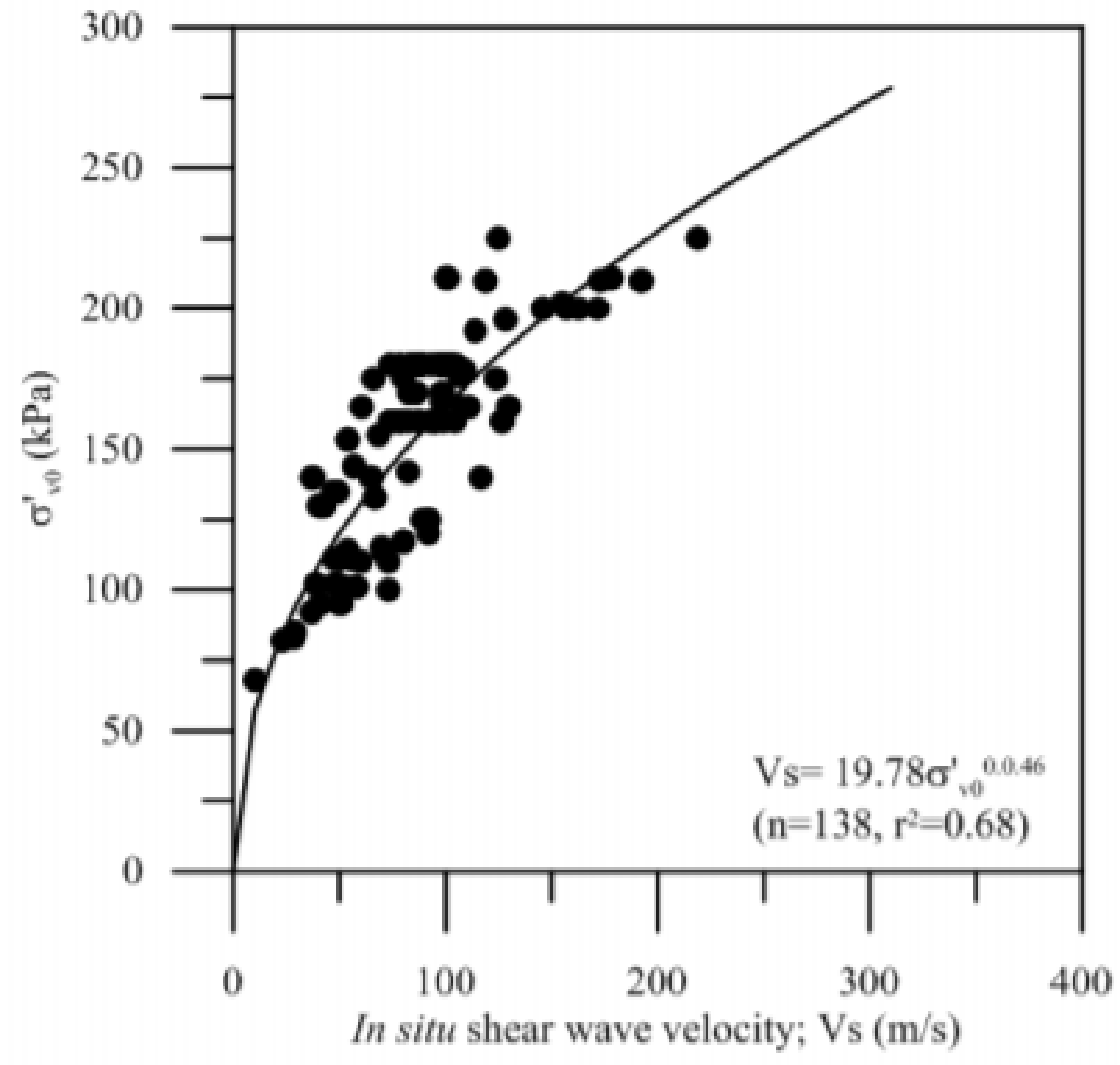

Figure 17: In situ shear wave velocity, against vertical effective stress (L'Heureux et al., 2017). 


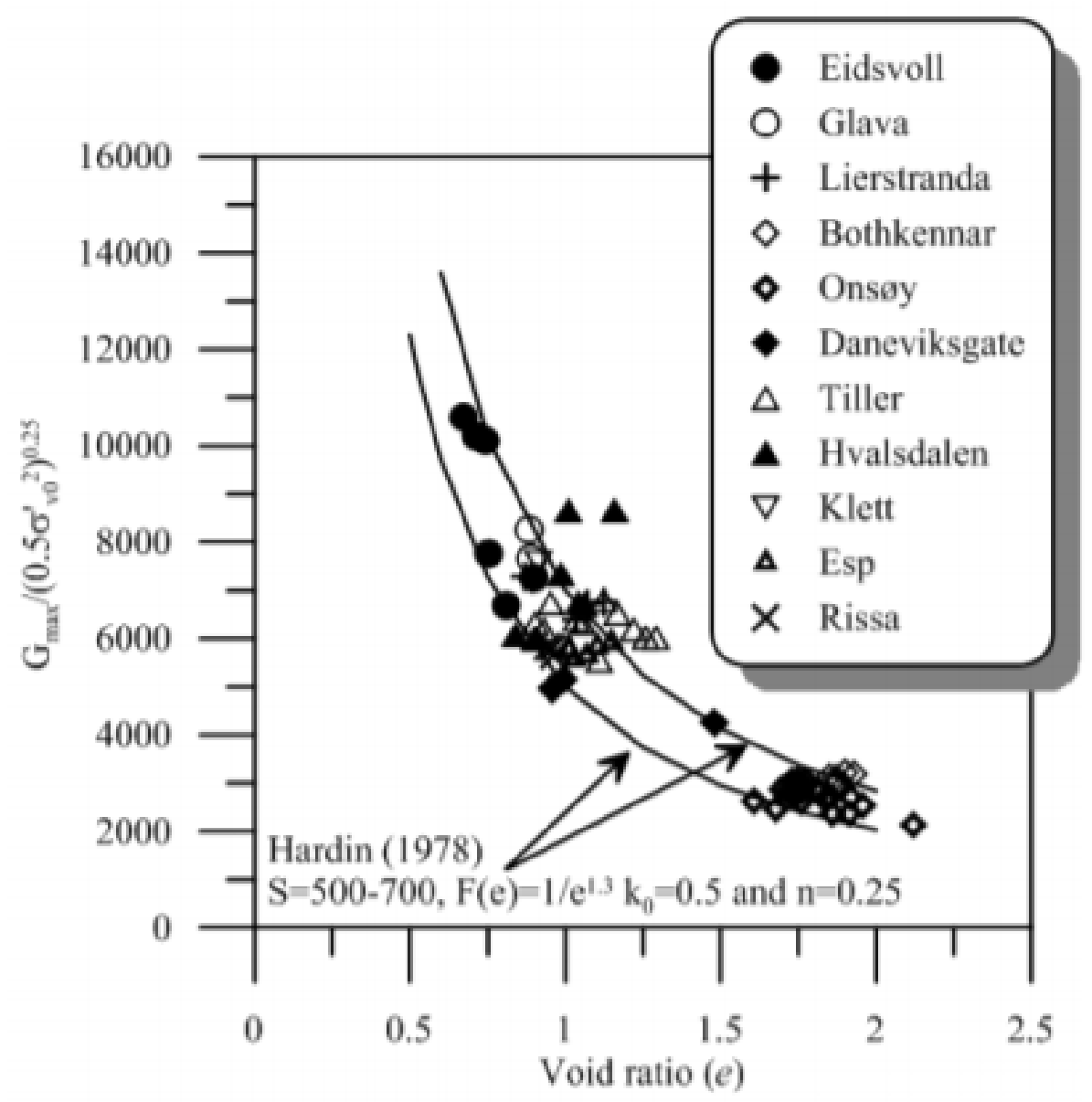

Figure 18: Void ratio, against $\mathrm{G}_{\max }$ (L’Heureux et al., 2017).

\subsubsection{Seismic Test for Quality Control and Assurance}

Quality control and assurance is important to guarantee the ideal performance of the soils before, during and after the construction in order to avoid the potential of liquefaction. Therefore, it is common practice to perform quality control and monitor the properties of the soils.

Besides using the resonant column test to evaluate the $G_{\max }$ of the soils, there are two seismic techniques such as seismic cone penetration and bender elements tests that have been used in past studies to evaluate the properties of the soils by measuring the 
velocity of the shear wave passing through the soil specimen. These techniques are discussed in depth in the sections below.

\subsubsection{Seismic Cone Penetration Test}

The Seismic cone penetration test (SCPT) is a technique commonly used to evaluate the liquefaction of the soil using the cyclic loading method by determining the small strain shear modulus of the soil. The small strain shear modulus of the soil can be calculated by measuring the shear wave velocity of the soil. Once the shear wave velocity, $V_{s}$, is known, the small strain shear modulus can be then calculated by using equation 5 mentioned previously. The fast drilling ( $20 \mathrm{~m}$ of penetration in 30 minutes), experiment data are repeatable and it yields near continuous data which makes SCPT the preferred choice over other methods.

The SCPT is a combination of the cone penetration test (CPT) with measurement of the shear wave velocity of the seismic waves (Robertson et al., 1992). The CPT with the ability of measuring the shear wave velocity is achieved by placing a small geophone or accelerometer inside a standard $10-\mathrm{cm}^{2}$ electric cone, and seismic wave velocities are measured during pauses in cone penetration (Robertson et al., 1992). Figure 19 illustrates the schematic diagram of the SCPT. 


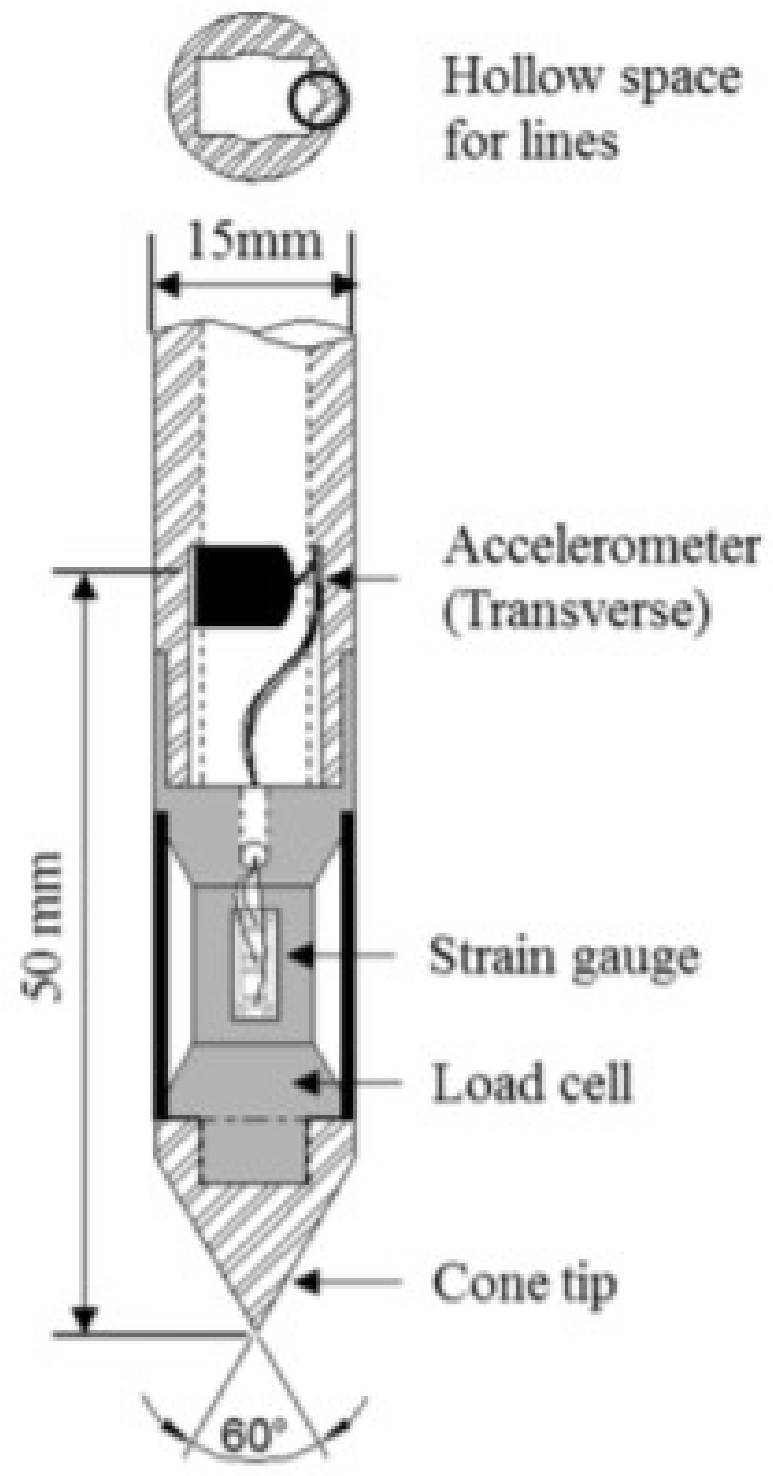

Figure 19: The schematic diagram of the SCPT (Lee et al, 2018).

\subsubsection{Seismic Cone Penetration Testing Procedure}

The SCPT consists of a means of producing a seismic wave, detectable by accelerometers or geophones, in the soil medium by hitting an anvil with a hammer (Robertson et al, 1986). The measurement of shear wave velocity obtained using the 
SCPT can be assessed by the detection of the wave arrival time with the use of the accelerometers at a certain depth, presented in equation 15 . Once the velocity of the shear wave is known, the shear modulus can be calculated using equation 5 . The density in the shear modulus equation can be estimated from the sample information.

$$
V_{s}=\frac{h}{t}
$$

Where $V_{s}$ is the shear wave velocity $(\mathrm{m} / \mathrm{s}), h$ is the distance between geophones (m) (in case of SCPT cone $\mathrm{h}=1.0 \mathrm{~m}$ ) and $\mathrm{t}$ is the travel time from the first to the second geophone (s). Figure 20 indicates the schematic diagram of SCPT and the position of the shear-wave source to the cone. An exemplary outcome of seismic test results obtained from a single accelerometer, is shown in Figure 21. 


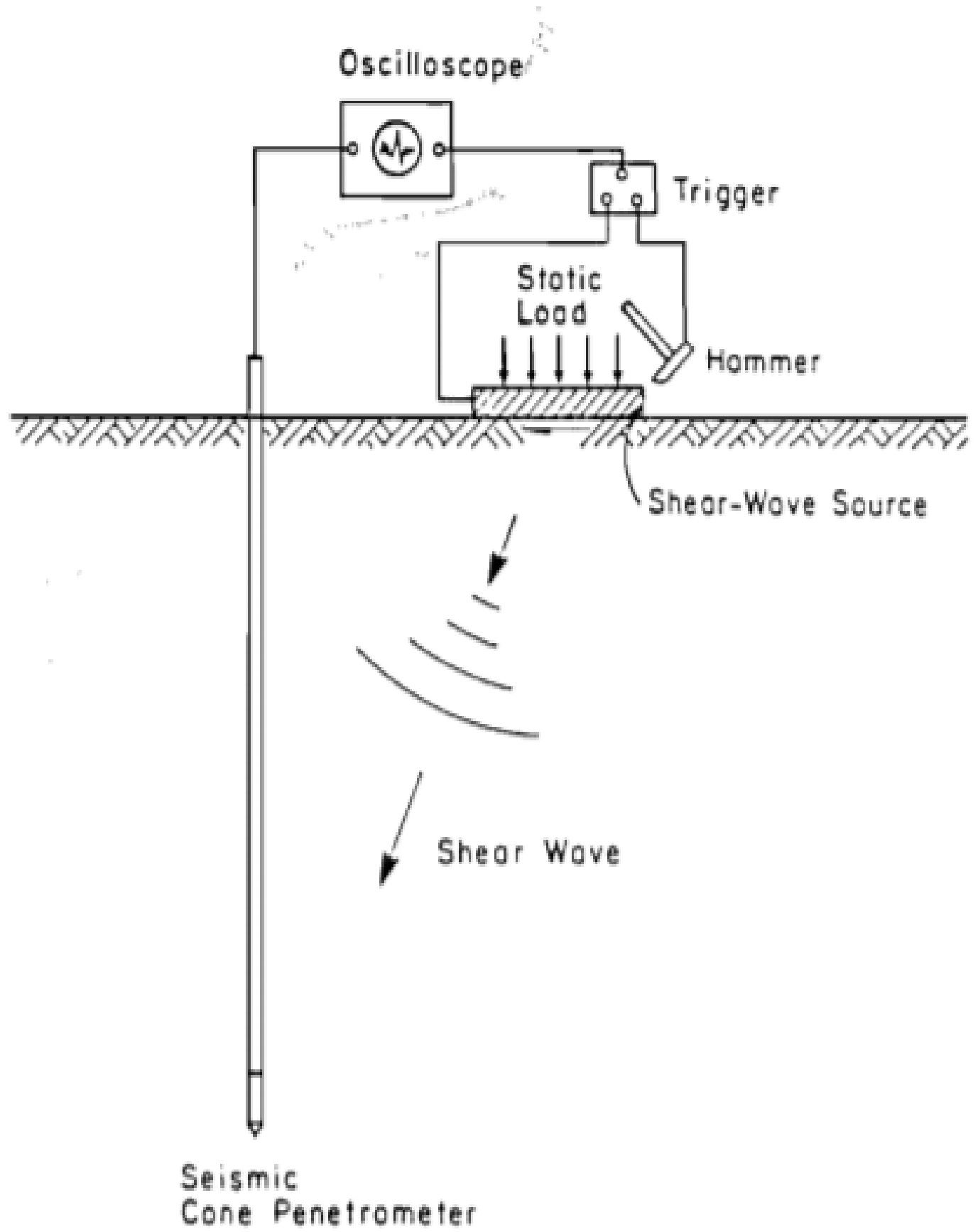

Figure 20: Schematic of SCPT and the shear-wave source is placed perpendicular to the cone (Robertson et al, 1986). 


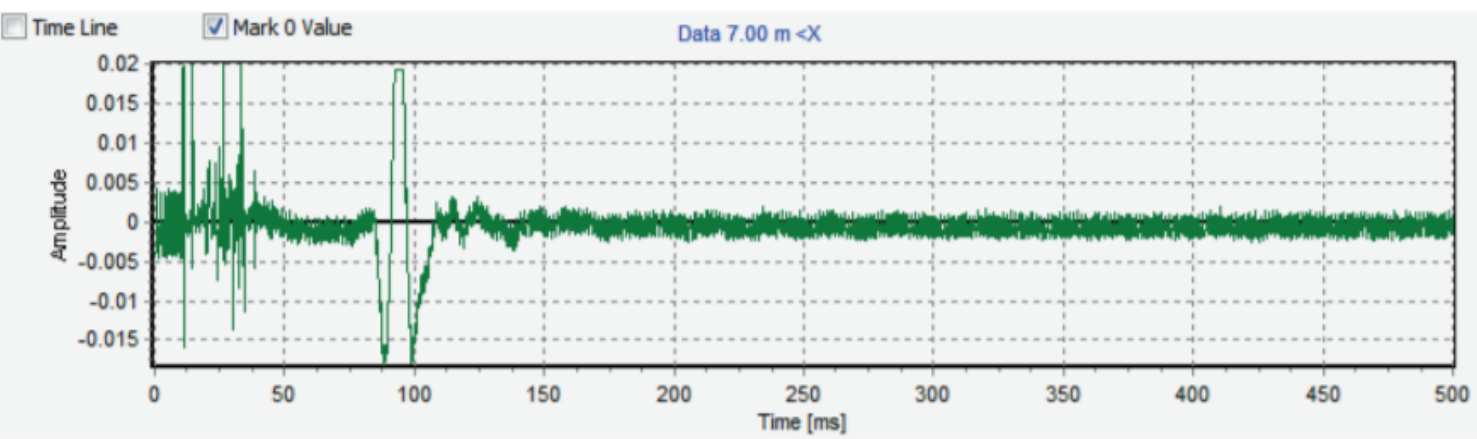

Figure 21: An example outcome of seismic test - a record of vibration in the $X$ direction

(Baginska, 2013).

\subsubsection{Bender Elements}

The bender element (BE) method is laboratory equipment used to obtain the shear wave velocity the soils and it has been used for the past 42 years. Shirley and Hampton (1978) was the first to measure the shear wave velocities in clay slurries using BEs and was able to measure the velocity as low as $2 \mathrm{~m} / \mathrm{s}$. The BEs consist a pair of bimorph transducers in which the bending motion is caused by the transmitting transducer when it is triggered by a small voltage, while the receiving transducer receives the vibration travelled through the specimen, producing a voltage output. The measurement of shear wave velocity for BEs can be calculated with equation 16 and the shear modulus can be determined using equation 17.

$$
V_{s}=\frac{L_{t t}}{t t}
$$

Where, $L_{t t}$ is the distance between elements and $t t$ is the time it takes for the wave to propagate through the medium. 
The BE test can be conducted either on the unconfined samples, or several apparatus such as trixial cell, oedometer and resonant column in order to determine the shear wave velocity measurements (Ferreira, 2018). Figure 22 illustrates a typical setup of BE system carried out in a trixial cell and Figure 23 illustrates the bender element probes for the unconfined test.

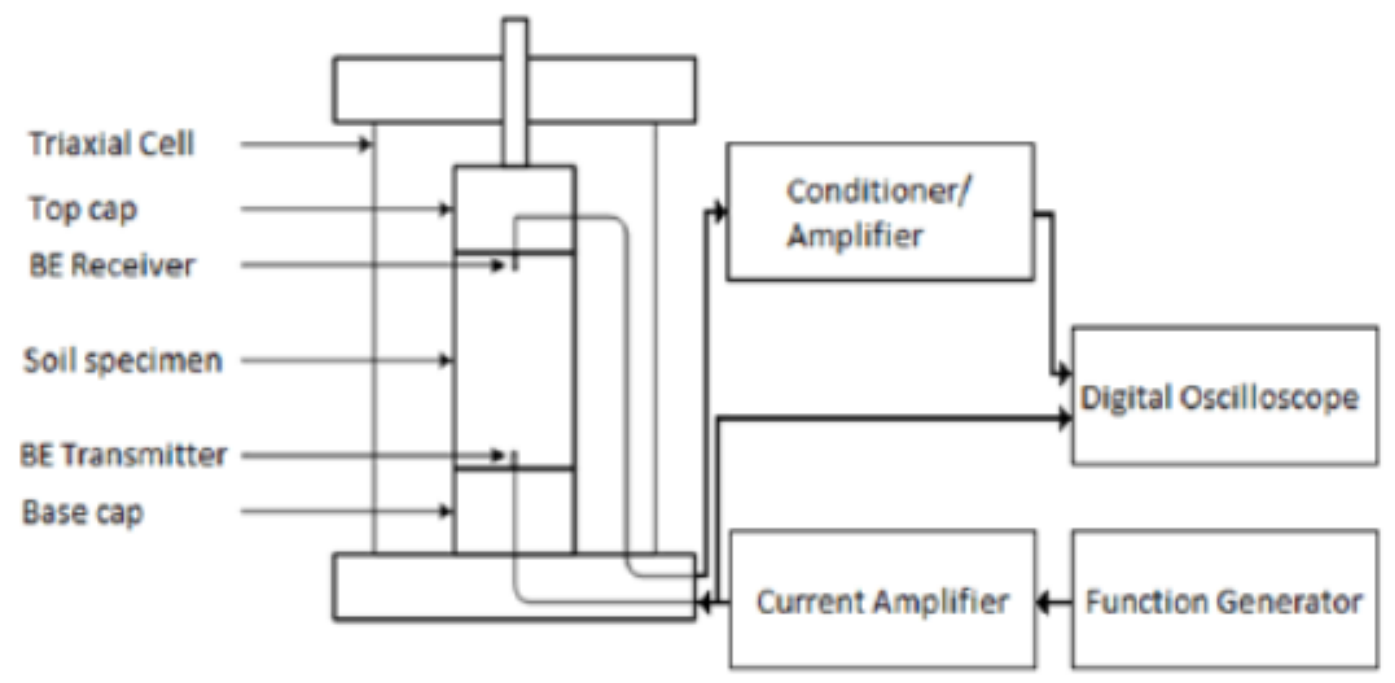

Figure 22: Schematic diagram of the BE system (Camacho-Tauta, 2011). 


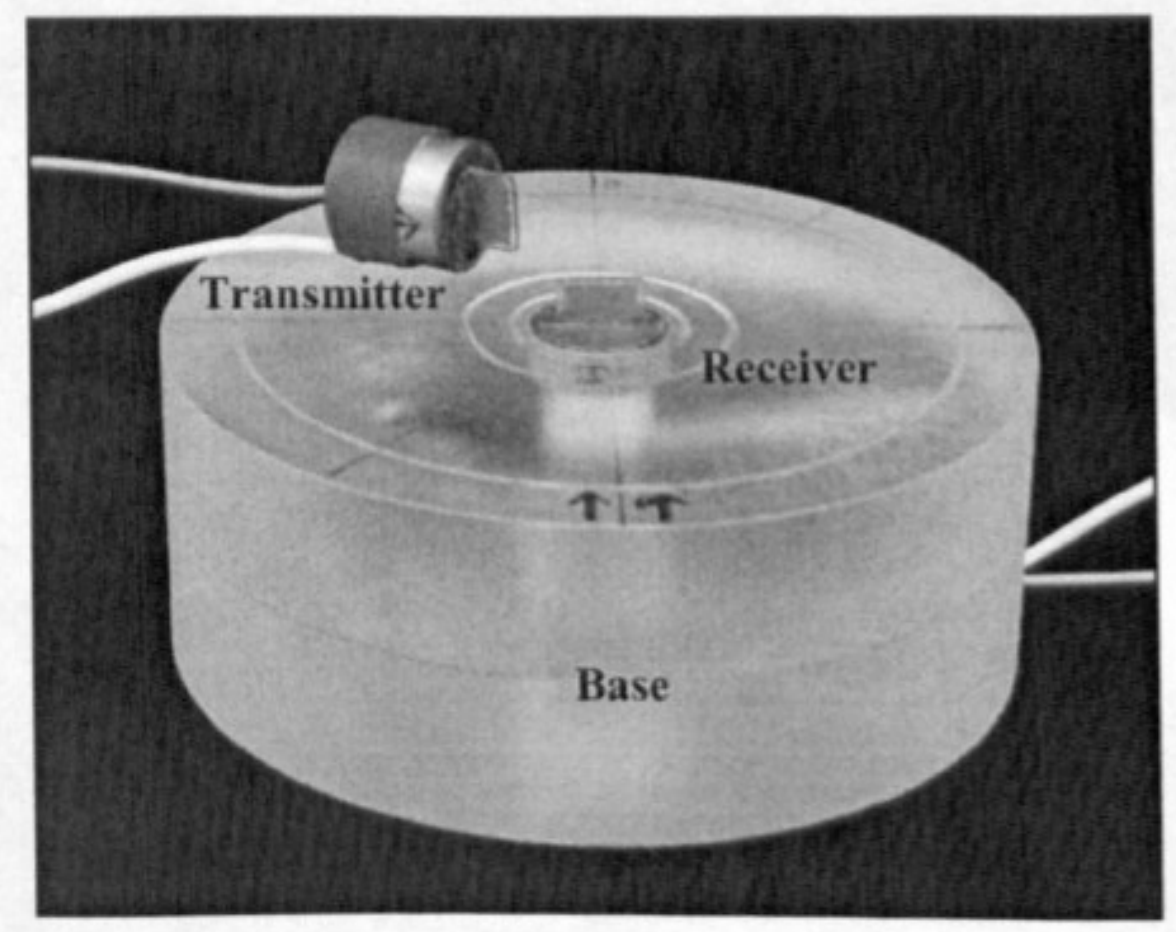

Figure 23: Bender element probes for the unconfined test (Chan, 2006).

There are several advantage of using the BE method such that the BE test is a relatively fast measurement method and is easy to use. In addition, minimal samples are required since different time intervals are used for testing the same sample.

\subsubsection{Properties of Bender Elements}

As mentioned previously, The BEs consist of a pair of piezoceramic of bimorph transducers which allows for the generation and detection of the shear wave propagating through the soil. The characteristic property of the bender element can be altered due to its polarity, resulting in the change of the polarization orientation (Camacho-Tauta, 2011). The change of the polarization orientation can be either in the same direction or in an opposite direction in order for the supply voltage to be applied to each layer 
individually, is called a parallel BE, presented in Figure 24a, and this arrangement is suitable when the BE is a transmitter (Camacho-Tauta, 2011). In addition, a pair consisting of two polarized elements placed in opposite directions operate in a series, illustrated in Figure 24b, and this placement is sufficient for the generating and converting mechanical energy into electrical energy, working as a receiver (CamachoTauta, 2011).

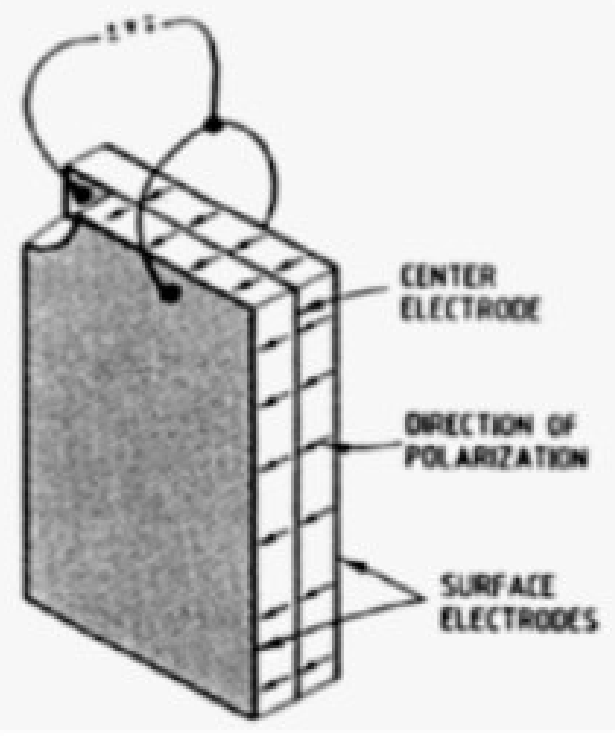

a)

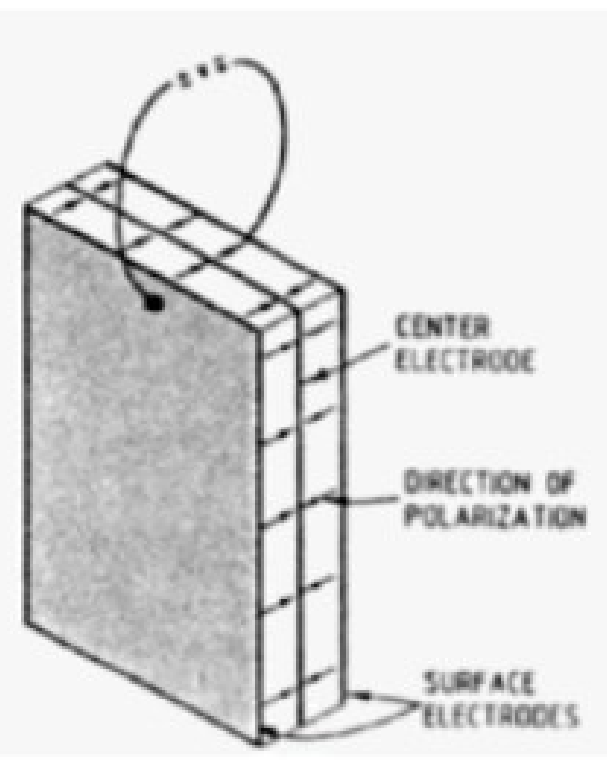

b)

Figure 24: Bender elements: a) parallel and b) series (Dyvik, 1985).

Figure 25 illustrates an example of the BE response to the single sinusoidal which is used to trigger the BE transmitter, and the receiving wave is illustrated on the same graph. 


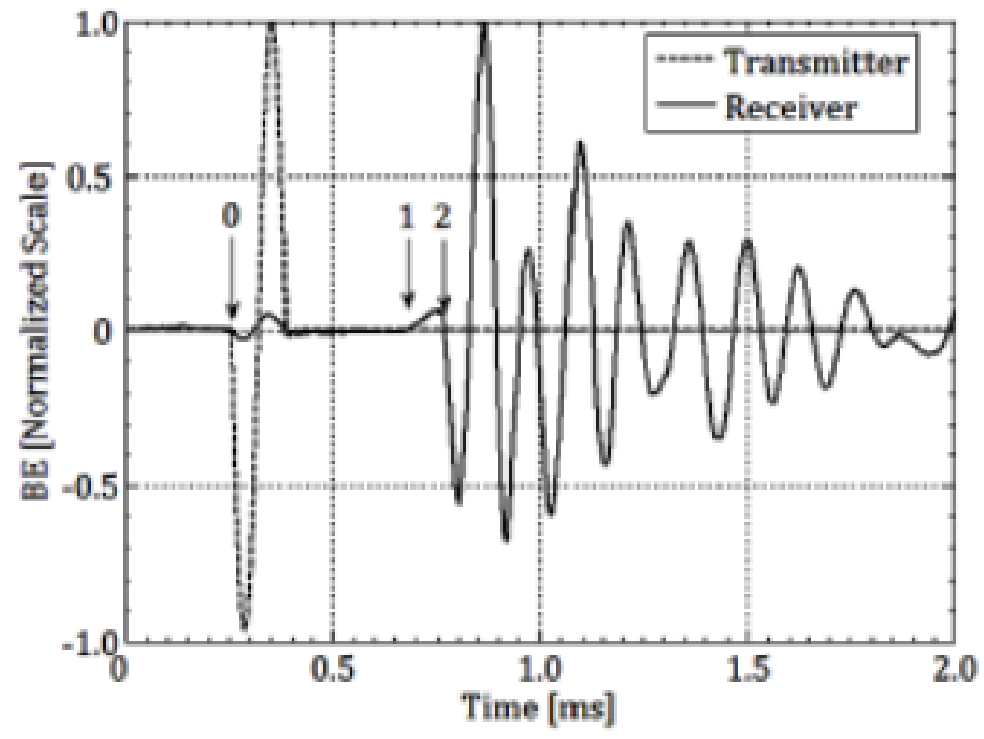

Figure 25: Transmitter and receiver time chart (Camacho-Tauta, 2011). 


\subsection{Oil Sand Tailings}

\subsubsection{Production of Oil Sand Tailings}

The oil sands play an essential role in the Canadian economy. Canada ranks third in the largest proven oil reserves with oil reserves of 172.5 billion barrels (NRC, 2016). In Canada, the deposition of the proven oil reserve are almost entirely located in three different areas in the province of Alberta: Athabasca, Peace River and Cold Lake, which is illustrated in Figure 26. Among all the regions, the Athabasca deposit is the largest deposit of the reserve oil and is the only one shallow enough to allow surface mining technique. As a result, the TSF located in Athabasca River is the one of the largest manmade structure and the landscape is so vast that it can be even visible from the International Space Station. Figure 27 illustrates the difference of Athabasca oil Sands area between 1984 and 2016. 


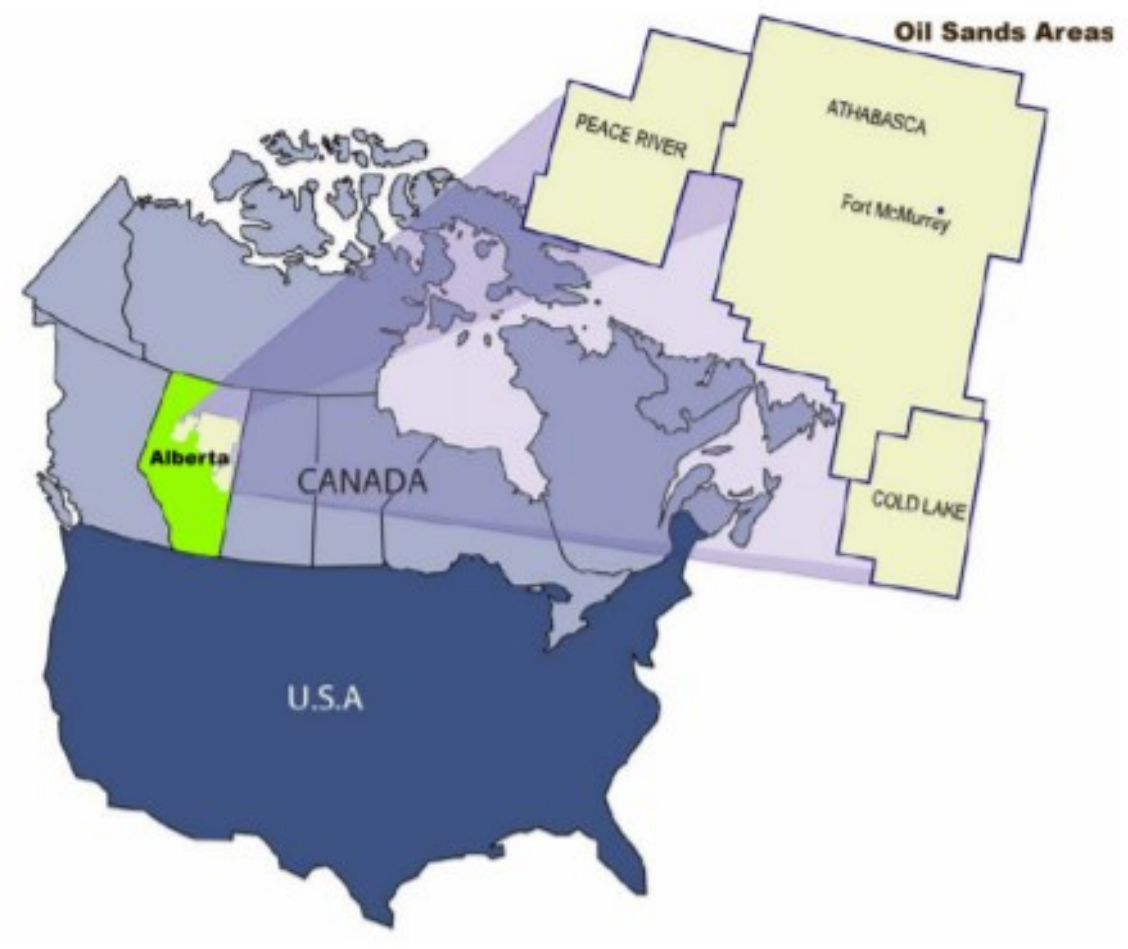

Figure 26: Alberta's three oil sands areas (AEUB, 2007).
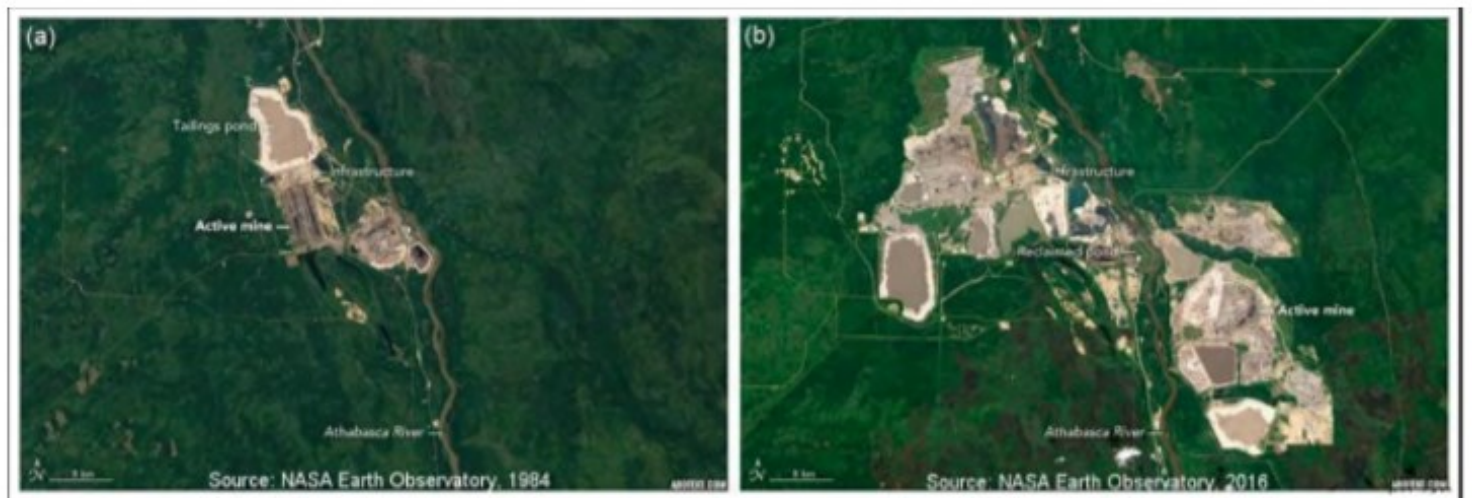

Figure 27: (a) The picture of Athabasca oil sands area in 1984 and (b) the picture of Athabasca oil sands area in 2016 (Nasa Earth Observatory, 2019). 
The oil sands are mainly of $75 \%$ to $80 \%$ inorganic material (mostly quartz sand), surrounded by a layer of $3 \%$ to $5 \%$ water and $3 \%$ to $12 \%$ clay and slit, and then covered with a $10 \%$ to $12 \%$ heavy oil, known as bitumen (National Energy Board, 2006). Figure 28 illustrates the general arrangement of these components of the oil sands.

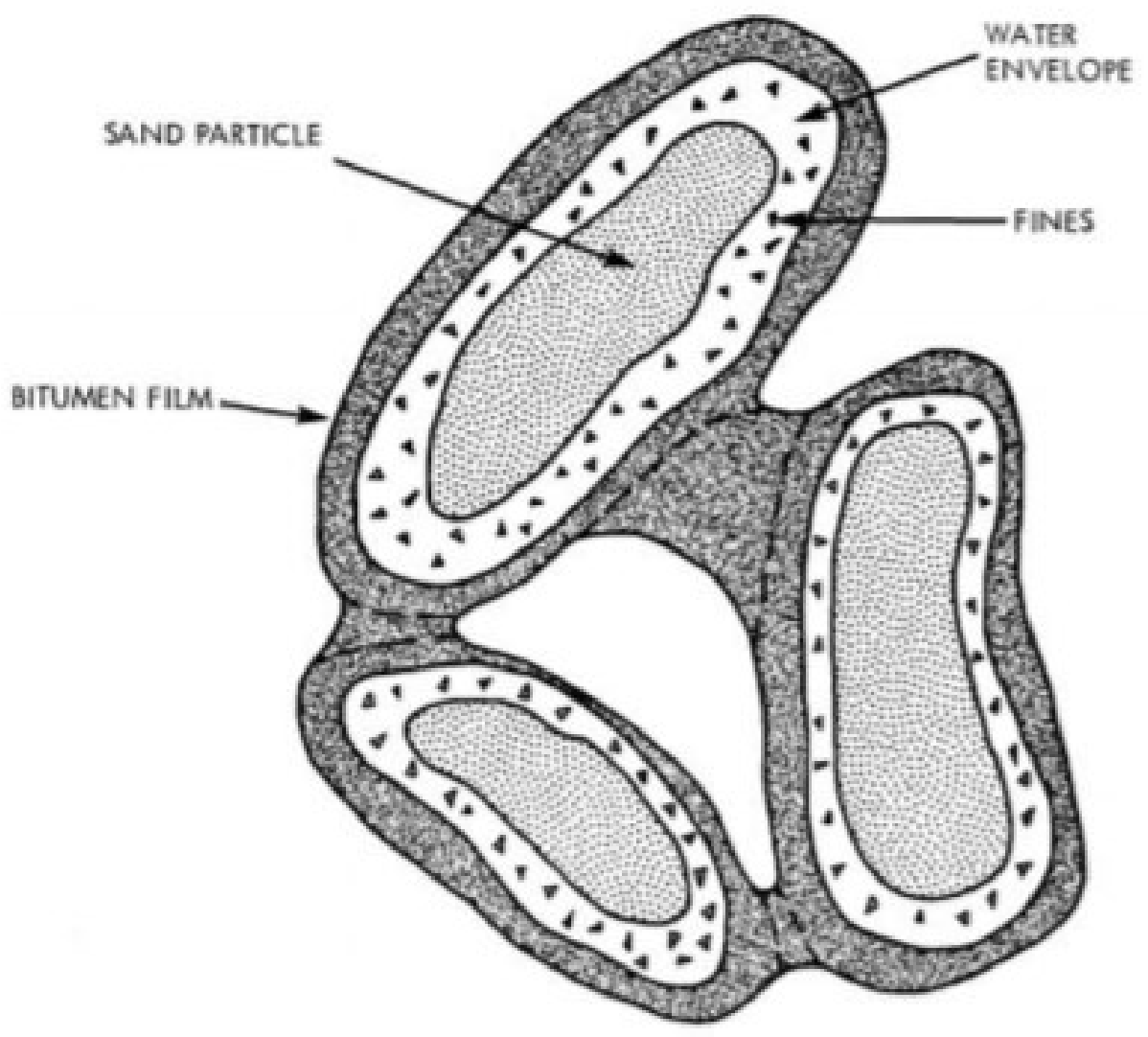

Figure 28: Arrangement of oil sand particles (ARC Tailings, 1977)

In Alberta, oil sands mining and extraction processes have led to the production of tremendous amount of volume of tailings. Tailings are mainly comprised of water, sand, fine clay particles, slit, other hydrocarbon and residual bitumen (Beier and Sego, 2008). These mixtures are typically transported and disposed in the large engineered dam and 
dykes facilities known as tailings storage facility (TSF) where tailings particles gradually settle and segregate, which is depicted in Figure 29. Sand with the densest solid settle to the bottom and water with the least dense floating to the top, separating the bitumen also known as fluid fine tailings (FFT) with the solid content in the order of $8 \%$ (OSRIN Report, 2010). After several years, the FFT will gradually settle to achieve approximate 30\% (w/w) solid content (Siddique et al, 2014; Thompson et al, 2017).

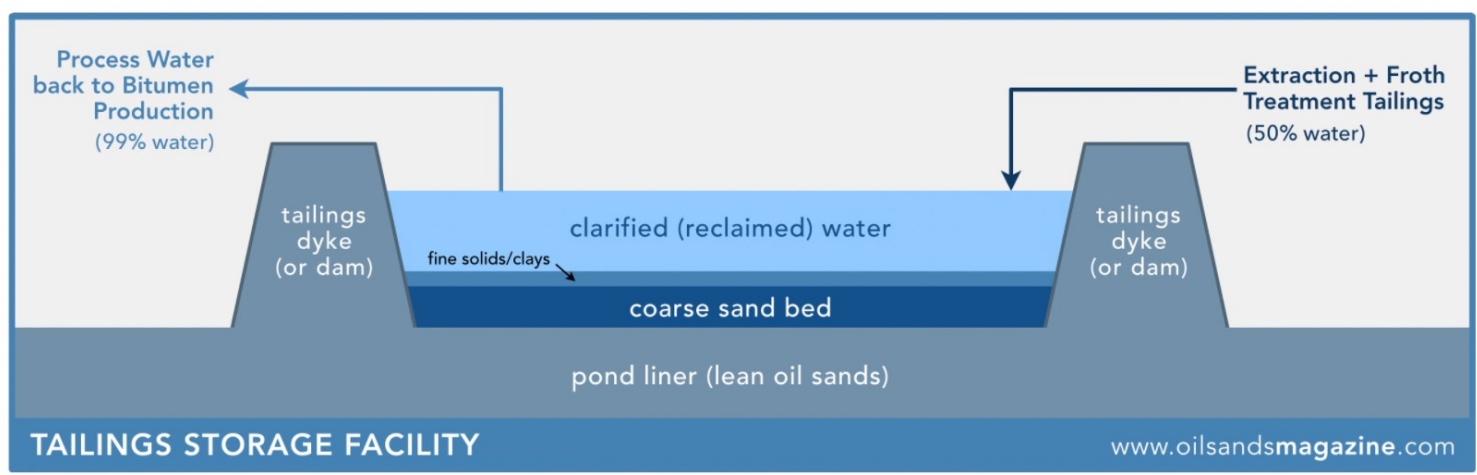

Figure 29: Management of Tailings Ponds (www.oilsandsmagazime.com).

The biggest challenged faced by most oil sands industries in tailing management is that tailings require a long period of time to reach full consolidation. The poor consolidation properties of the FFT often lead to generation of massive volume of tailings. The continuous accumulation of FFT has raised concern to the public in term of environmental protection and land use. In response to this concern, numerous researches have been conducted, with the aim of minimizing volume of tailings and increase the strength of FFT. 


\subsubsection{The Extraction Process of Bitumen}

The method of extracting the bitumen was first proposed by Dr. Karl Clark in 1920 using the Clark Hot Water Extraction (CWHE) process. This technique involves mixing hot water and $\mathrm{NaOH}$ with oil sands in order to liberate the bitumen (Shaw, 1996).

Figure 28 depicts the schematic diagram of the bitumen extraction from oil sands using CHWE process. In the bitumen extraction process, after oil sands are mine and the oil sand lumps are crushed, the oil sands will undergo 3 stages in the CHWE process. The initial stage of this process is called conditioning in which the use of $\mathrm{NaOH}$ is involved to maintain the $\mathrm{pH}$ level of the solution between 8.0 and 8.5. The purpose of adding the $\mathrm{NaOH}$ is to increase the first $10 \mathrm{~nm}$ of water film between bitumen and sands in order to easily separate the bitumen from the sand particles (Takamura, 1982). As a result, the separation of bitumen become easy and the clay particle would disperse into aqueous phase due to the increased surface charge of solids (Bakhtiari, 2015). Figure 30 illustrates the release of bitumen by increasing the electrostatic repulsive forces between bitumen and sands (Jeeravipoolvarn, 2005). The second stage is called primary separation and this stage involves mixing the hot water with the solutions to better separate the sand particles and the bitumen (Jeeravipoolvarn, 2005). The sand particles settle to the bottom and they become part of the tailings steam. In addition, the bitumen is separated as a froth which floats to primary separation vessels. The final stage of this process is called scavenging and this stage involves using de-aeration to further extract the bitumen from the bitumen froth (Yang, 2010). The bitumen froth consists of bitumen, water, solids and air. 


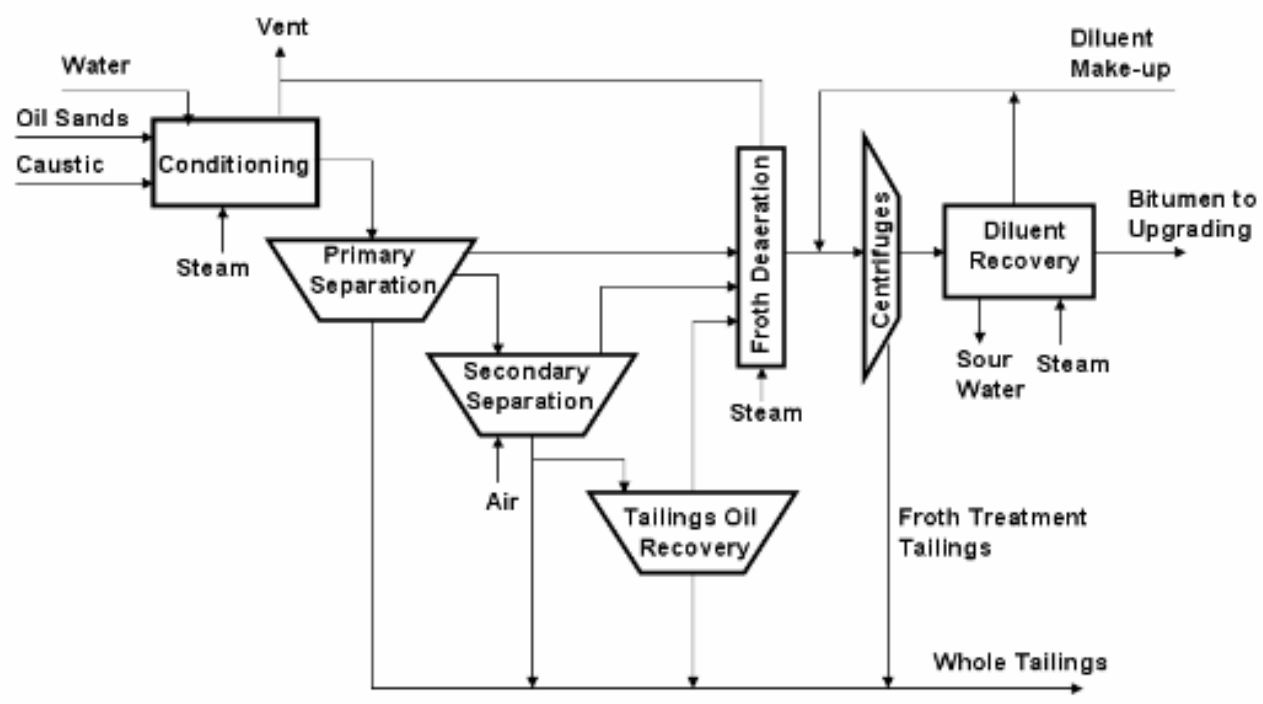

Figure 30: The schematic of Clark Hot Water Extraction Process (Chalaturnyk, R.J. et al., 2004).

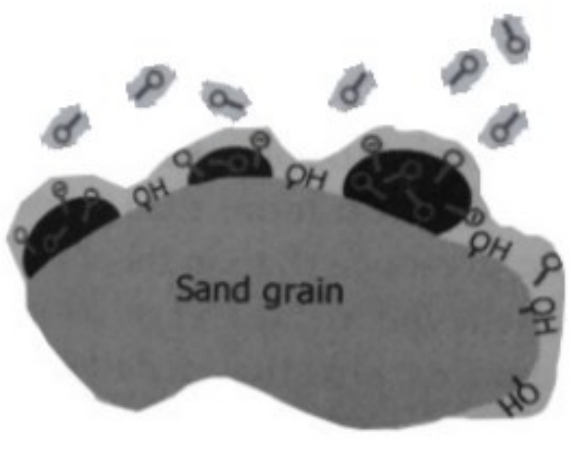

a)

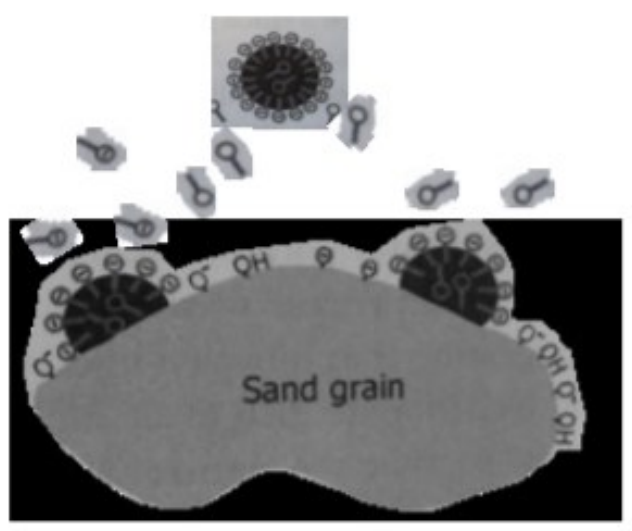

b)

Figure 31: The effect of $\mathrm{NaOH}$ on release of surfactants and hydrolysis sands. a) Low $\mathrm{pH}$ and b) High pH (Masliyah, 2011). 


\subsubsection{Tailings Disposal Method}

As mentioned previously, tailings are mainly comprised of water, sand, fine clay particles, slit, other hydrocarbon and residual bitumen (Beier and Sego, 2008). The tailings generated from the extracted are typically transported and stored in the large engineered dam and dykes facilities also known as tailings storage facility (TSF), shown in Figure 32.

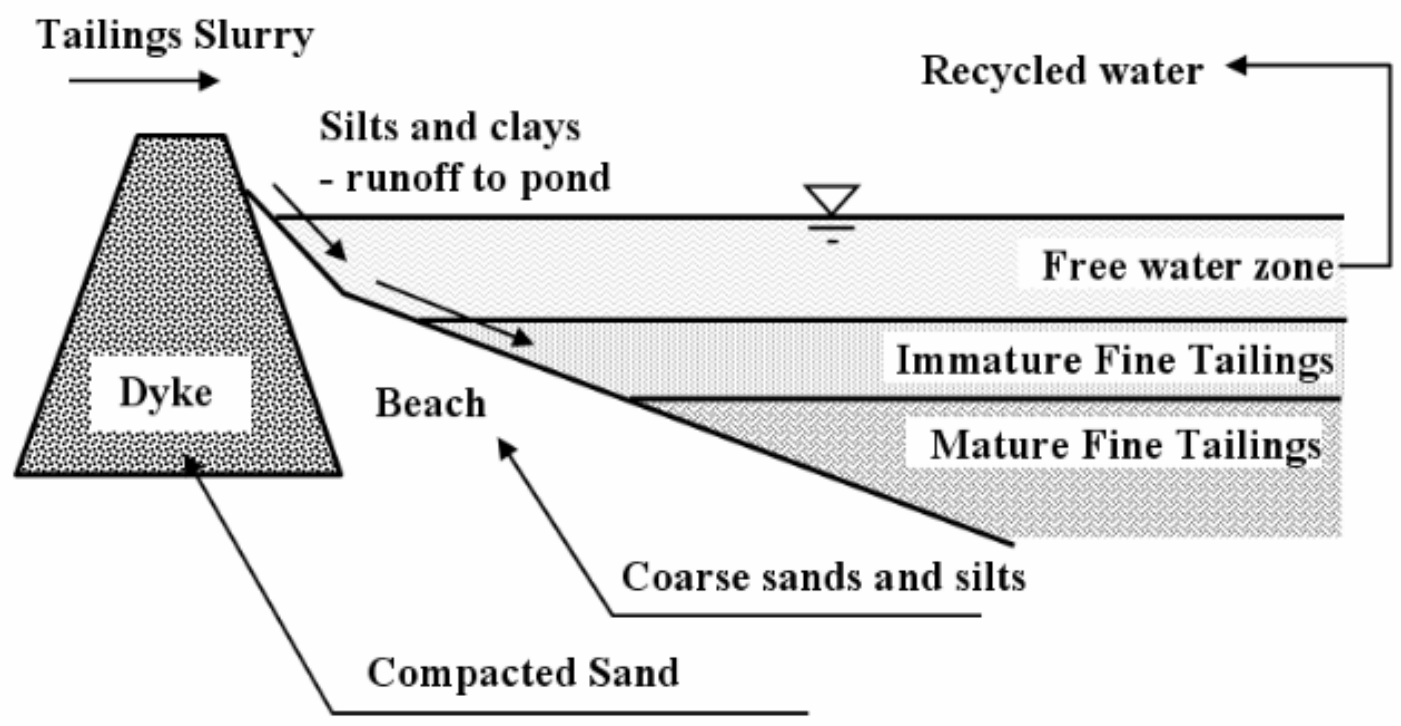

Figure 32: Oil sands tailings basin (Fine Tailings Fundamental Consortium, 1995).

From Figure 32, the dyke and beach are formed from the coarse solids of the tailings while the fine solids and residual bitumen will discharge into the ponds with the solids content of an approximate $8 \%$. Over time, water will separate from the tailings and float to the top of the tailings pond which is also known as free water zone. In this zone, water is recycled and pumped back to the extraction process. Under the free water zone is the immature fine tailing in which 
the fine tailings has the solids content lesser than $30 \%$. At the very bottom stage of the tailings pond is the mature fine tailings or fluid fine tailings. At this zone, the tailings has consolidated to achieve a solid content of $30 \%$ and no further consolidation taking place after that.

\subsubsection{Technologies for the Treatment of Fluid Fine Tailings}

The biggest challenged faced by most oil sands industries in tailing management is that tailings take a long period of time to reach full consolidation. When FFT achieve a solid content of $30 \%$, dewatering becomes an issue. As a result, the poor consolidation properties of the FFT often lead to an accumulation volume of tailings. In response to this situation, considerable efforts are made by industry and researchers to implement technologies for the treatment of FFT. Therefore, implementation of technologies to treat FFT are divided into four groups (BGC, 2010):

1. Physical/Mechanical Processes

2. Natural Process

3. Chemical Treatment

4. Mixture/Co-disposal

\subsubsection{Physical/Mechanical Processes}

These processes involve separating water from solids. Several technologies associated with physical/mechanical processes are as follows:

1. Filtered Whole Tailings: Filtration is one of the most common methods used in the industries for solid-liquid separation. The pilot-scale of this 
experiment was conducted on a different bitumen extraction process in the mid-1990s. However, this experiment turned out to be unsuccessful due to the coarse particles settle rapidly and would eventually build up a thick penetrable filter cake (BGC, 2010). As a result, this would cause the fines particle to settle on to the surface and blocking the filtration pathway. This method was attempted again in the laboratory-scale and the results indicate that it is impossible to filter more than $4 \%$ fines without using the flocculant and the average mean of the fines content of the whole tailings stream is about $18 \%$ (Xu et al., 2008)

2. Centrifuge fine tailings: The centrifuge method is achieved by applying thousands of time of gravity in order to separate the fluid from the material, increasing the solid content to $60 \%$ (BGC, 2008).

3. Thermal Drying FFT: The thermal drying involves heating up the FFT in the oven in order to reduce the moisture content of FFT. This method could remove the moisture content of FFT higher than other dewatering technologies, in which $90 \%$ of solid content is achievable with thermal drying (BCG, 2008).

\subsubsection{Natural Process}

The natural process involves separating water from solids using environmental or geophysical. The followings are some technologies associated with natural process:

1. Evaporation/Drying: The method is done by allowing the FFT to "selfdrying" to remove the moisture content by evaporation. The 
evaporation/dying technique is the most cost effective way of dewatering FFT. However, evaporation method might be impossible in some regions due to climate, for instance, Northern Alberta.

2. Freeze/thaw: This process involves freezing the FFT and then frozen mass is allowed to thaw the following summer (BGC, 2010). A significant amount of water content has been released when $5 \mathrm{~cm}$ to $15 \mathrm{~cm}$ of thin layers are subjected to freeze-thaw cycles (Dawson et al., 1993; Johnson et al., 1993) By the end of this process, it was found that there is a significant increase in the solids content of FFT from $35 \%$ to $56 \%$ (Beier et al., 2009).

\subsubsection{Chemical Treatment}

Increasing the dewatering rate and improving the strength of the FFT using the polymer-aided flocculation of fine clay particles has been studied extensively by the oil sands industries. By mixing the flocculants with FFT, this reaction will create a bridge formation between the fine particles in the FFT in order to create a large aggregates, presented in Figure 33 (Salam, 2020). As a result, these aggregates will settle more rapidly and significant high solid content can be achieved. 


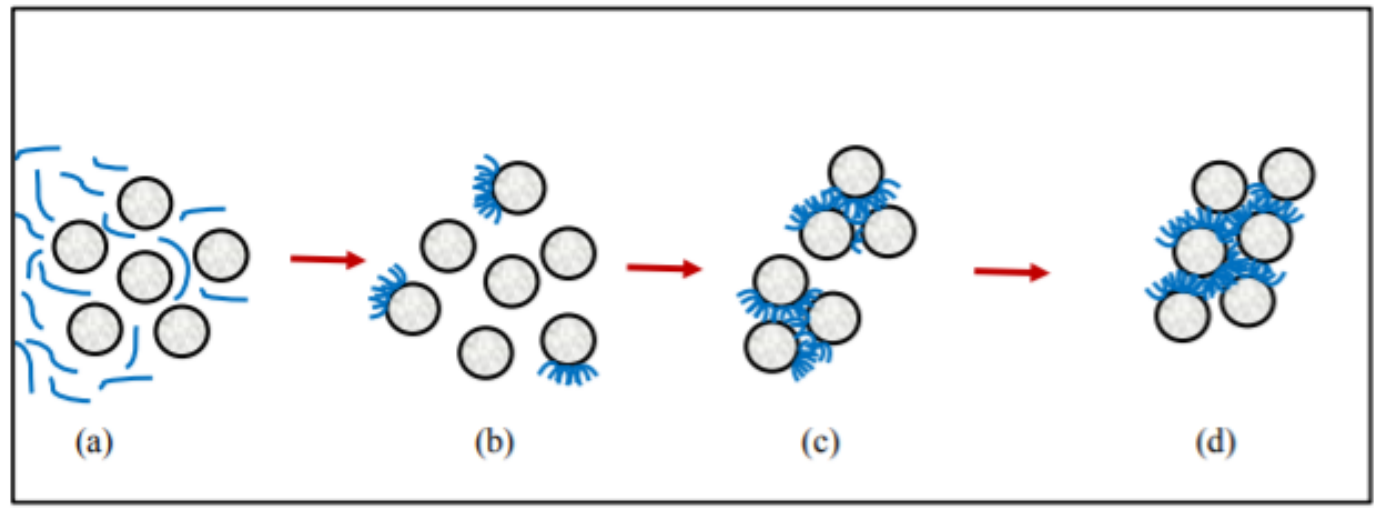

Figure 33: Bridging formation of fine tailings of FFT (adapted from Kitchener, 1972).

\subsubsection{Mixture/Co-disposal}

Mixture/co-disposal technologies involve mixing FFT with denser solid materials in order to enhance the density of FFT. One of the mixture/co-disposal technologies is composite/consolidate tailings (CT) and this technology was developed at the University of Alberta (Caughill et al., 1993). The CT process involves mixing the coarse sand solid with FFT (4:1 sand to fines ratio) with an amendment (typically gypsum) to create a nonsegregating slurry to produce a slurry density of approximately $60 \%$ solids (BGC, 2010). 


\section{Chapter 3: Material Characterization and Experimental Procedures}

\subsection{Introduction}

The purpose of this chapter is to introduce the material and equipment used in the research. This includes i) characterization of the oil sands tailings, ii) a detail description of the UPV test apparatus and experimental procedures to interrogate the changes in flocculated fluid fine tailings during settlement. A description of the methodology used to calibrate the ultrasonic transducers is also presented in this chapter.

\subsection{Oil Sands Tailings}

In this study, oil sands tailings used were obtained from an oil sands extraction operation in Northern Alberta, Canada and was delivered to Carleton University, Ottawa, Canada. In addition, the tailings were then shipped to the NDT (Non-Destructive Testing) laboratory at the University of Waterloo for ultrasonic testing. Tailings will settle during transport. Therefore, before the tailings were characterized or used in any experiments, the tailings were remixed with their bleed water (using a spatula for 2 minutes) to reinstate their composition and recover their initial solid content.

\subsection{The Properties of Oil Sands Tailings}

Several laboratory tests and analyses were conducted on the tailings in order to monitor the changes in properties such as their physical and mineralogical and chemical characteristics as time progresses. The main objective to characterize the properties of oil sands tailings is so that the changes of properties could be monitored. The test results could also be used to compare the properties of the FFT used in this experiment with the 
properties of the FFT used in previous studies. The following table illustrates the difference between the properties of FFT used in the current experiment and other studies.

Table 1: Geotechnical properties of unamended FFT (compared with other FFTs) (Salam, 2020).

\begin{tabular}{|c|c|c|c|c|c|c|}
\hline Property & Unit & $\begin{array}{c}\text { ASTM } \\
\text { Standard }\end{array}$ & $\begin{array}{c}\text { Current } \\
\text { Study } \\
(2021)\end{array}$ & $\begin{array}{c}\text { Salam } \\
(2020)\end{array}$ & $\begin{array}{c}\text { Mizani } \\
(2016)\end{array}$ & $\begin{array}{c}\text { Yao } \\
(2016)\end{array}$ \\
\hline Solids content & $\%$ & $\mathrm{D} 2216-19$ & 31.3 & 31 & 33.4 & 32 \\
\hline Water content & $\%$ & $\mathrm{D} 2216-19$ & 224.7 & 222.6 & 199.6 & 213 \\
\hline Specific gravity & & $\mathrm{D} 854-10$ & 2.2 & 2.2 & 2.2 & 2.3 \\
\hline $\begin{array}{c}\text { Bitumen } \\
\text { content }\end{array}$ & $\%$ & $\mathrm{D} 95-05$ & & 1.41 & 2.9 & 1.3 \\
\hline $\begin{array}{c}\text { Total bulk } \\
\text { density }\end{array}$ & $\mathrm{g} / \mathrm{cm} 3$ & $\mathrm{D} 7263-09$ & 1.2 & 1.2 & 1.2 & 1.2 \\
\hline
\end{tabular}

How the basic properties were calculated (solids content $\left(\mathrm{C}_{\mathrm{s}}\right)$, gravimetric water content $(\mathrm{GWC})$, specific gravity $\left(\mathrm{G}_{\mathrm{s}}\right)$, bitumen content, void ratio, methylene blue index (MBI) test, mineralogy, pore-water chemistry and particle size distribution) are described in Appendix A.

\subsection{Preparation of Polymer Stock Solution}

An anionic polyacrylamide (PAM) polymer A3338 is the flocculants used to condition the FFT. Two grams of polymer A3338 was placed on the weighing paper and was weighed using an analytical balance (Fisher scientific, Sartorius AG Germany, LE225D). $498 \mathrm{~mL}$ of deionized water was poured into a $1000 \mathrm{~mL}$ glass beaker with 2 gram of polymer A3338. The jar tester (Phipps and Bird, PB 700 Jar Tester), illustrated in Figure 34. Mixing was initially set up to 200 RPM to stir the flocculants and deionized 
water in the beaker together for 5 minutes. After 5 minutes, the speed was reduced to 125 RPM and continued stirring for the following 55 minutes. After 55 minutes, the polymer stock solution was finally ready and left for maturation for an hour.

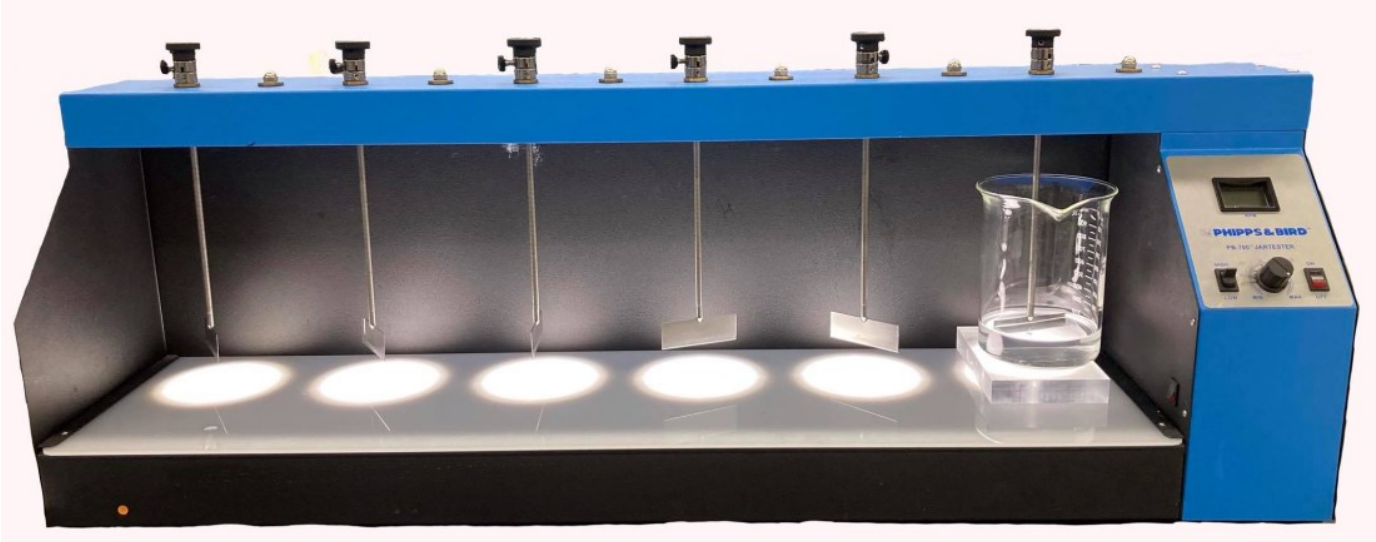

Figure 34: Preparation of the polymer stock solution using Jar tester. 


\subsection{Preparation of Flocculated FFT (fFFT)}

To condition the tailings, $300 \mathrm{~mL}$ of FFT was poured into an empty bucket. Using the $600 \mathrm{PPM}$ dose, $180 \mathrm{~mL}$ of polymer stock solution was transferred into another beaker. The overhead stirrer was set up to 250 RPM to stir the FFT. The $180 \mathrm{~mL}$ of the polymer stock solution was then poured in the bucket and was mixed with the FFT for 20 seconds. This procedure is similar to those adopted in a wide range of studies to simulate field flocculated FFT (Mizani et al., 2017). The reader, however, should be aware that multiple techniques are used in industry and academia in the preparation of fFFT such as trialled which was adapted from the Northern Alberta Institute of Technology (NAIT) (Salam, 2020). This technique used in this study is only used to facilitate comparison with fFFT samples generated in other studies (Salam, 2020). 


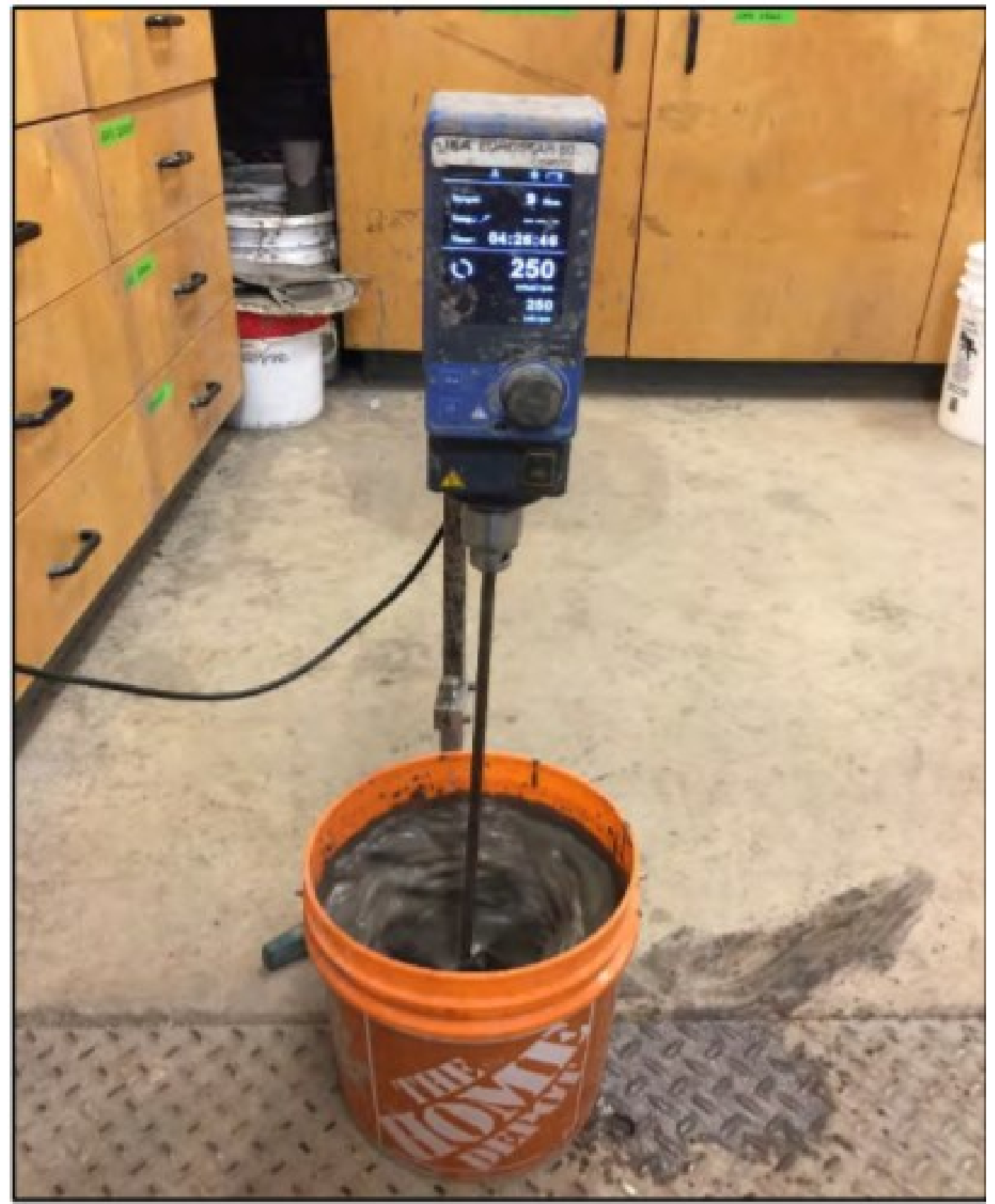

Figure 35: The mixing of the of the polymer stock solution with the FFT. 


\subsection{Settling test}

After mixing the polymer with FFT, the settling test was performed in three different polymer dosages (0 PPM, 600 PPM and 1000 PPM) prior to the ultrasonic testing. The main objective of the settling test is to see the response of the tailings to the different dosages of polymer as well as to ensure a consistent quality. In this experiment, six graduated cylinders are used to evaluate the change in the solid-liquid interface (mudline) as a function of time, and thus, a settling profile is generated, illustrated in

Figure 36. The settlement of the solid particles can be then calculated using the following equation:

$$
\text { Settlement }(\%)=\left[\frac{\text { Initial Height }- \text { Elevation Height }}{\text { Initial Height }}\right] \times 100 \%
$$

Where elevation height is the settlement of the tailings-water interface. 


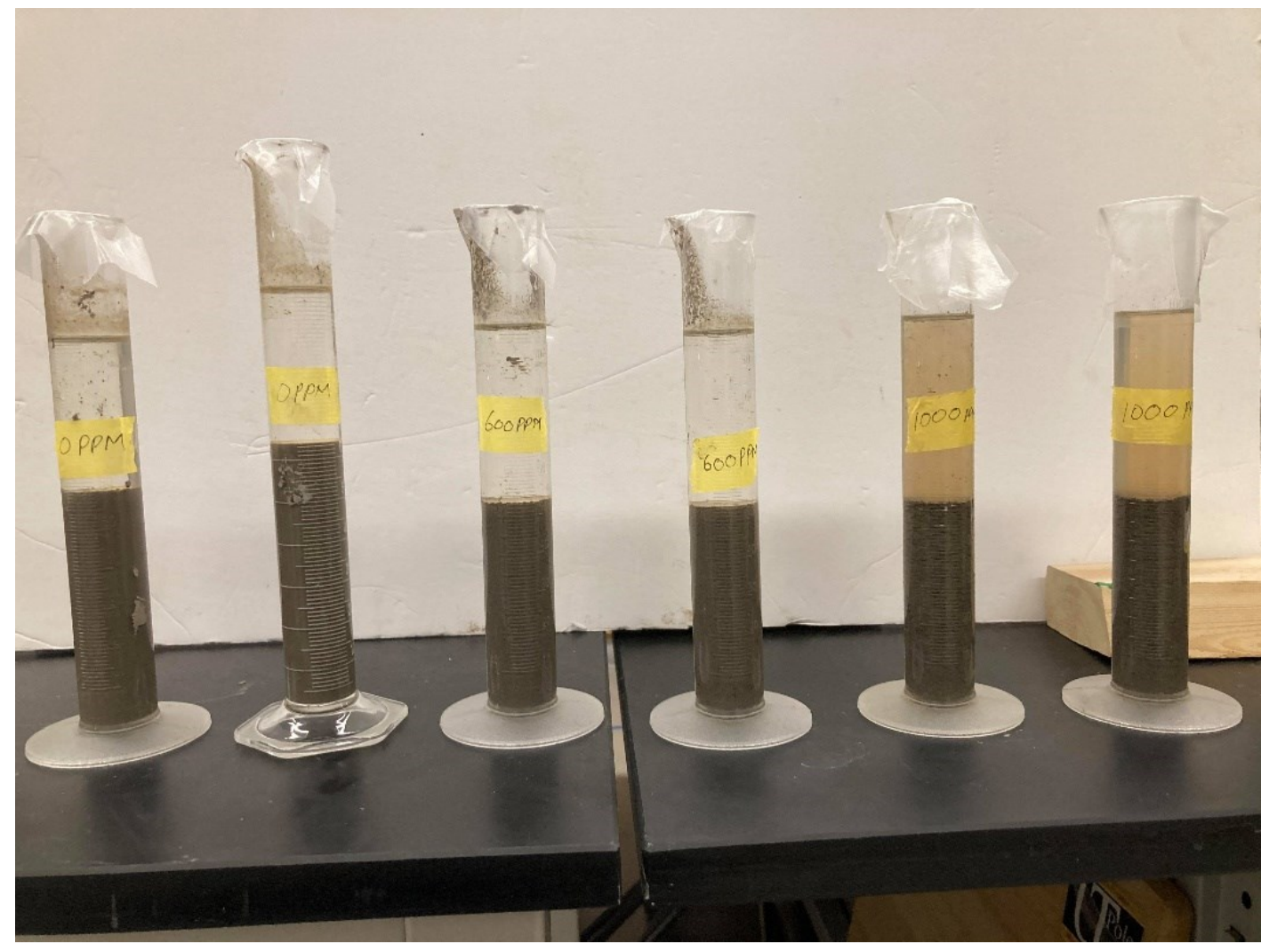

Figure 36: The settling test performed on the graduated cylinder, each with a height of $16.8 \mathrm{~cm}$, with different polymer dosages. 


\subsection{Calibration of Ultrasonic Equipment}

According to the ASTM E1316 - 11b, the characterization of instrument is an important procedure required prior to any testing in order to obtain more effective and reliable results and this same goes to the transducers in the UPV method. In ultrasonic testing, the ultrasonic transducers themselves play an important role as they interact with the medium and therefore influence signal properties. Therefore, the calibration of the ultrasonic transducers is essential, conventional methods such as reference standard bars and face to face procedure were used to calibrate the ultrasonic transducers to determine the delay time introduced by the instrumentation itself and the coupling between the transducer and the medium. In the reference standard bars procedure, the calibration is performed using steel bars (length of 49.2, 124, 158 and $198 \mathrm{~mm}$ and diameter of 49.75 $\mathrm{mm}$ ) and PVC bars (length of 51.08, 101.12, 150.7, $200 \mathrm{~mm}$ and diameter of $50.75 \mathrm{~mm}$ ), illustrated in Figure 37. In addition, the calibration was also performed using water inside the experimental apparatus and the experimental alone. Figure 38 illustrates the employed configurations of the characterization instrumentation. 


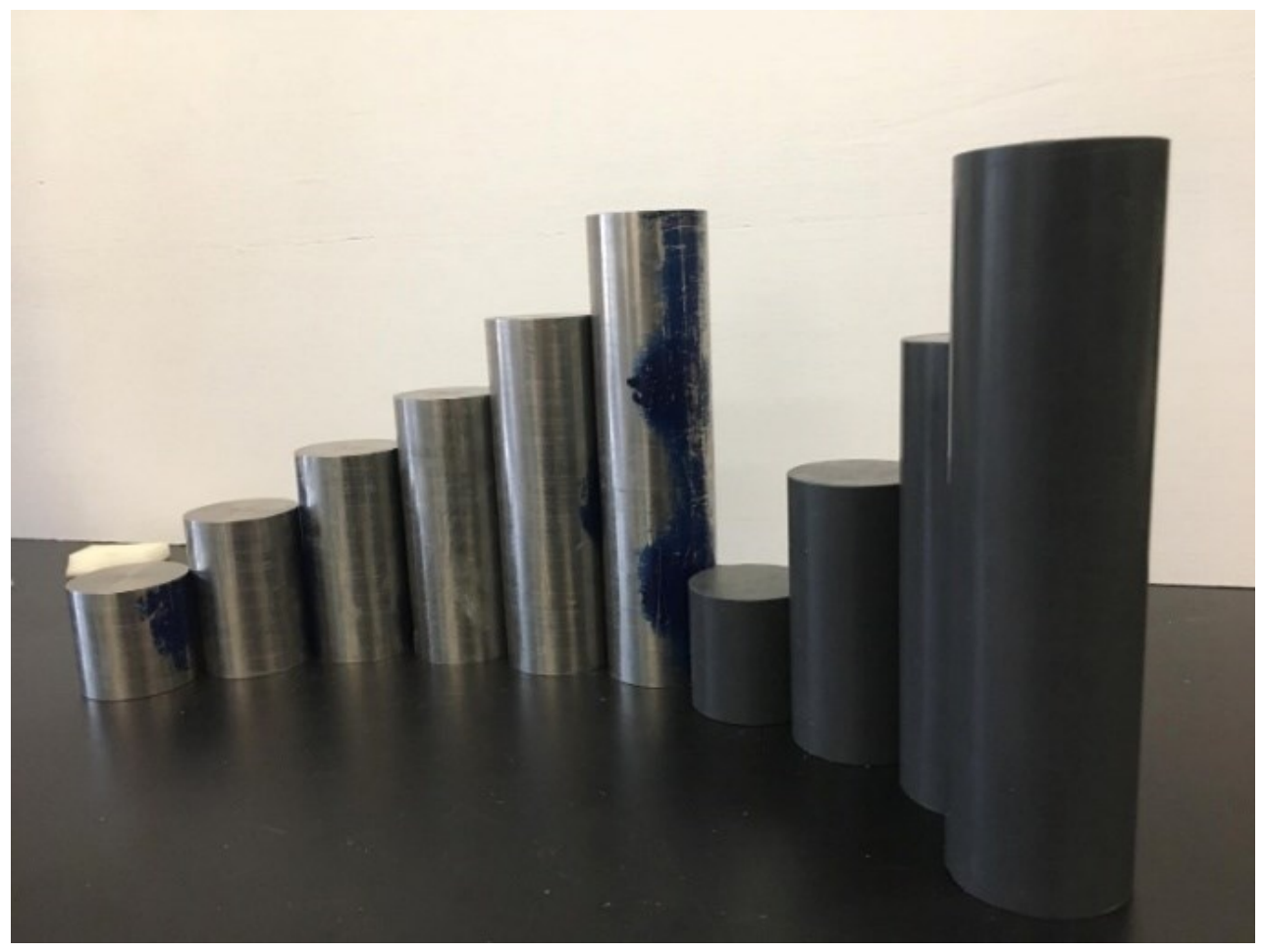

Figure 37: Standard calibration reference steel and PVC bars

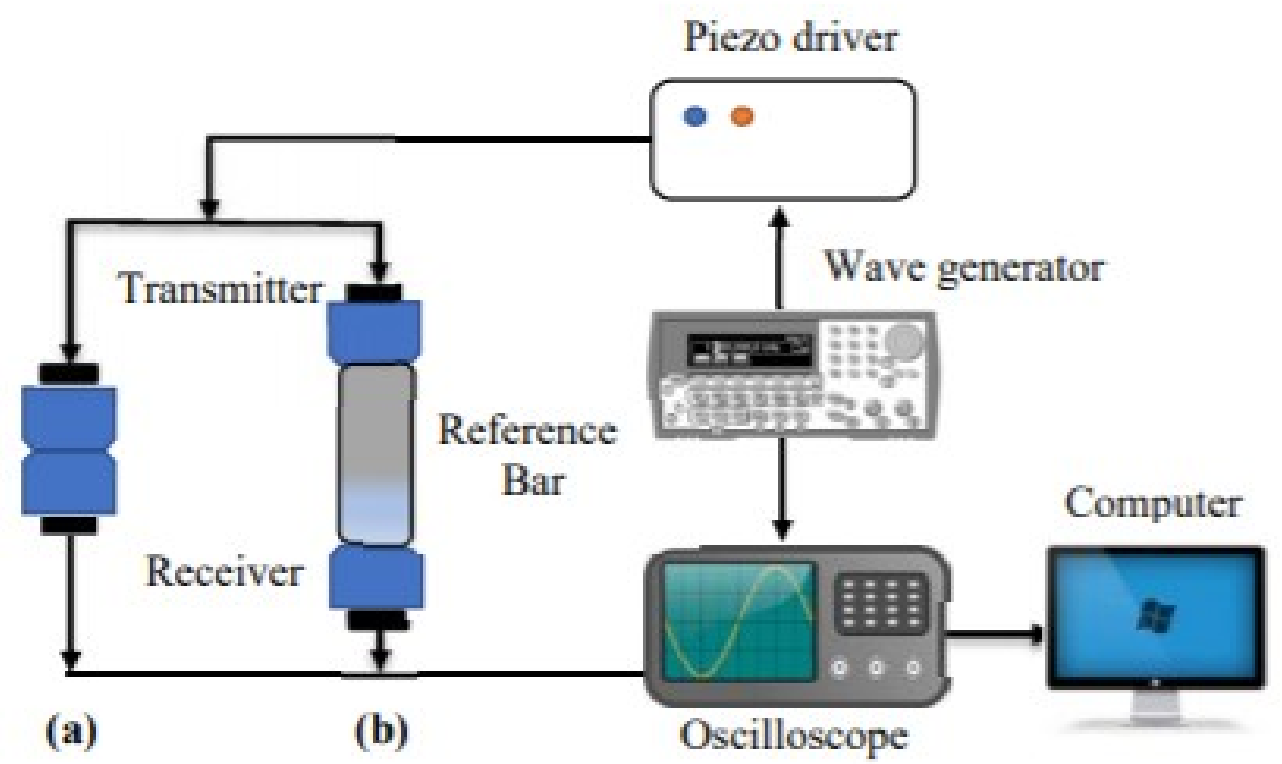

Figure 38: Calibration test setup: (a) face to face and (b) reference standard bar (Fartosy, 2018) 


\subsection{D - Printed Equipment}

The 3D - printed equipment for this experiment consist of the column and the transducers holders, which were designed using AutoCAD software and produced by a $3 \mathrm{D}$ - printer. Information on the 3D printing of the holders and the column such as drafting software requirements as well as material of the column and holders are described in Appendix C. The advantages of using the 3D printing are also described in the section.

\subsubsection{D - Column}

The 3D - column consists of three separate cylinders and the base which were designed to contain the fFFT for the ultrasonic testing. The height and diameter of each of the cylinder are $185 \mathrm{~mm}$ and $110 \mathrm{~mm}$, respectively. Each cylinder is comprised of column's plates and embedded aluminum bars (length of $12.4 \mathrm{~mm}$, height of $130 \mathrm{~mm}$ and $1 \mathrm{~mm}$ in thickness), illustrated in Figure 39 and 40, respectively. The purpose of the column plates are to provide a place for compressional transducers to be connected while the aluminum bars are for shear transducers. In addition, the bender elements were also installed in the column but they are not used as part of this experiment. 


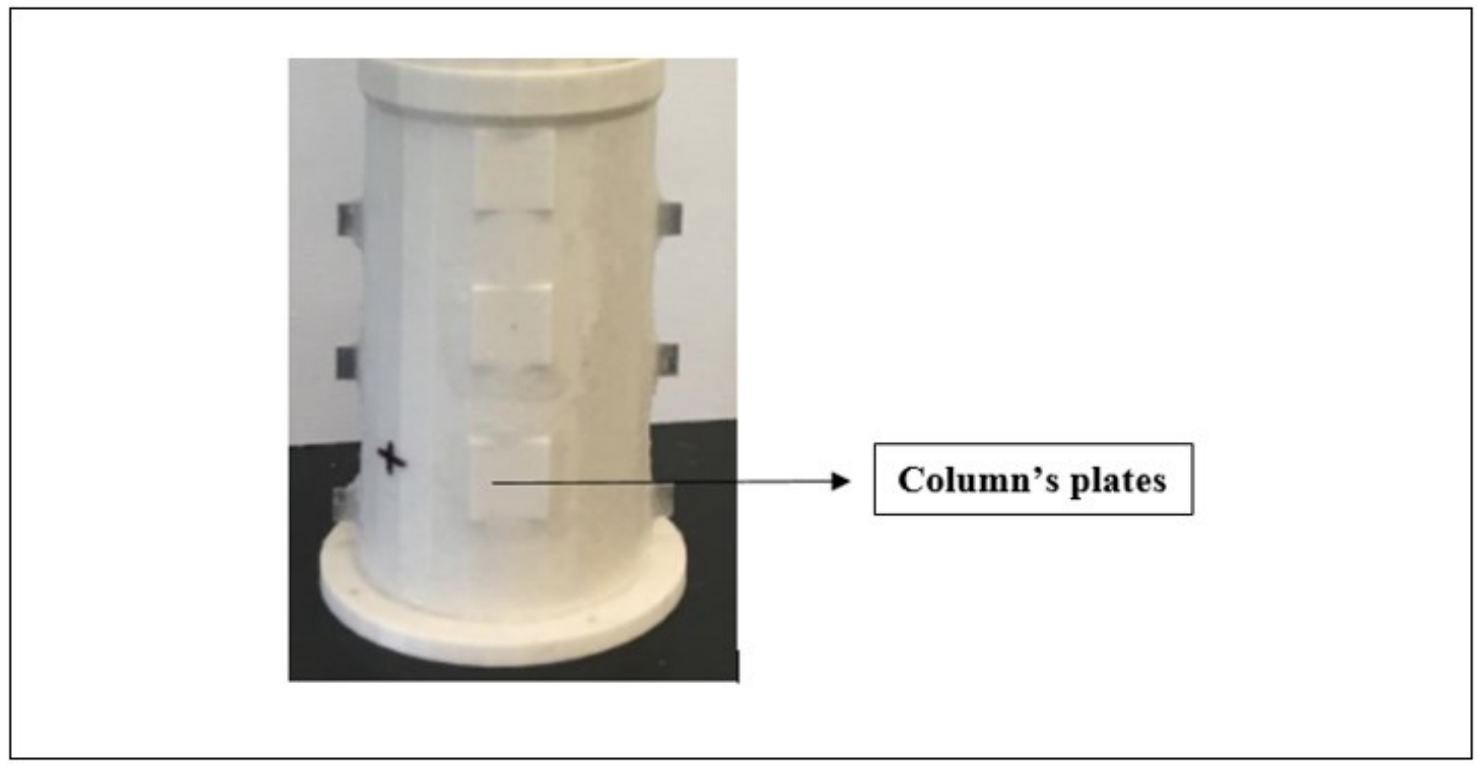

Figure 39: Column's plates.

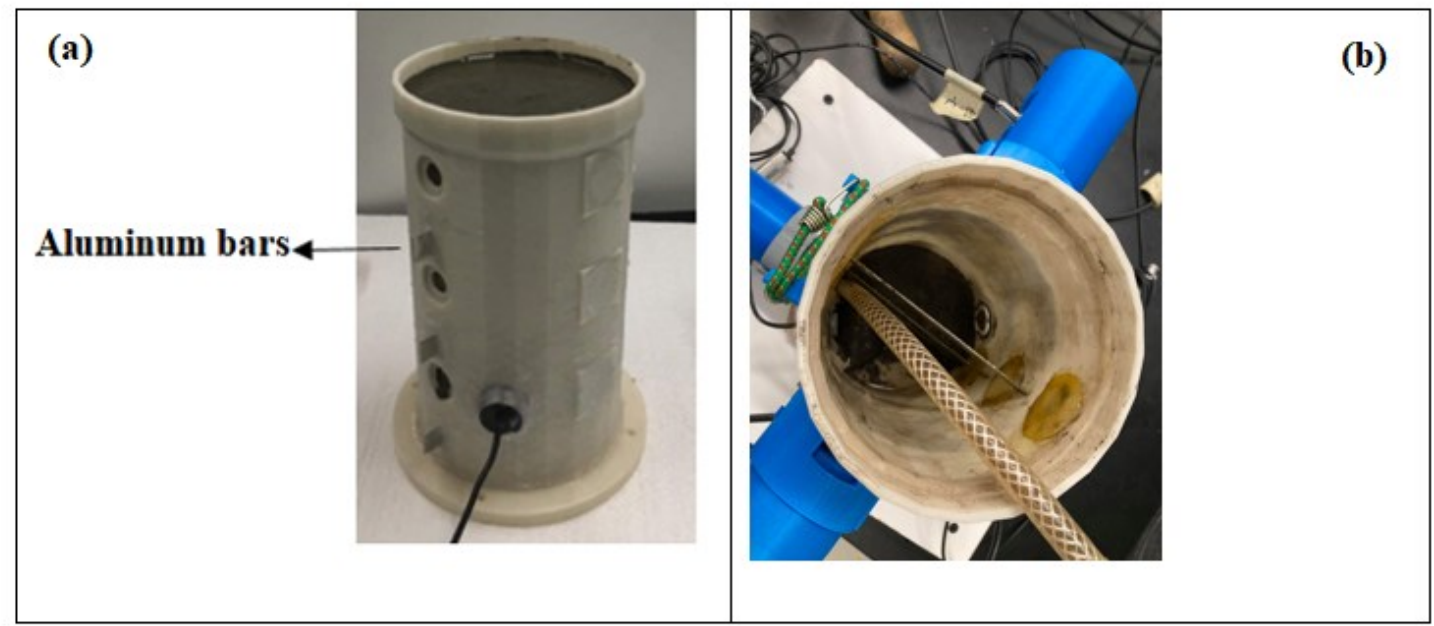

Figure 40: The embedded aluminum bars of the column: (a) side view and (b) top view.

\subsubsection{D - Holders}

The 3D - holders were also designed for the experiment setup. The purpose of the 3D - holders are used to stabilize both compressional and shear transducers and hold them in place while conducting testing on the column's plates and aluminum bars, 
respectively. As well, they are used to eliminate the inconsistency caused by human error and provide a more reliable results. Figure 41 depicts the attachment of the 3D-holders on the 3D-cylinder prototype.

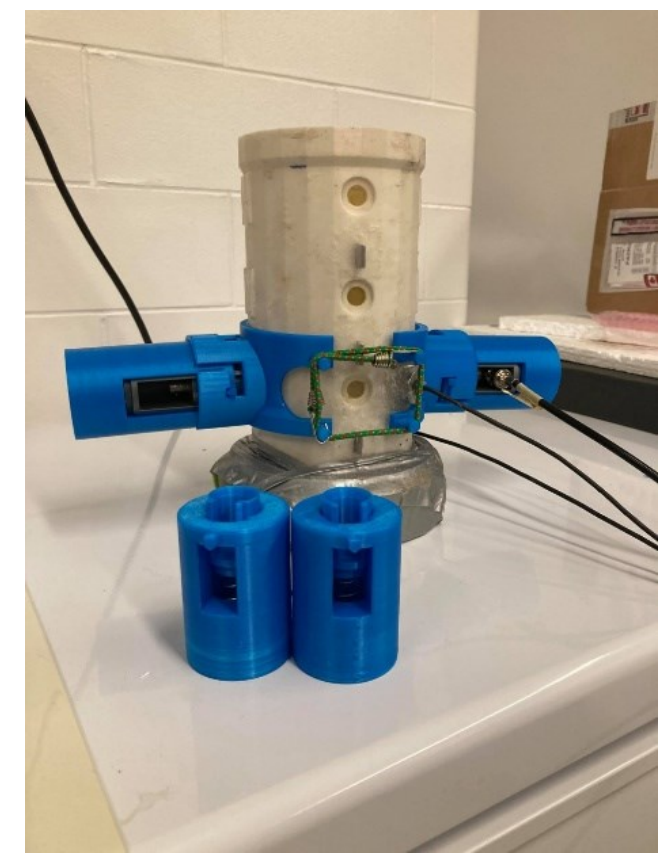

Figure 41: The 3D - holders attached to the columns.

\subsection{Ultrasonic Pulse Velocity (UPV) method}

Studying the wave velocity and wave attenuation to interrogate the changes in properties such as stiffness, density and structuration of the oil sands tailings is the main objective of this research. Thus, the UPV method is selected to evaluate the change in wave velocity and wave attenuation to determine the changes in properties occur in fFFT.

\subsubsection{Wave Velocity}

To calculate the wave velocities, the measurements of the travel time of the Pwaves and S-waves are required and these measurements can be obtained from the UPV 
test by allowing the waves to interact with the column filled with fFFT between transmitting and receiving transducers. In this study, the typical waveform from $1 \mathrm{~min}$ to Day 30 are obtained and recorded. The arrival time of the wave velocity for each day is obtained by the first peak of the waves instead of selecting the actual first arrival as it was not prominent to make a clear selection of the arrival time. To improve the reliable results of the wave velocities, the measured arrival time is subtracted with the measured time delay, in which the delay time of the instrumentation is determined using the standard calibration specimens such as PVC and steel bars of different lengths. Once the arrival time is known, the P-wave and S-wave velocities can be calculated using the equations presented in Chapter 2.

\subsubsection{Wave Attenuation}

In this test, the wave attenuation was done by processing The $\mathrm{P}$-waves and Swaves time signal data obtained from the ultrasonic testing, which is then converted to a frequency spectrum using fast Fourier transform (FFT) with the help of Python and MATLAB code. Moreover, the Fourier spectrum is used to compute the area under the curve in order to determine the material attenuation that occurs over time. In addition, the time windows are used in this test in order to minimize the effect of wave reflections in the calculation of the Fourier spectra. 


\subsection{Ultrasonic Pulse Velocity (UPV) Method Experiment Setup}

A schematic diagram of the UPV setup is illustrated in Figure 42. The UPV experiment setup used to interrogate the fFFT during sedimentation include; the 3D -

columns and holders, wave generator (Keysight 33210A), voltage amplifier, oscilloscope (Keysight DSO-X 3014A) and amplifier (Krohn-Hite). As well, a piezoelectric transducer such as the $54 \mathrm{kHz}$ P-wave transducers and $50 \mathrm{kHz}$ S-wave transducers are used in this study, illustrated in Figure 43(a) and 43(b). The 3D - column with the total height of 555 $\mathrm{mm}$ and with the diameter of $110 \mathrm{~mm}$ was designed to contain the fFFT with the purpose of ultrasonic testing. The ultrasonic transducers were supported with the $3 \mathrm{D}-$ holders to ensure stability of the transducers and they were then attached to the columns in order to monitor the fFFT, shown in Figure xx. In addition, the ultrasonic couplant gel such as gel agent (Ultragel II) was used to eliminate potential air pocket and to assure good contact. A wave generator is used to provide a different input signal to the transmitter. The signals received are then filtered through the voltage amplifier with a high pass filter, a cutoff frequency of $100 \mathrm{kHz}$ and $20 \mathrm{DB}$ gain. Finally, the readings are taken and repeated for 30 days and stored by the oscilloscope. 


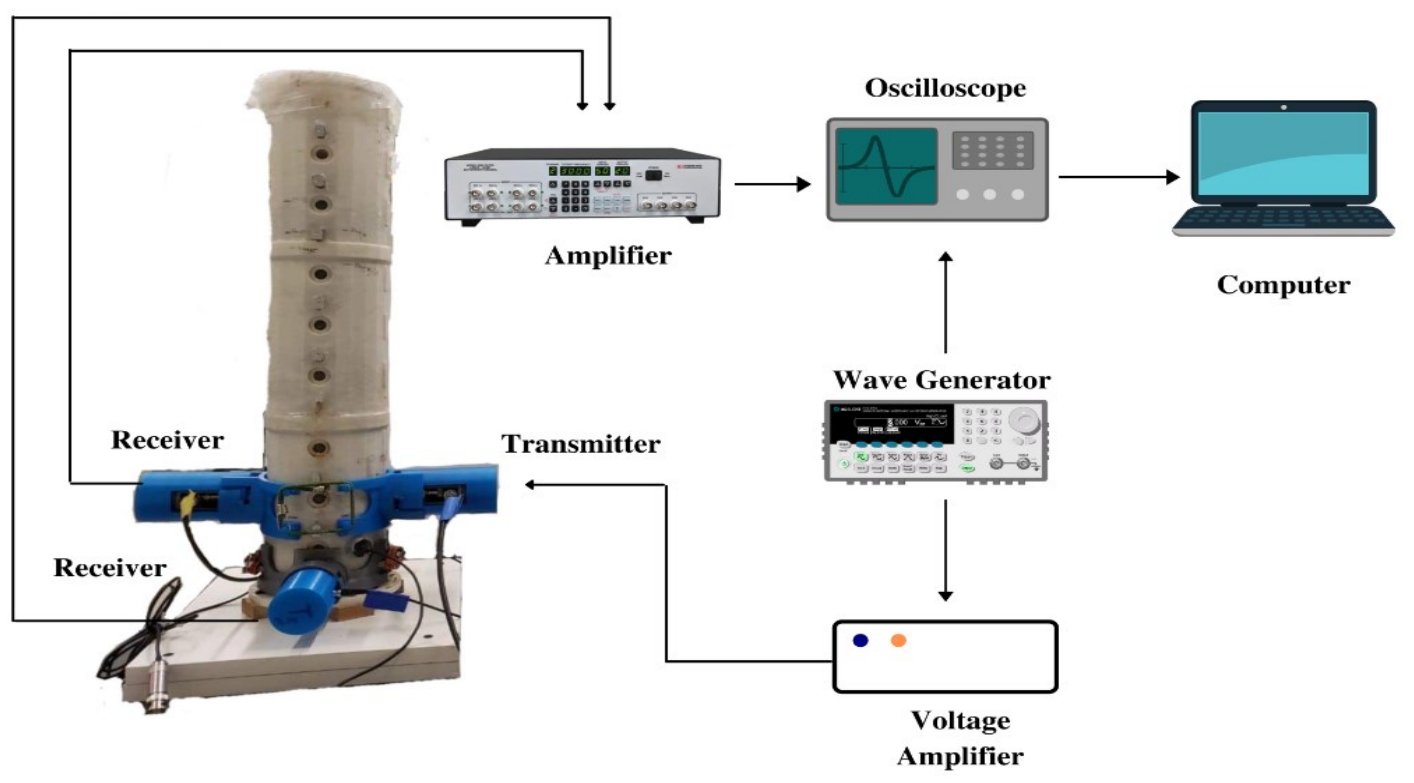

Figure 42: Ultrasonic pulse velocity (UPV) set up.

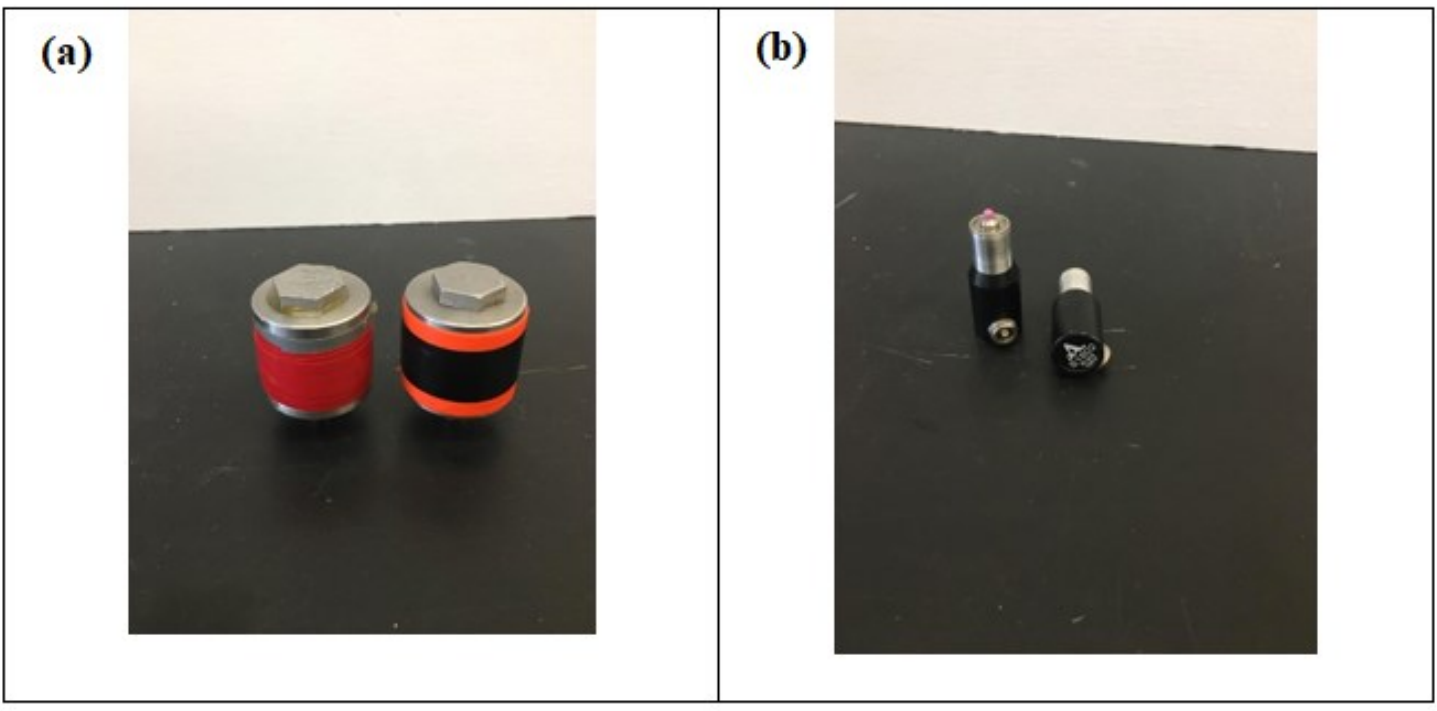

Figure 43: Ultrasonic transducers: (a) $54 \mathrm{kHz}$ P-wave transducers and (b) $50 \mathrm{kHz} \mathrm{S}$ wave transducers. 
In this test, the experiment is modified such that when the P-waves were sent, one P-waves and two S-waves were received, where in order to differentiate, the S-waves will be label as shear \#1 and shear \#2. When the S-waves were sent, one S-waves and two Pwaves were received, where $\mathrm{P}$-waves will be label as compressional \#1 and compressional \#2. The arrangements of P-transmitter/receiver, S-transmitter/receiver, Ptransmitter/S-receiver and S-transmitter/P-transmitter used in this experiment are described as follow:

- P-transmitter/receiver: the arrangement of the transducers when the transmitter and receiver are both P-waves are directly opposite to one another at the column's plates.

- S-transmitter/receiver: the arrangement of the transducers when the transmitter and receiver are both S-waves are directly opposite to one another at the aluminum bar.

- P-transmitter/S-receiver: the arrangement of the transducers when the transmitter is $\mathrm{P}$-waves and receiver is $\mathrm{S}$-waves is the $\mathrm{P}$-waves placed on the column's plates adjacent to S-waves placed on the aluminum bar.

- S-transmitter/P-transmitter: the arrangement of the transducers when the transmitter is $\mathrm{S}$-waves and receiver is $\mathrm{P}$-waves is the $\mathrm{S}$-waves placed on aluminum bar adjacent to P-waves placed on the column's plates. 


\section{Chapter 4: Results and Discussion}

\subsection{The Settling Tests}

\subsubsection{Graduated Cylinders}

The settling tests were done in order to ensure the quality of the sample as well as to ensure it is identical to the samples which are commonly used. Figure 44 illustrates the settlement rate over a 14-day period in three different polymer dosages (0 PPM, 600 PPM and 1000 PPM).

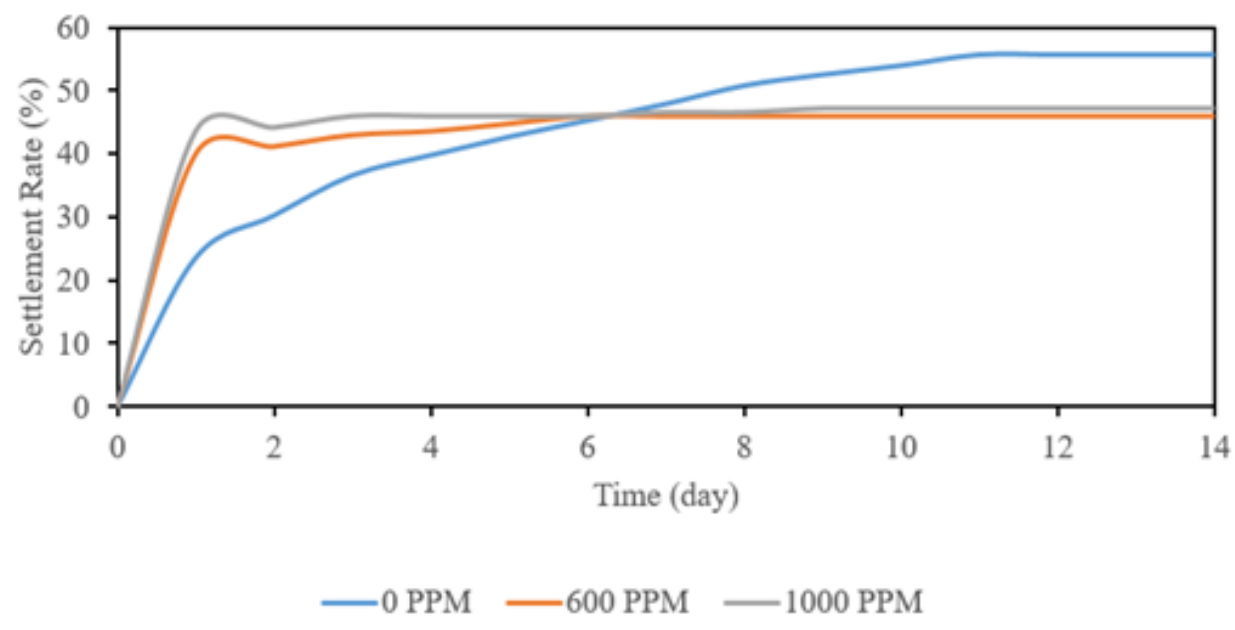

Figure 44: The settlement rate vs time obtained from the flocculated FFT conducted on the graduated cylinder for the 14-day period.

On the graph, it is shown that there is a significant increase in the settlement rate for 600 PPM and 1000 PPM dosage from day 0 to day 2 before they become constant. However, for the dosage of 0 PPM, there is a steady increase in settlement rate from day 0 to day 11 before it becomes constant. From the results, it can be interpreted that the 
FFT mixed with the polymer stock solution settle with the higher rate in a shorter time frame compared with the FFT without the polymer stock solution. This is the expected result for this material (Salam, 2020).

\subsubsection{Settlement of fFFT in the 3D - Column}

Figure 45 depicts the settling test performed on the 3D - column and Figure 46 illustrates the elevation of the fFFT as function of time. As mentioned previous, the settling level can be viewed from the membrane and the transparency of the $3 \mathrm{D}-$ column. The result obtained in Figure 45 shows a steady decrease in settlement rate from day 0 to day 46. The dosage used in this sample was 600 PPM of polymer stock solution.

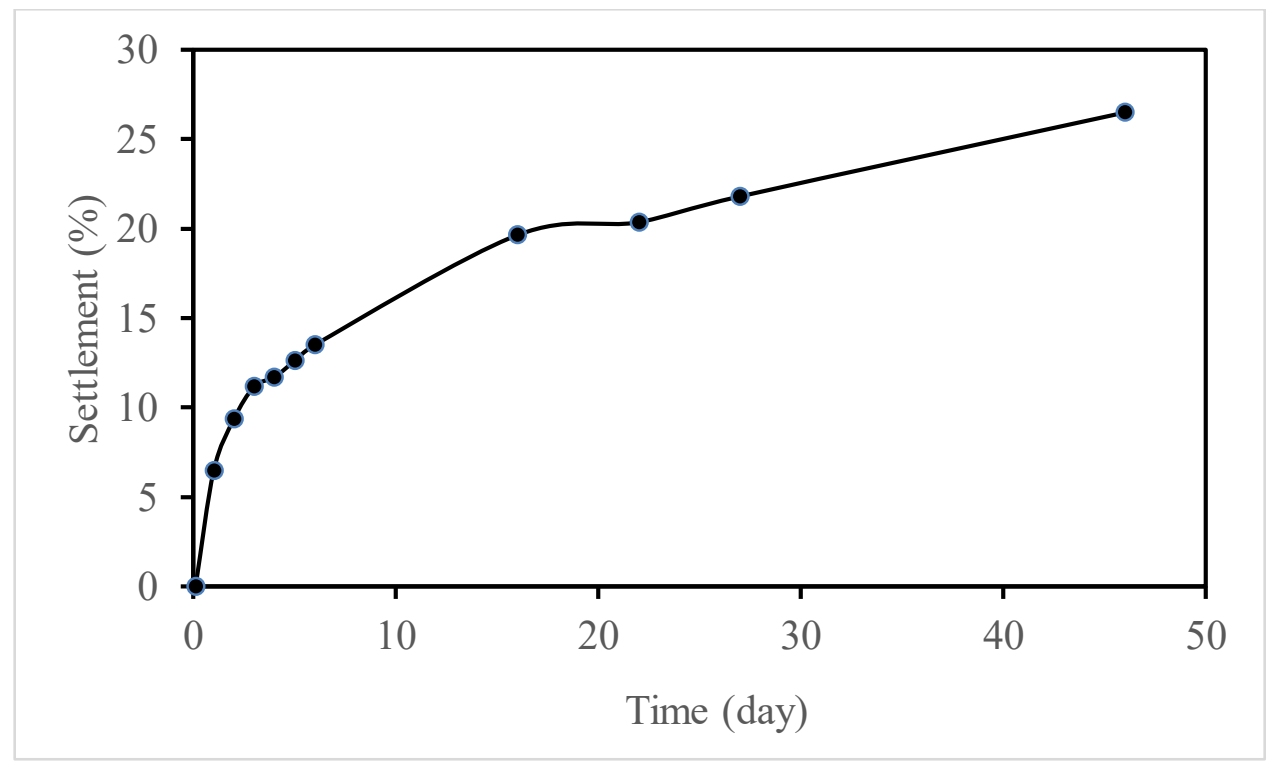

Figure 45: The settlement rate vs time obtained from the fFFT conducted on the 3D Column for the 46-day period (600-PPM polymer dosage). 


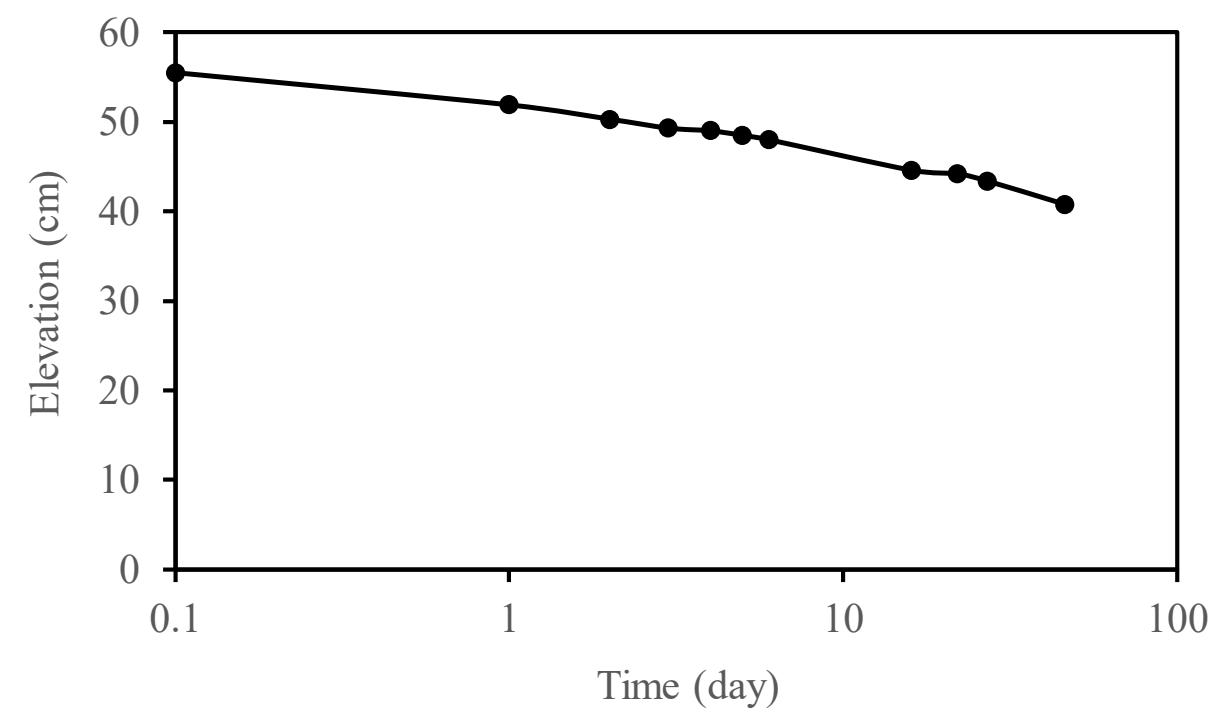

Figure 46: The elevation of the fFFT as function of time (600-PPM polymer dosage).

\subsection{Gravimetric Water Content at Various Height of the Column}

Figure 47 illustrates the final gravimetric water content profile with depth at various height of the column from the 600 PPM.

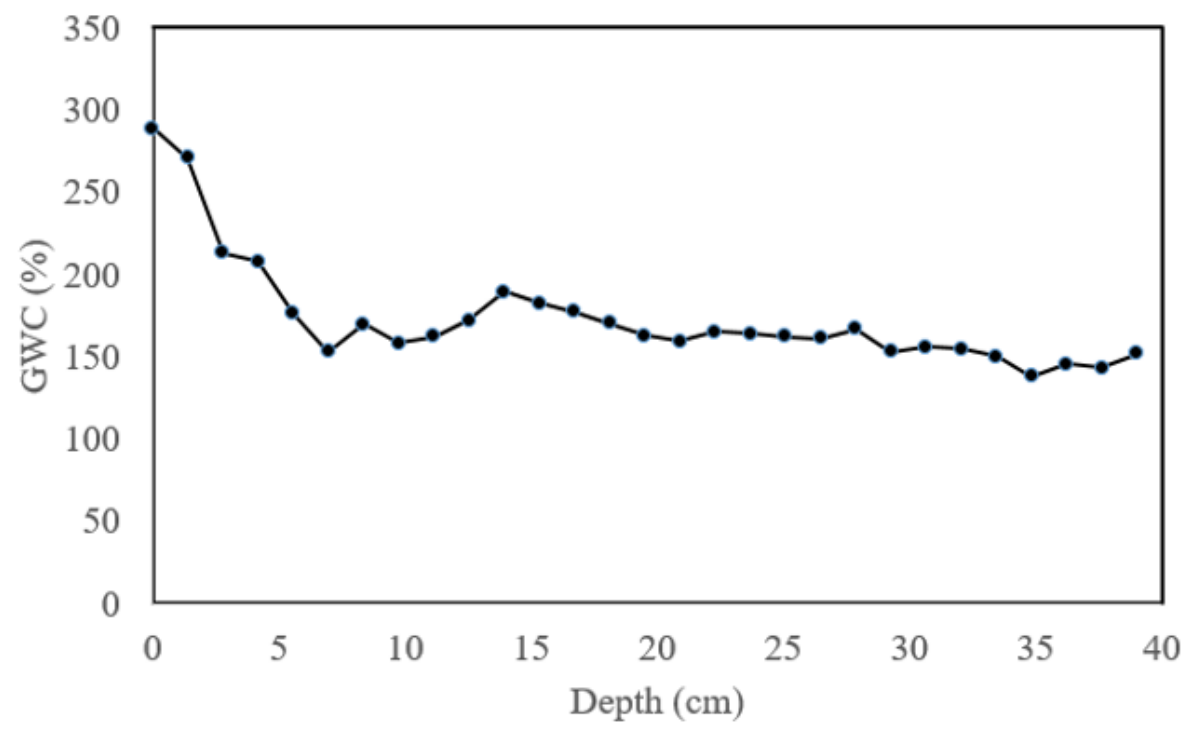

Figure 47: Gravimetric water content (GWC) at various depths in the column after 2 months. 
The GWC was conducted two months after ultrasonic testing. In this experiment, the sample were first collected from the surface, going down in increment of approximately $1.4 \mathrm{~cm}$. it can be seen from the figure the $\mathrm{GWC}$ declines with depth due to the consolidation of fFFT. The results is typical, in that there is a significant variation in density near the surface, but less variation as depth increases. This is linked to power form of the compressibility curve.

\section{Large Strain Consolidation simulations}

The column settlement data was analyzed using a large strain consolidation model, in order to provide additional information on the likely distribution of density with depth. The following two functions were employed for the hydraulic conductivity and the compressibility:

$$
\begin{gathered}
k=H_{1} e^{H_{2}} \\
e=C_{1}\left(\sigma^{1}\right)^{C_{2}}
\end{gathered}
$$

Where $k$ is the hydraulic conductivity, e is the void ratio, $\sigma^{1}$ is the vertical effective stress, and $\mathrm{C}_{1}, \mathrm{C}_{2}, \mathrm{H}_{1}$ and $\mathrm{H}_{2}$ is the empirical material parameters for compressibility and hydraulic conductivity constitutive relationship, respectively. Where, $\mathrm{C}_{1}=2.8422, \mathrm{C}_{2}=-0.284, \mathrm{H}_{1}=3 \mathrm{E}-10$ and $\mathrm{H}_{2}=5$.

Given the elevation of the transducers, simulation was run to obtain the void ratio over time. The estimated density over time then can be calculated once the void ratio measurements are known. 
The fits to the settlement data and measured and modelled settlement rate are shown in Figure 48 and 49 below. The modelled densities at different heights are used to do additional comparisons with ultrasonic measurements at those location.

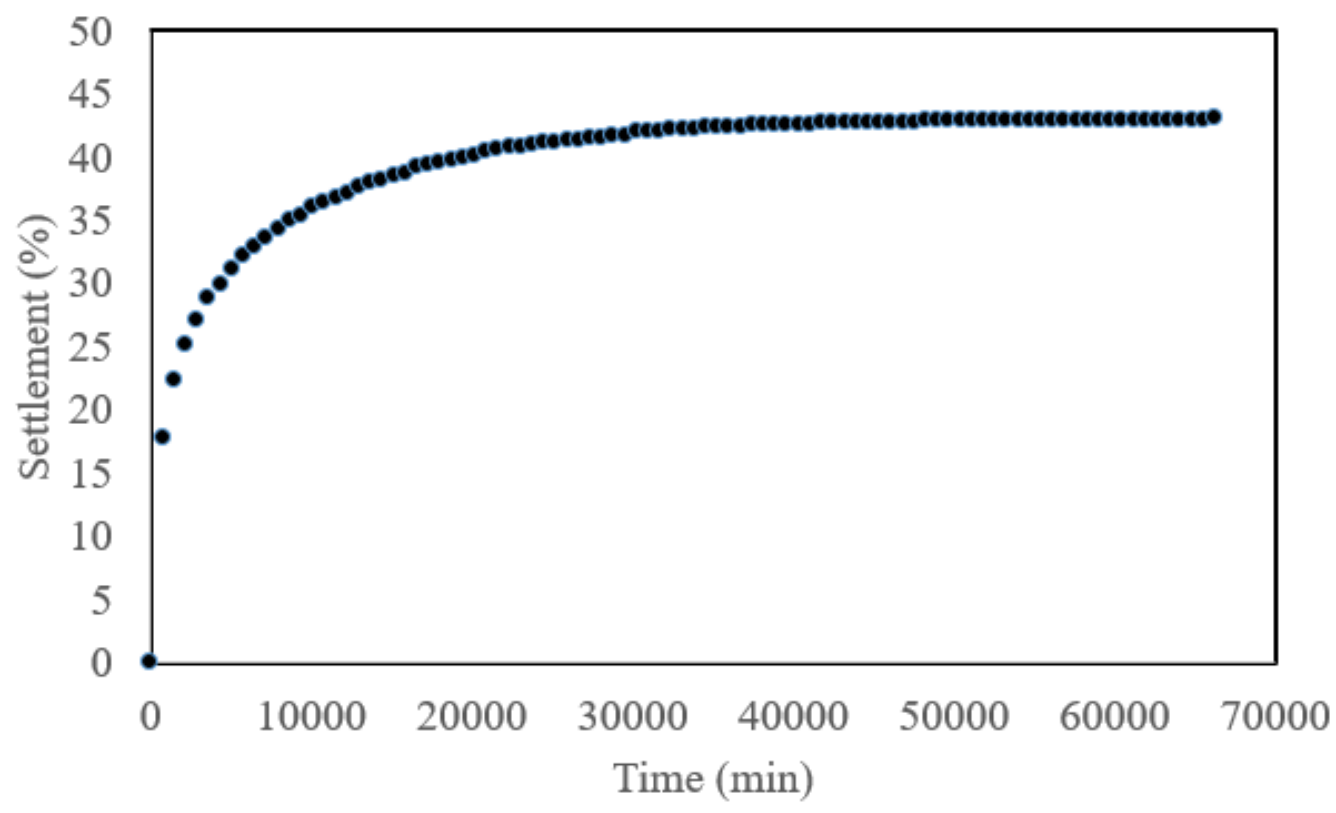

Figure 48: The settlement rate vs time at transducer estimated by modelling.

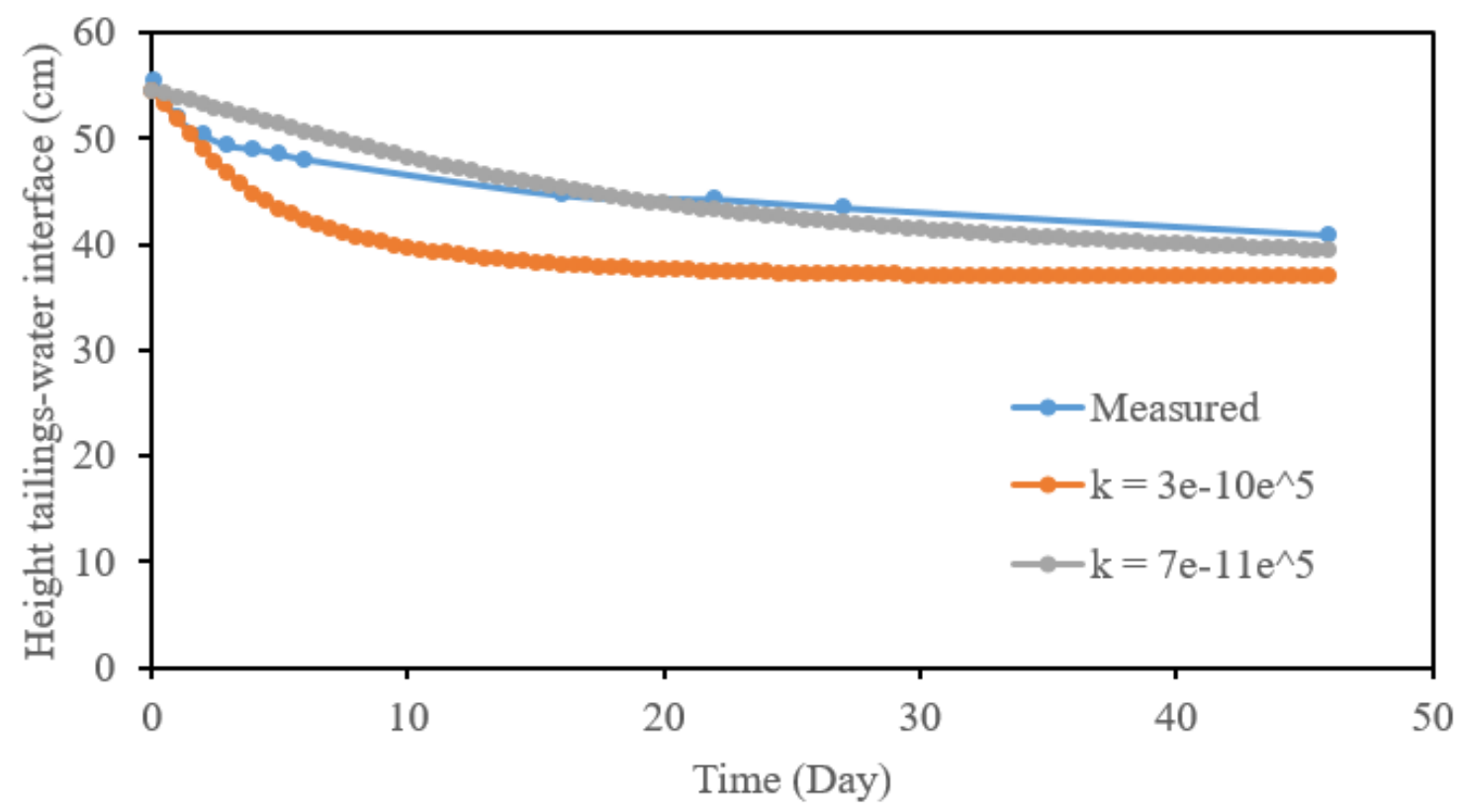

Figure 49: Modelled vs measured settlement. 
Two simulations with different hydraulic conductivity are plotted on Figure 49 to compare with measured settlement rate. The settlement rate obtained from the hydraulic conductivity of $7 e-11 e^{5}$ has better agreement with the measured settlement rate. However, since the focus is from day 1 to day 3 , the settlement rate obtained from the conductivity of $3 e-10 e^{5}$ is chosen since it shows a better agreement for the 1-3 day with the measured settlement rate.

The compressibility function can be used to estimate the expected variation of void ratio with depth at the end of consolidation. As shown in Figure 50, the expected add measured final profiles are reasonably similar.

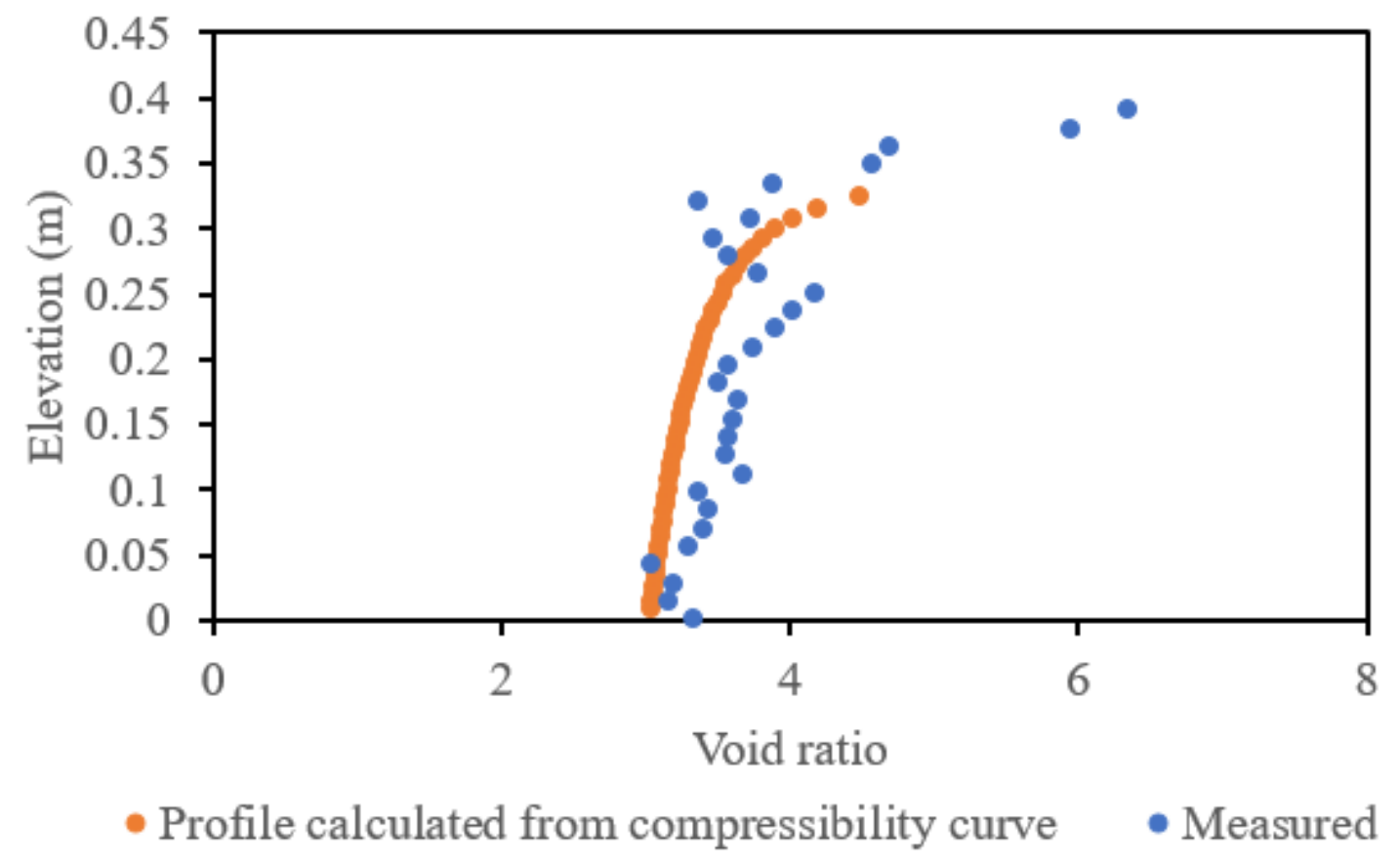

Figure 50: Actual final density distribution vs expected distribution from a fitted compressibility curve. 


\subsection{UPV Calibration of Ultrasonic Transducers}

\subsubsection{The calibration of ultrasonic transducer on reference standard bars}

Figure 51(a) and 51(b) illustrate the calibration time plotted against corresponding length performed using compressional and shear transducers, respectively. The velocities of each material for both p-wave and s-wave tests were calculated using the trend line, the results are shown in Table 2 . 

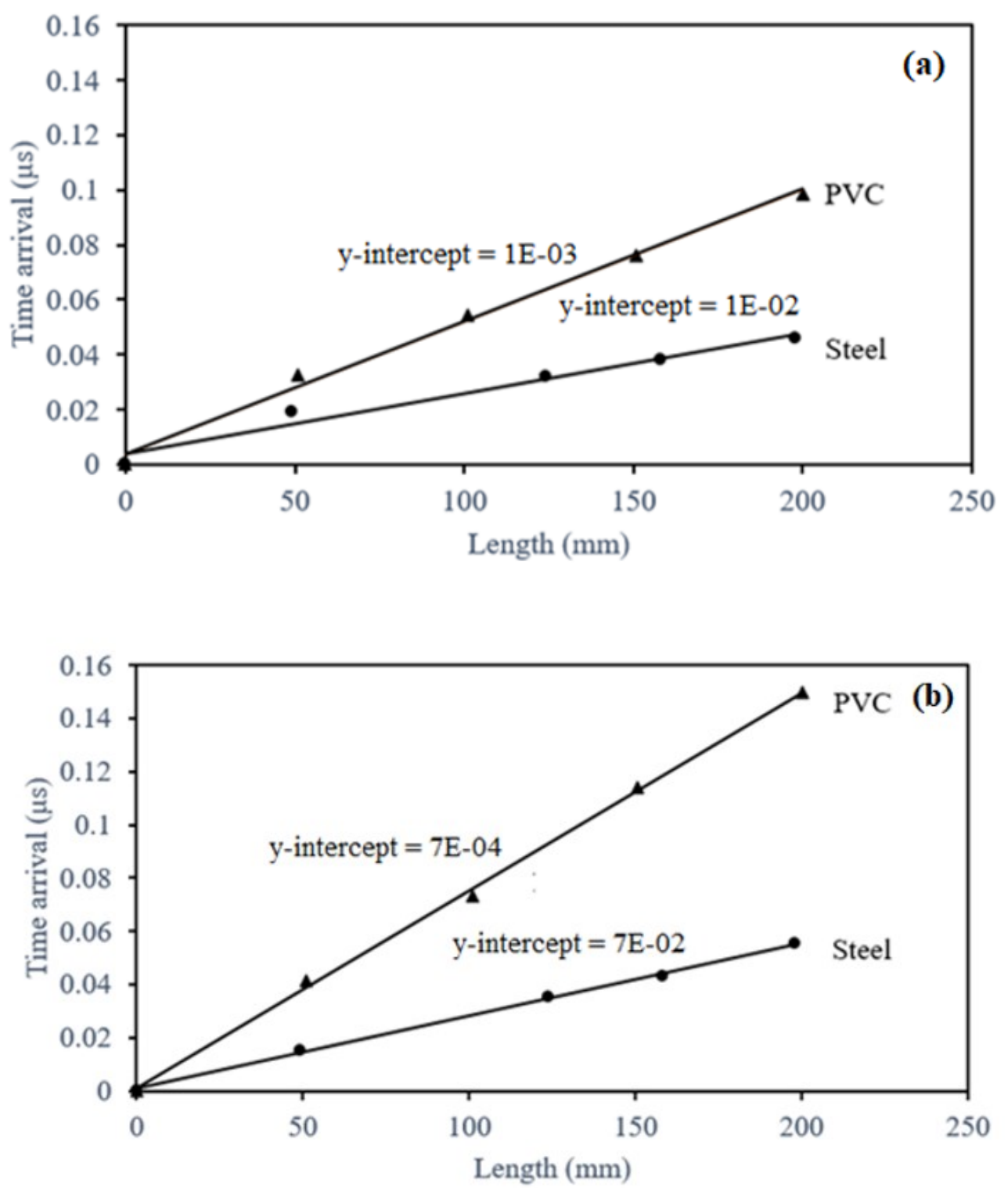

Figure 51: Calibration results obtained from the steel and PVC (a) using compressional transducers and (b) shear transducers.

The y-intercept on the graphs indicate the delay time introduced by the instrumentation, which was then used to deduct from the arrival time of each test obtained from the column experiments to provide more reliable results. 


\subsubsection{The calibration of ultrasonic transducers in the empty column}

The wave signal shown in Figure 52 was obtained from the empty column by placing p-wave transducers at different section (bottom, middle and top) of the column's plates. The pulse velocity shown in the Table 2 was then calculated by dividing the diameter of the column $(110 \mathrm{~mm})$ with the first arrival time and the average velocity was found to be $1199.8 \mathrm{~m} / \mathrm{s}$.
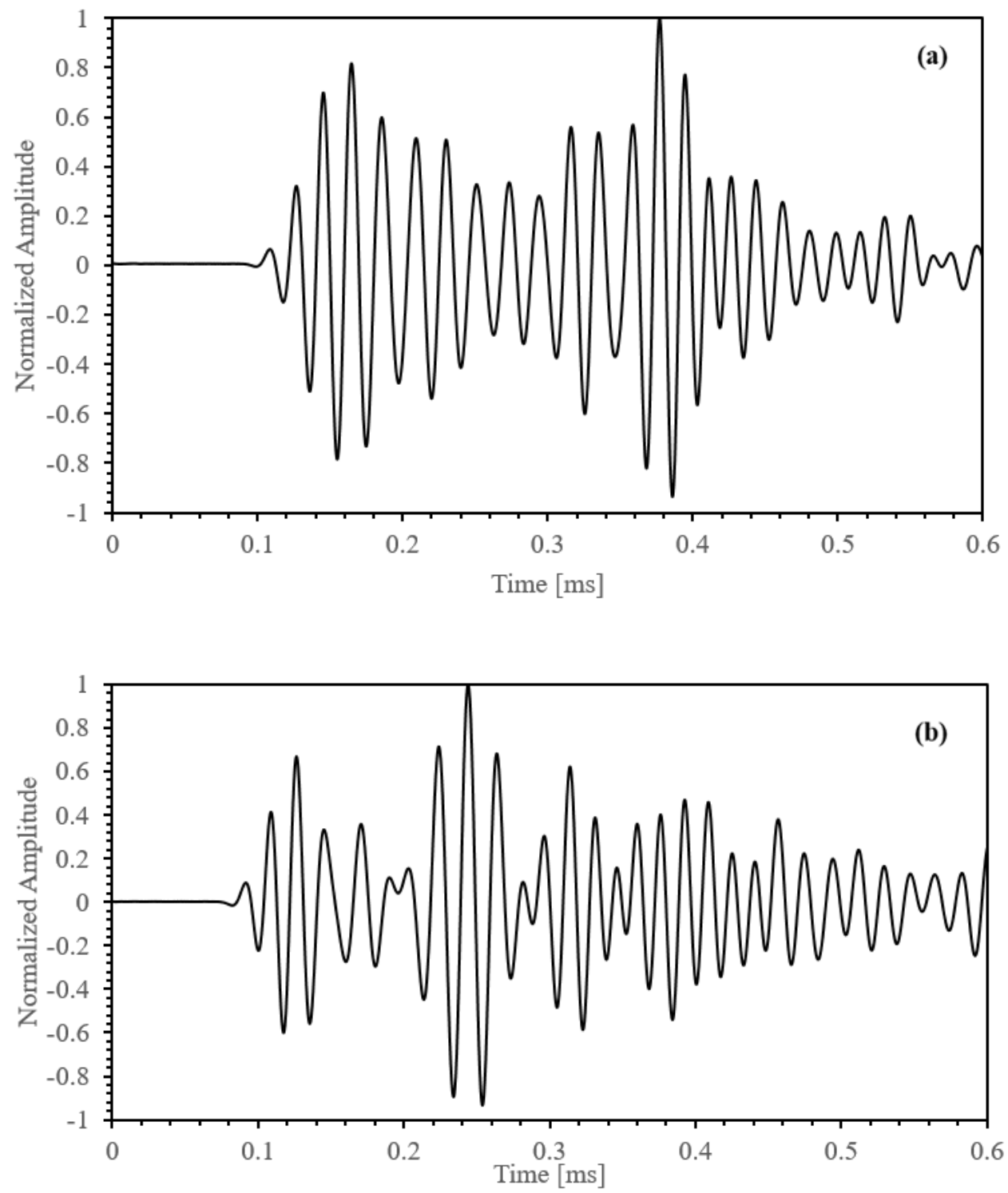


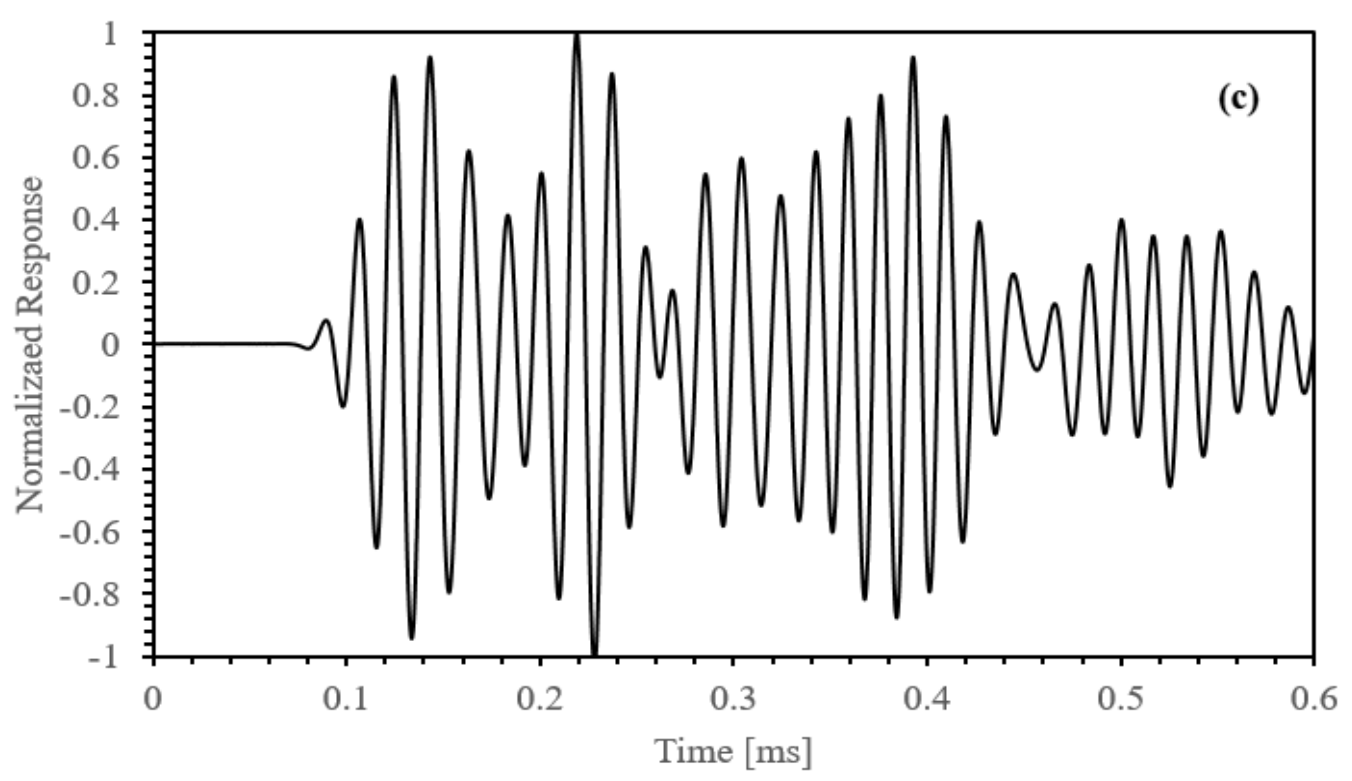

Figure 52: Wave signal of empty column obtained by placing $p$-wave transducers at different section of the cylinder's plate: (a) Bottom, (b) Middle and (c) Top.

Table 2: velocity measurement obtained from the empty column using p-wave transducers with diameter of the column of $110 \mathrm{~mm}$

\begin{tabular}{cccc}
\hline Section & $\begin{array}{c}\text { First time arrival } \\
{[\mu \mathrm{s}]}\end{array}$ & $\begin{array}{c}\text { Amplitude } \\
{[\mathrm{mv}]}\end{array}$ & $\begin{array}{c}\text { Velocity } \\
{[\mathrm{m} / \mathrm{s}]}\end{array}$ \\
\hline Bottom & 92.6 & 232.5 & 1187.9 \\
Middle & 92.5 & 311.6 & 1189.2 \\
Top & 90 & 377.6 & 1222.2 \\
\hline \multicolumn{3}{c}{ Average Velocity $[\mathrm{m} / \mathrm{s}]$} & 1199.8 \\
\hline
\end{tabular}

The calculated velocity was then used to compare with the expected wave velocity of air, which is found to be $330 \mathrm{~m} / \mathrm{s}$. The huge difference in wave velocity in this calibration test is due to the waves are propagating around the column and through the air. This information is important as the wave obtained from the column can be 
subtracted from the actual test when the column is filled with fFFT in order to just obtain the waves propagate through the fFFT only.

In addition, the wave signal shown in Figure 53 was obtained from the empty column by placing s-waves transducers at different section (bottom, middle and top) of the aluminum bar. The pulse velocity shown in the Table 3 was then calculated by dividing the length of the aluminum bar $(130 \mathrm{~mm})$ with the first arrival time and the average velocity was found to be $3838.7 \mathrm{~m} / \mathrm{s}$.

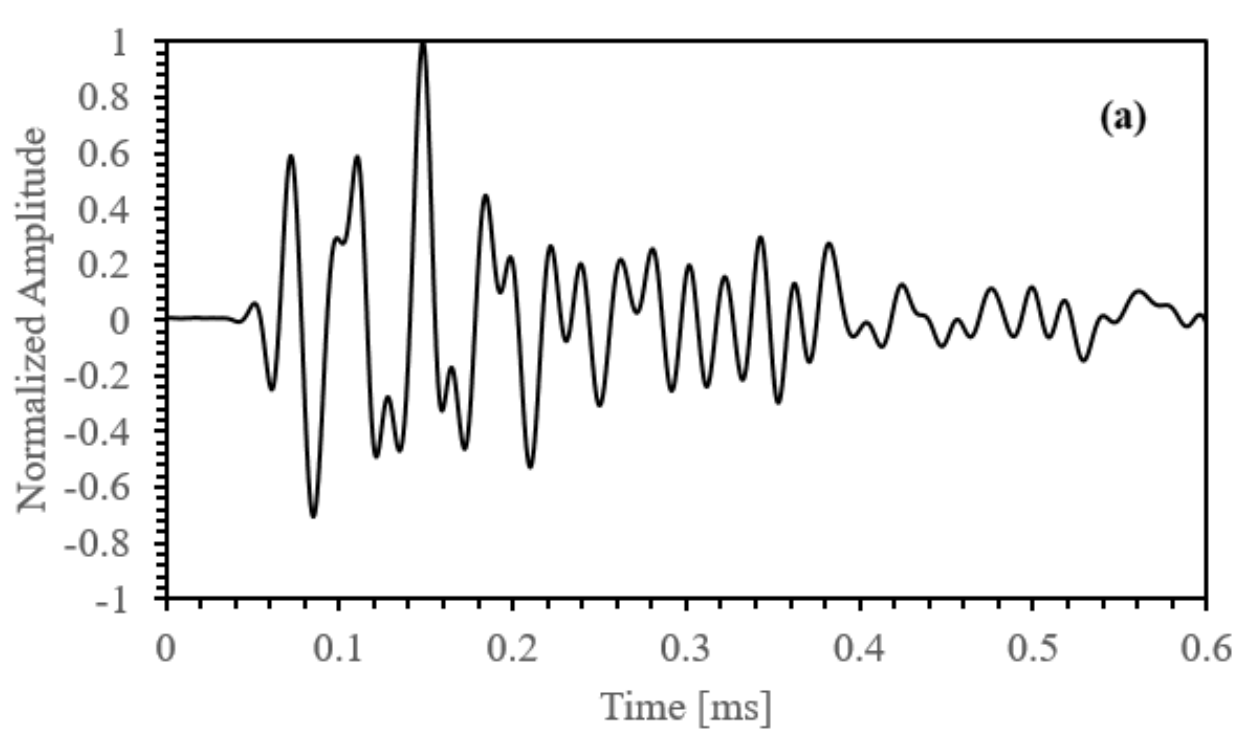



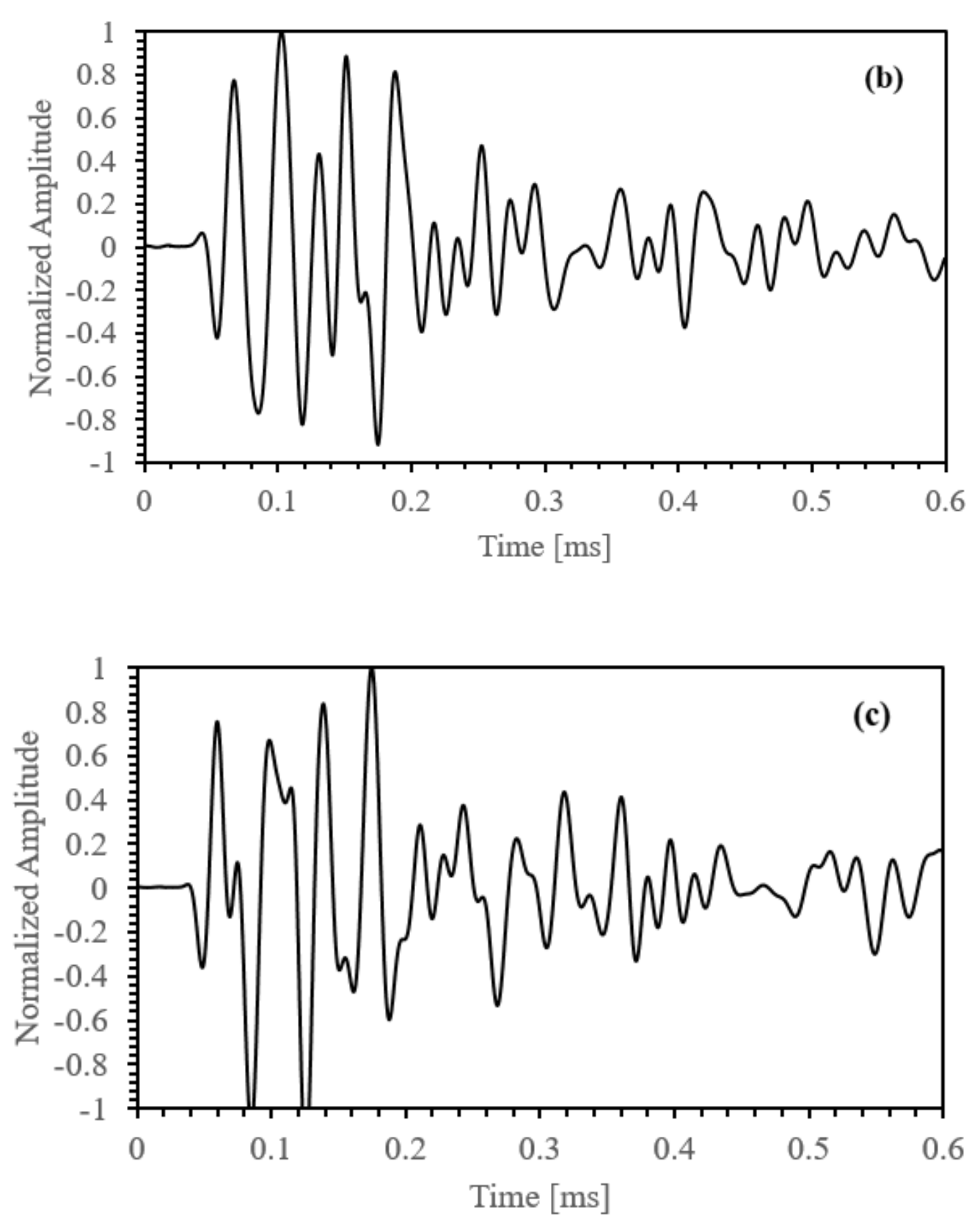

Figure 53: Wave signal of empty column obtained by placing s-wave transducers at different section of the aluminum bar: (a) Bottom, (b) Middle and (c) Top. 
Table 3: Velocity measurement obtained from the empty column using s-wave transducers with length of the aluminum bar of $130 \mathrm{~mm}$

\begin{tabular}{cccc}
\hline Section & $\begin{array}{c}\text { Time of flight } \\
{[\mu \mathrm{s}]}\end{array}$ & $\begin{array}{c}\text { Amplitude } \\
{[\mathrm{mv}]}\end{array}$ & $\begin{array}{c}\text { Velocity } \\
{[\mathrm{m} / \mathrm{s}]}\end{array}$ \\
\hline Bottom & 34 & 154.1 & 3823.6 \\
Middle & 33.6 & 195.7 & 3869.0 \\
Top & 34 & 208.8 & 3823.5 \\
\hline \multicolumn{3}{c}{ Average Velocity $[\mathrm{m} / \mathrm{s}]$} & 3838.7 \\
\hline
\end{tabular}

The calculated average velocity was then used to compare with the expected shear wave velocity of the aluminum material, which is found to be $3130 \mathrm{~m} / \mathrm{s}$ (Dakota Ultrasonics, North Dakota). The differences was calculated to be $22.6 \%$ and the calculated velocity is slightly different from the expected velocity. The slight difference in velocity is probably due to the dimension (thickness and length) of the aluminum bars used in this experiment which is different from the size used in the reference.

\subsubsection{The calibration of ultrasonic transducer in the column filled with water}

The wave signal shown in Figure 54 was obtained from the column filled with water by placing $\mathrm{p}$-wave transducers at different section (bottom, middle and top) of the column's plate. The pulse velocity shown in the Table 4 was then calculated by dividing the diameter of the cylinder $(110 \mathrm{~mm})$ with the first arrival time and the average velocity was found to be $1359.8 \mathrm{~m} / \mathrm{s}$. 

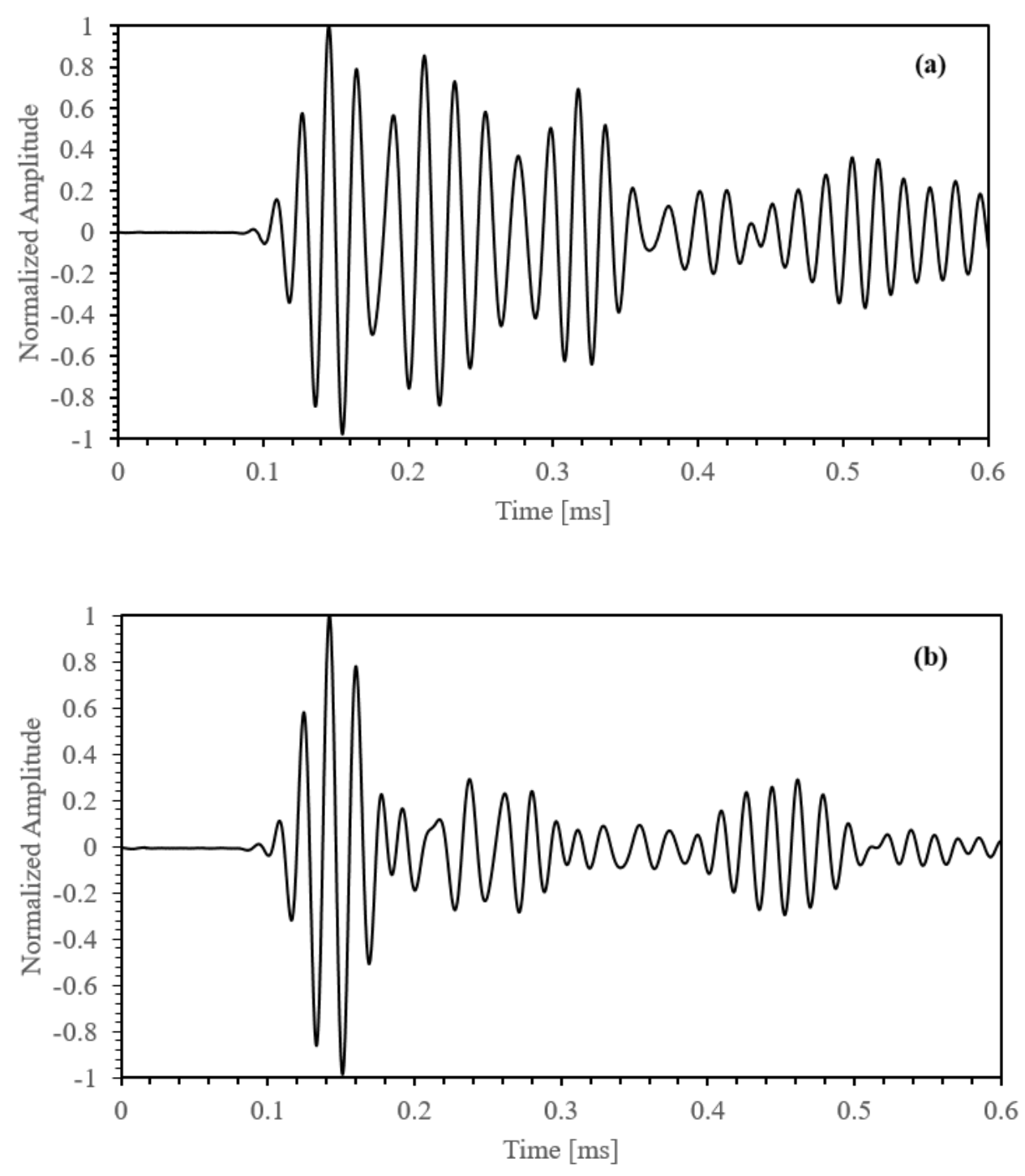


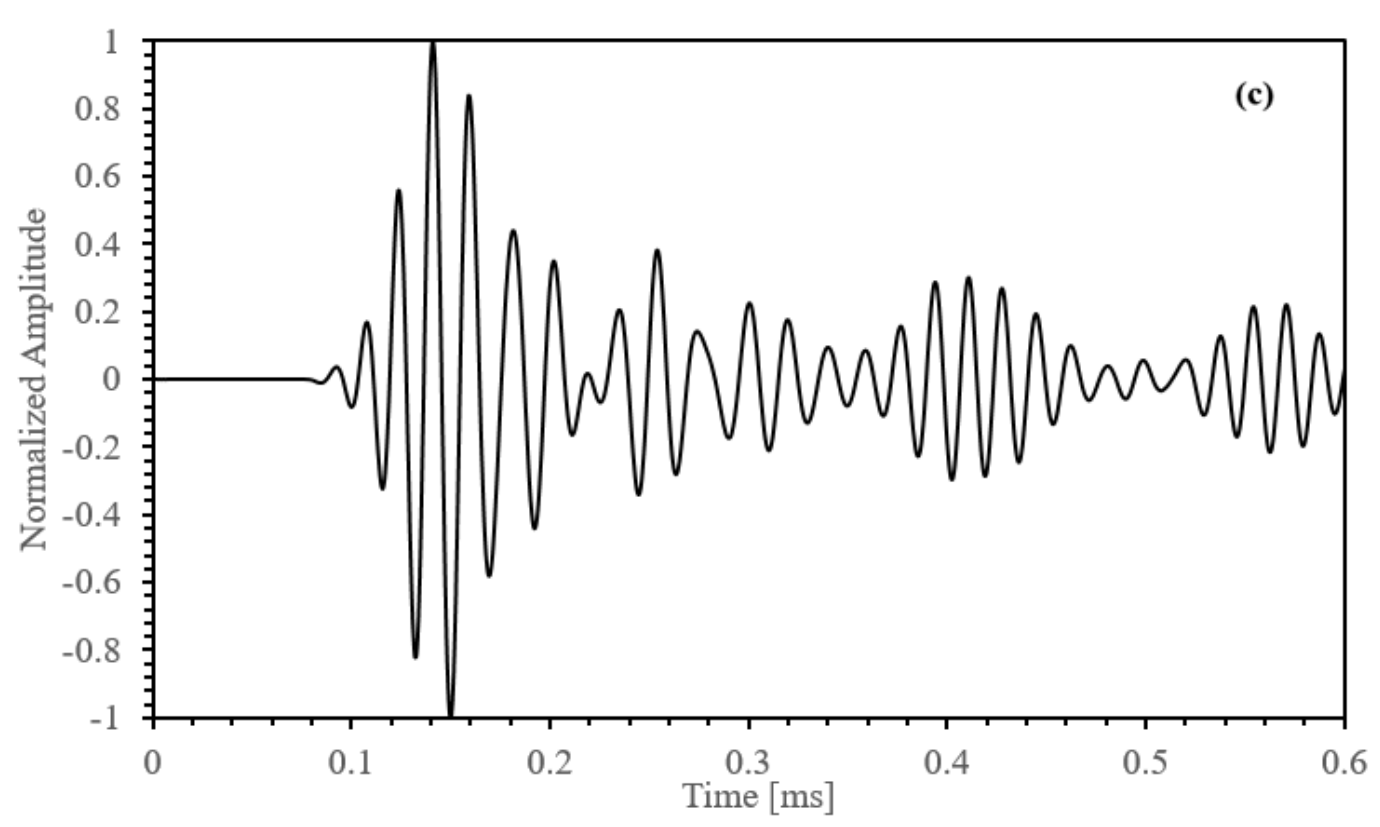

Figure 54: Wave signal of column filled with water obtained by placing $p$-wave transducers at different section of the aluminum bar: (a) Bottom, (b) Middle and (c) Top.

Table 4: Velocity measurement obtained from the column filled with water using $p$-wave transducers with length of the aluminum bar of $130 \mathrm{~mm}$.

\begin{tabular}{cccc}
\hline Section & $\begin{array}{c}\text { First time arrival } \\
{[\mu \mathrm{s}]}\end{array}$ & $\begin{array}{c}\text { Amplitude } \\
{[\mathrm{mv}]}\end{array}$ & $\begin{array}{c}\text { Velocity } \\
{[\mathrm{m} / \mathrm{s}]}\end{array}$ \\
\hline Bottom & 81.8 & 140 & 1344.7 \\
Middle & 81 & 296 & 1358.0 \\
Top & 79.9 & 471 & 1376.7 \\
\hline \multicolumn{3}{c}{ Average Velocity $[\mathrm{m} / \mathrm{s}]$} & 1359.8 \\
\hline
\end{tabular}

The calculated velocity was then used to compare with the expected wave velocity of water, which is found to be $1473 \mathrm{~m} / \mathrm{s}$ (Dakota Ultrasonics, North Dakota). The difference was calculated to be $7.7 \%$ and the calculated velocity is closed to the expected velocity of the water. 
In addition, the typical wave signal shown in Figure 55 was obtained from the columns filled with water by placing shear transducers at different section (bottom, middle and top) of the aluminum bar. The pulse velocity shown in the Table 5 was then calculated by dividing the length of the aluminum bar $(130 \mathrm{~mm})$ with the first arrival time and the average velocity was found to be $3665.5 \mathrm{~m} / \mathrm{s}$.
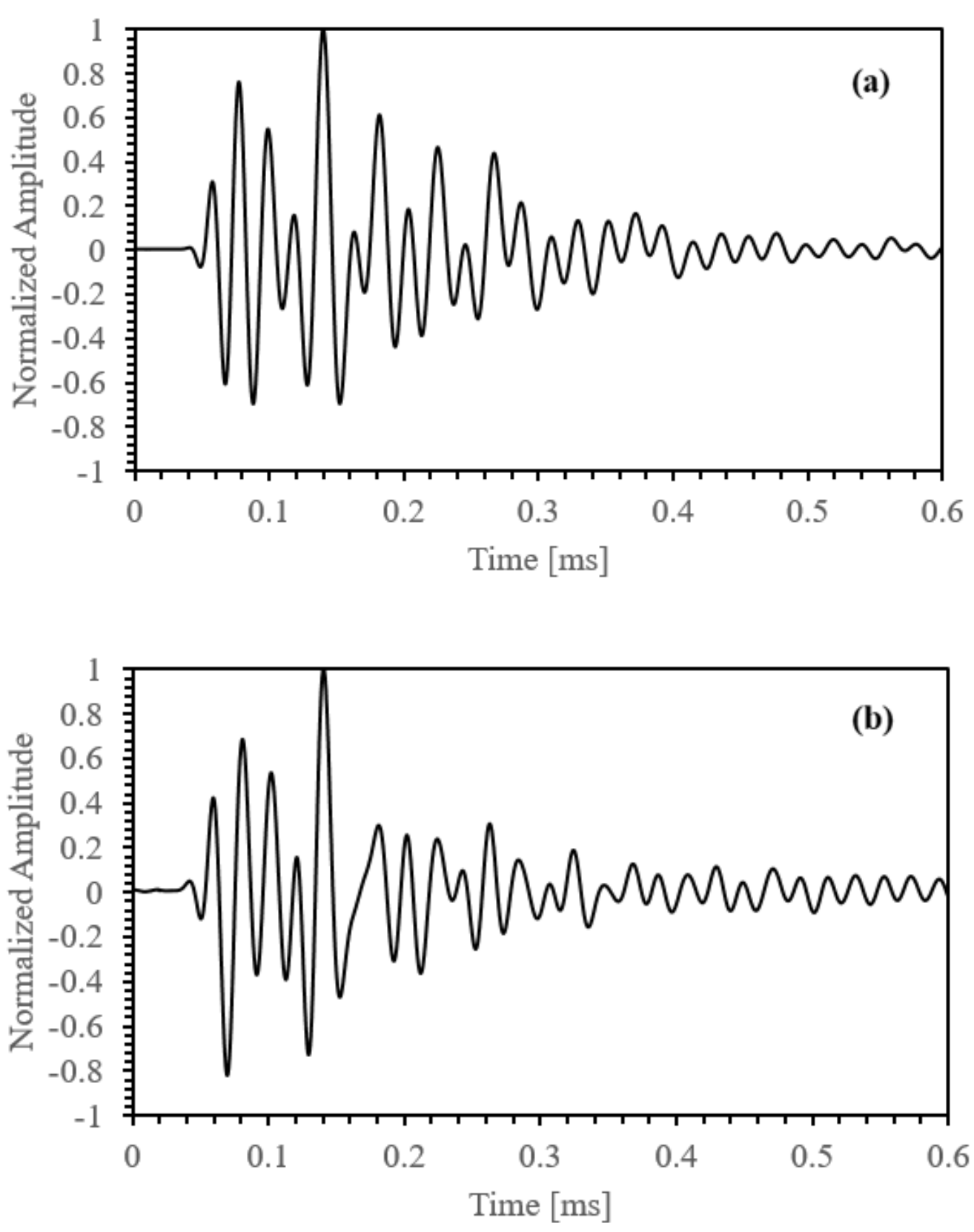


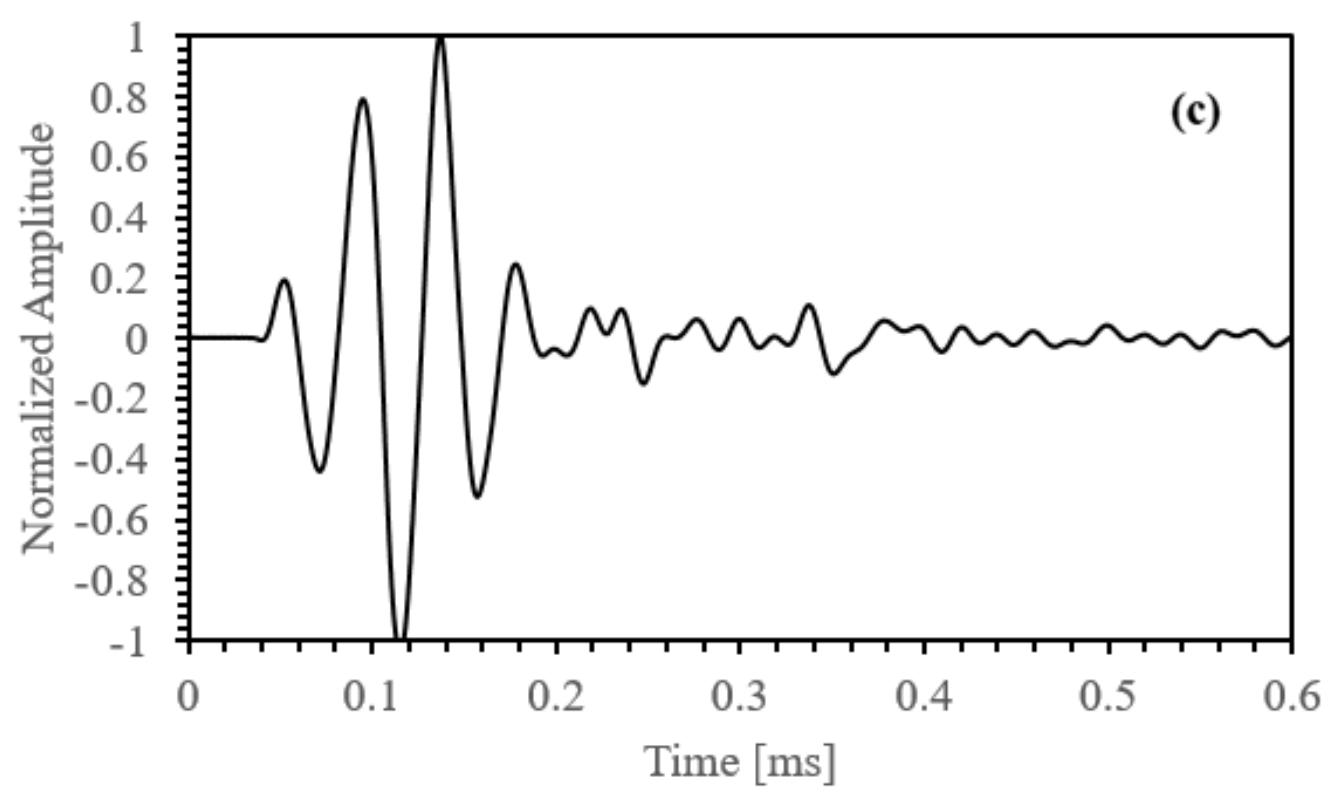

Figure 55: Wave signal of column filled with water obtained by placing s-wave transducers at different section of the aluminum bar: (a) Bottom, (b) Middle and (c) Top.

Table 5: Velocity measurement obtained from the column filled with water using s-wave transducers with length of the aluminum bar of $130 \mathrm{~mm}$.

\begin{tabular}{cccc}
\hline Section & $\begin{array}{c}\text { Time of flight } \\
{[\mu \mathrm{s}]}\end{array}$ & $\begin{array}{c}\text { Amplitude } \\
{[\mathrm{mv}]}\end{array}$ & $\begin{array}{c}\text { Velocity } \\
{[\mathrm{m} / \mathrm{s}]}\end{array}$ \\
\hline Bottom & 36.2 & 195.7 & 3591.2 \\
Middle & 35.6 & 185 & 3651.7 \\
Top & 34.8 & 166 & 3735.6 \\
\hline \multicolumn{3}{c}{ Average Velocity $[\mathrm{m} / \mathrm{s}]$} & 3665.5 \\
\hline
\end{tabular}

Since that fFFT consists mostly water, this information obtained from the column filled with water using $\mathrm{p}$-wave and s-wave will be important measurements to predict the behavior of waves obtained from the fFFT. 


\subsection{Column test with ultrasonic interrogation of fFFT}

Data from ultrasonic interrogation to detect changes and trends in the properties of fFFT using s-wave and p-wave transducers, was analyzed to obtain wave velocities and wave attenuation patterns. The evolutions of these wave characteristics over time is described in the following sections.

\subsubsection{Wave Velocities}

The following figures present ultrasonic data from a P-transducers and Stransducers that were located at heights of $60 \mathrm{~mm}$ and $40 \mathrm{~mm}$, respectively. Figure 56, $58,60,62,64$ and 66 show waveform evolutions over different pairing of emitted and received waves. For instance, Figure 56 is for $\mathrm{p}$-wave emitted - $\mathrm{p}$ wave received, Figure 58 is for shear wave emitted - p wave received (compressional \#1), Figure 60 is for swave emitted $-\mathrm{s}$ wave received, Figure 62 is for $\mathrm{p}$-wave emitted $-\mathrm{s}$ wave received (shear $\# 1$ ), Figure 64 is for p-wave emitted - shear wave received (shear \#2) and Figure 66 is for s-wave emitted and p-wave received (compressional \#2). In addition Figure 57, 59, 61, 63,65 and 67 show the wave velocity as the function of time. The arrival time is determined by the first peak of the wave instead of selecting the actual first arrival as it was not prominent to make a clear selection of the arrival time. 


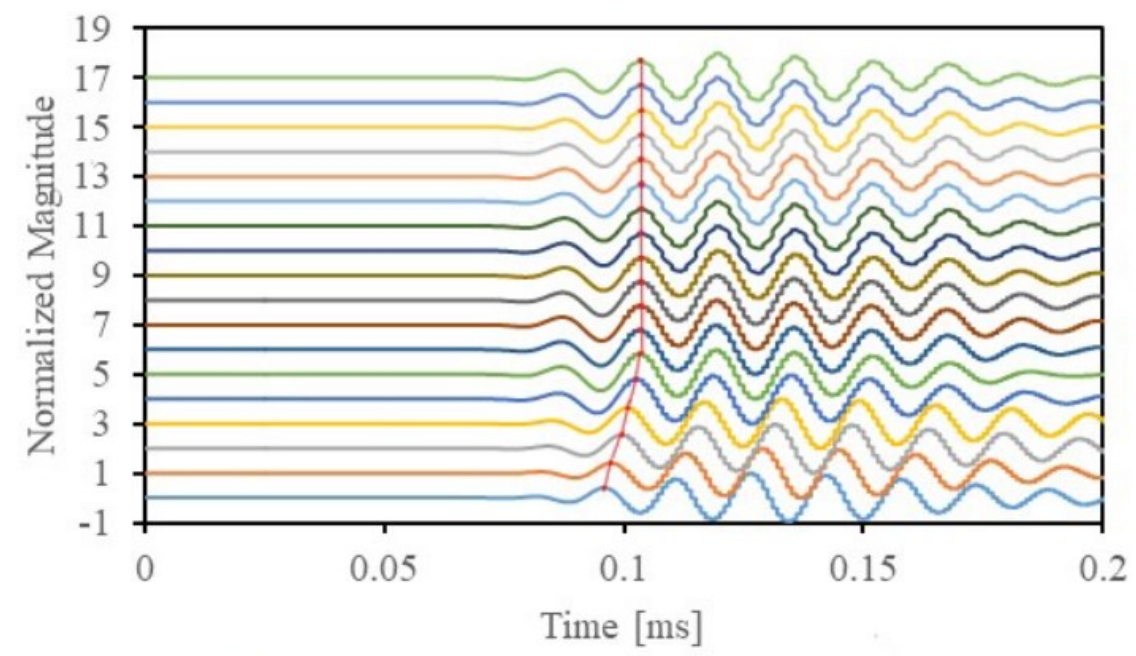

$-8 \mathrm{~min}-32 \mathrm{~min}-128 \mathrm{~min}-256 \mathrm{~min} \longrightarrow$ Day $1-$ Day 2

-Day 3 -Day 4 - Day 5 -Day 10 -Day 11 -Day 12

- Day 15 - Day 21 - Day 23 - Day 26 - Day 28 - Day 30

Figure 56: Waveforms at the specific times, showing the selection of arrival times used to calculate wave velocity (compressional transmitter/receiver).

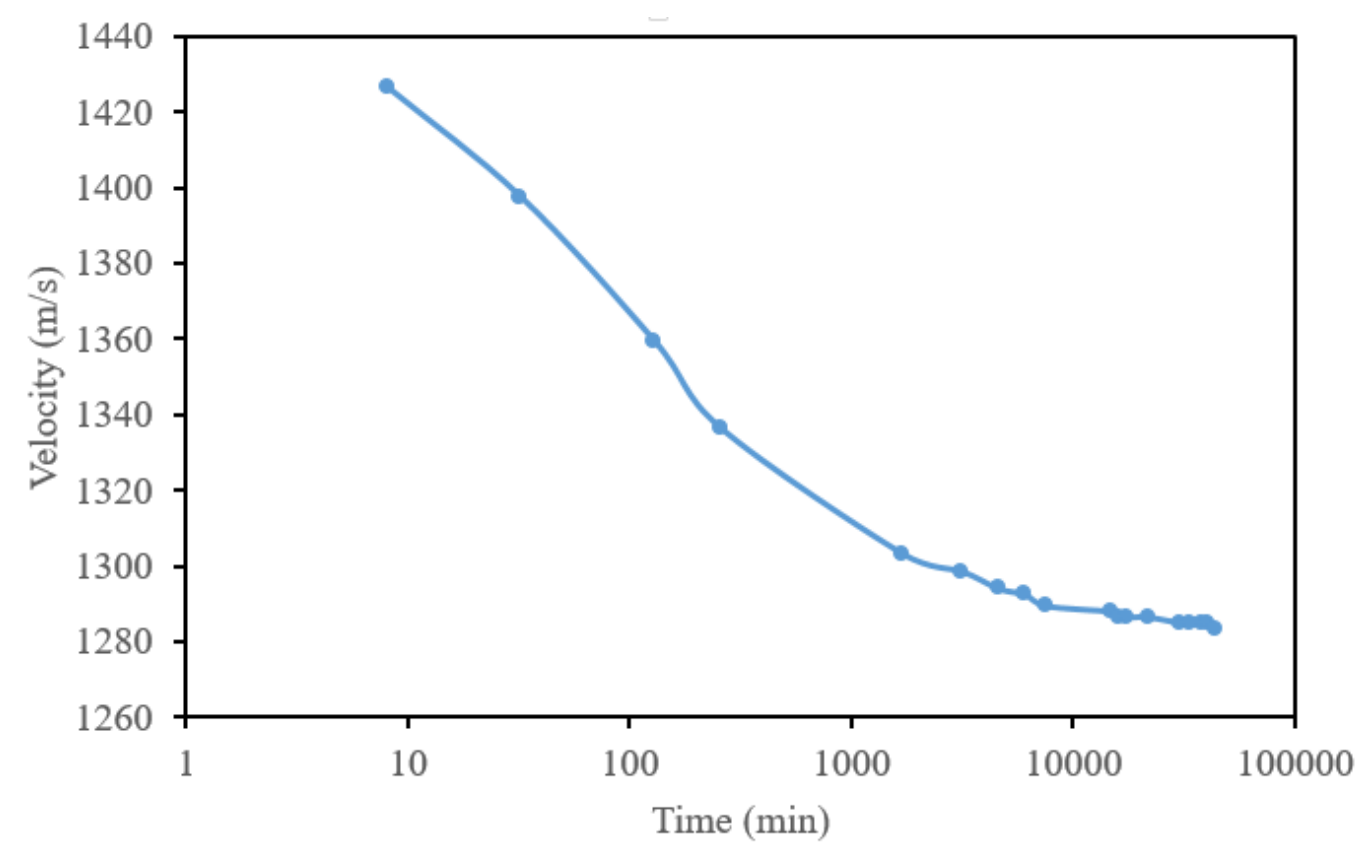

Figure 57: The wave velocity as a function of time (compressional transmitter/receiver). 


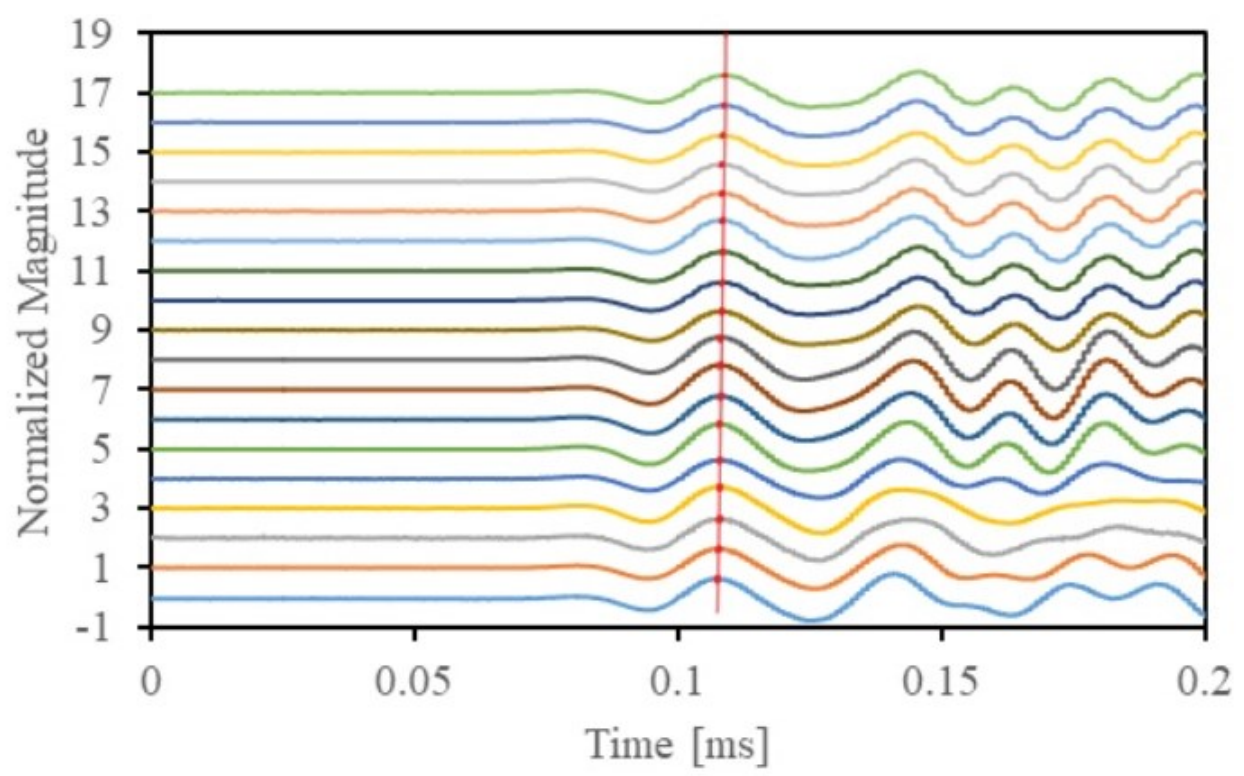

$-8 \mathrm{~min}-32 \mathrm{~min}-128 \mathrm{~min}-256 \mathrm{~min} \longrightarrow$ Day $1-$ Day 2

—Day 3 -Day 4 - Day 5 -Day 10 -Day 11 - Day 12

—Day 15 -Day 21 - Day 23 -Day 26 —Day 28 - Day 30

Figure 58: Waveforms at the specific times, showing the selection of arrival times used to calculate wave velocity (compressional transmitter/shear \#1 receiver).

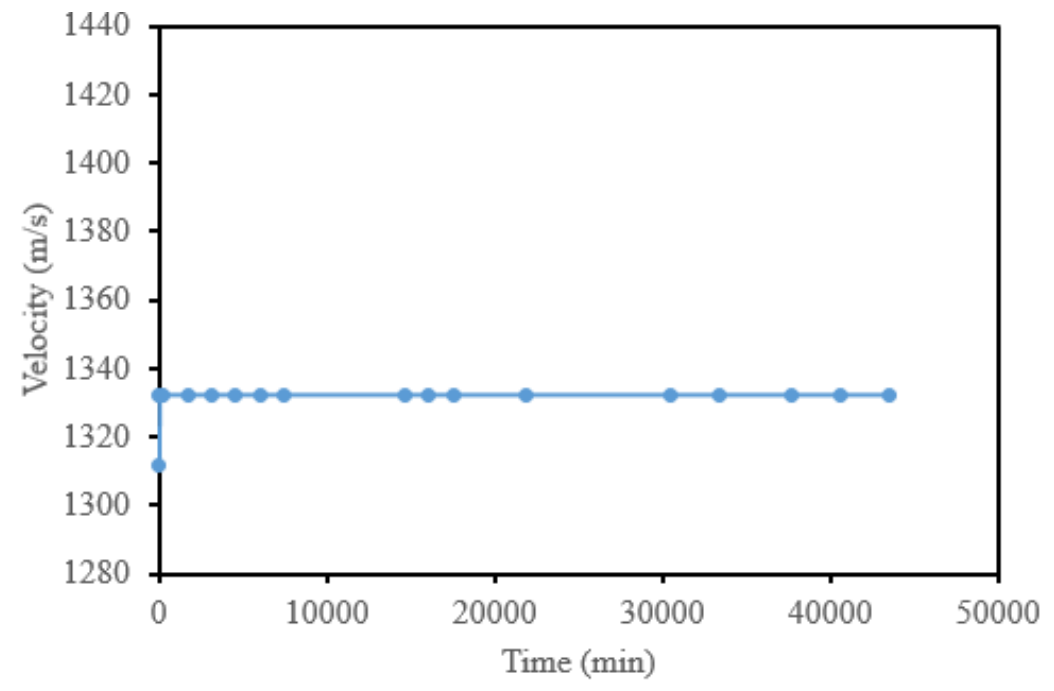

Figure 59: The wave velocity in the function of time (compressional transmitter/shear \#1 receiver). 


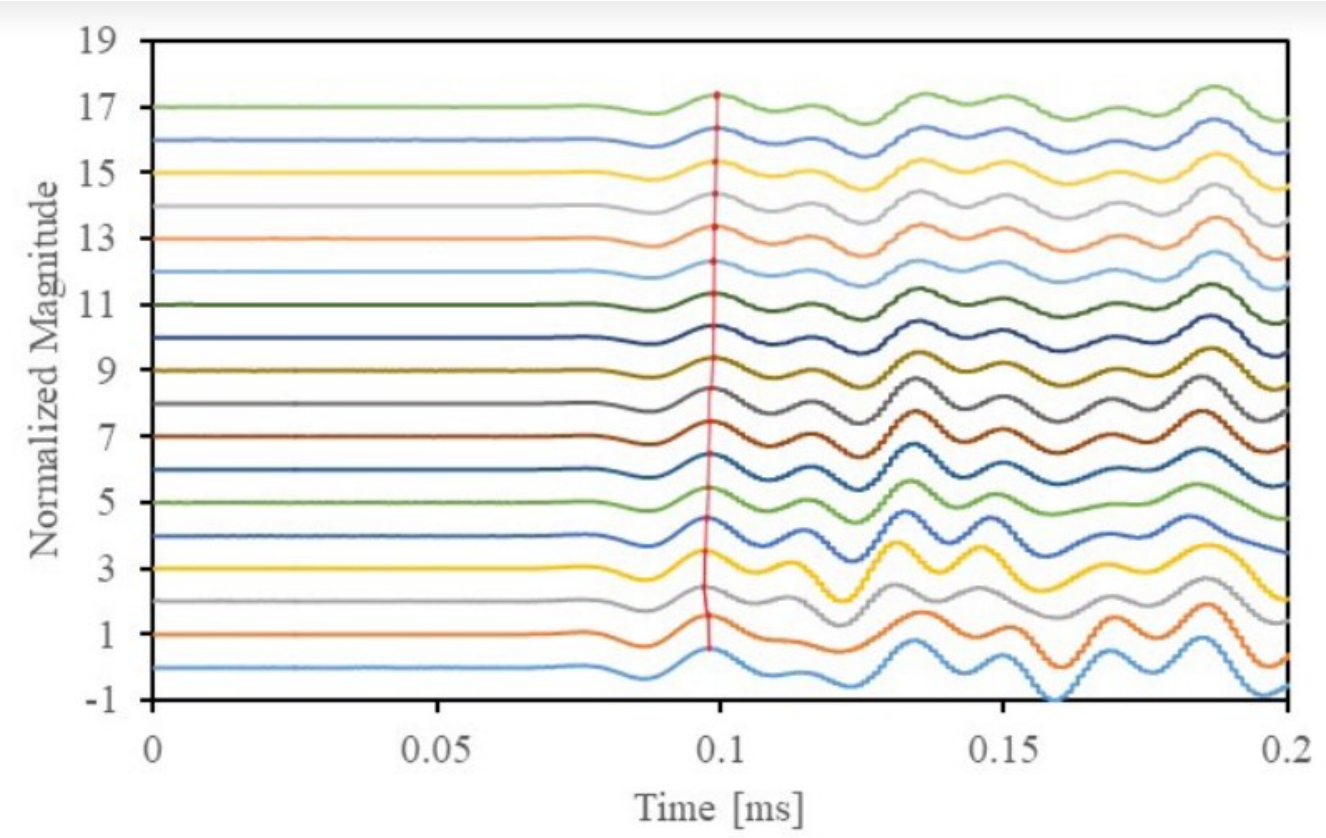

$$
\begin{aligned}
& -8 \mathrm{~min}-32 \mathrm{~min}-128 \mathrm{~min}-256 \mathrm{~min} \text {-Day } 1-D a y 2 \\
& \text {-Day } 3 \text {-Day } 4 \text {-Day } 5 \text {-Day } 10 \text {-Day } 11 \text {-Day } 12 \\
& \text {-Day } 15 \text {-Day } 21 \text { - Day } 23 \text {-Day } 26 \text {-Day } 28 \text { - Day } 30
\end{aligned}
$$

Figure 60: Waveforms at the specific times, showing the selection of arrival times used to calculate wave velocity (Compressional transmitter/shear \#2 receiver).

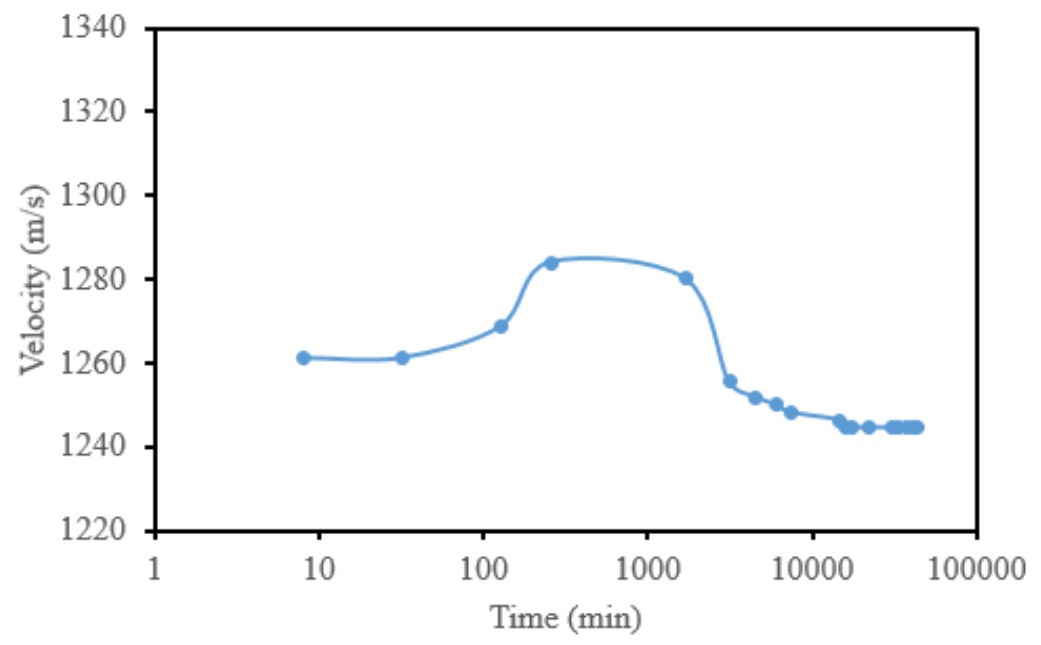

Figure 61: The wave velocity in the function of time (Compressional transmitter/shear $\# 2$ receiver). 


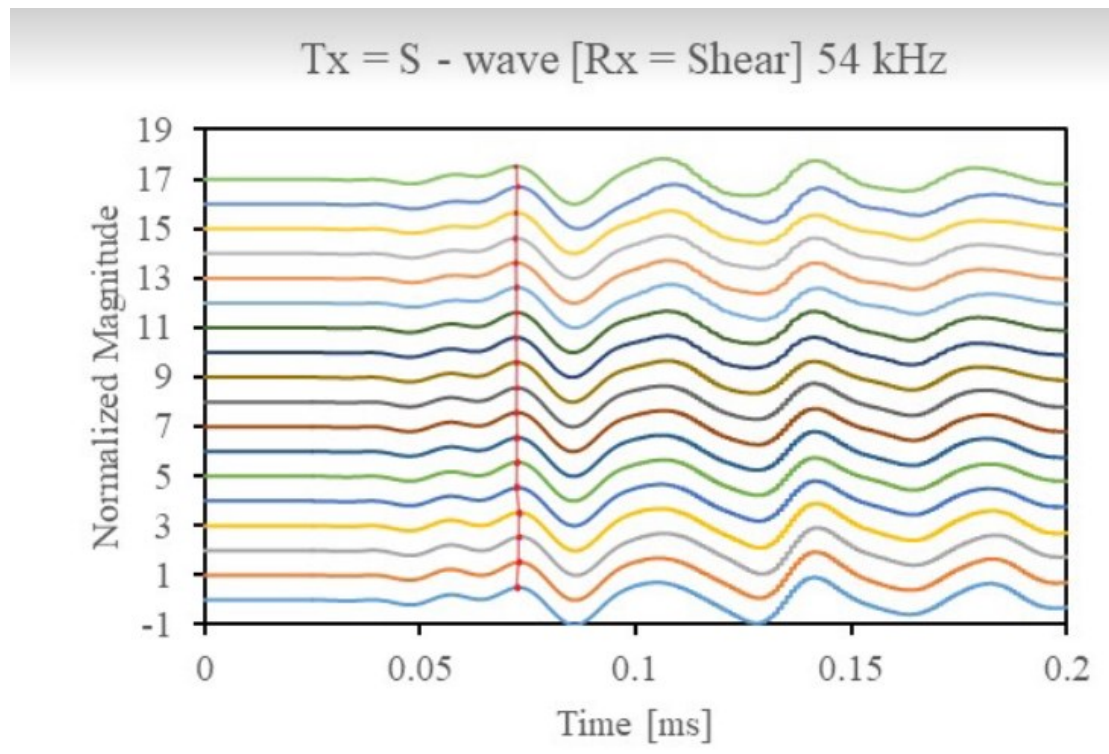

$-1 \mathrm{~min}-32 \mathrm{~min}-128 \mathrm{~min}-256 \mathrm{~min}$-Day $1-$ Day 2
Day $3-$ Day $4-$ Day $5-$ Day $10-$ Day $11-$ Day 12
Day $15-$ Day $21-$ Day $23-$ Day $26-$ Day $28-$ Day 30

Figure 62: Waveforms at the specific times, showing the selection of arrival times used to calculate wave velocity (shear transmitter/receiver).

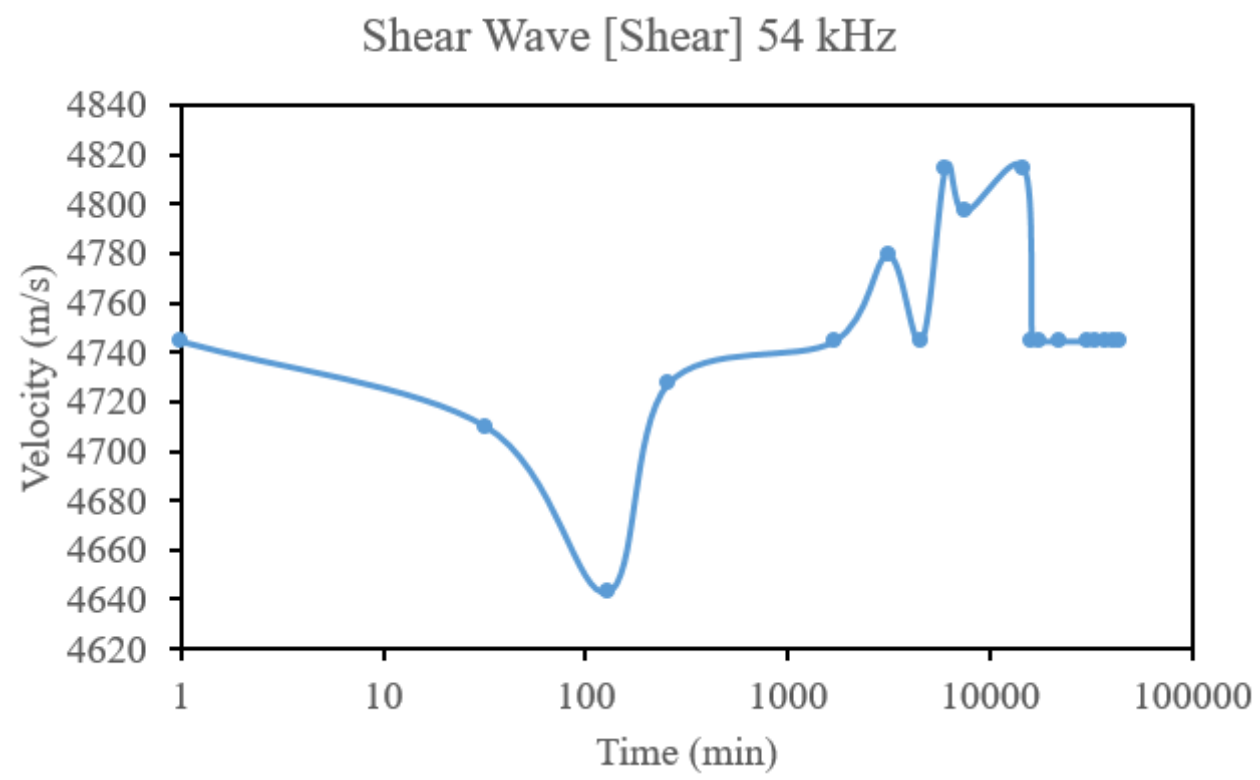

Figure 63: The wave velocity as a function of time (shear transmitter/receiver). 


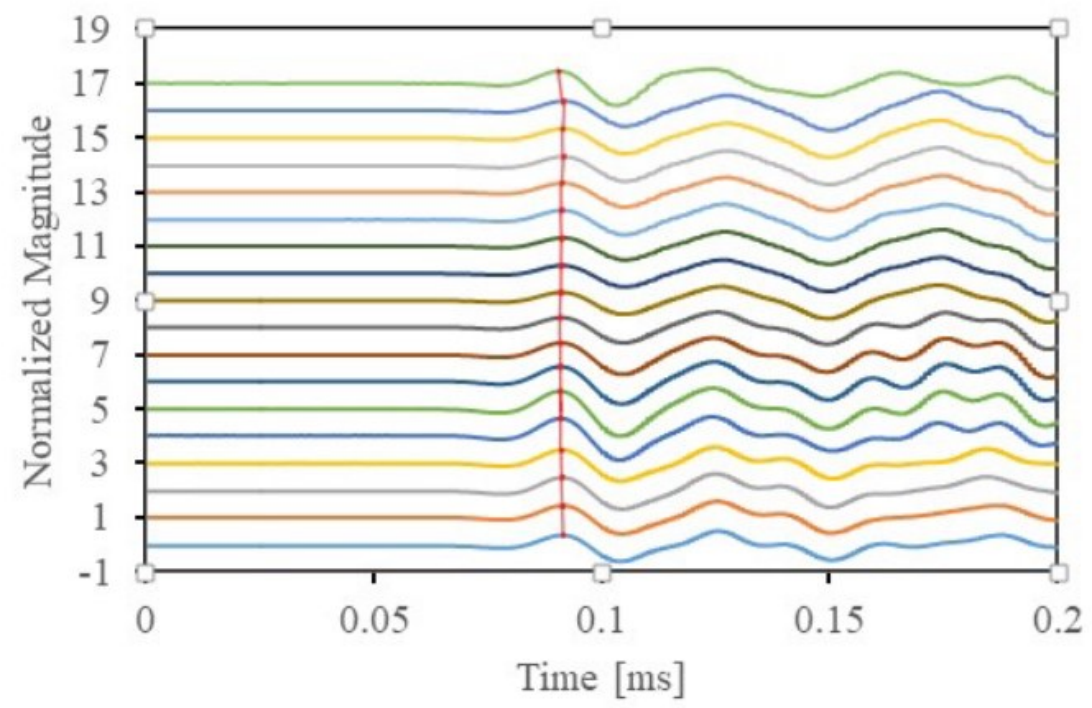

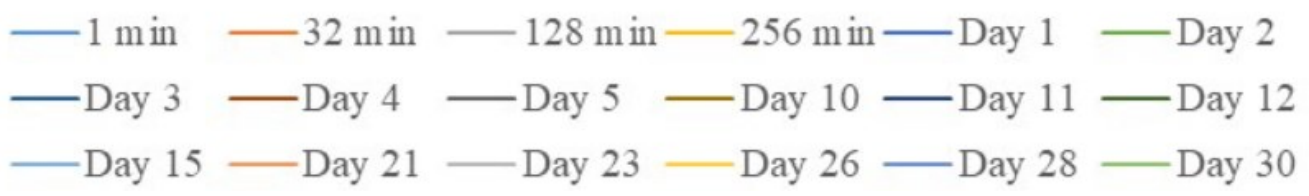

Figure 64: Waveforms at the specific times, showing the selection of arrival times used to calculate wave velocity (shear transmitter/compressional \#1 receiver).

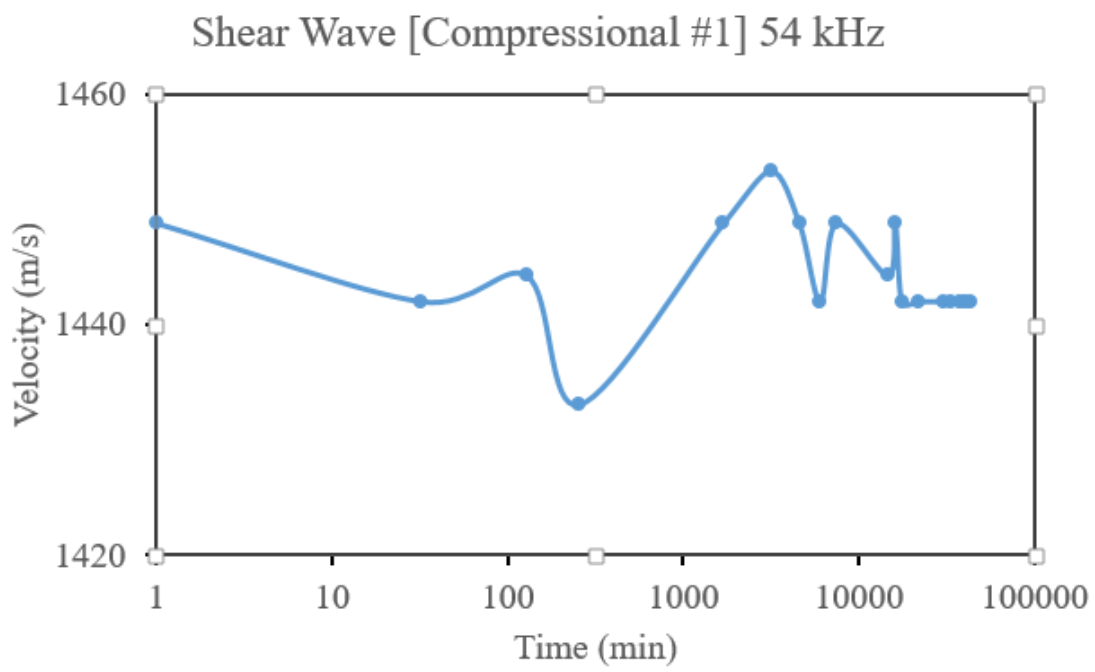

Figure 65: The wave velocity as a function of time (shear transmitter/compressional \#1 receiver). 


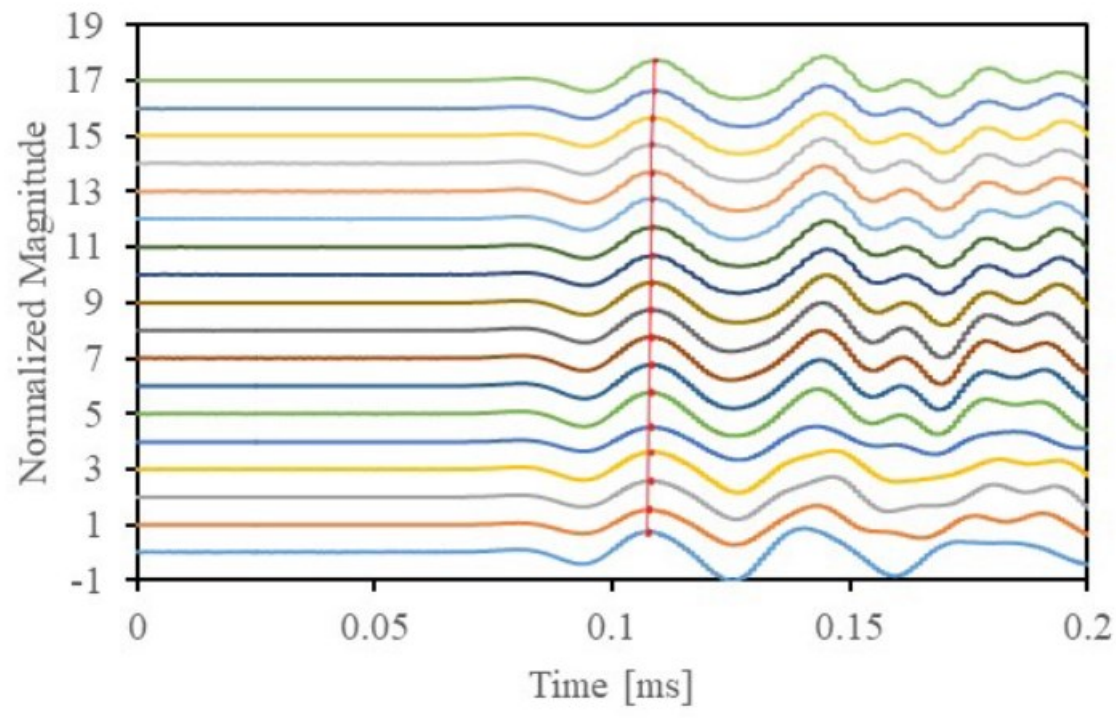

$-1 \mathrm{~min}-32 \mathrm{~min}-128 \mathrm{~min}-256 \mathrm{~min} \longrightarrow$ Day $1-$ Day 2

-Day 3 - Day 4 - Day 5 - Day 10 - Day 11 - Day 12

-Day 15 -Day 21 - Day 23 - Day 26 - Day 28 - Day 30

Figure 66: Waveforms at the specific times, showing the selection of arrival times used to calculate wave velocity (shear transmitter/compressional $\# 2$ receiver).

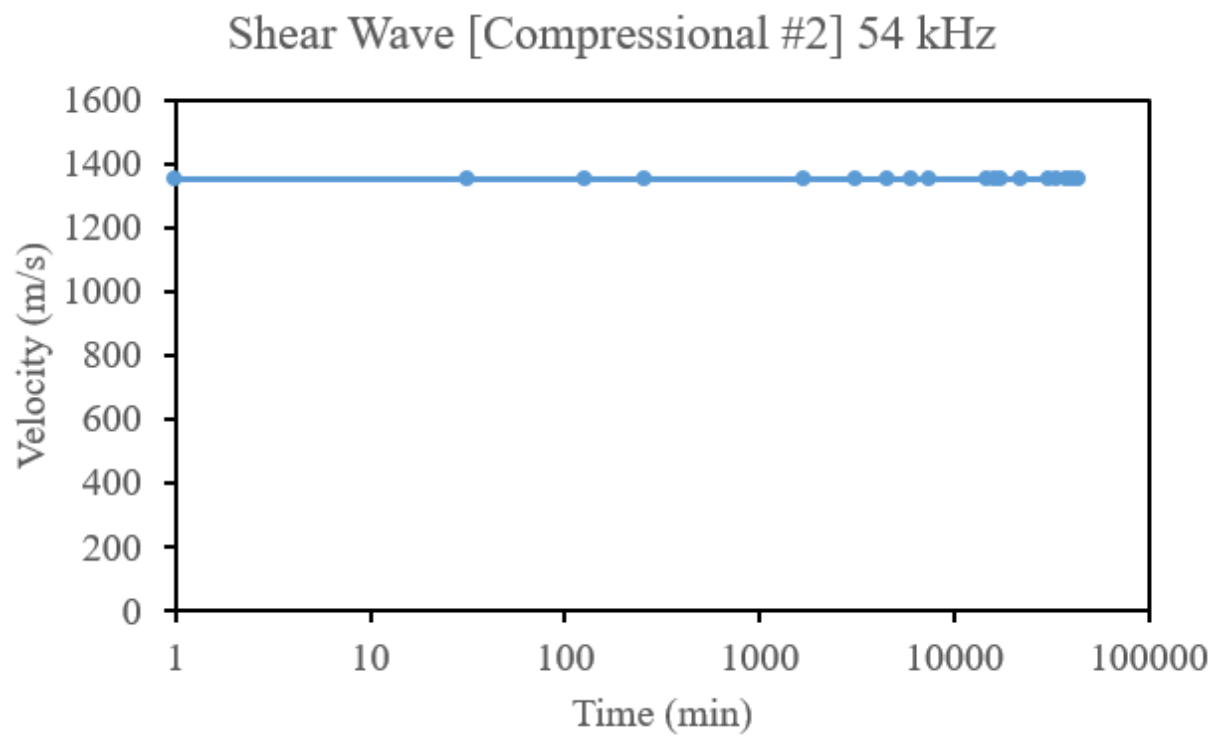

Figure 67: The wave velocity in the function of time (shear transmitter/compressional \#2 receiver). 
The wave velocity in Figure 54 shows a steady decrease. However, the wave velocity graphs illustrate in Figure 56, 58, 60, 62, and 64 show either constant or fluctuation of wave velocities over time.

\subsubsection{Wave Attenuation from the UPV test}

The wave attenuation of UPV test was done by processing the typical waveform into the fast Fourier transform which then allows for the calculation of the area under the curve in order to analyze the attenuation that occur over time. In addition, in this test, the Waveform (without window) is split into two sections, labelled as window 1 and window 2, illustrated in Figure 68(a). Figure 69(a) and 70(a) illustrate the waveform of window 1 and window 2 , respectively. The purpose of using the time windows in this study is to reduce the effect of wave reflections in the calculation of the Fourier spectra in order to conduct clearer analysis. From Figure 68(c), 69(c) and 70(c), the area under the curve from the two selected bandwidth ranging from $0-40 \mathrm{kHz}$ and $40-90 \mathrm{kHz}$ were determined.

Waveform analysis is only presented for the case of $\mathrm{P}-\mathrm{P}$, as it presents the clearest trend from all the data. Analysis of all the data, however, is presented in Appendix B. 

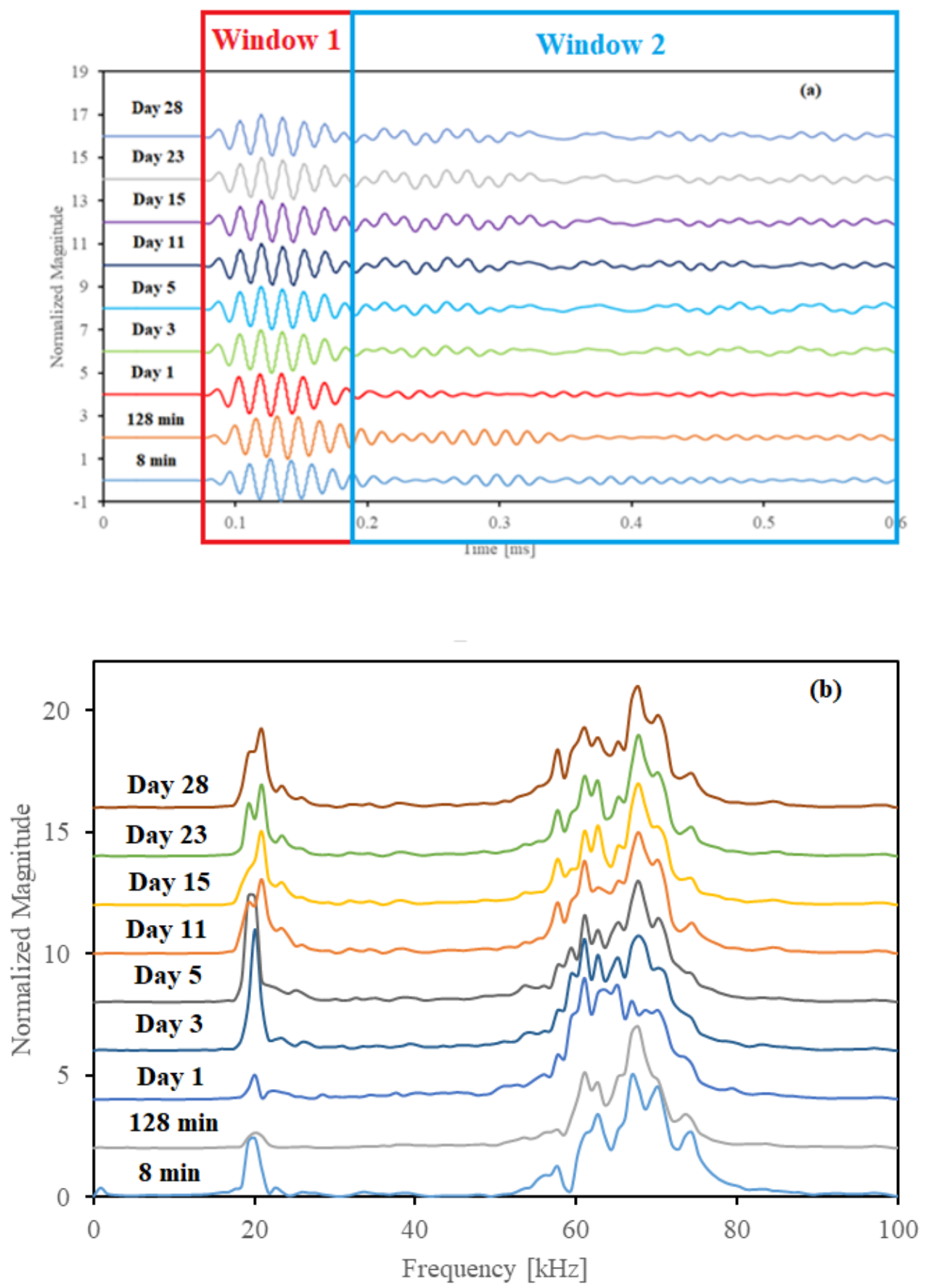

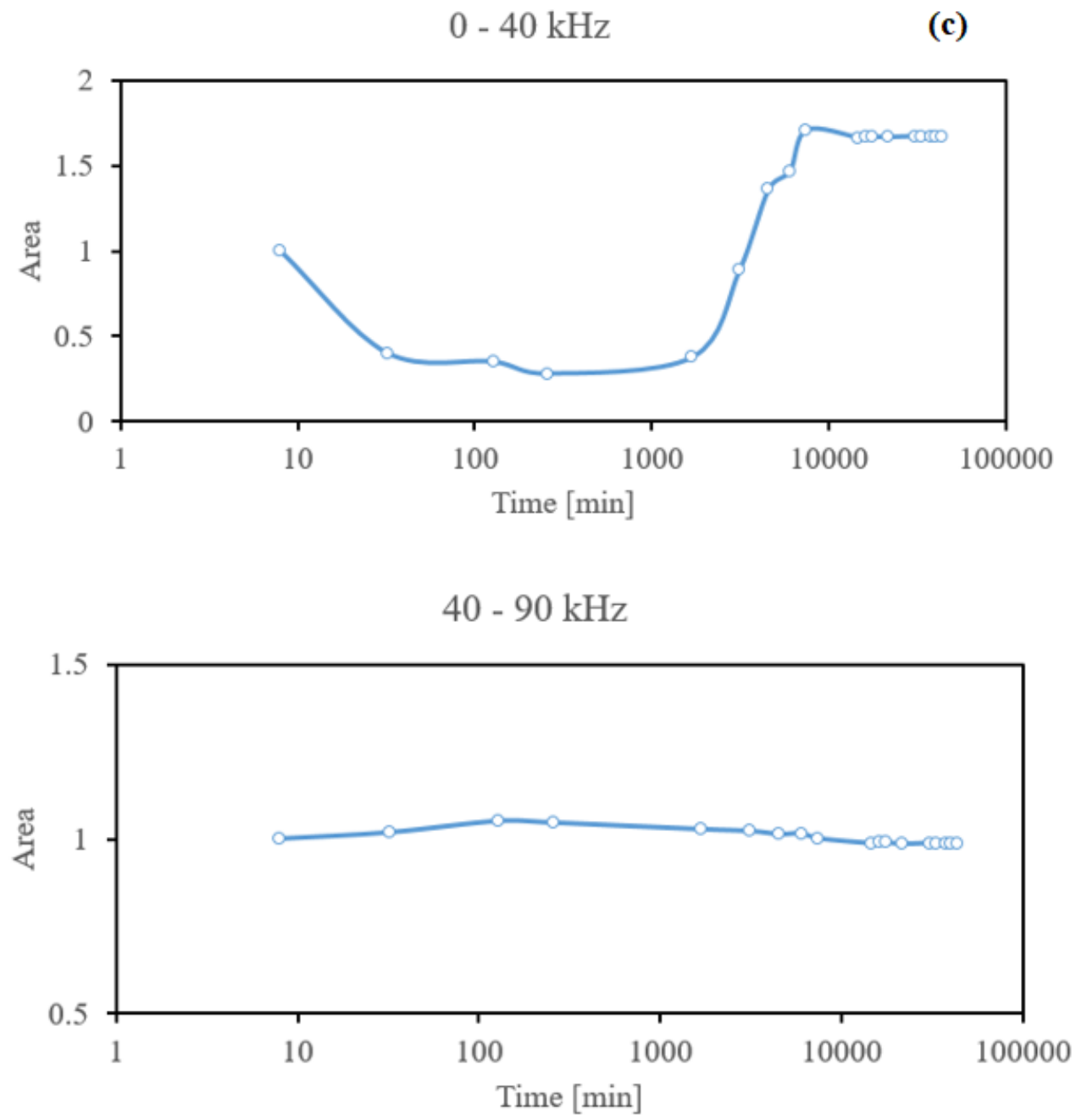

Figure 68: Without Window (compressional transmitter/receiver): (a) Time signal, (b) FFT, (c) Area under the curve in the function of time. 

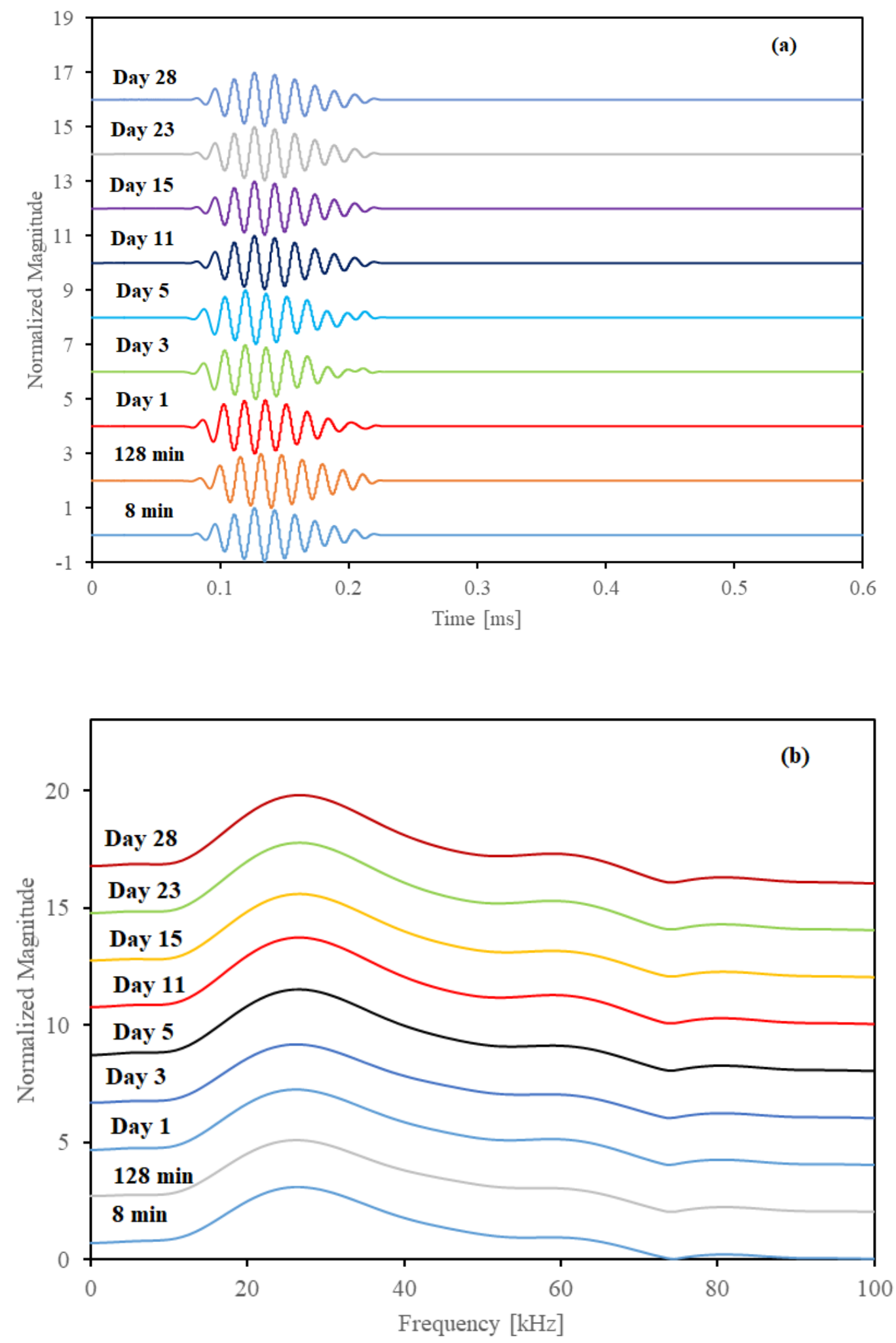


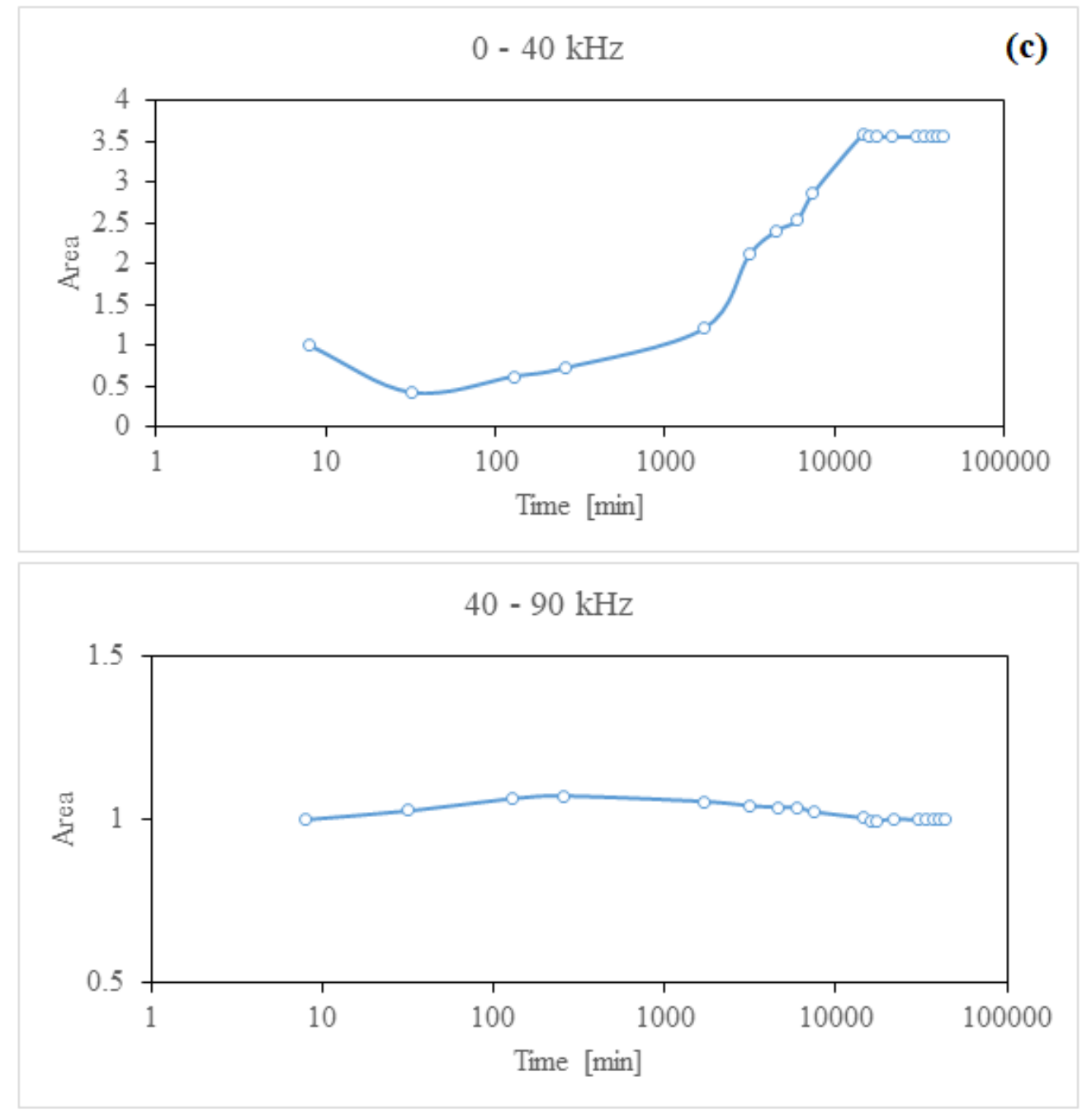

Figure 69: Window 1 (compressional transmitter/receiver): (a) Time signal, (b) FFT, (c) Area under the curve in the function of time. 

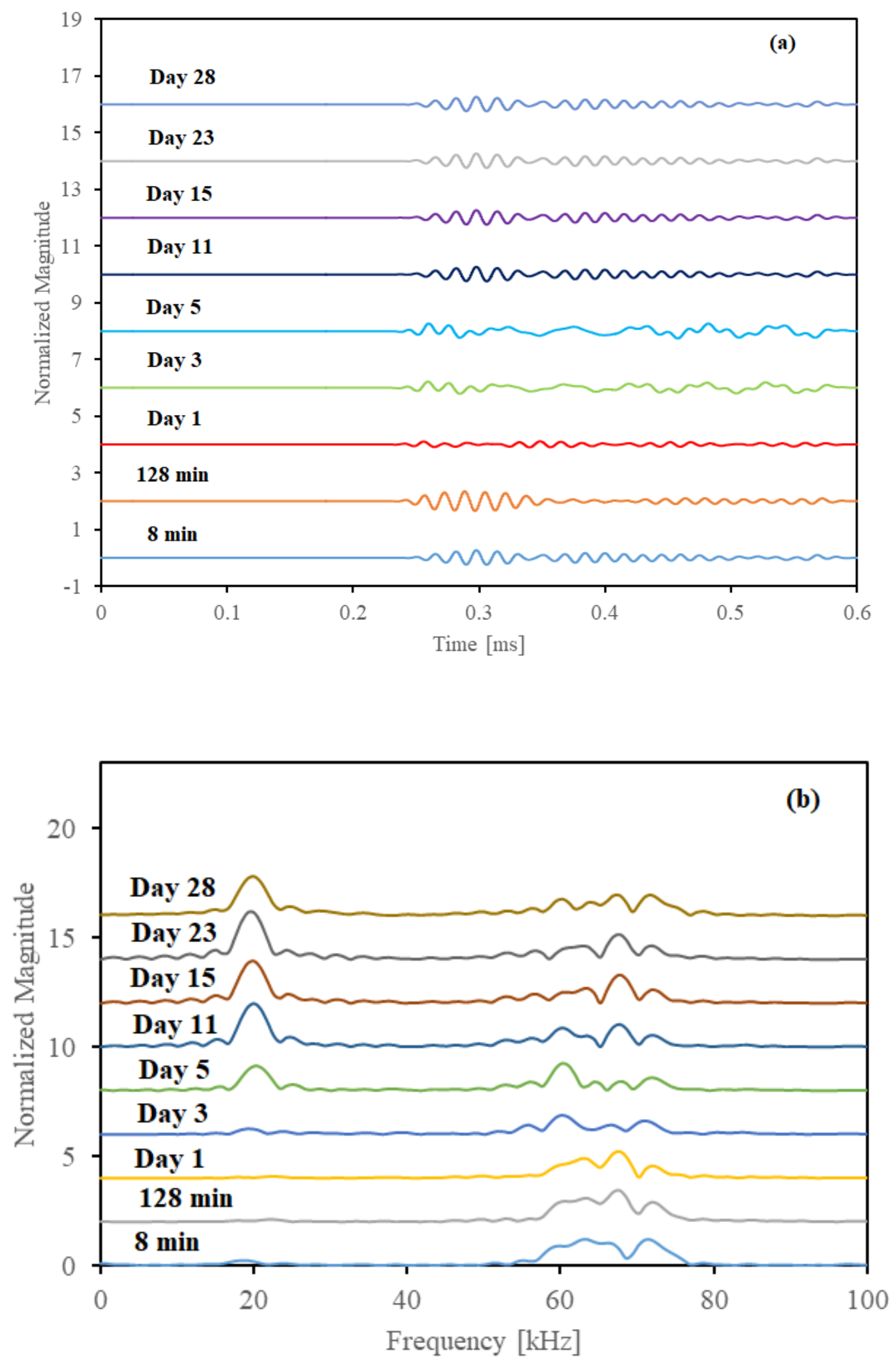


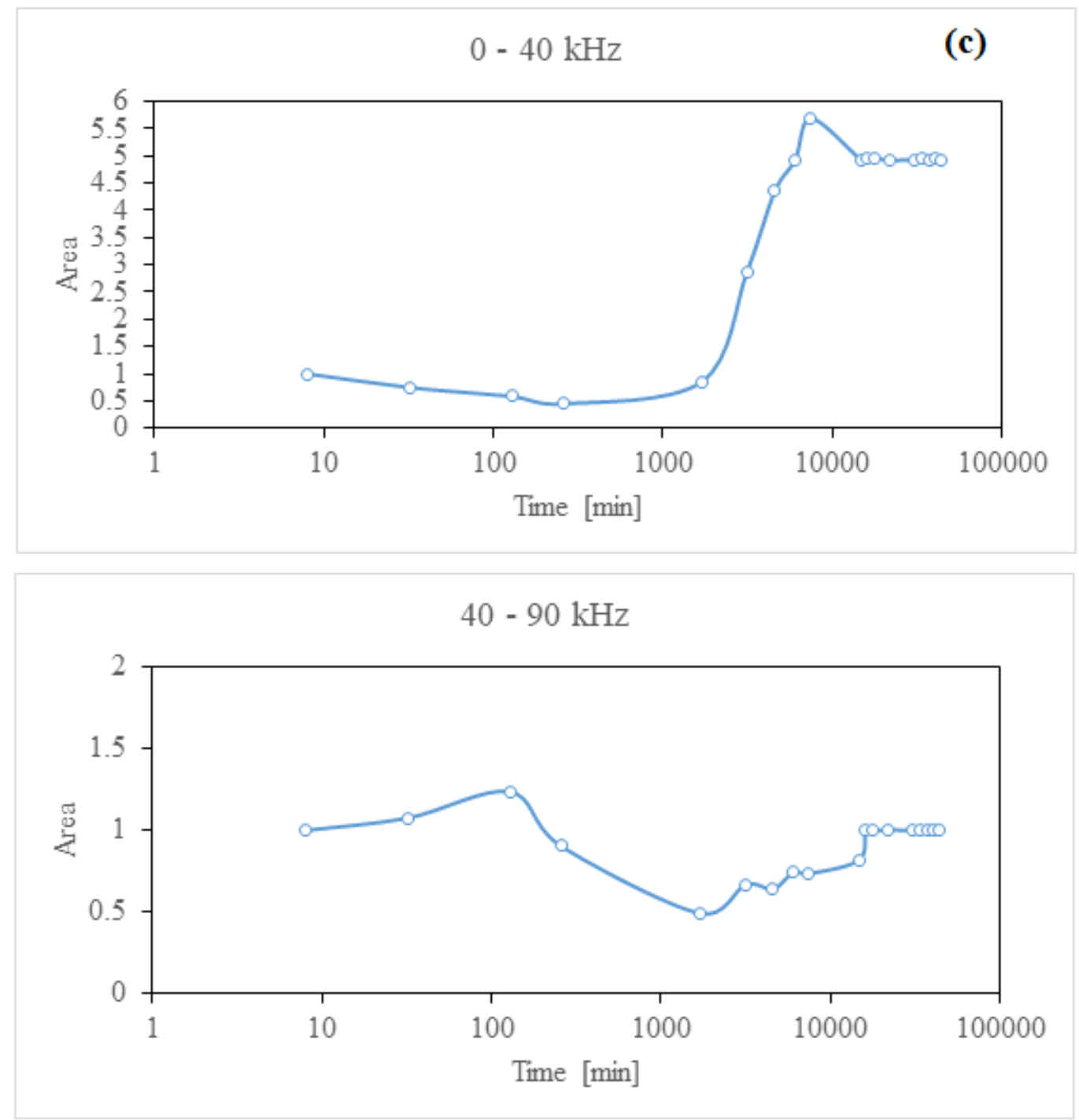

Figure 70: Window 2 (compressional transmitter/receiver): (a) Time signal, (b) FFT, (c) Area under the curve in the function of time.

The area under the curve against days for each frequency graphs were plotted in order to analyze the changes in wave attenuation, illustrated in Figure 68(c), 69(c) and 70 (c). On the figures, frequency bandwidth ranging from $0-40 \mathrm{kHz}$ shows an increasing trend for all the windows before they become constant after day 10. As mentioned 
previously, a reduction in wave amplitude in the wave attenuation can indicate a degradation or loss of material strength (Ensminger \& Bond, 2011).

Therefore, the results shown that there is an increase in area over time in the frequency bandwidth ranging from $0-40 \mathrm{kHz}$, this could be due to the increase in density and stiffness of the fFFT during consolidation. For the attenuation test, the results shown in Figure 68, 69 and 70 are obtained from both p-transmitter and p-receiver and the results show a clear trend. In addition, the wave attenuation results obtained from swave or p-wave-s-wave combinations are presented in Appendix B as they did not show useful trends.

Figure 71 illustrates the fast Fourier transform of water and this was obtained from where the transducers were located at the bottom of the column. It was used to compare with the fast Fourier transform of fFFT shown in Figure 68(b). For water, even though, there is a peak in a frequency bandwidth ranging from $10-30 \mathrm{kHz}$, it is still much smaller than the peaks appear at the same frequency bandwidth in fFFT. This could be interpreted the frequency bandwidth from $10-30 \mathrm{kHz}$ was actually showing the behavior of the specimen tested while the frequency bandwidth between $40-80 \mathrm{kHz}$ was triggered by the transducers. 


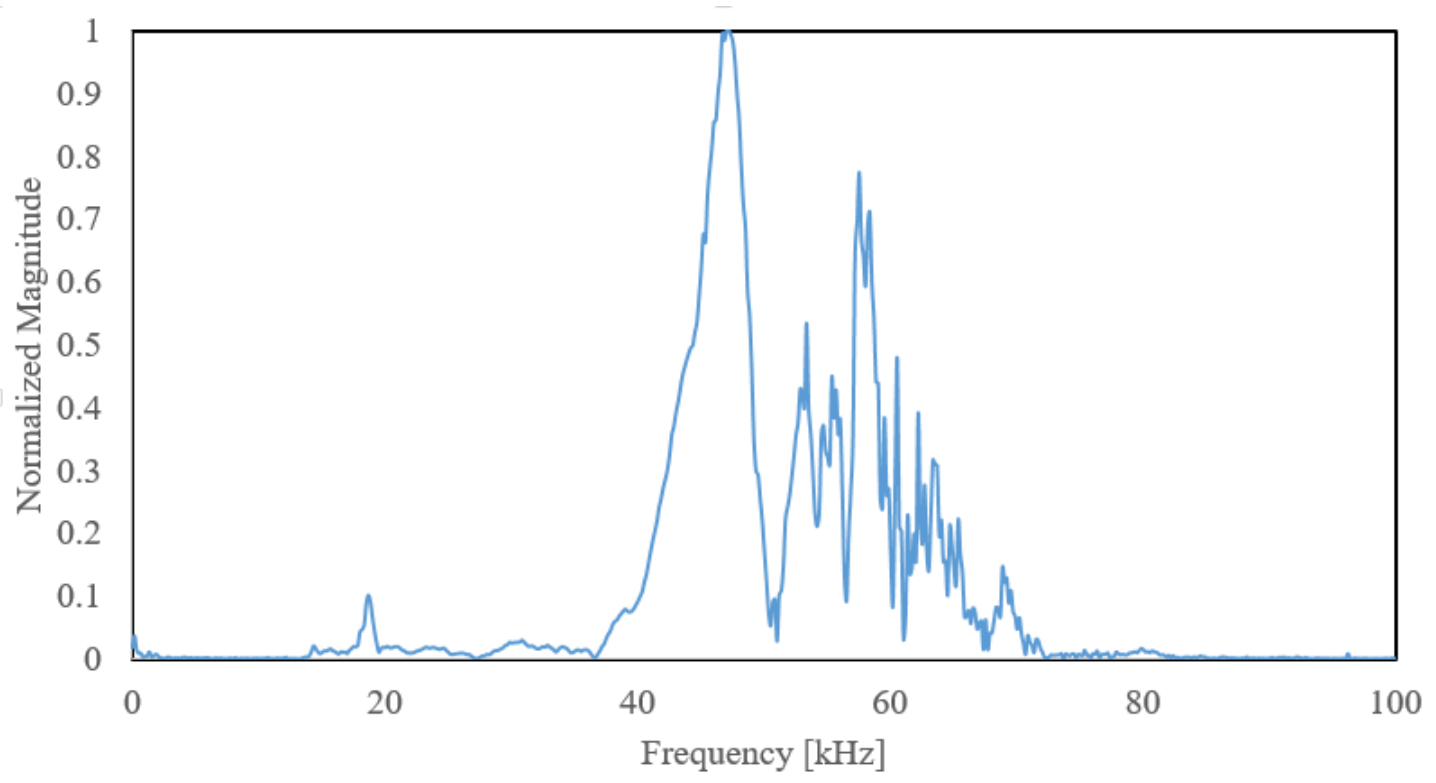

Figure 71: Fast Fourier transform of Water.

\subsubsection{The Density Obtained from Wave Velocity using a Constant Constrained}

\section{Modulus}

The wave velocity equation is also equivalent to the square root of constrained modulus over the density. Therefore, the change in density of the FFT obtained from the wave velocity over time can be determined using Equation 1 in Chapter 2 (Section 2.2.1) by assuming a single value of constrained modulus. The assumption of constant constrained modulus may not be reflected in real life, however, it is used in this study as the objective is to determine the absolute changes of the FFT's properties, not the absolute values. 


\subsubsection{Relationship between Density and the Velocity or Attenuation}

The settlement of the fFFT in the column was calculated and compared it with the attenuation and density obtained from the velocity measurements, illustrated in the following four figures. The velocity and attenuation are compared with both the average density calculated from the settlement of the column, and the density at the bottom of the column adjacent to the transducers estimated using large strain consolidation modelling.

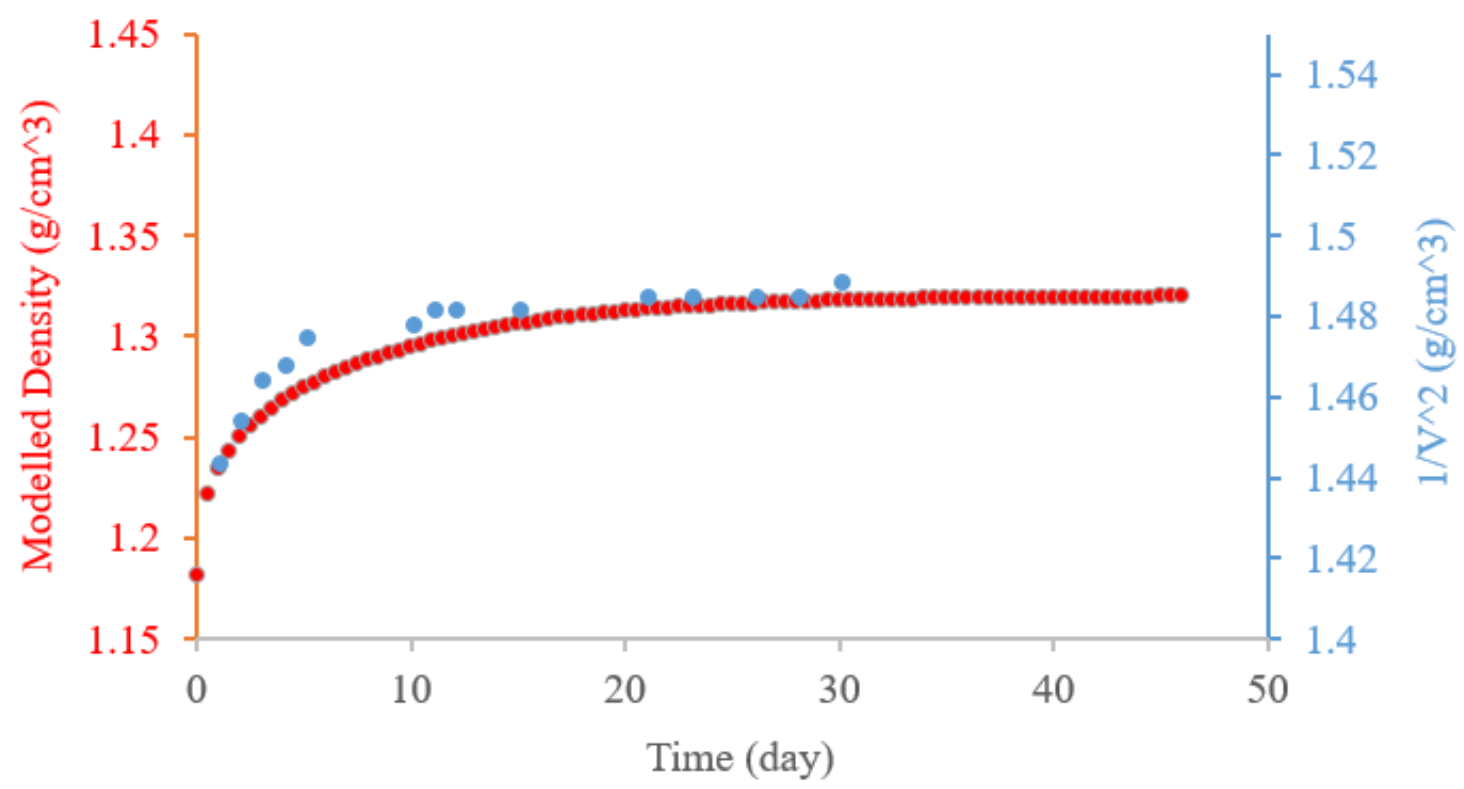

Figure 72: Modelled density vs $1 / \mathrm{V}^{\wedge} 2$. 


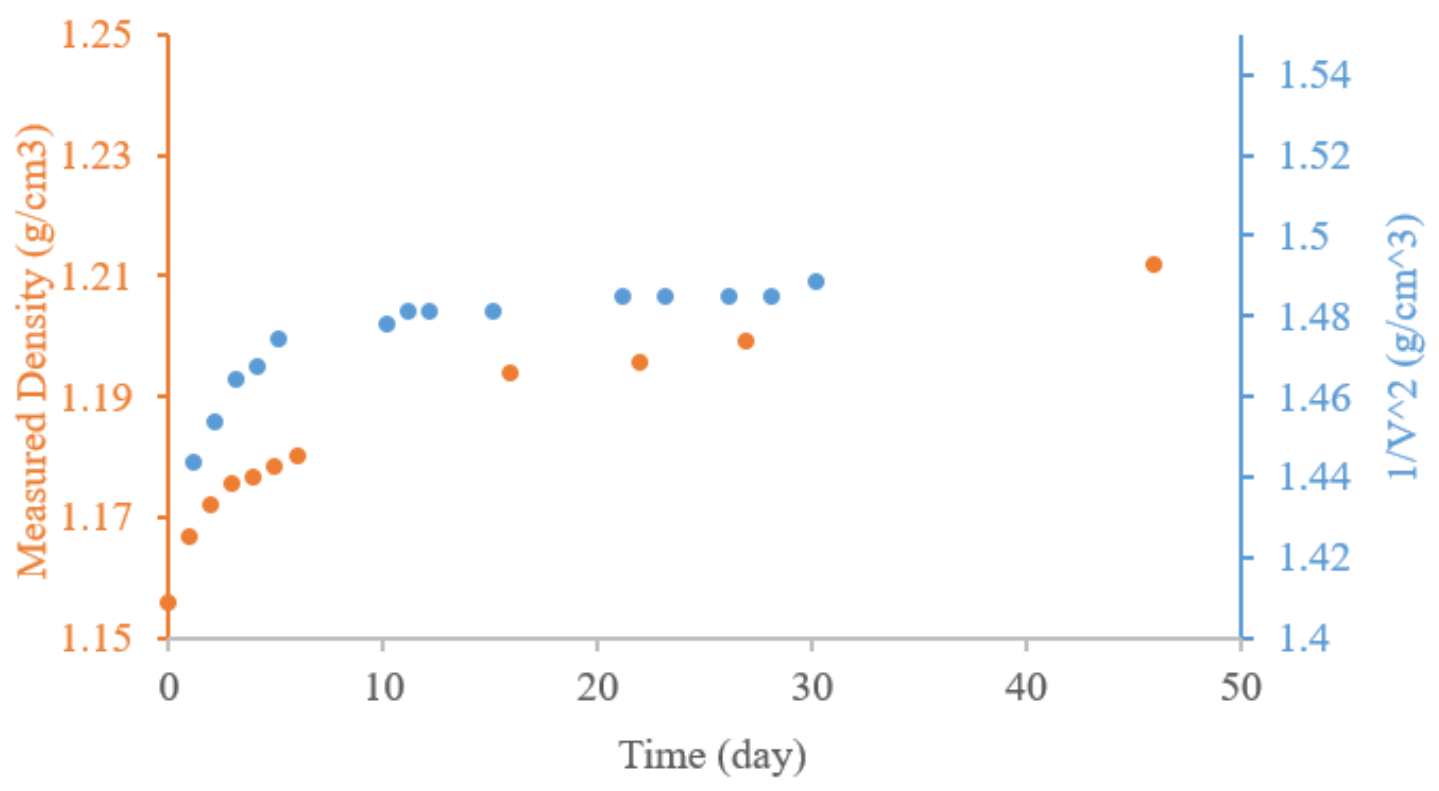

Figure 73: Measured Density vs $1 / \mathrm{V}^{\wedge} 2$.

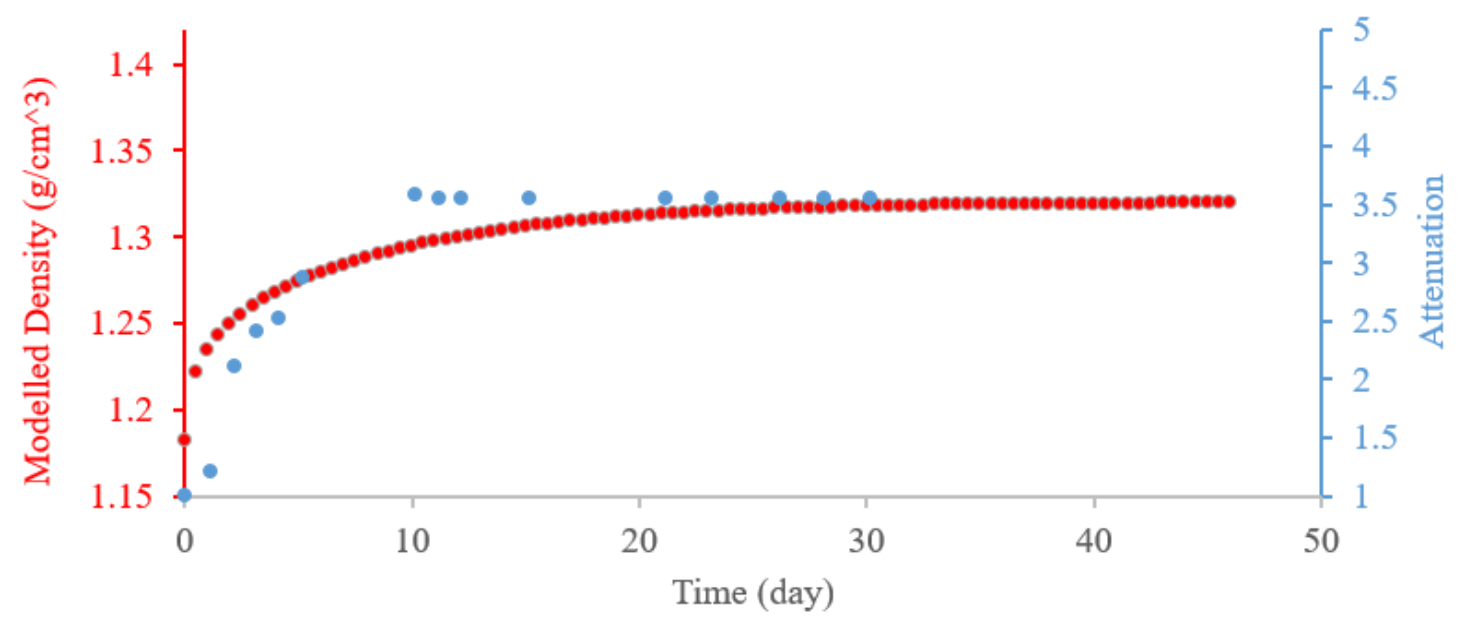

Figure 74: Modelled Density vs attenuation. 


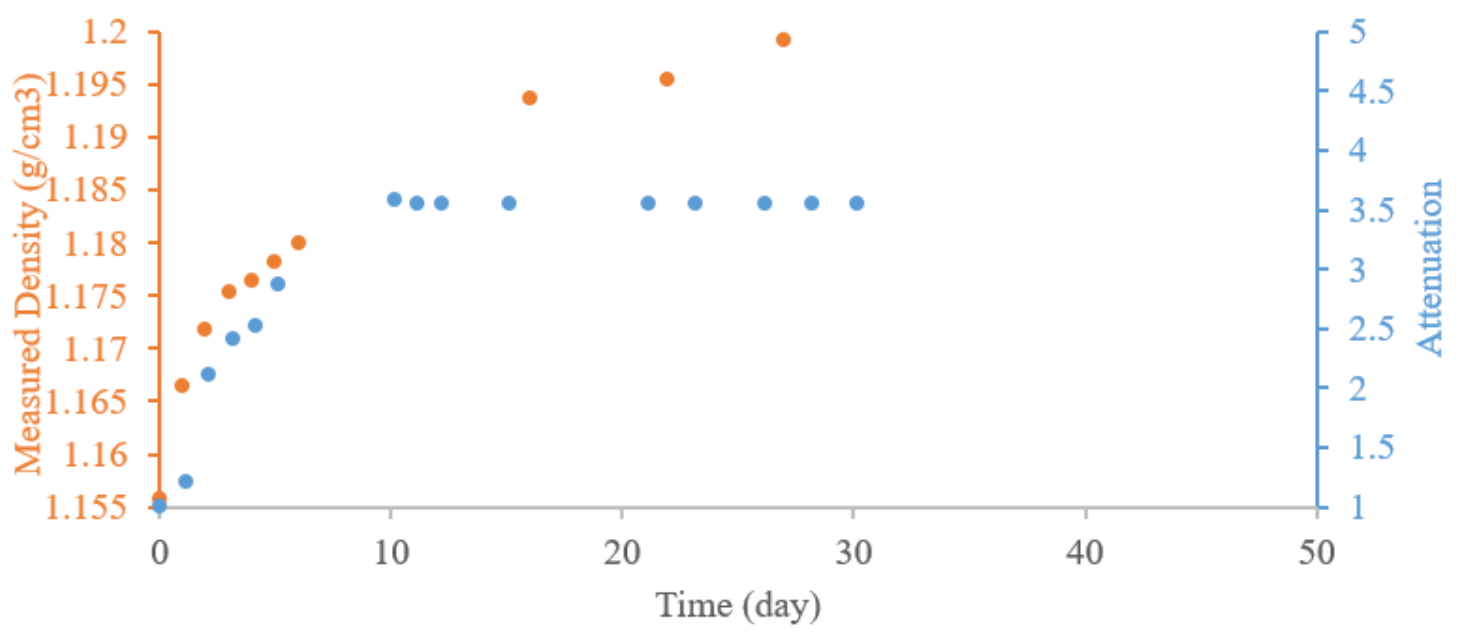

Figure 75: Measured Density vs attenuation.

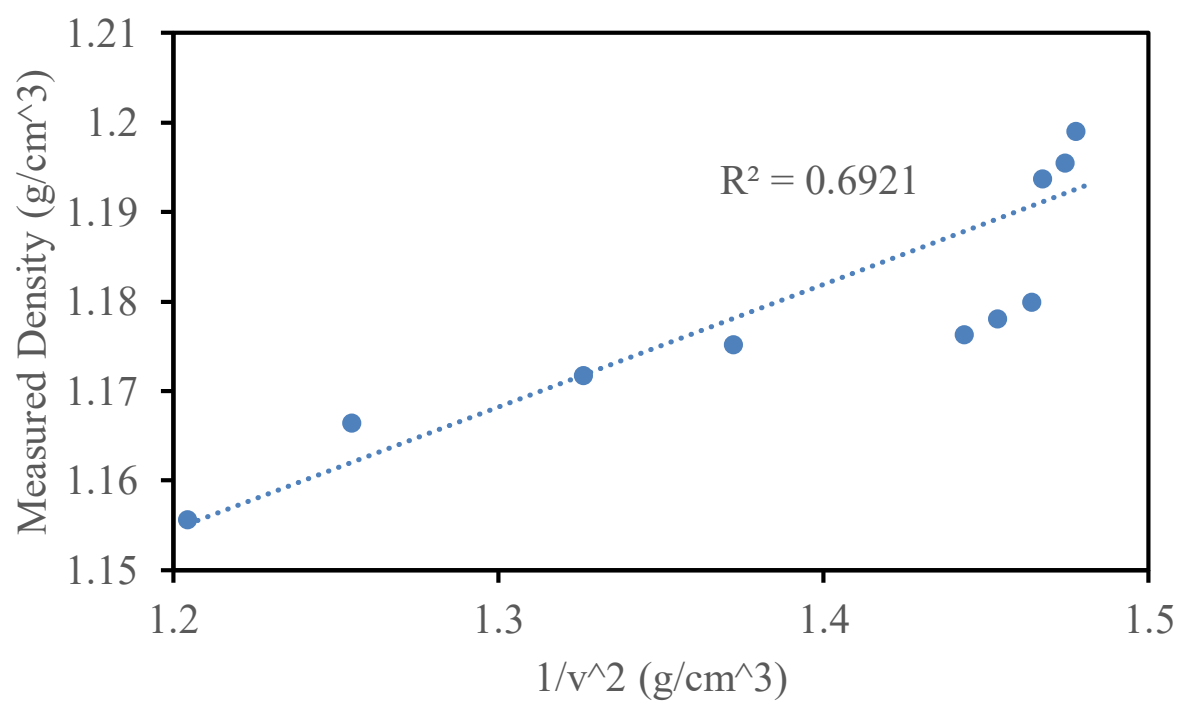

Figure 76: Measured Density vs $1 / \mathrm{V}^{\wedge} 2$. 


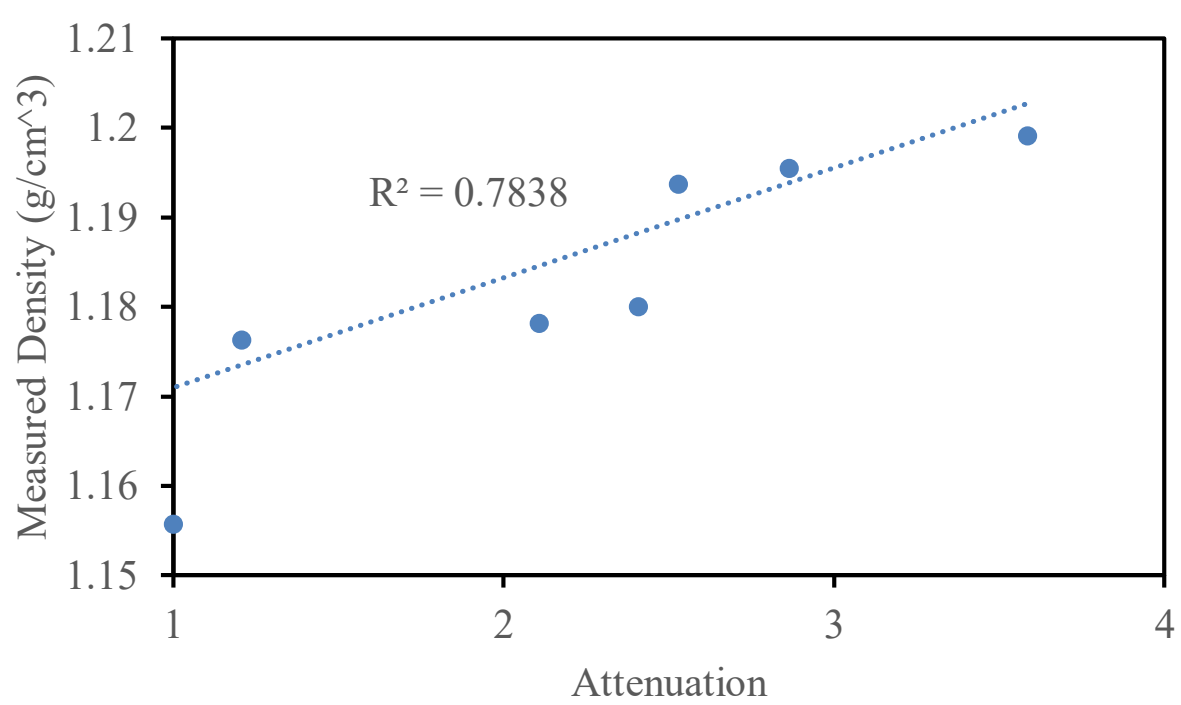

Figure 77: Measured Density vs attenuation.

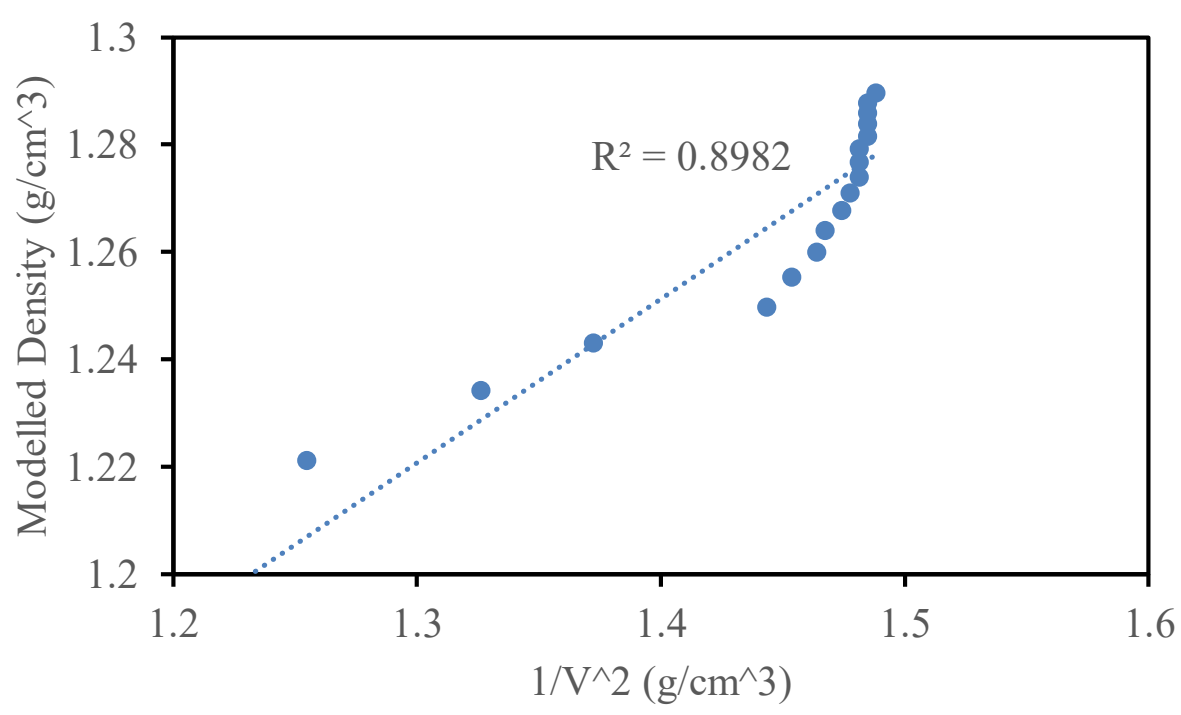

Figure 78: Modelled Density vs 1/V^2. 


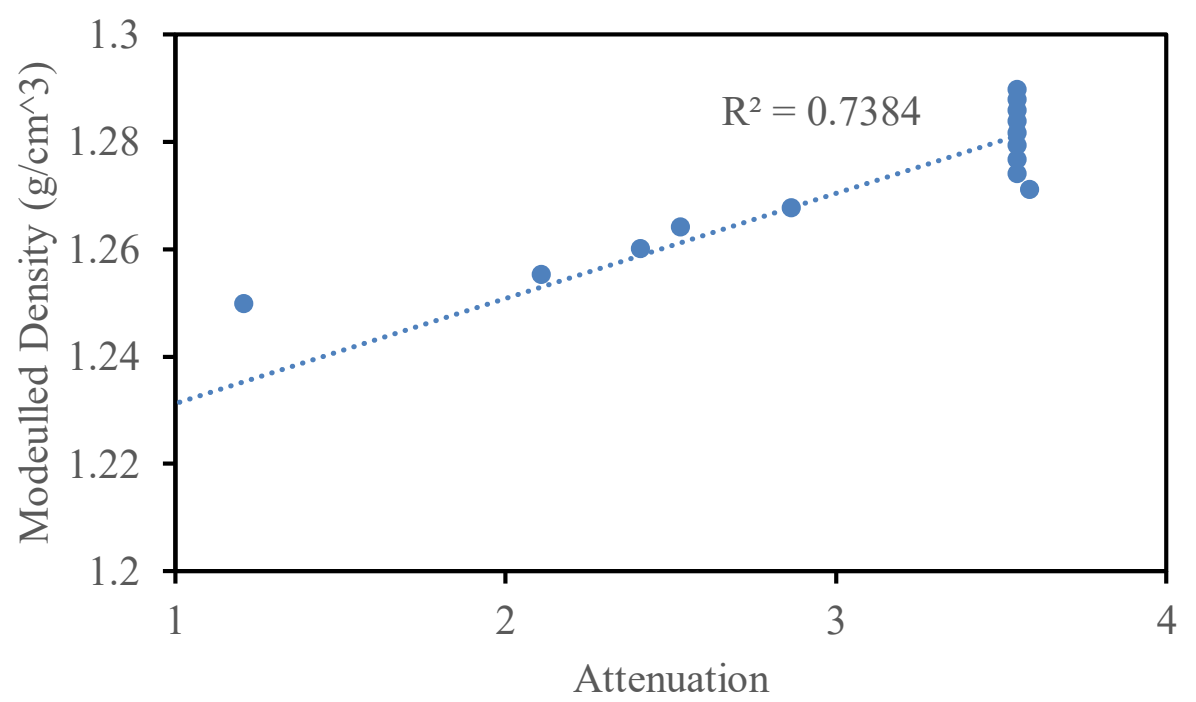

Figure 79: Modelled Density vs attenuation.

Results show a strong correlation between density obtained from model, and density obtained from velocity, with slightly better agreement between the estimated density at the transducer and the attenuation. Thus, UPV test used in this study is sensitive enough to detect the changes in density in the fFFT, using P-waves. This technique may be most useful to study changes in density at early times in sedimentation columns. 


\section{Chapter 5: Conclusion and Recommendation}

Understanding the changes in engineering properties such as stiffness, density and structuration of the fFFT is the most important to ensure the seamless reclamation process and the success of the optimization of tailing management. Thus, the UPV method is used in this study to interrogate the fFFT as a function of time.

Initially, to improve the reliability of the UPV test, the ultrasonic equipment is calibrated by using different procedures (i.e steel and PVC reference standard bars, water and air). The calibration test done in the reference standard bars provide the delay time introduced by the instrumentation. The delay time is then subtracted from the arrival time of each test in order to provide more reliable results. In addition, the calibration test are further performed in water and air in order to interpret the information conveyed by the recorded signal.

Next, the wave velocity results presented in this study show that there is a steady decrease of wave velocity throughout the whole experiment. The settling rate of the particles is influenced by the density. Therefore, this can be interpreted that during the consolidation of the fFFT over time, the density of fFFT increases, causing the wave velocity to decrease.

Finally, the wave attenuation test is also conducted in this study in order to evaluate the behavior in the properties of fFFT through the change in the wave amplitude. The wave attenuation results presented in this study show that the area under the curve obtained from the frequency bandwidth ranging from $0-40 \mathrm{kHz}$ show an evidence trend 
line until day 10 before it become constant. The increase in the area might be caused by the density of fFFT is increasing over time during settlement.

During testing, the experiment was attempted to study the whole column from the bottom to the top. However, due to only one set of available transducers and holders for the P-waves and S-waves, the user has to move the transducers and holders each time after testing. This results in interference and inconsistent results.

Thus, in the end, the testing was only conducted at the very bottom of the column. Both attenuation and density obtained from the velocity measurements are compared with the settlement of fFFT in the column. The results show that the wave velocity and wave attenuation from p-wave data are indeed sensitive enough to detect the changes in fFFT as the results illustrated in the wave velocity and wave attenuation show an evident trend in the time relative changes in velocity and attenuation. The results also show a good correlation between settlement and attenuation as well as density obtained from the velocity measurements. However, data using s-wave or p-wave-s-wave combinations did not show useful trends. 


\section{Recommendations for Future Study}

The following recommendations are made for further research on interrogating the oil sands tailing during sedimentation using ultrasonic:

- To overcome with the inconsistency of the results obtained from the ultrasonic testing, more holders could be fabricated to hold the transducers in place at different heights on the column.

- It is recommended to study the whole column, as this will give a result in changes in properties of the fFFT in each section's height of the column. However, multiple holders and transducers will be required to avoid inconsistency from movement of the equipment.

- Further analysis should be conducted on the results from shear transducers. Knowing now that the p-wave results correlate strongly to density, may now help interpreting the s-wave data to properly understand the changes in fFFT. 


\section{Bibliography or References}

ASTM C597-16, Standard Test Method for Pulse Velocity through Concrete, ASTM International, West Conshohocken, PA, 2016.

American Society for Testing and Materials. (2011). ASTM E1316-11b: Standard Terminology for Nondestructive Examinations. West Conshohocken, PA.

ASTM E127 - 20, Standard Practice for Fabrication and Control of Flat Bottomed Hole Ultrasonic Standard Reference Blocks, PA.

ASTM E428 - 08, Standard Practice for Fabrication and Control of Metal, Other than Aluminium, Reference Blocks Used in Ultrasonic Testing, PA, 2013.

Aki, K., and Richards, P. G. (1980). Quantitative Seismology-Theory and Methods, volume IWH Freeman and company. New York.

ARC, CTFAOIL SANDS, 1977. CLAY TAILINGS FROM ALBERTA OIL SANDS AND OTHER SOURCES. A REVIEW Prepared by the Alberta Research Council 11315 -87 Avenue, Edmonton.

Alberta Energy and Utilities Board, Alberta's reserves 2006 and supply/demand outlook 2007 - 2016, Farhood Rahnama, coord., Alberta Energy and Utilities Board, Calgary, Alberta, Canada, 2007.Bungey, J.H., Millard, S.G., \& Grantham, M.G. (2014). Testing of Concrete in Structures. Crc Press;

BGC Engineering Inc. (2010). Oil sands tailings technology review. Oil Sands Research and Information Network, University of Alberta, School of Energy and the Environment, Edmonton, Alberta, OSRIN Report No. TR-1. 
Budhu, M. (1999). Soil Mechanics and Foundations. John Wiley \& Sons, Inc.

Burland, J.B., Longworth, T.I., and Moore, J.F.A. 1977. Study of ground and progressive failure caused by a deep excavation in Oxford clay. Ge'otechnique, 27(4): 557591.

Baginska, I., Janecki, W., and Sobotka, M. (2013). On the Interpretation of Seismic Cone Penetration Test (SCPT) Results. "Studia Geotechnica et Mechanica, Vol XXXV, No 4.

Beier, N., M. Alostaz and D. Sego, 2009. Natural dewatering strategies for oil sands fine tailings. IN: Tailings and Mine Waste '09, Banff, Alberta. University of Alberta, Department of Civil \& Environmental Engineering, Edmonton, Alberta.

Bakhtiari, M.T. (2015). Role of Sodium Hydroxide in Bitumen Extraction: Production of Natural Surfactants and Slime Coating (Ph.D.’s dissertation, University of Alberta).

Chalaturnyk, R.J., J.D. Scott and B. Ozum, 2004. Environmentally Acceptable Deposition of Oil Sands Tailings, SWEMP 2004, 8 International Symposium on Environmental Issues and Waste Management in Energy and Mineral Production May 17-20, 2004 th Antalya, Turkey, 6p.

“Crude Oil Facts.” Government of Canada, 6 Oct. 2020, www.nrcan.gc.ca/sciencedata/data-analysis/energy-data-analysis/energy-facts/crude-oil-facts/20064. 
Caughill DL, Morgenstern NR, Scott JD (1993) Geotechnics of nonsegregating oil sand tailings. Can Geotech J 30:801-811

Camacho-Tauta, J. (2011). Evaluation of the small-strain stiffness of soil by nonconventional dynamic testing methods [PhD Thesis], Lisbon: Technical University of Lisbon.

Chan, C. (2006). A Laboratory Investigation of Shear Wave Velocity in Stabilised Soft Soils (P.hD's dissertation, University of Sheffield).

“Crude Oil Facts." Government of Canada, 6 Oct. 2020, www.nrcan.gc.ca/sciencedata/data-analysis/energy-data-analysis/energy-facts/crude-oil-facts/20064.

Campbell, Gaylon. "Application of a Dew Point Method to Obtain the Soil Water Characteris.” SpringerLink, 2007, link.springer.com.

Dyvik, R. and Madshus, C. (1985). Lab measurements of Gmax using bender elements, Proc, ASCE Annual Convention on Advances in the Art of Testing Soils under Cyclic Conditions, Detroit, Michigan, pp. 186-196.

Dawson, R.F. and Sego, D.C. (1993). Design concepts for thin layered freeze-thaw dewatering systems. Proceedings of the 46th Canadian Geotechnical Conference, Saskatoon, pp. 283-288

Ensminger, D., and Bond, L,. J. (2011). Ultrasonics: Fundamentals, Technologies, and Application: CRC Press. 
Eun. J., and Lee, J. (2012).”Effect of Soil Parameters on Elastic Characteristics of Subgrade Materials.” J. Mater. Civ. Eng., 25(10), 1943-5533 https://ascelibrary.org/doi/10.1061/\%28ASCE\%29MT.1943-5533.0000390

Ercikdi, Bayram, et al. "Strength and Ultrasonic Properties of Cemented Paste Backfill." Ultrasonics, Elsevier, 27 Apr. 2013.

Fine Tailings Fundamentals Consortium. (1995). "Vol I, Clark Hot Water Extraction Fine Tailings" In: Advances in Oil Sands Tailings Research, Alberta Department of Energy, Oil Sands and Research Division, Publisher.

François, B. \& Laloui, L. (2008). ACMEG-TS: A constitutive model for unsaturated soils under non-isothermal conditions. International Journal for Numerical and Analytical Methods in Geomechanics, 32(16): 1955-1988.

Fartosy, S.H.L., Non-Destructive of Damage in Concrete with Application in Shallow Foundation [PhD Thesis], Waterloo: University of Waterloo, 2018

Ginzel, E., \& Turnbull, B. (2016). Determining Approximate Acoustic Properties of Materials. NDT. net Dec.

Godinho, J.P, De Souza Junioir, T.F, Medeiros, M.H.F. and Silva, M.S.A. (2019). Factors influencing ultrasonic pulse velocity in concrete

Hong, R. (2012). Damage Detection in Fiber Reinforced Concrete with Ultrasonic Pulse Velocity Testing (Master's dissertation, University of Maryland). 
Helmenstine, A.M., Ph.D. "How the Shear Modulus Describes Material Rigidity." ThoughtCo, 2019, www.thoughtco.com/shear-modulus-4176406.

Hardin, B.O. \& Richart, E.F.Jr. (1963). Elastic Wave Velocities in Granular Soils. Journal of the Soil Mechanics and Foundation Division, ASCE, vol. 89, no. SM1, pp. 33-65.

Jeeravipoolvarn, S. (2005). Compression Behaviour of Thixotropic Oil Sands Tailings (Master's dissertation, University of Alberta)

Maier, Julia. "Poisson Ratio - an Overview | ScienceDirect Topics." Stiffness-Based Approach to Fatigue-Life Prediction of Composite Materials, 2020, www.sciencedirect.com/topics/materials-science/poisson-ratio.

Jefferies, M. and Been, K. (2000). Implication for critical state theory from isotropic compression and sand, Geotechnique, Vol.50, No4. Pp. 419-429

Johnson, R.L., P. Bork, E.A.D. Allen, W.H. James and L. Koverny, 1993. Oil sands sludge dewatering by freeze-thaw and evapotranspiration. Alberta Land Conservation and Reclamation Council, Reclamation Research Technical Advisory Committee Report No. RRTAC 93-8. 247 pp

Karaman K., Cihangir F., Ercikdi B., \& Kesimal, A. (2010). The effect of specimen length on ultrasonic P-wave velocity in clayey - carbonate rocks, 49(4), 37 - 45 
Lee, J.S., and Santamarina, J.C. (2005). Bender Elements: Performance and Signal Interpretation." Journal of Geotechnical and Geoenvironmental Engineering, American Society of Civil Engineers, 131(9), 1063-1070

Li, F., Zhao, Y., Cao, P., \& Hu, N. (2018). Mixing of ultrasonic Lamb waves in thin plates with quadratic nonlinearity. Elsevier, Vol 87, $33-43$

Lee, M.G., Cho, H.I., Kim, J.H., Park, H.J., \& Kim, D.S. (2018). Development of Seismic CPT for Evaluation In-Flight Soil Properties in Centrifuge Model Test. KSCE Journal of Civil Engineering, 22(2): 544-554

L'Heureux, Jean-Sebastien, and Michael Long. "Relationship between Shear-Wave Velocity and Geotechnical Parameters for Norwegian Clays." Journal of Geotechnical and Geoenvironmental Engineering, vol. 143, no. 6, 2017, p. 04017013. Crossref, doi: 10.1061/(asce)gt.1943-5606.0001645.

Malhotra, V. M., \& Carino, N. J. (2003). Handbook on Nondestructive Testing of Concrete Second Edition. CRC press.

Masliyah, J. H., Czarnecki, J., \& Xu, Z. H. (2011). Handbook on theory and practice of bitumen recovery from Athabasca oil sands, volume 1: Theoretical basis. Canada: Kingsley Knowledge Publishing.

Nicolaisen, J. (2015) Oil sands tailings management projects:low return, business critical “Oil Sands History and Development." Institute for Oil Sands Innovation, 2016. 
Ndagi, A., Umar, A.A., \& Jaafar, M.S. (2019). Non-destructive assessment of concrete deterioration by ultrasonic pulse velocity: A review.

NASA Earth Observatory. (2019). Retrieved from https://earthobservatory.nasa.gov/images

Pembina Institute, and Jodi McNeill. "Tailings Ponds: The Worst Is yet to Come." Pembina Institute, 10 Oct. 2017, www.pembina.org/blog/tailings-ponds-worst-yetcome.

Pestana, J.M. and Whittle, A.J. (1995). Compression model for cohesionless soils, Geotechnique, Vol.45, No.4, pp. 611-631

R.C. Shaw, L.L. Schramm, and J. Czarnecki, Suspensions in the hot water flotation process for Canadian oil sands, in Suspensions: Fundamentals and Applications in the Petroleum Industry, Advances in Chemistry Series 251, L.L. Schramm, Ed., ACS, Washington, DC, USA, 1996.

Robertson, P.K., Woeller, D.J., \& Finn.W.D.L. (1992). Seismic Cone PenetrationTest for evaluating liquefaction potential under cyclic loading.

Salam, M.A., Effect of polymers on short- and long-term dewatering of oil sands tailings [PhD Thesis], Ottawa: Carleton University, 2020.

Siddique, T., Kuznetsov, P., Kuznetsova, A., Li, C., Young,R., Arocena, J.M., Foght, J.M. (2014b). Microbially-accelerated consolidation of oil sands tailings. Pathway II: solid phase biogeochemistry. Front. Microbiol. 5 (Article 107). 
Santamarina, J.C, Klein, K.A. and Fam, M.A. (2001). Soils and waves, John Wiley and Sons, Inc., New York.

Thompson, D.K., Motta F.L., Soares J.B.P., (2017) Investigation on the flocculation of oil sands mature fine tailings with alkoxysilanes. Miner.Eng.111. 90-99

Takamura, Koichi. "Microscopic Structure of Athabasca Oil Sand.” Wiley Online Library, 1 Aug. 1982, onlinelibrary.wiley.com/doi/abs/10.1002/cjce.5450600416.

Tariq, A., Yanful, E.K.: A review of bindrs used in cemented paste tailings for underground and surface disposal practices. J. Environ. Manage. 131, 138-149 (2013)

Taukoor, V., Rutherford, C.J., and Olson, S.M. (2019). A semi-empirical relationship for the small-strain shear modulus of soft clays. "

Qi, C. and Fourie, A. (2019). “Cemented paste backfill for mineral tailings management: Review and future perspective, Mineral Engineering, Vol 144.

Wu, Y.C., NDT Applications for the Assessment of Asphalt Pavements, Plate Thickness, and Steel-Grout Coupling [M.A.Sc Thesis], Waterloo: University of Waterloo, 2012.

Wu, D., Zhang, Y., Liu, Y.: Mechanical performance and ultrasonic properties of cemented gangue backfill with admixture of fly ash. Ultrasonics 64, 89-96 (2016) 
Xu, Y., Dabros, T., and Kan, J. (2008). Filterability of oil sands tailings. Process Safety and Environmental Protection, Vol. 86, No. 4, pp. 268-276

Yang, F. (2010). Impact of Solvents Treatment on the Wettability of Froth Solids (Master's dissertation, University of Alberta) 


\section{Appendices}

\section{Appendix A}

\section{A.1 Geotechnical Characterization Test Results}

\section{Solid Content $\left(\mathrm{C}_{\mathrm{s}}\right)$}

After mixing, a small portion of the tailings was collected and placed in the three separate aluminum dishes and oven dry it for 24 hours in the temperature of $105^{\circ} \mathrm{C}$ in order to obtain the solid content of the specimen. The solid content $\left(\mathrm{C}_{\mathrm{s}}\right)$ of the oil sands tailing used in this experiment can be calculated using the following equation:

$$
C_{s}=\frac{M_{s}}{M_{S}+M_{W}} \times 100 \%
$$

Where $C_{s}$, is the solid content, and it is expressed in $\%, M_{S}$ is the mass of solid and $M_{W}$ is the mass of water. The average of the solids contents of the three samples was taken as final solids content of the oil sands tailing.

\section{Gravimetric Water Content (GWC)}

In addition, the water content of the oil sands tailing is determined by oven dry the sample at the temperature of $105^{\circ} \mathrm{C}$ for 24 hours. The purpose of this test is to remove the water portion of the oil sands tailings and the water content $\left(\mathrm{C}_{\mathrm{w}}\right)$ can be calculated using the following equation (Mizani, 2016): 


$$
C_{w}=\frac{M_{w}}{M_{s}+M_{w}} \times 100 \%
$$

Where $C_{w}$, is the gravimetric water content, and it is expressed in $\%, M_{s}$ is the mass of solid and $M_{W}$ is the mass of water.

\section{Specific Gravity $\left(\mathbf{G}_{\mathbf{s}}\right)$}

For soils, the specific gravity $\left(\mathrm{G}_{\mathrm{s}}\right)$ can be calculated using the following equation:

$$
G_{s}=\frac{\rho_{s}}{\rho_{w}}
$$

Where $\rho_{s}$, is the unit weight of the solids and $\rho_{w}$ is the unit weight of water

The specific gravity of the FFT was determined based on the ASTM standard of ASTM D $854-10$.

\section{Bitumen Content}

Based on Dean-Stark distillation extraction method (ASTM D95 - 05), the bitumen content can be calculated using the following equation:

$$
\text { Bitumen content }=\frac{M_{b}}{M_{T}} \times 100
$$

Where $M_{b}=$ mass of bitumen in the FFT sample (in grams) and $M_{T}=$ total mass of FFT (which includes water, solids, bitumen, and other minerals) (in grams). 


\section{Void Ratio}

The void ratio is the ratio of volume of voids to the volume of soil particles, which is illustrated in the equation below:

$$
e=\frac{V_{v}}{V_{S}}
$$

Where, $V_{v}$ is the volume of voids (air and water), $V_{s}$ is the volume of solids

\section{Total bulk density}

The total bulk density of the soil is the ratio of the total mass of soil (mass of water and solids) to the total volume, illustrated in the following equation:

$$
\rho=\frac{M_{s}+M_{w}}{V_{T}}
$$

Where, $M_{S}$ is the mass of solids of FFT, $M_{w}$ is the mass of water in FFT and $V_{T}$ is the volume of FFT.

\section{Particle size distribution (fines content)}

The particles size distribution of FFT was determined using a combination of wet sieving and sedimentation (hydrometer) analysis (ASTM D7928-16). In the wet sieving, the particle of the FFT which passed through the 75 - micron sieve (\#200 sieve) were collected and oven-dried. For the quantitative determination of the distribution of particles sizes which was finer than 75 - micron sieve, the hydrometer method was used on the fine-grained portion of FFT. Figure 80 illustrated the complete gradation curve 
showing the percentage of sand, silt and clay in the sample as a percent of the total dry weight (Salam, 2020).

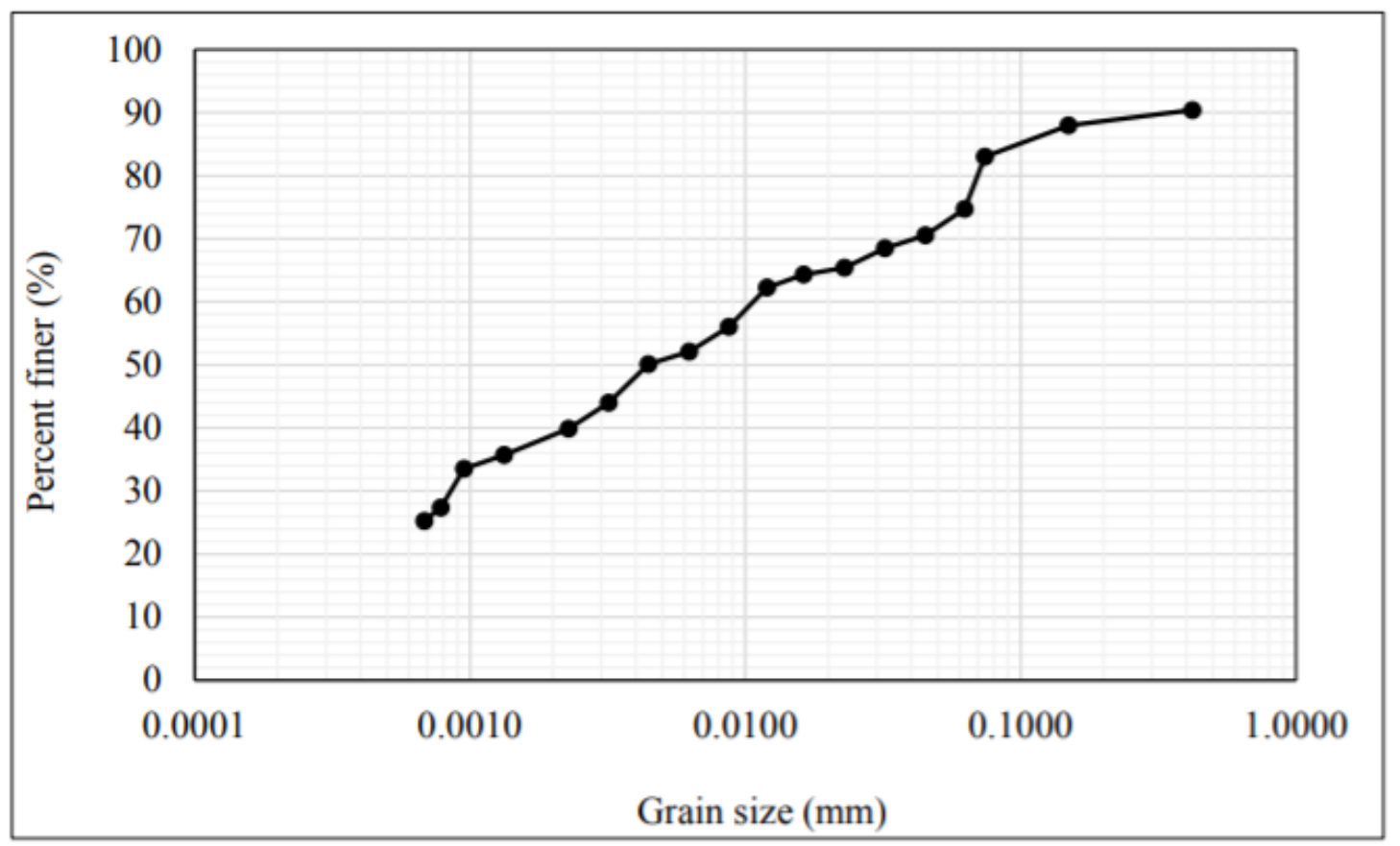

Figure 80: Particle size distribution of FFT from wet sieve and the hydrometer analyses (Salam, 2020). 


\section{Pore-water chemistry}

The pore water samples were sent to an external laboratory (AGAT Laboratory) in order to determine the major cations and anion concentrations, conductivity, $\mathrm{pH}$, total solids and alkalinity. Table 6 illustrated the result of the pore water chemistry analyses.

Table 6: Pore water chemistry of untreated FFT, Day-7 fFFT, and Day 42 fFFT samples (Salam, 2020).

\begin{tabular}{|l|l|l|l|l|}
\hline Parameter & Unit & Untreated & Day-7 fFFT & Day-42 fFFT \\
& & FFT sample & sample & sample \\
\hline Electrical Conductivity & $\mu \mathrm{S} / \mathrm{cm}$ & 1590 & 1610 & 1660 \\
\hline $\mathrm{pH}$ & $\mathrm{pH}$ & 8.55 & 8.11 & 8.23 \\
\hline Total Hardness (As CaCO 3 ) & $\mathrm{mg} / \mathrm{L}$ & 79.5 & 75.2 & 78 \\
\hline Total Dissolved Solids & $\mathrm{mg} / \mathrm{L}$ & 1050 & 1080 & 1110 \\
\hline Total Suspended Solids & $\mathrm{mg} / \mathrm{L}$ & 54 & 1830 & 250 \\
\hline Alkalinity (As CaCO 3 ) & $\mathrm{mg} / \mathrm{L}$ & 580 & 487 & 501 \\
\hline Fluoride & $\mathrm{mg} / \mathrm{L}$ & 3.27 & 2.86 & 186 \\
\hline Chloride & $\mathrm{mg} / \mathrm{L}$ & 182 & 26 & 5.26 \\
\hline
\end{tabular}




\begin{tabular}{|c|c|c|c|c|}
\hline Nitrate as $\mathrm{N}$ & $\mathrm{mg} / \mathrm{L}$ & $<0.25$ & $<0.25$ & $<0.25$ \\
\hline Sulphate & $\mathrm{mg} / \mathrm{L}$ & 61 & 142 & 188 \\
\hline Calcium & $\mathrm{mg} / \mathrm{L}$ & 15.2 & 14.5 & 14.1 \\
\hline Magnesium & $\mathrm{mg} / \mathrm{L}$ & 10.1 & 9.46 & 10.4 \\
\hline Sodium & $\mathrm{mg} / \mathrm{L}$ & 340 & 345 & 360 \\
\hline Potassium & $\mathrm{mg} / \mathrm{L}$ & 14.1 & 15.7 & 15.8 \\
\hline Total Iron & $\mathrm{mg} / \mathrm{L}$ & 1.25 & 2.2 & 2.95 \\
\hline Total Manganese & $\mathrm{mg} / \mathrm{L}$ & 0.089 & 0.604 & 0.089 \\
\hline Iron $\left(\mathrm{Fe}^{++}\right)$ & $\mathrm{mg} / \mathrm{L}$ & $<0.05$ & $<0.05$ & $<0.05$ \\
\hline Iron $\left(\mathrm{Fe}^{++++}\right)$ & $\mathrm{mg} / \mathrm{L}$ & 1.25 & 2.2 & 2.95 \\
\hline$\%$ Difference/Ion Balance & $\%$ & 4.14 & 2.22 & 4.7 \\
\hline
\end{tabular}




\section{Clay content (Methylene blue index test)}

The clay content in the unamended FFT sample and flocculated FFT sample were shipped to external laboratory (AGAT Laboratories) for the methylene blue index (MBI) test (Salam, 2020). This test was done by using the methylene blue to absorb clay surface and replace the cation ( 2020). The percentage of the clay in FFT can be calculated using the following equation:

$$
\% \text { Clay }=\frac{M B I \frac{m e q}{100 g}+0.04}{0.14}
$$

Where, MBI is expressed in meq/100g (milliquivalents of methylene blue per $100 \mathrm{~g}$ of FFT sample). The MBI was calculated by the number of milliliters of methylene added to the test and absorbed a given mass of a sample (Salam, 2020). Table 7 shows the results obtained from MBI test conducted on the unamended FFT, Day-7 fFFT, and Day-42 fFFT samples (Salam, 2020).

Table 8: MBI test data and percentage of the clay-sized fraction of unamended FFT (Salam, 2020)

\begin{tabular}{|c|c|c|c|c|}
\hline Sample & Mass $(\mathrm{g})$ & Methylene Blue volume $(\mathrm{mL})$ & $\mathrm{meq} / 100 \mathrm{~g}$ & $\%$ clay \\
\hline Unamended FFT & 2.01 & 6.50 & 3.93 & 28.36 \\
\hline fFFT (Day-7) & 2.05 & 9.50 & 4.63 & 33.36 \\
\hline fFFT (Day-42) & 2.03 & 13.50 & 6.65 & 47.79 \\
\hline
\end{tabular}




\section{Mineralogical Composition}

The mineralogical composition of three samples (unamended FFT, Day-7 fFFT, and Day-42 fFFT) were determined by analyzing both bulk and clay portions of the samples, using the quantitative X-ray diffraction analysis (XRD) (Salam, 2020). Table 8 and 9 illustrate the non-clay minerals and the associated weight fractions, and clay minerals $(<2 \mu \mathrm{m})$ and the associated weight fractions.

Table 8: Non-clay minerals in the FFT samples (from the XRD analysis) (Salam, 2020)

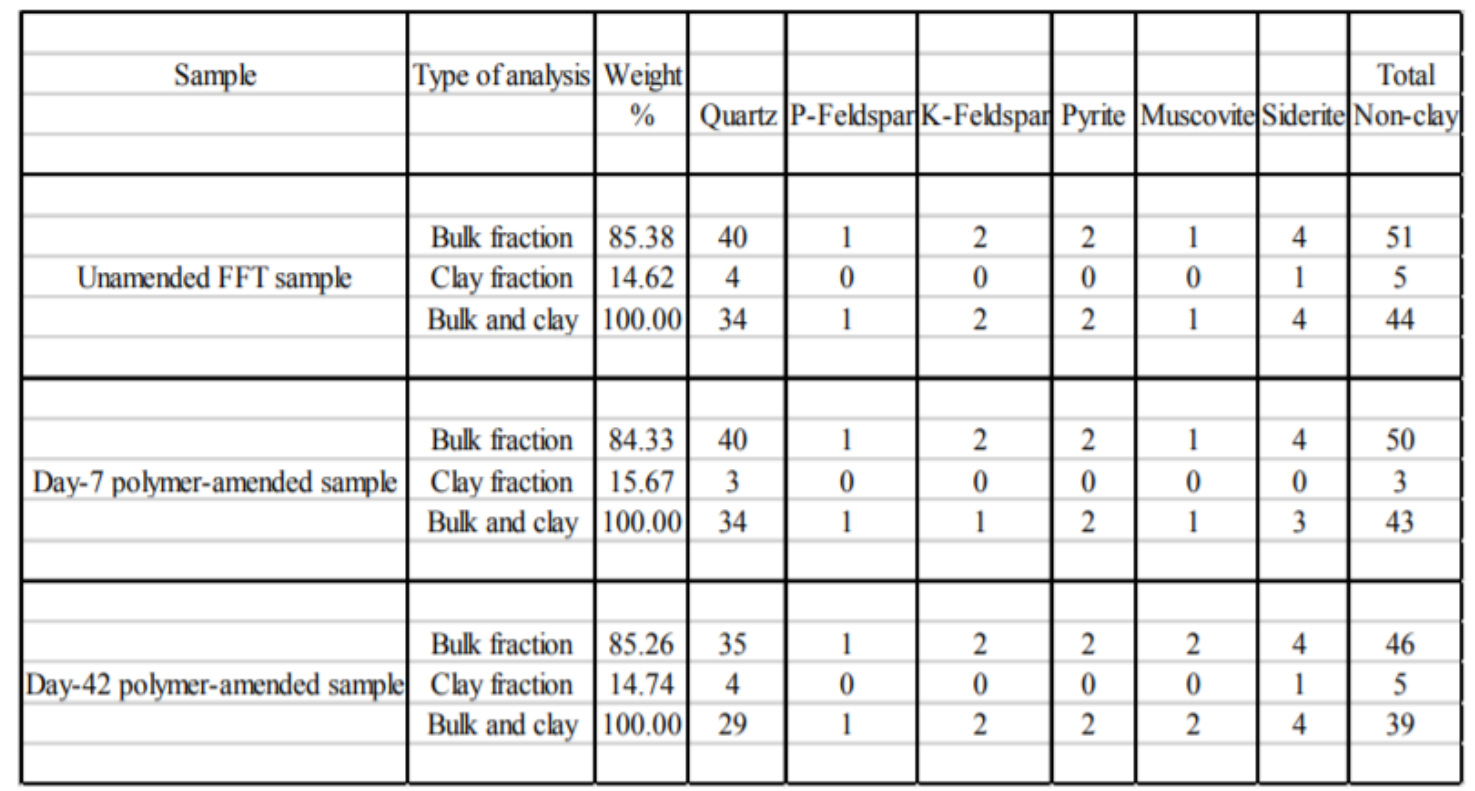


Table 9: Clay minerals in the FFT samples (from the XRD analysis) (Salam, 2020)

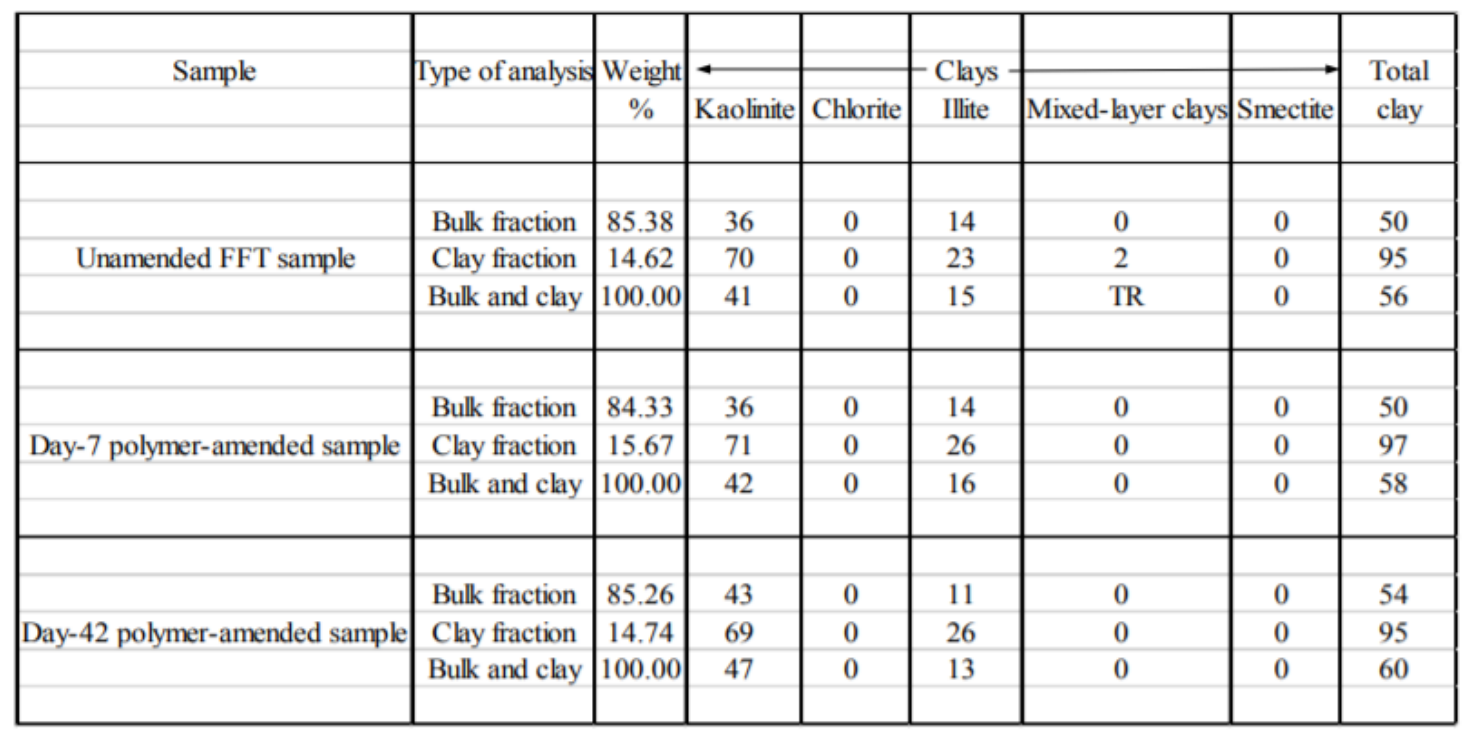




\section{Appendix B}

\section{B.1 Wave Attenuation}

The following figures are the wave attenuation results obtained from the s-wave and p-wave-s-wave combinations. However, those results were either consistent or fluctuate. Thus, they did not show useful trends.

(a)

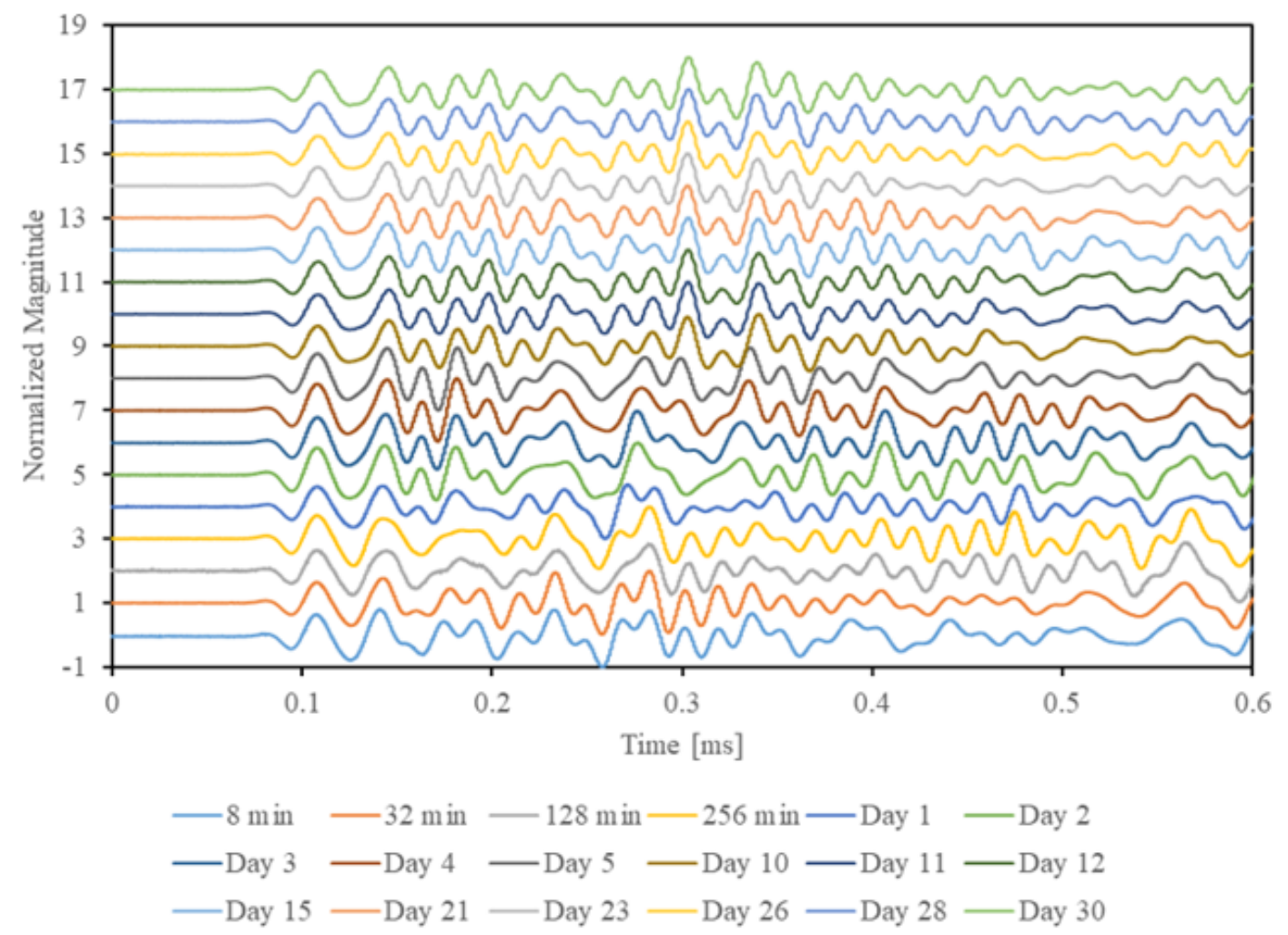


(b)

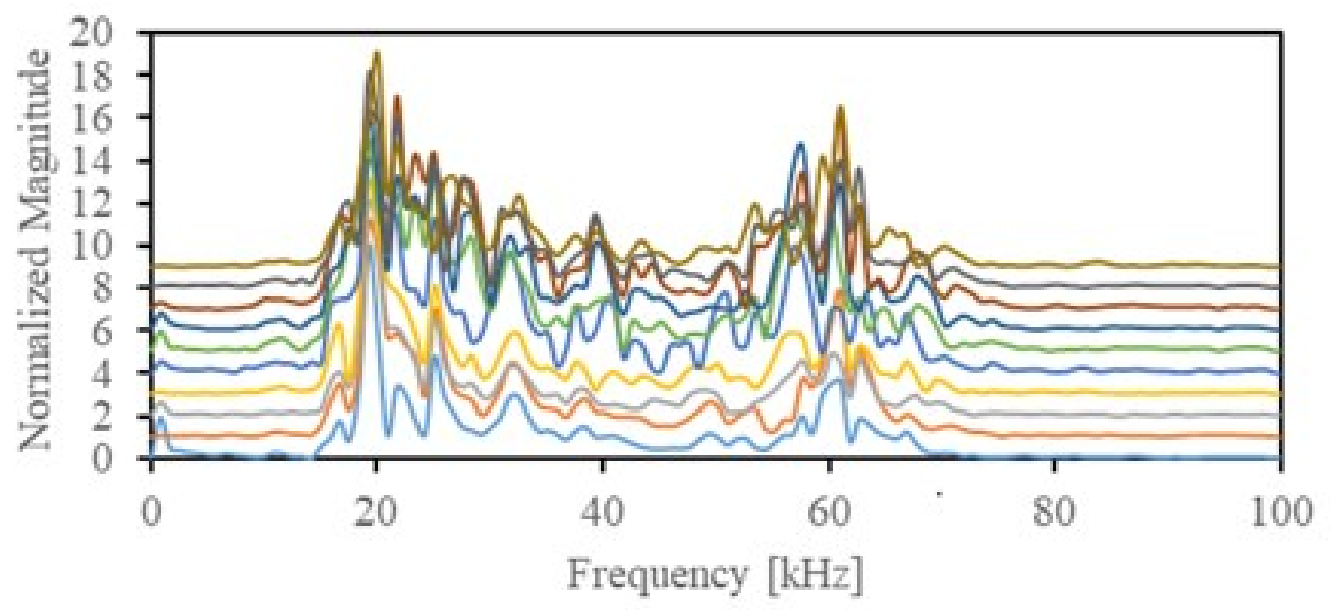

$-8 \mathrm{~min}-32 \mathrm{~min}-128 \mathrm{~min}-256 \mathrm{~min}-$ Day 1 -Day 2 -Day 3 -Day 4 -Day 5 -Day 10

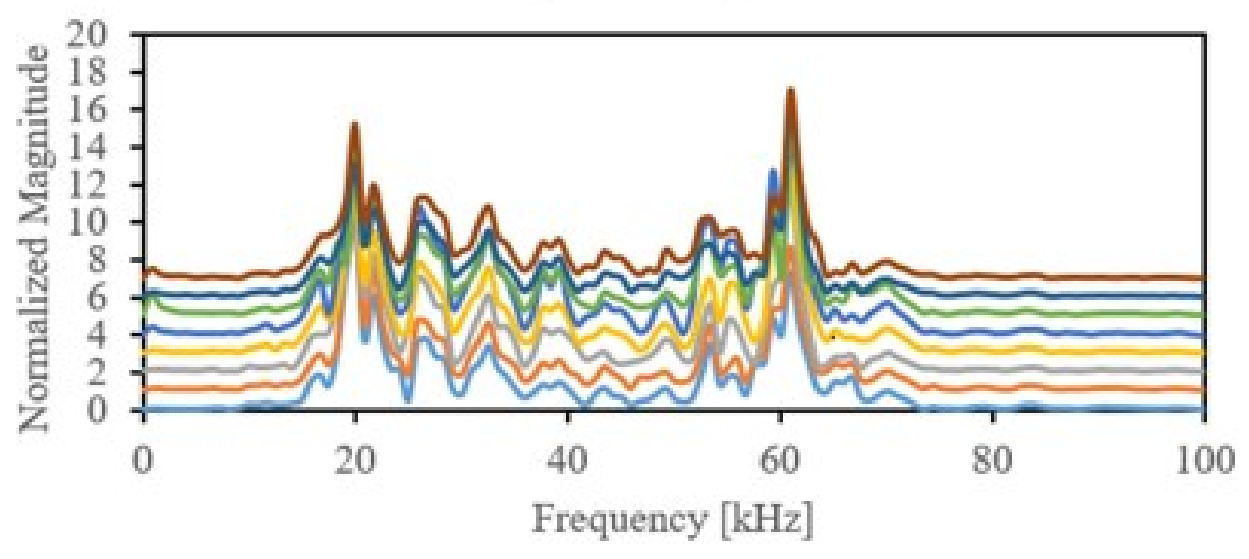

-Day 11 - Day 12 - Day 15 - Day 21

-Day 23 - Day 26 - Day 28 - Day 30 
(c)

$0-40 \mathrm{kHz}$
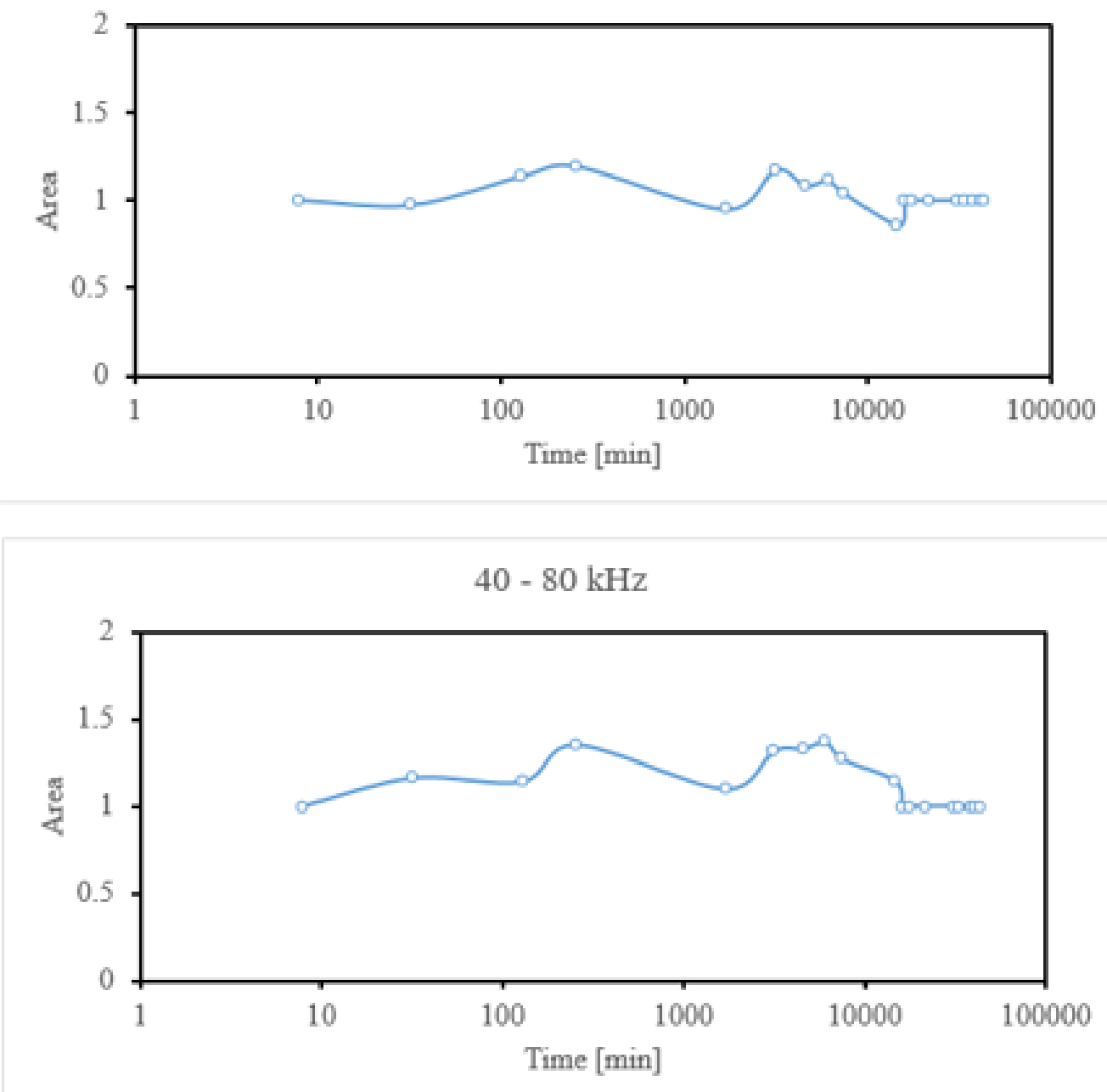

Figure 81: Without Window (compressional transmitter/receiver): (a) Time signal, (b) FFT, (c) Area under the curve in the function of time. 
(a)

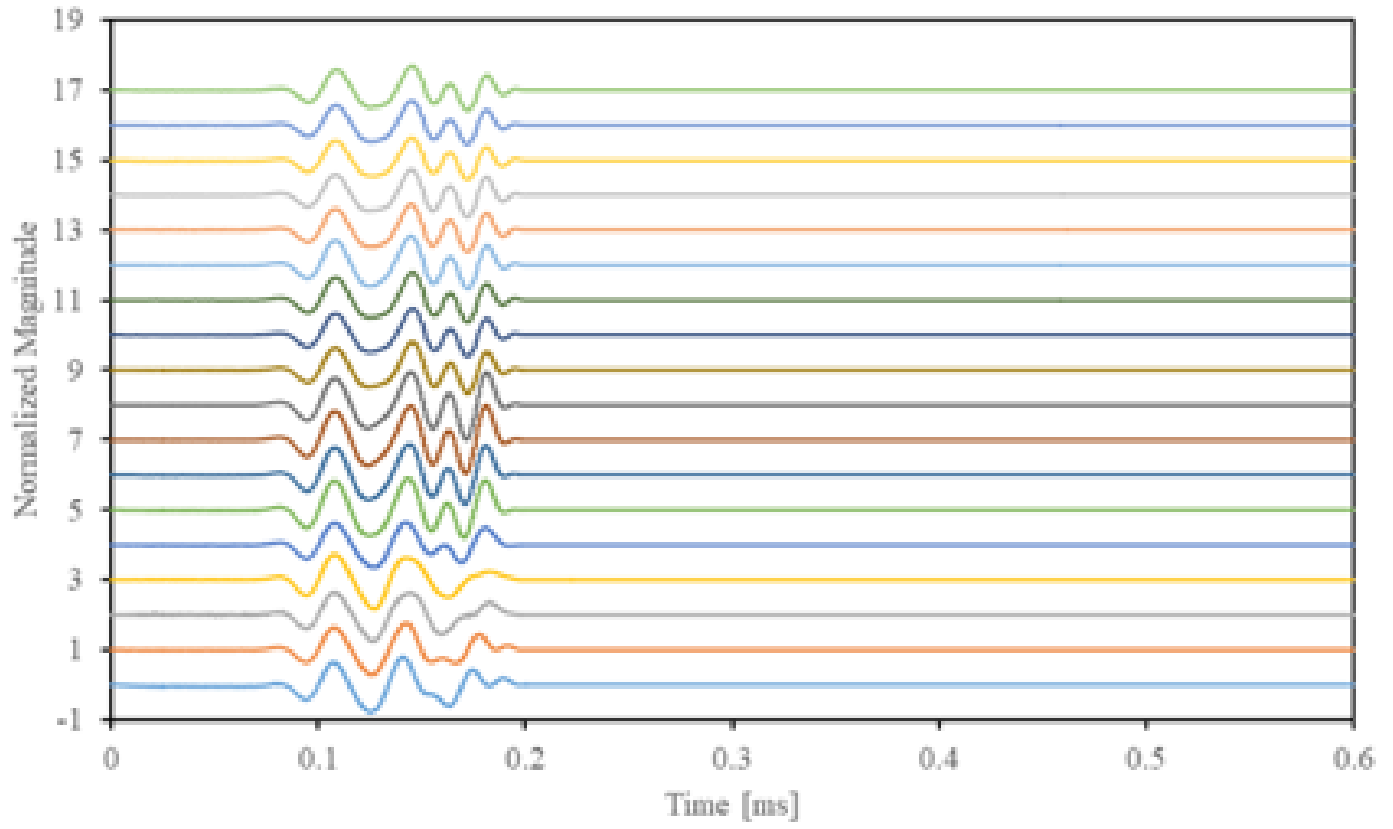

$-8 \min -32 \mathrm{~min}-128 \min -256 \min$-Day $1-D a y 2$

-Day 3 -Day 4 -Day 5 -Day 10 -Day 11 -Day 12

-Day 15 - Day 21 - Day 23 - Day 26 - Day 28 - Day 30 
(b)

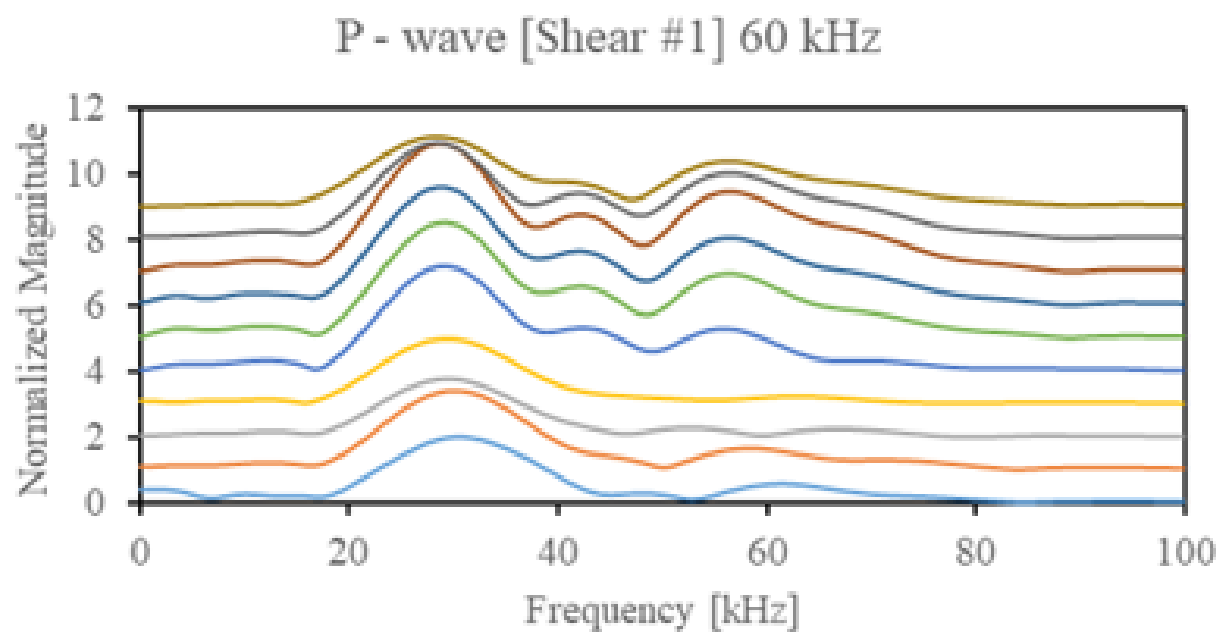

$-8 \mathrm{~min}-32 \mathrm{~min}-128 \mathrm{~min}-256 \mathrm{~min}$-Day 1

—Day 2 -Day 3 -Day 4 -Day 5 - Day 10

P - wave [Shear \#1] $60 \mathrm{kHz}$

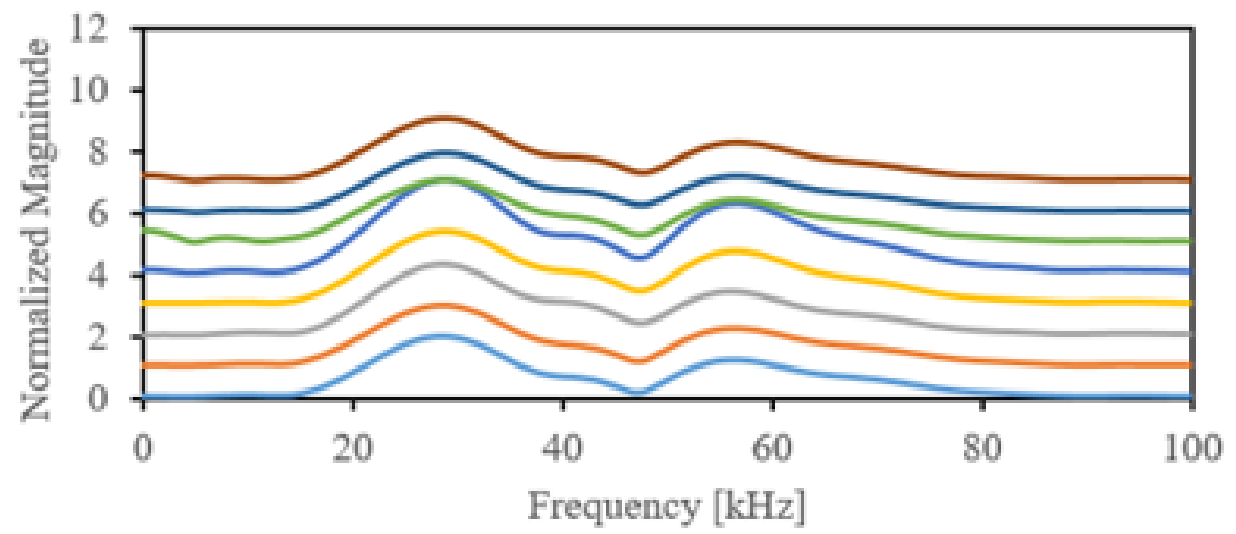

-Day 11 - Day $12-$ Day $15-$ Day 21

-Day 23 - Day $26-$ Day $28-$ Day 30 
(c)
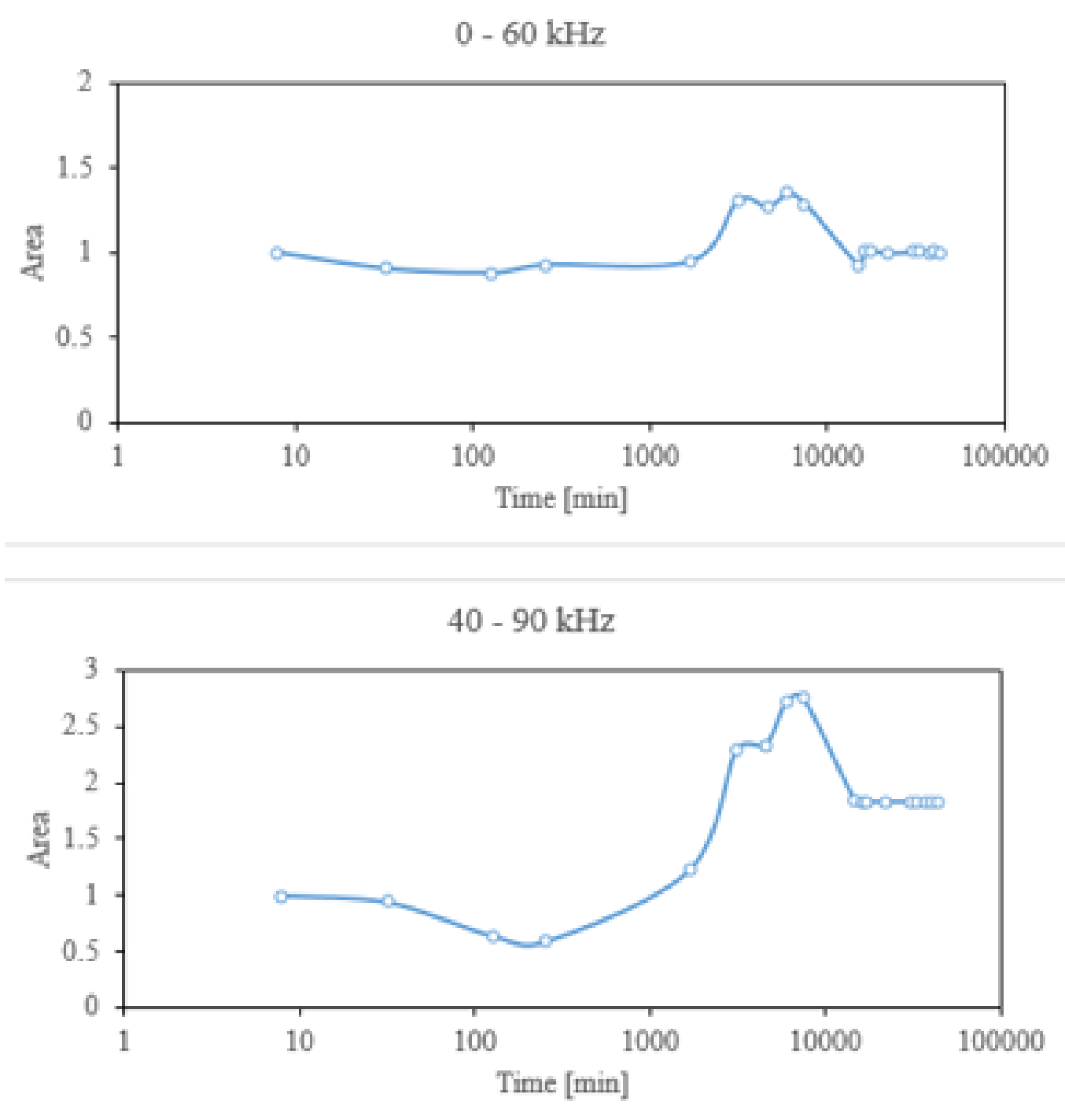

Figure 82: Window 1 (compressional transmitter/shear \#1 receiver): (a) Time signal, (b) FFT, (c) Area under the curve in the function of time. 
(a)

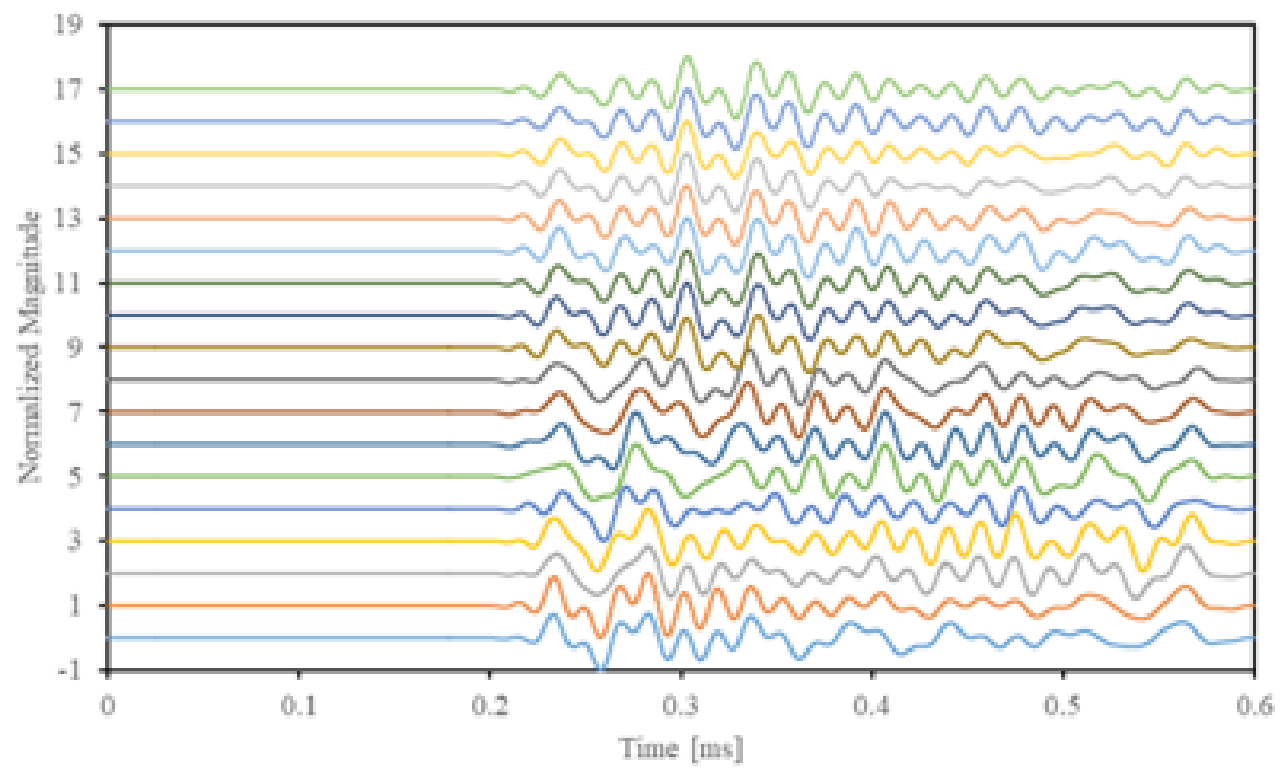

$-8 \min -32 \min -128 \min -256 \min -$ Day $1-D a y 2$

-Day 3 -Day 4 -Day 5 -Day 10 -Day 11 - Day 12

-Day 15 - Day 21 - Day 23 - Day 26 - Day 28 - Day 30 
(b)

P - wave [Shear \#1] $60 \mathrm{kHz}$

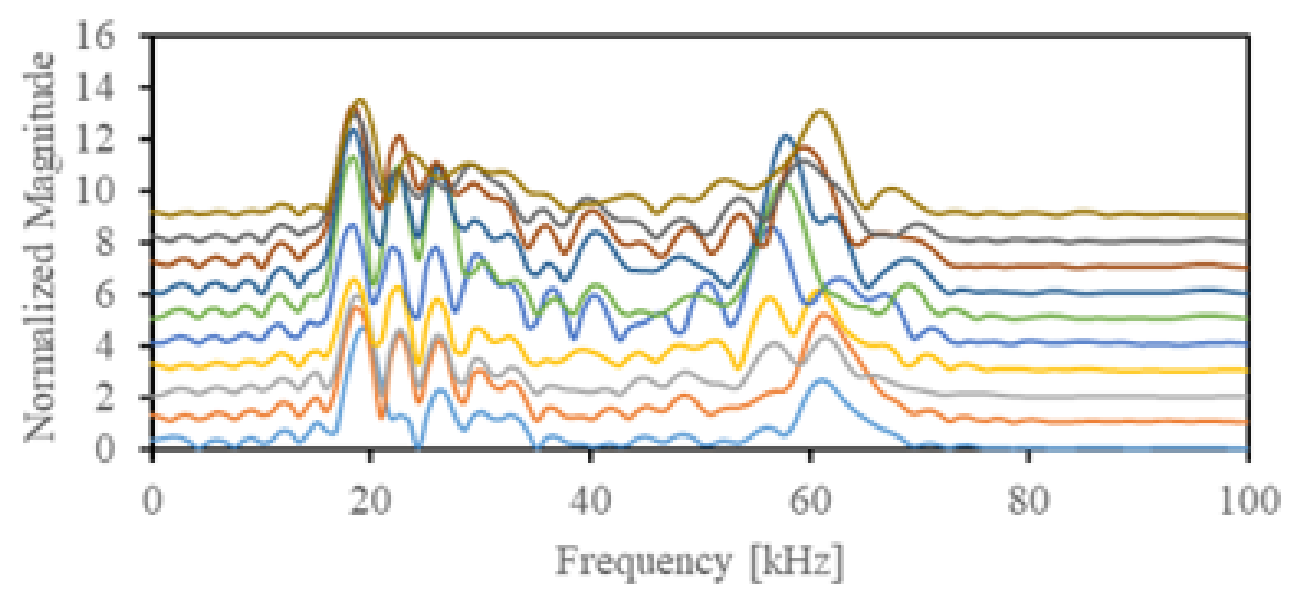

$-8 \mathrm{~min}-32 \mathrm{~min}-128 \mathrm{~min}-256 \mathrm{~min} \longrightarrow$ Day 1

-Day 2 -Day 3 - Day 4 -Day 5 -Day 10

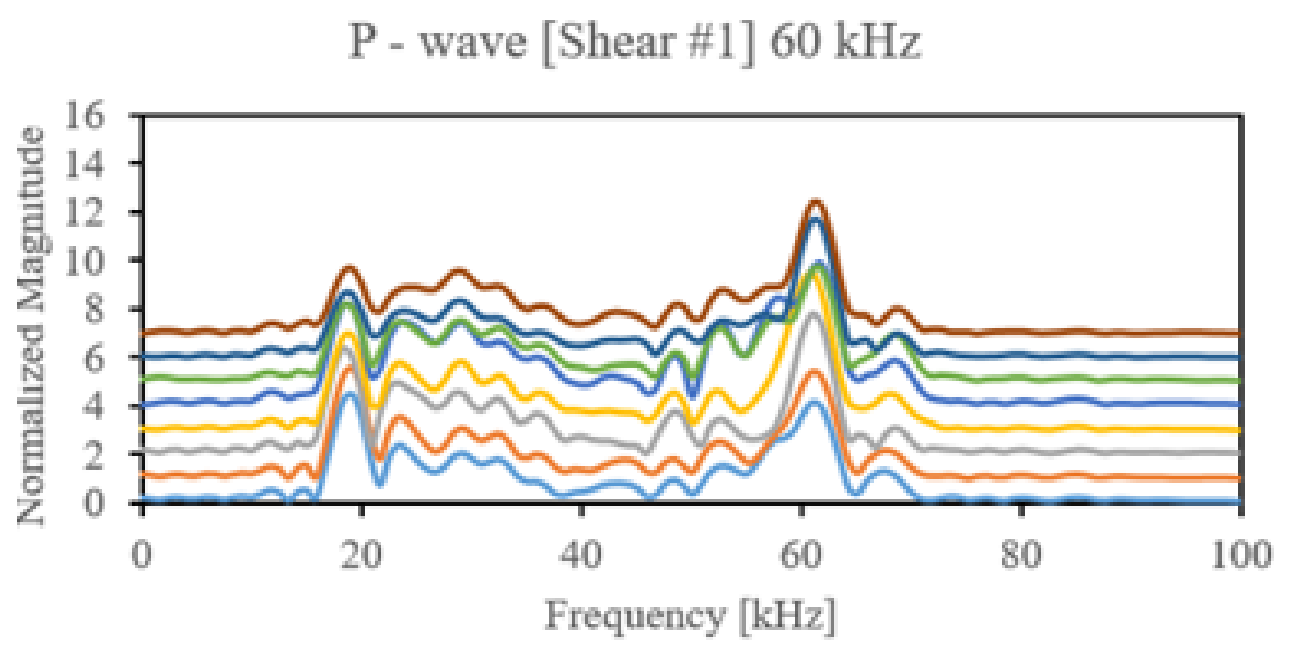

-Day 11 - Day 12 - Day $15-$ Day 21

—Day 23 - Day 26 - Day 28 - Day 30 
(c)
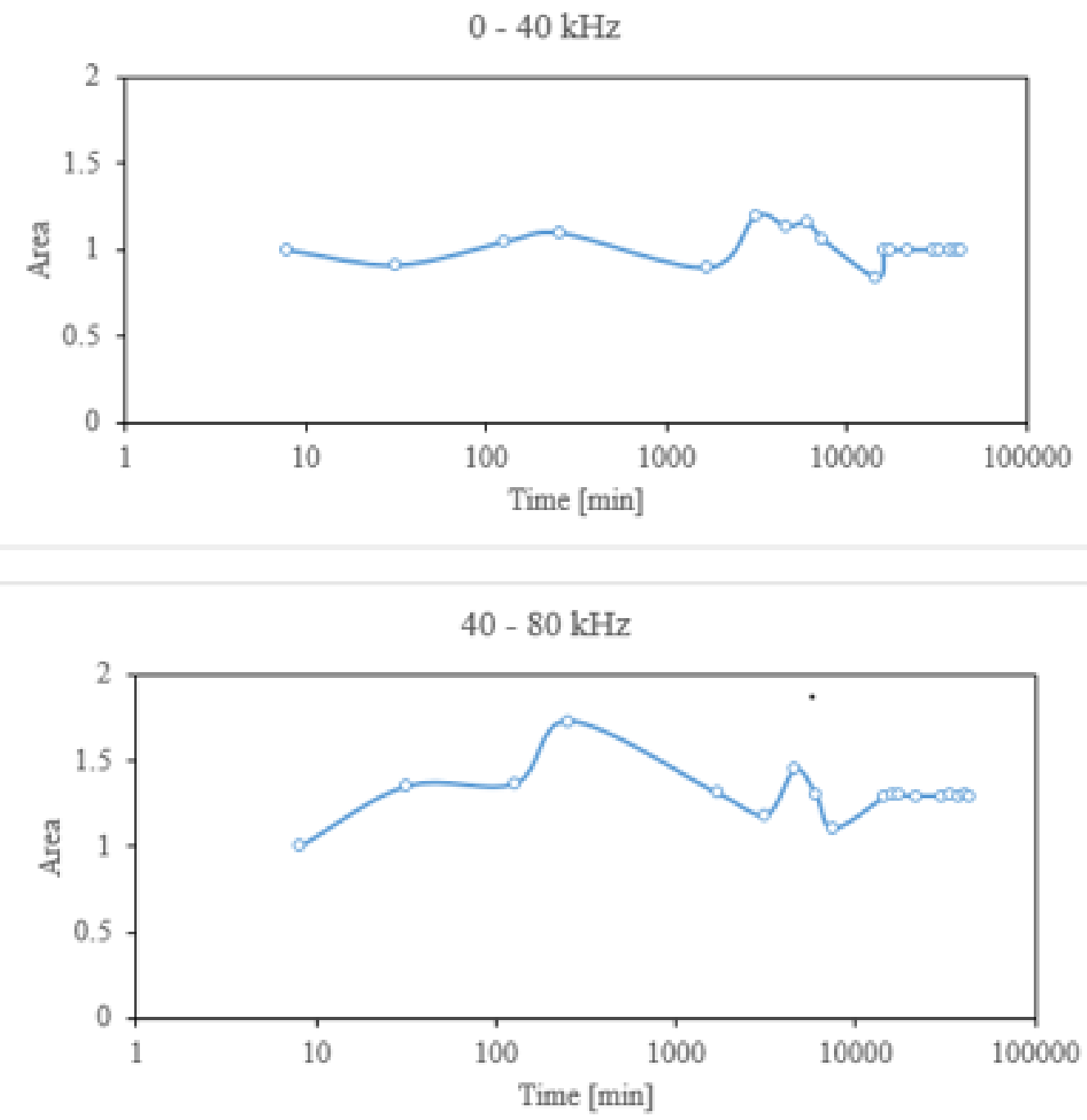

Figure 83: Window 2 (compressional transmitter/shear \#1 receiver): (a) Time signal, (b) FFT, (c) Area under the curve in the function of time. 
(a)

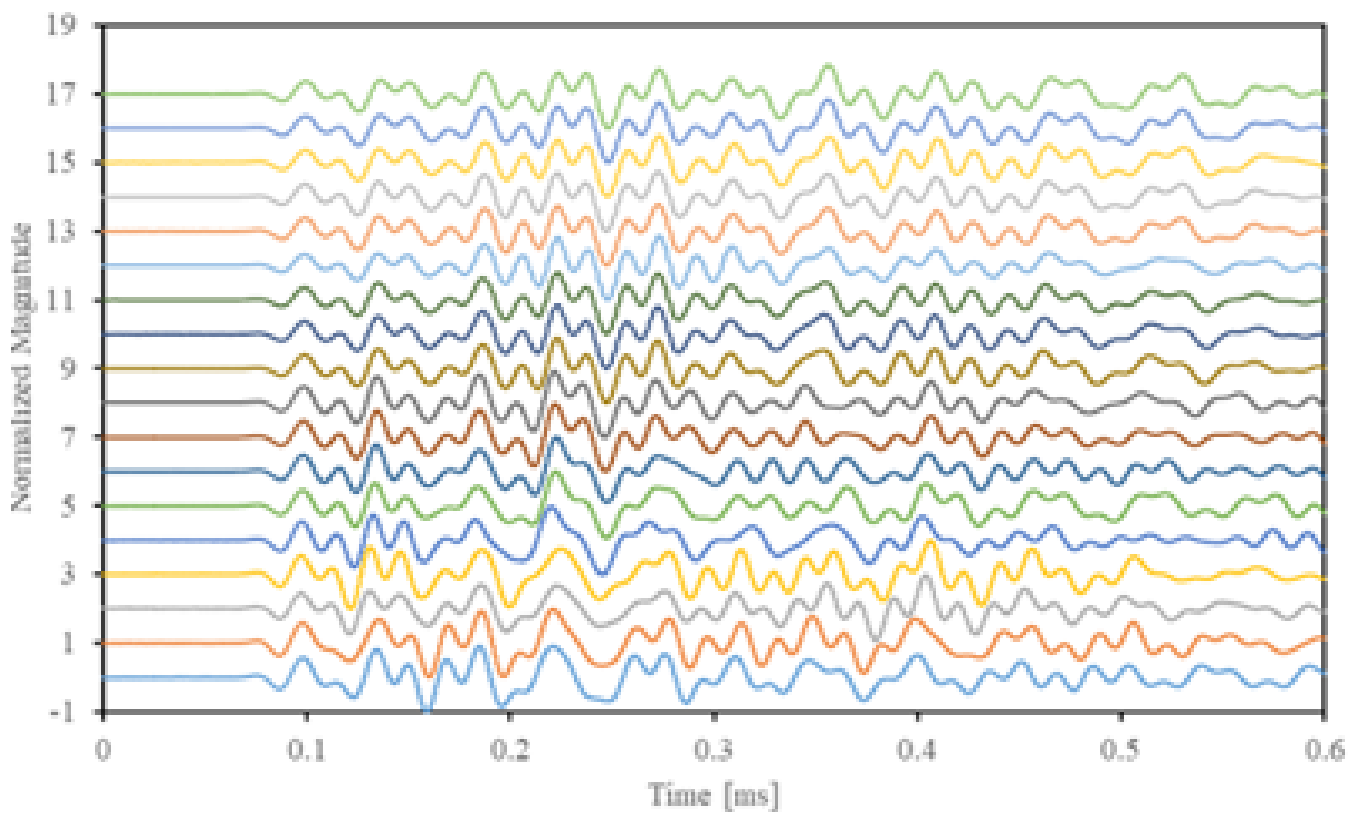

$-8 \min -32 \min -128 \min -256 \min -$ Day $1-$ Day 2

-Day 3 -Day 4 -Day 5 -Day 10 -Day 11 -Day 12

-Day 15 -Day 21 -Day 23 - Day 26 -Day 28 - Day 30 
(b)

P - wave [Shear \#2] $60 \mathrm{kHz}$

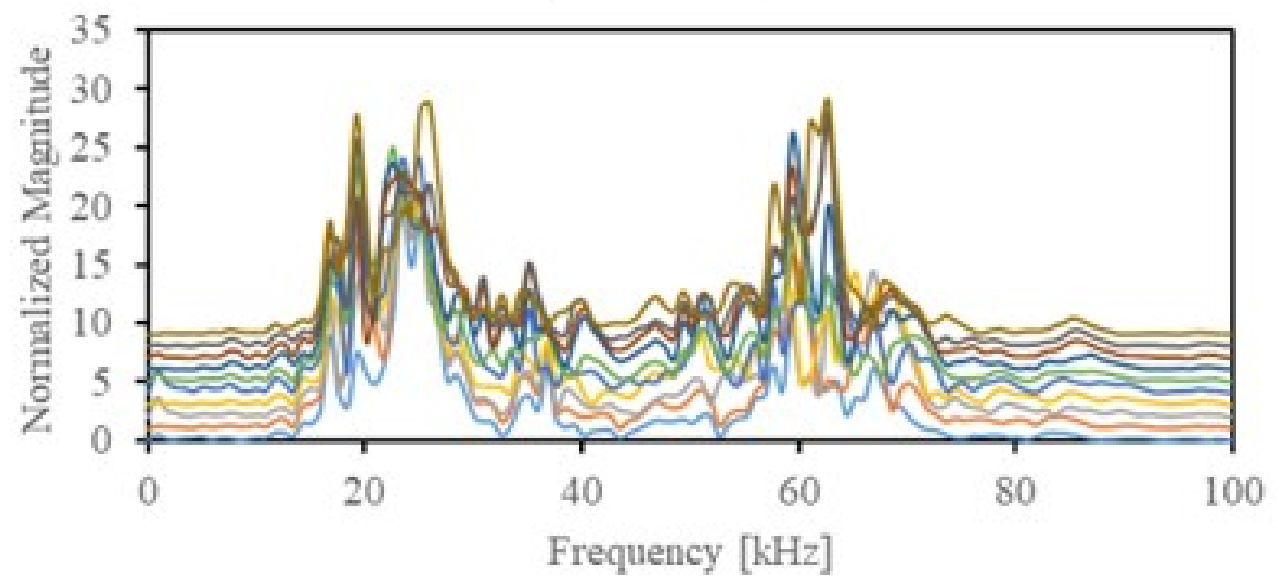

$-8 \mathrm{~min}-32 \mathrm{~min}-128 \mathrm{~min}-256 \mathrm{~min} \longrightarrow$ Day 1

-Day 2 -Day 3 -Day 4 -Day 5 -Day 10

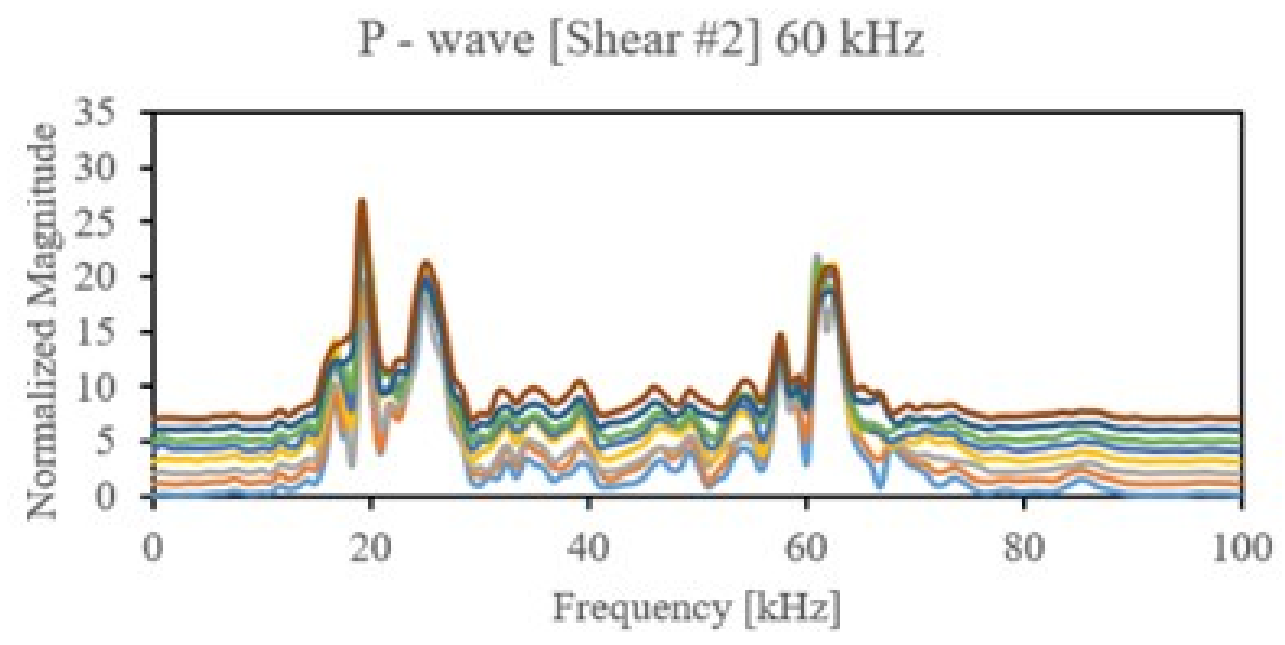

-Day 11 - Day 12 - Day 15 - Day 21

-Day 23 - Day 26 - Day 28 - Day 30 
(c)
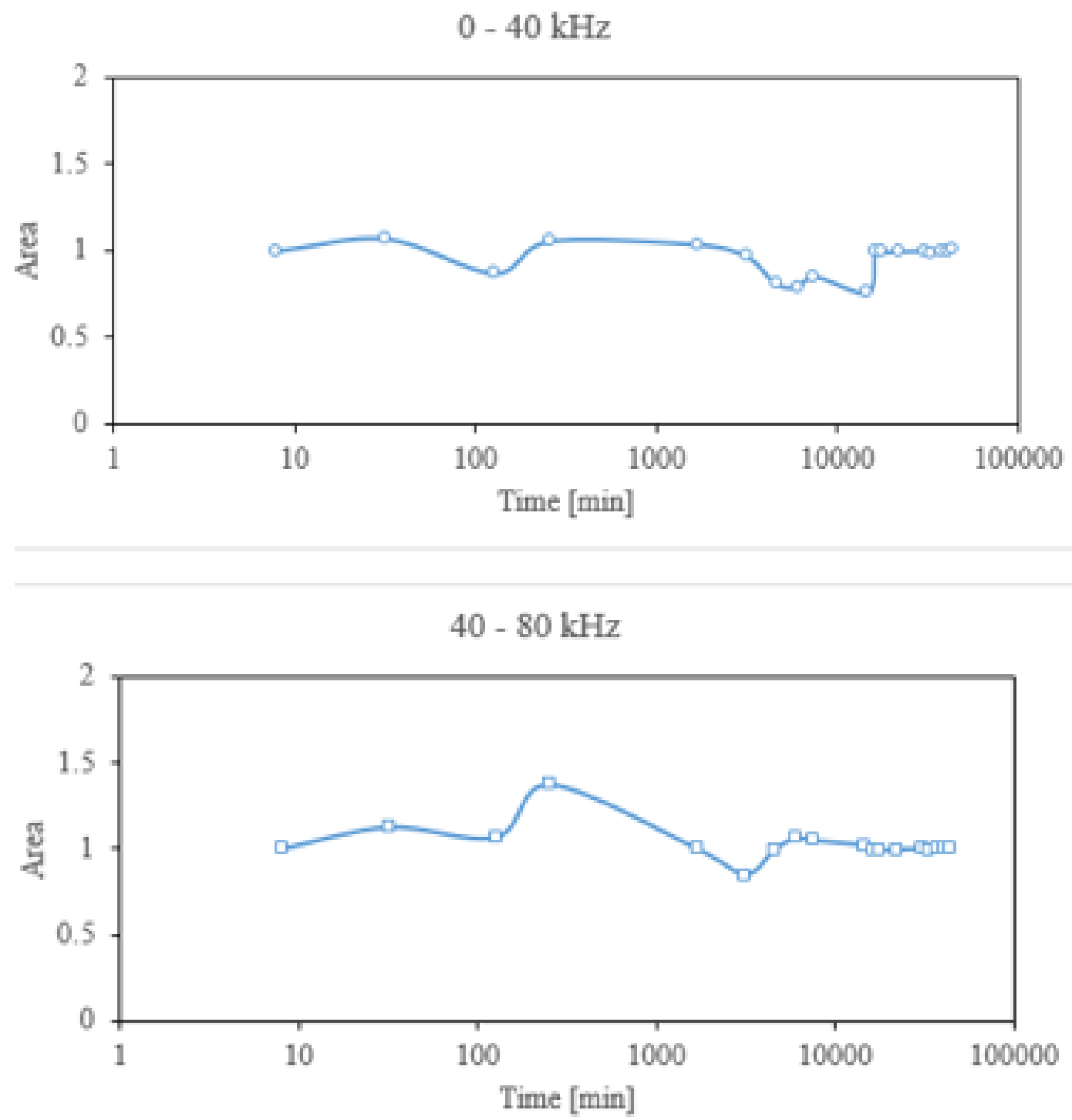

Figure 84: Without Window (compressional transmitter/shear \#2 receiver): (a) Time signal, (b) FFT, (c) Area under the curve in the function of time. 
(a)

P- wave [Shear $\# 2] 60 \mathrm{kHz}$

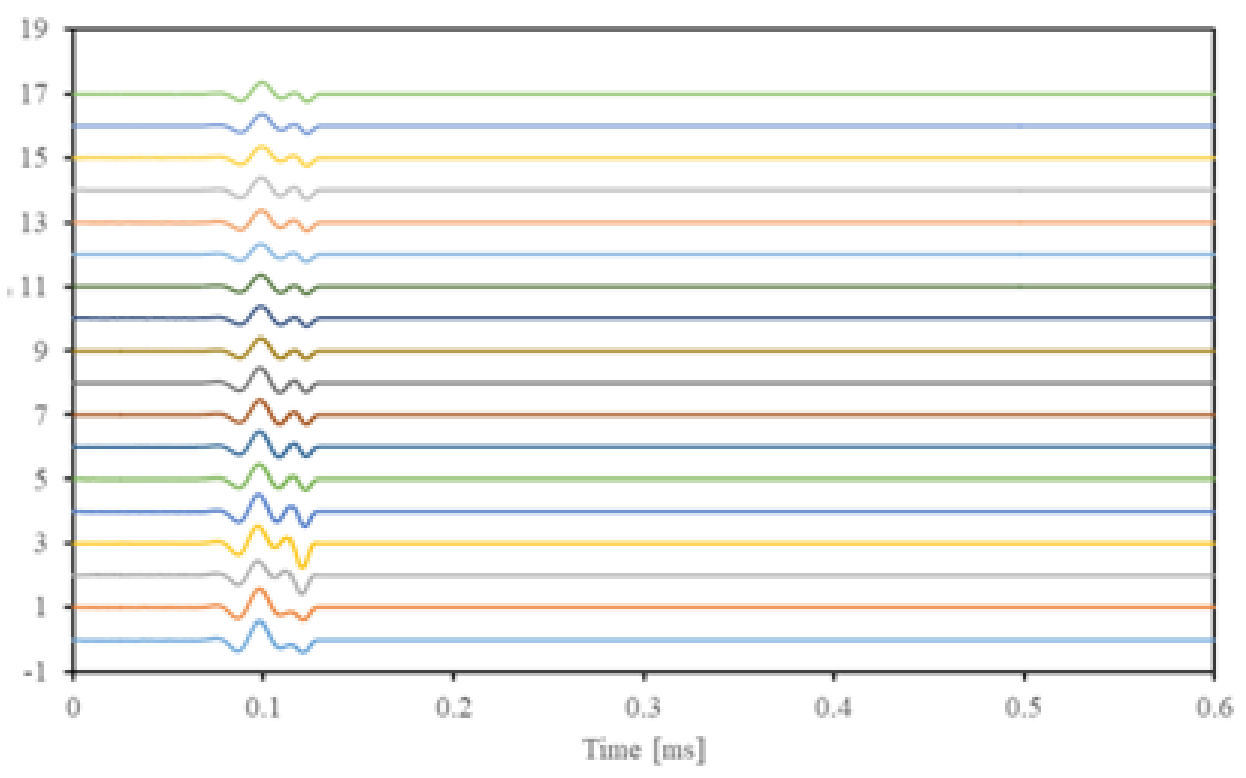

$-8 \min -32 \min -128 \min -256 \min -$ Day $1-$ Day 2

-Day 3 -Day 4 -Day 5 -Day $10-$ Day 11 -Day 12

-Day 15 -Day 21 - Day 23 - Day 26 - Day 28 - Day 30 
(b)

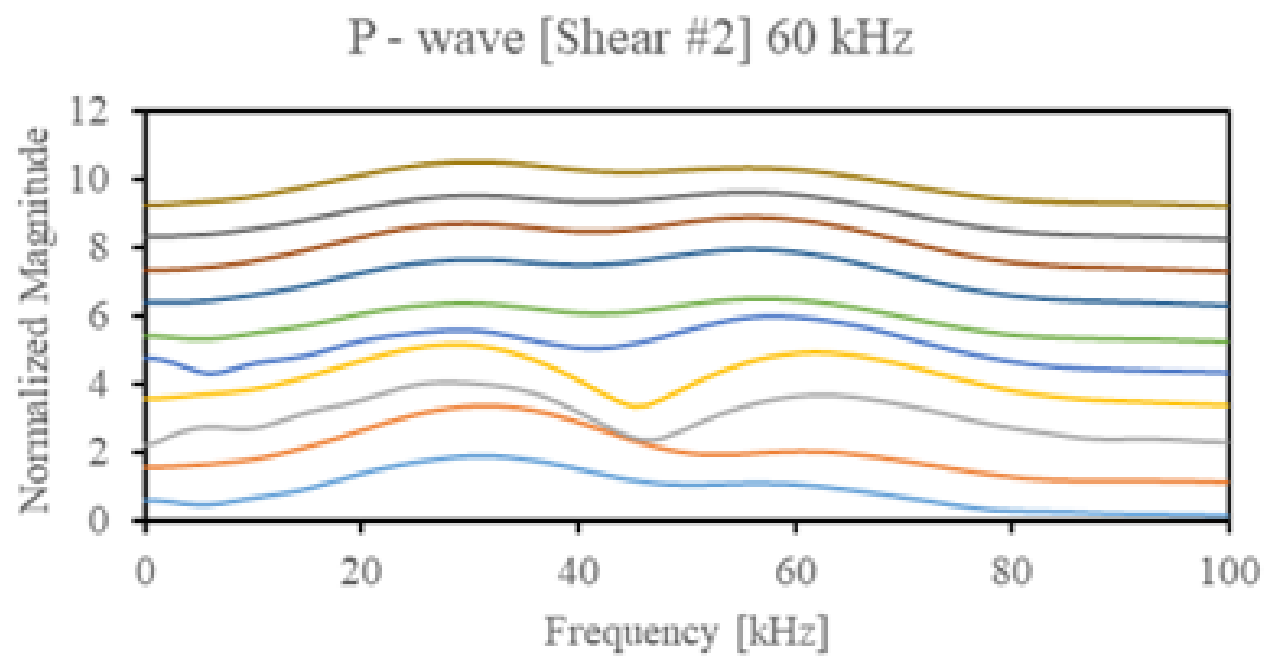

$$
\begin{gathered}
-8 \mathrm{~min}-32 \mathrm{~min}-128 \mathrm{~min}-256 \mathrm{~min}-\text { Day } 1 \\
\text { Day } 2-\text { Day } 3-\text { Day } 4-\text { Day } 5-\text { Day } 10 \\
\text { P - wave [Shear \#2] } 60 \mathrm{kHz}
\end{gathered}
$$

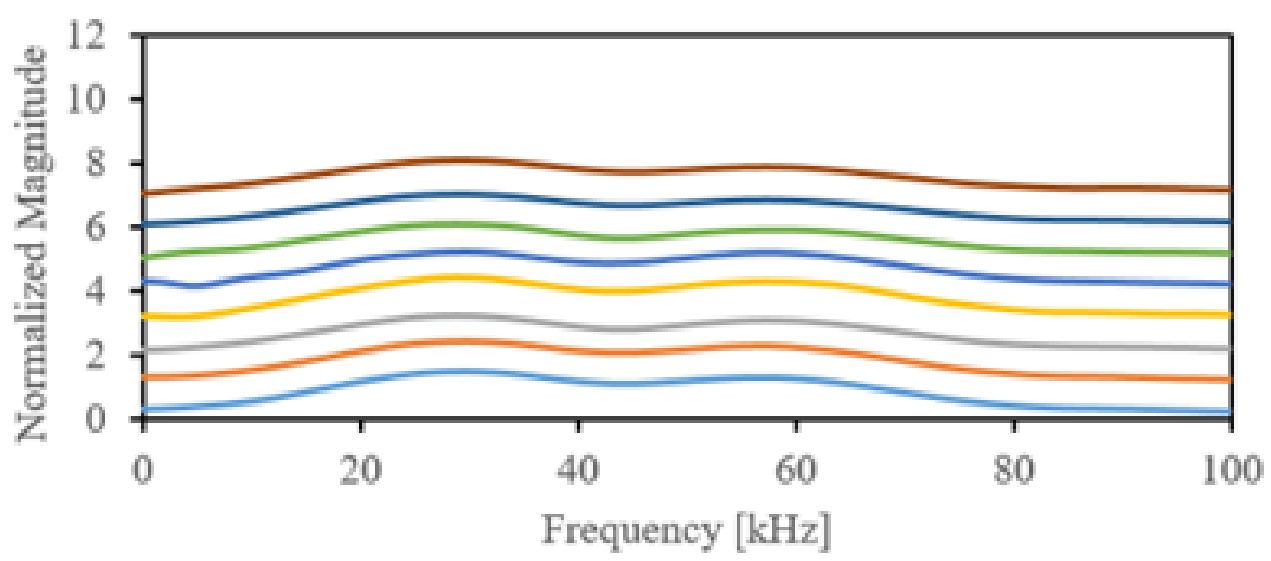

-Day 11 - Day 12 - Day 15 - Day 21

-Day 23 - Day 26 - Day 28 -Day 30 
(c)

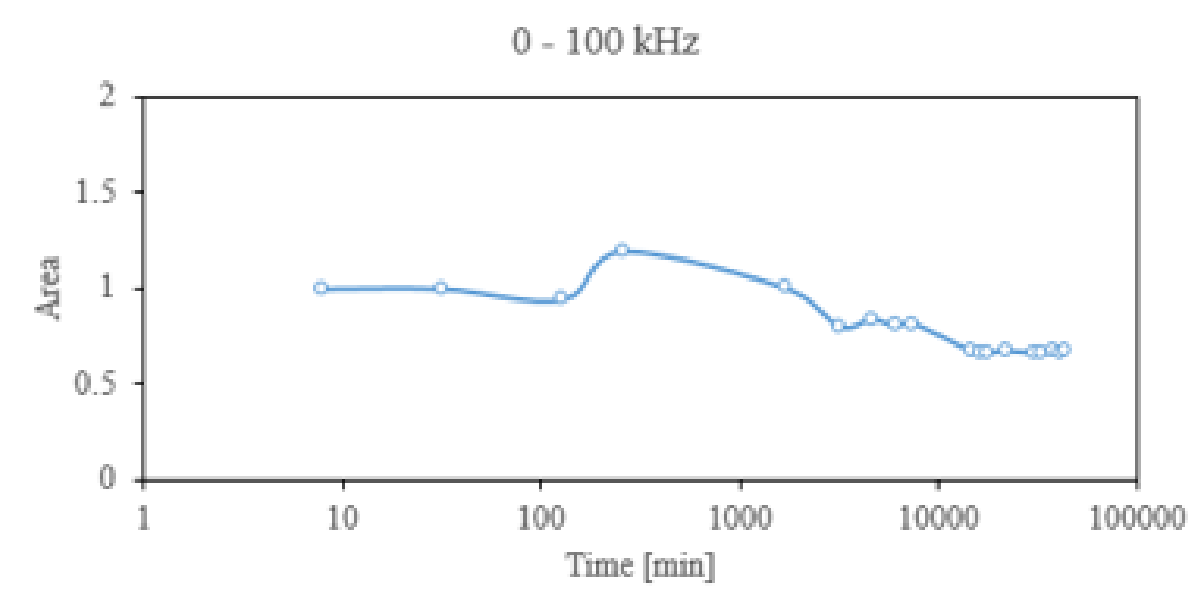

Figure 85: Window 1 (compressional transmitter/shear \#2 receiver): (a) Time signal, (b) FFT, (c) Area under the curve in the function of time. 
(a)

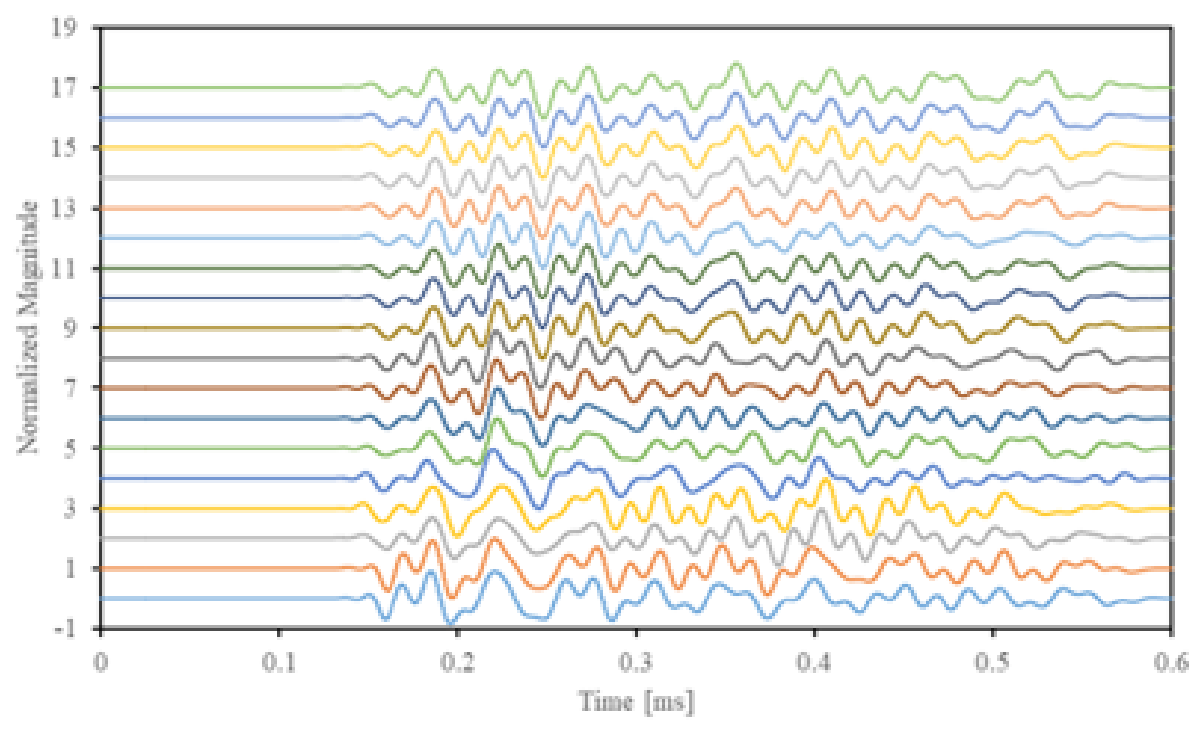

$-8 \min -32 \min -128 \mathrm{~min}-256 \mathrm{~min}-$ Day $1-$ Day 2
-Day $3-$ Day $4-$ Day $5-$ Day $10-$ Day $11-$ Day 12
-Day $15-$ Day $21-$ Day $23-$ Day $26-$ Day $28-$ Day 30 
(b)

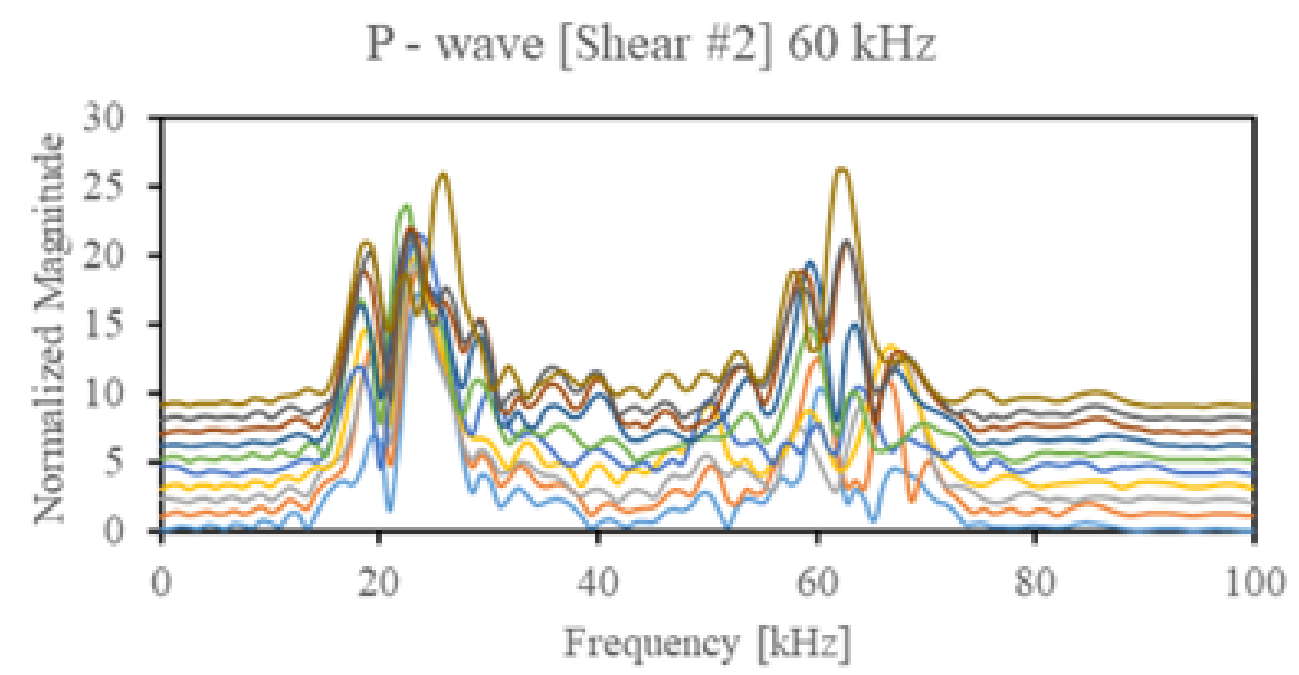

$-8 \mathrm{~min}-32 \mathrm{~min}-128 \mathrm{~min}-256 \mathrm{~min} \longrightarrow$ Day 1

-Day 2 -Day 3 -Day 4 -Day 5 -Day 10

$\mathrm{P}$ - wave [Shear \#2] $60 \mathrm{kHz}$

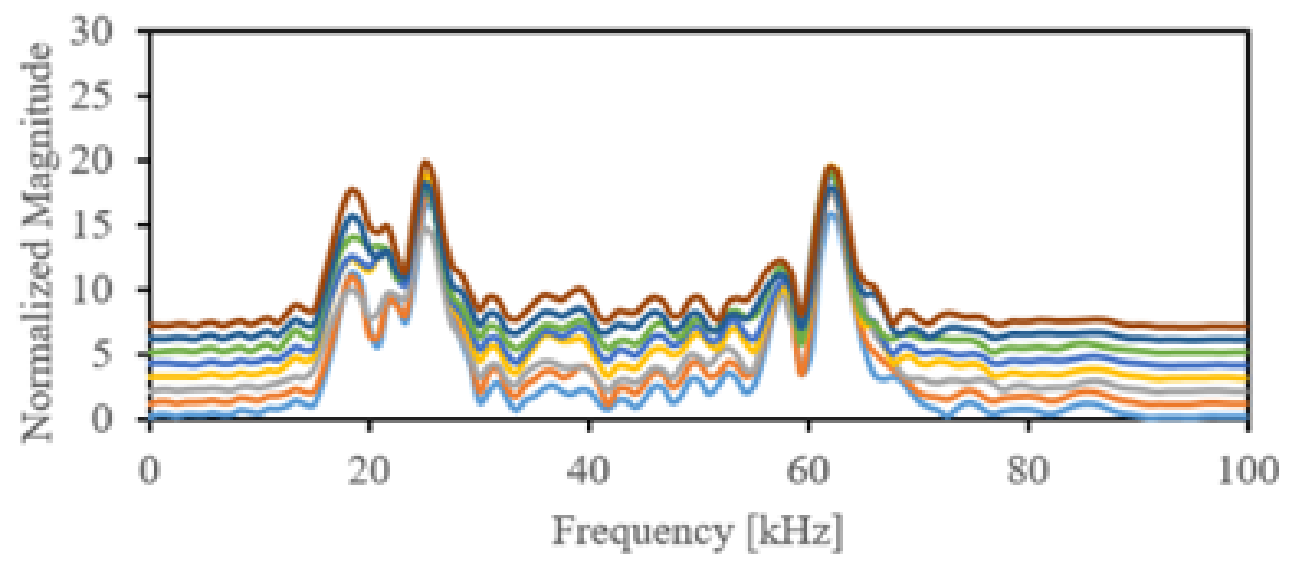

-Day 11 - Day 12 - Day $15-$ Day 21

—Day 23 - Day 26 - Day 28 - Day 30 
(c)
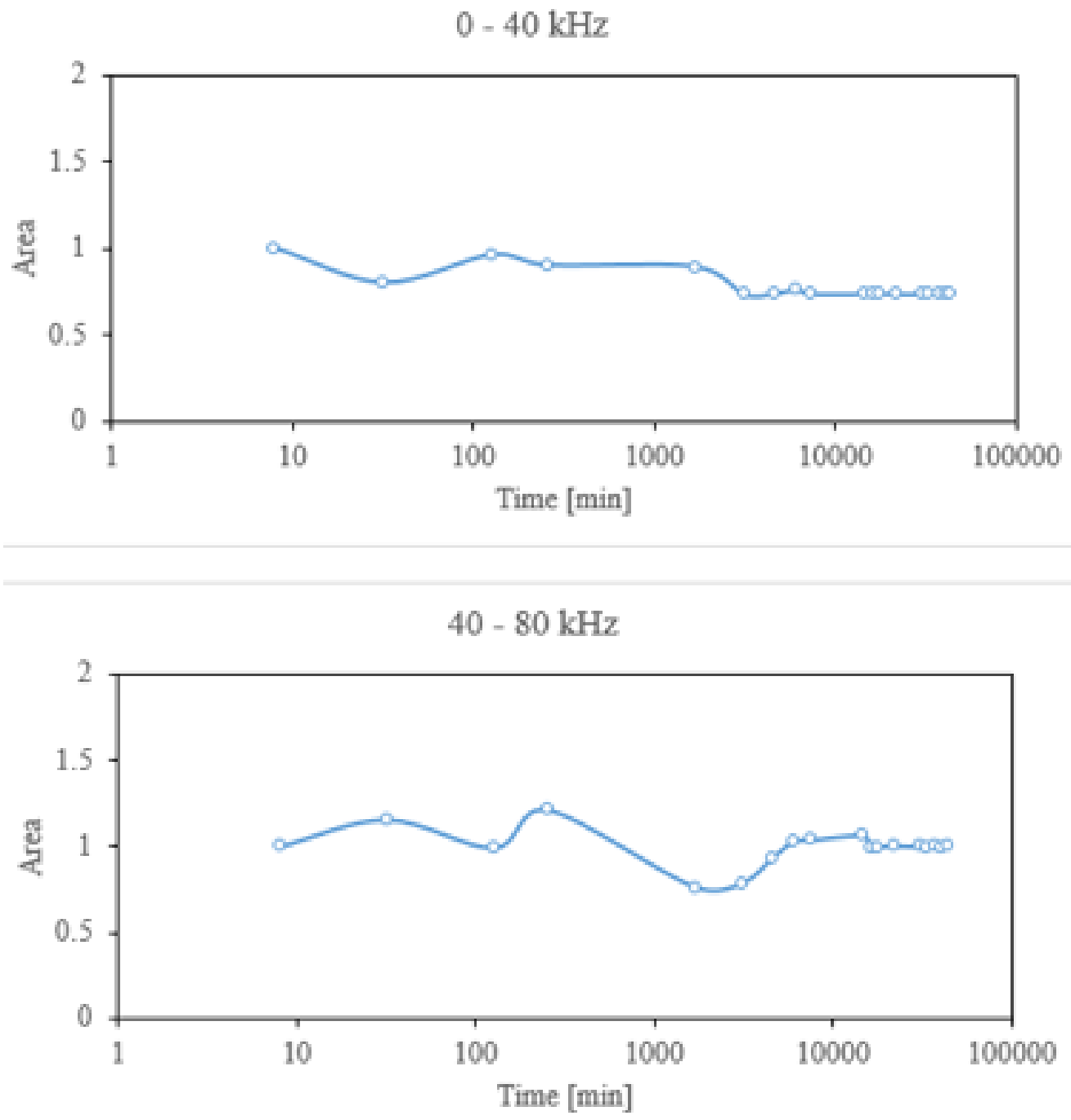

Figure 86: Window 2 (compressional transmitter/shear \#1 receiver): (a) Time signal, (b) FFT, (c) Area under the curve in the function of time. 
(a)

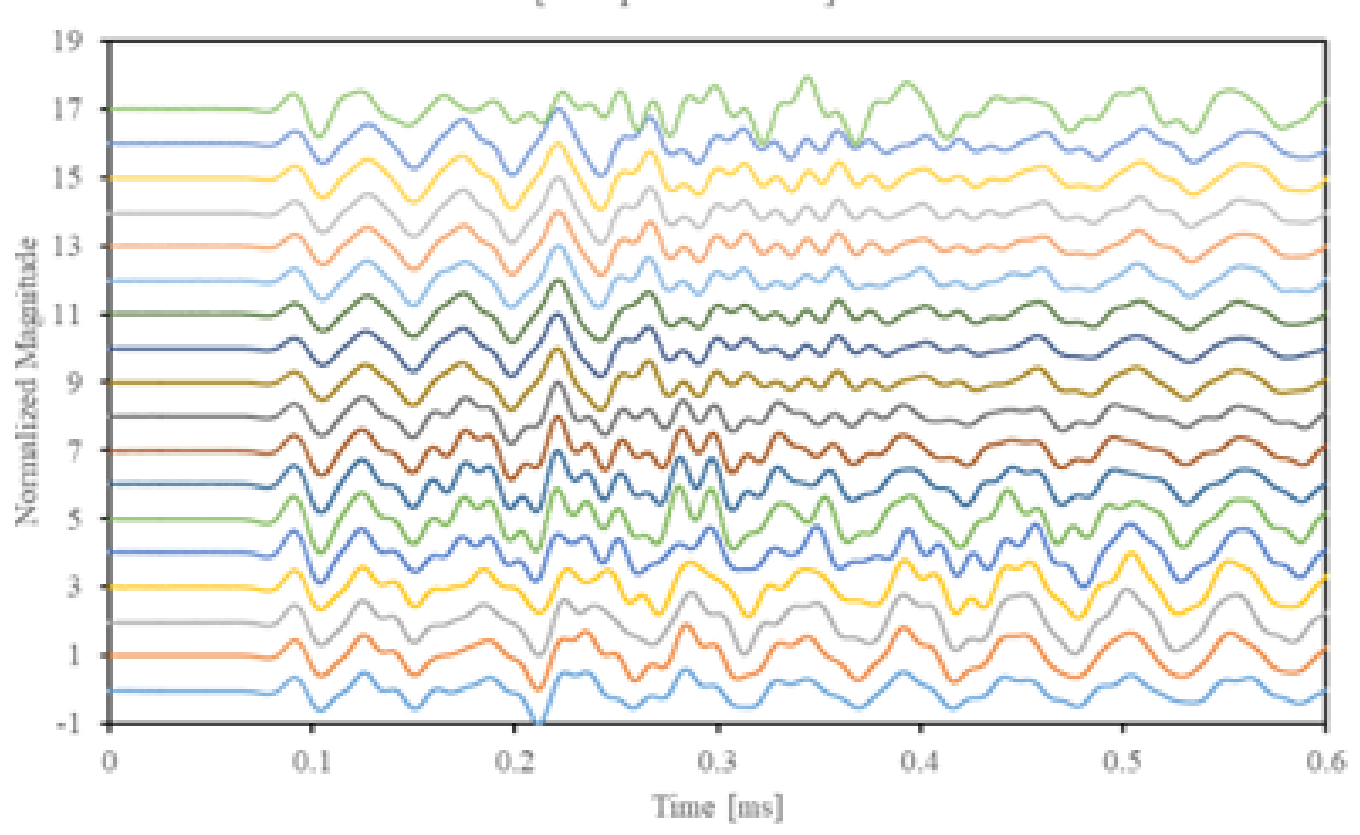

$-1 \min -32 \min -128 \min -256 \min -$ Day $1-$ Day 2
-Day $3-$ Day $4-$ Day $5-$ Day $10-$ Day $11-$ Day 12
-Day $15-$ Day $21-$ Day $23-$ Day $26-$ Day $28-$ Day 30 
(b)

$\mathrm{S}$ - wave [Compressional \#1] $54 \mathrm{kHz}$

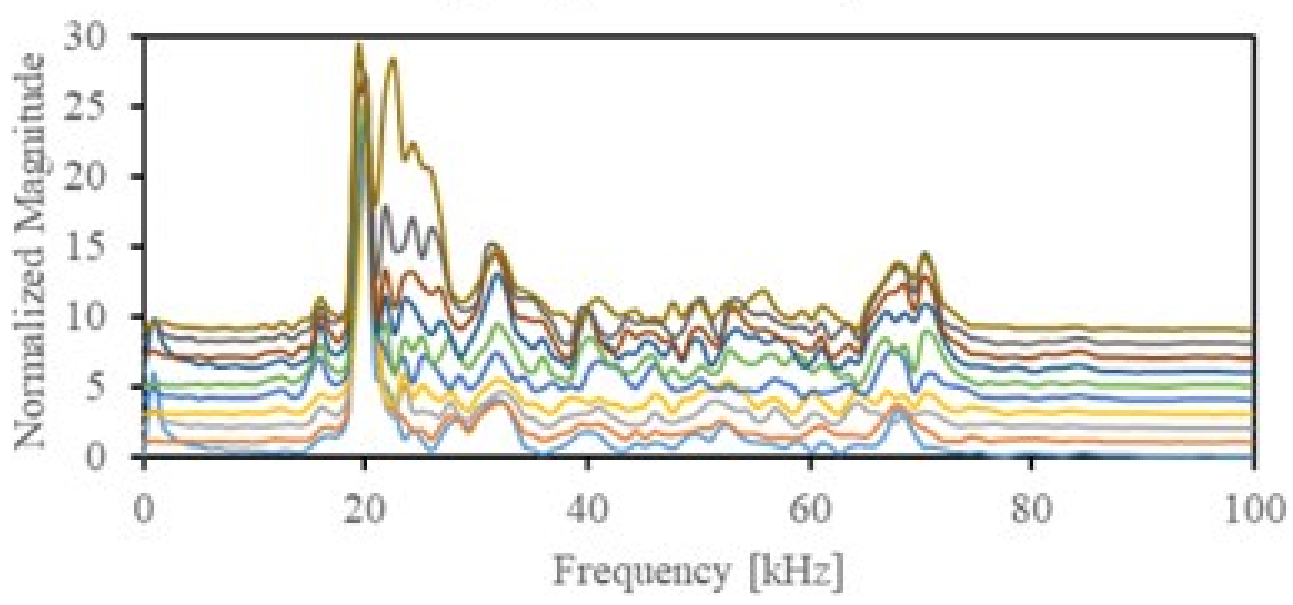

$-1 \mathrm{~min}-32 \mathrm{~min}-128 \mathrm{~min}-256 \mathrm{~min}-$ Day 1

-Day 2 -Day 3 -Day 4 -Day 5 -Day 10

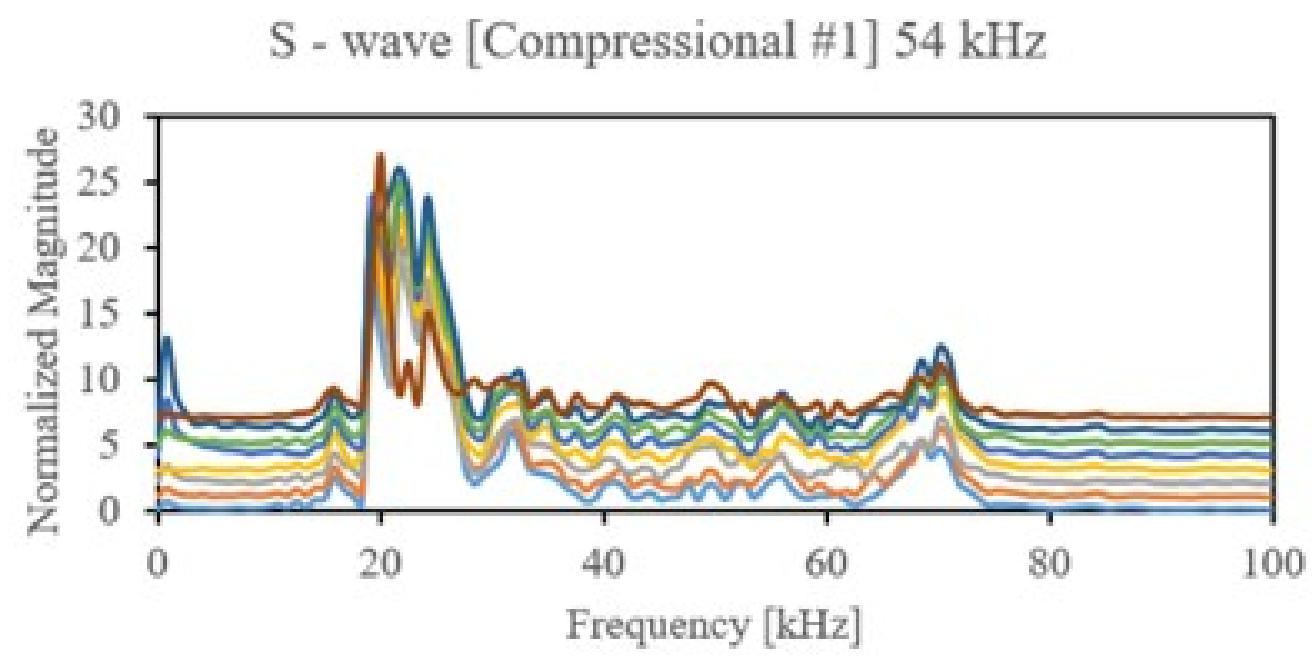

-Day 11 - Day 12 - Day 15 - Day 21

—Day 23 -Day 26 - Day 28 -Day 30 
(c)
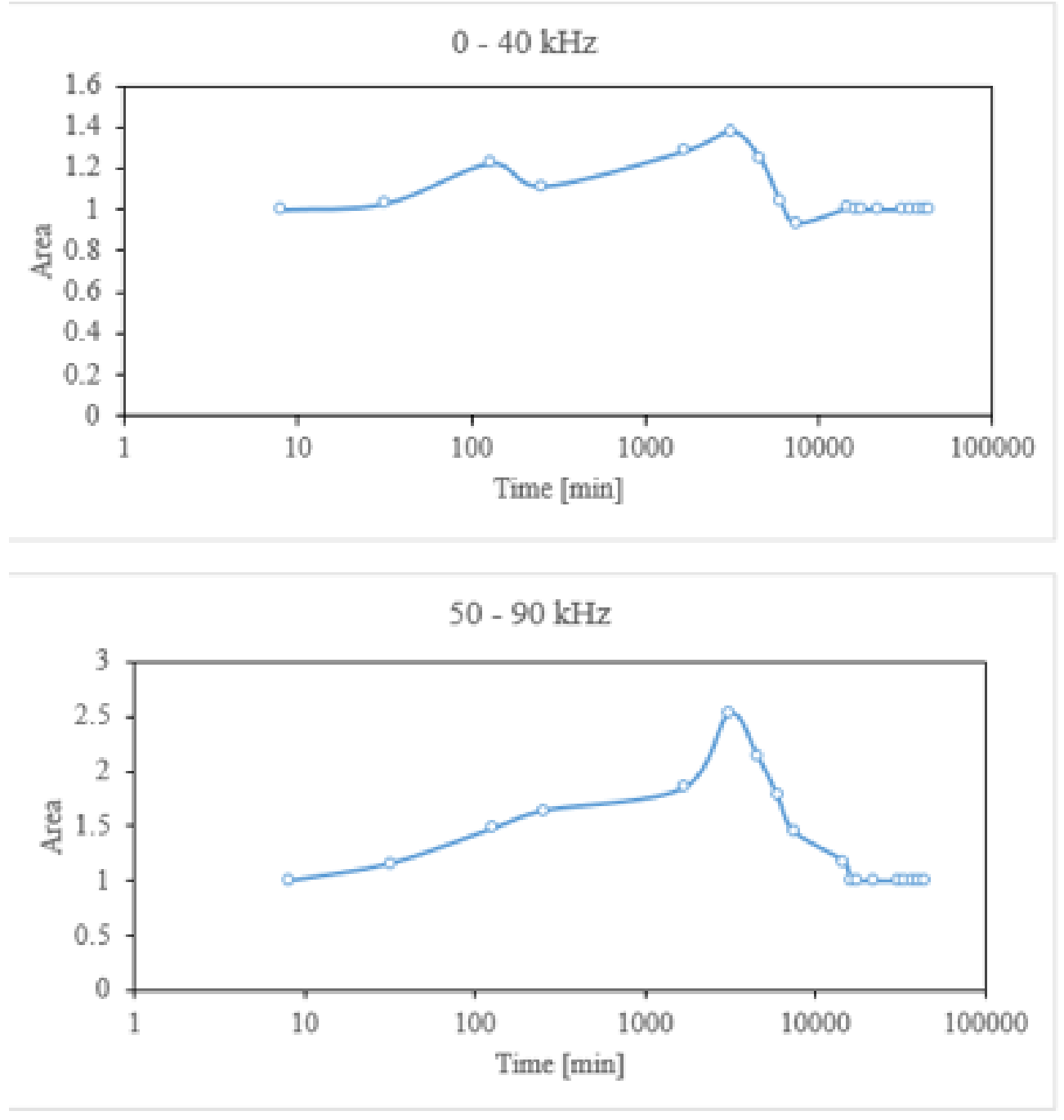

Figure 87: Without window (shear transmitter/compressional \#1 receiver): (a) Time signal, (b) FFT, (c) Area under the curve in the function of time. 
(a)

S - wave [Compressional \#1] $54 \mathrm{kHz}$

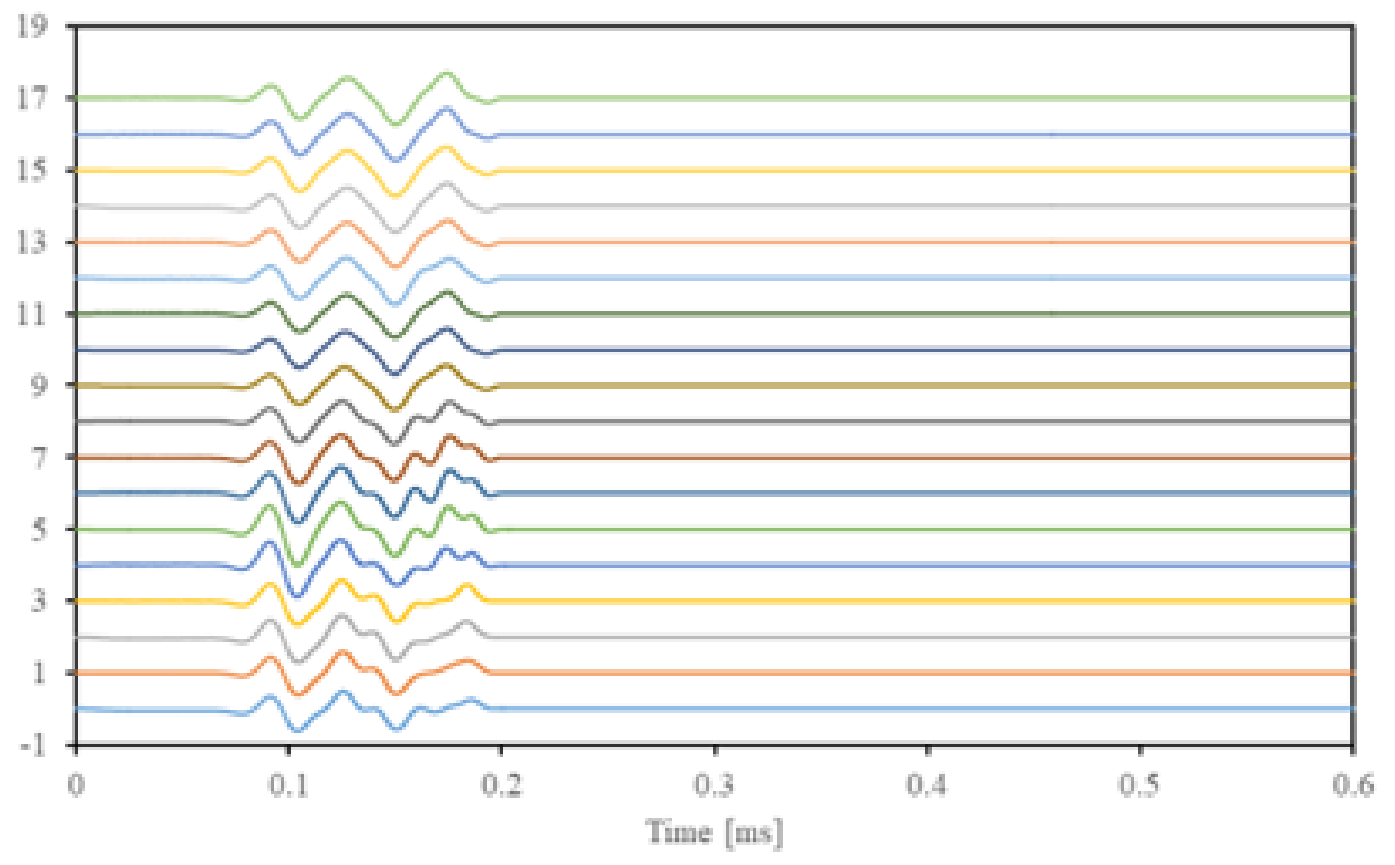

- $1 \mathrm{~min}-32 \mathrm{~min}-128 \mathrm{~min}-256 \mathrm{~min}$ - Day $1-$ Day 2

-Day 3 -Day 4 -Day 5 -Day 10 - Day 11 - Day 12

- Day 15 - Day 21 - Day 23 - Day 26 - Day 28 - Day 30 
(b)

$\mathrm{S}$ - wave [Compressional \#1] $54 \mathrm{kHz}$

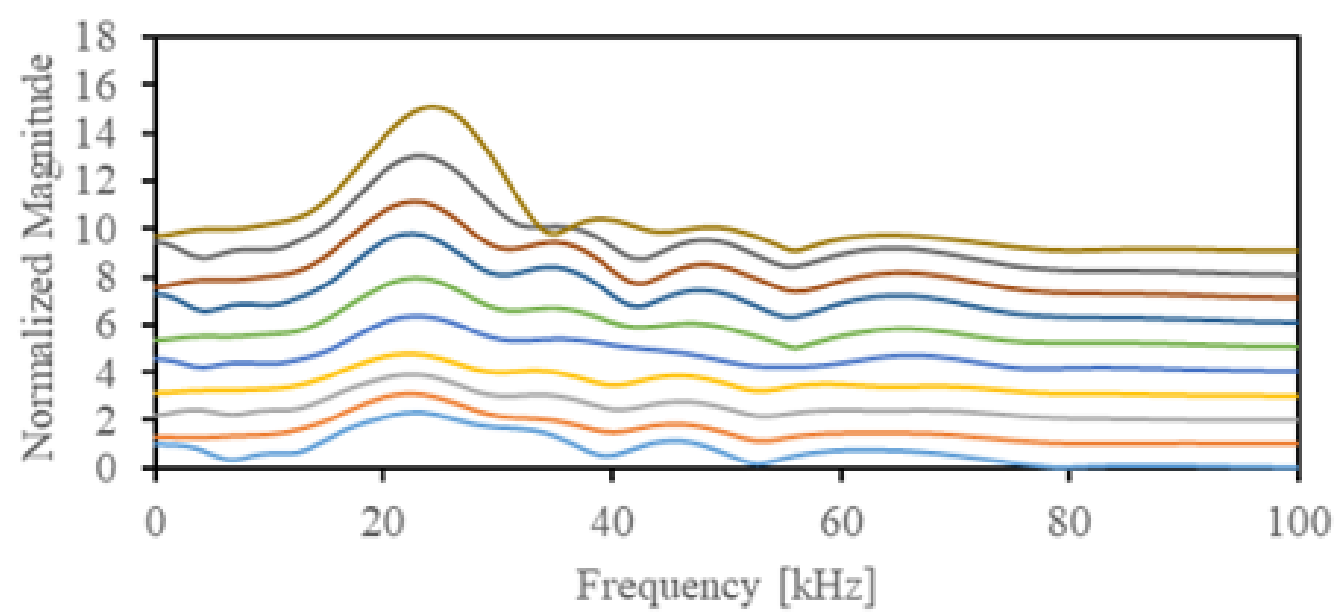

$-1 \mathrm{~min}-32 \mathrm{~min}-128 \mathrm{~min}-256 \mathrm{~min}$ - Day 1

—Day 2 -Day 3 -Day 4 -Day 5 -Day 10

$\mathrm{S}$ - wave [Compressional \#1] $54 \mathrm{kHz}$

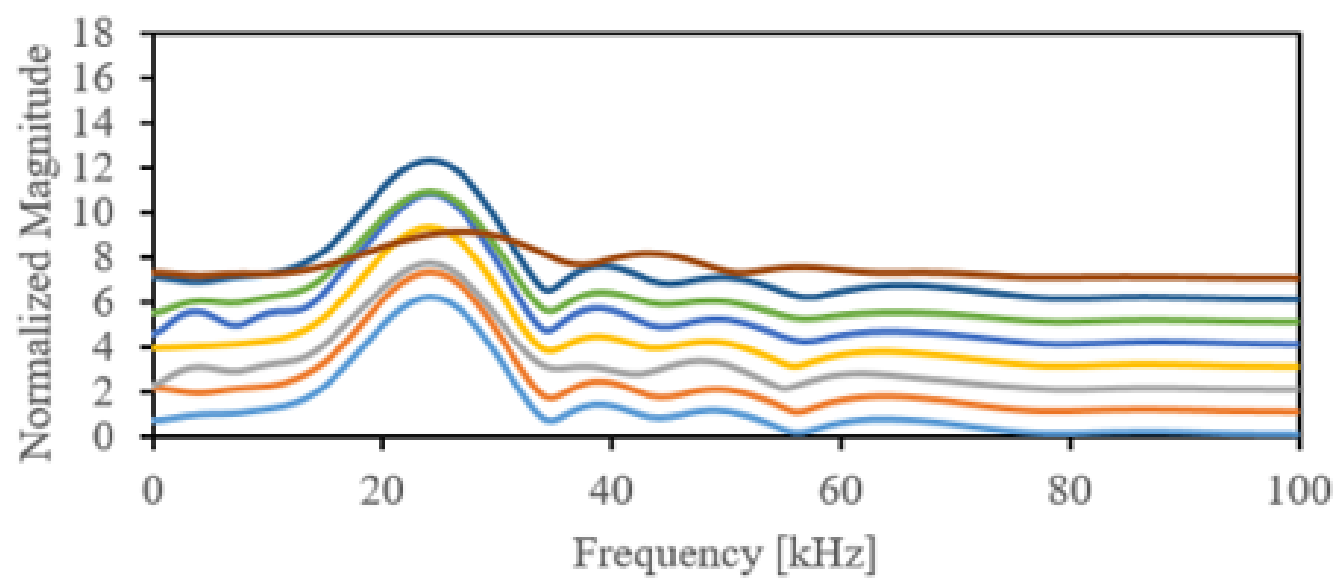

—Day 11 - Day 12 - Day 15 - Day 21

—Day 23 -Day 26 -Day 28 -Day 30 
(c)
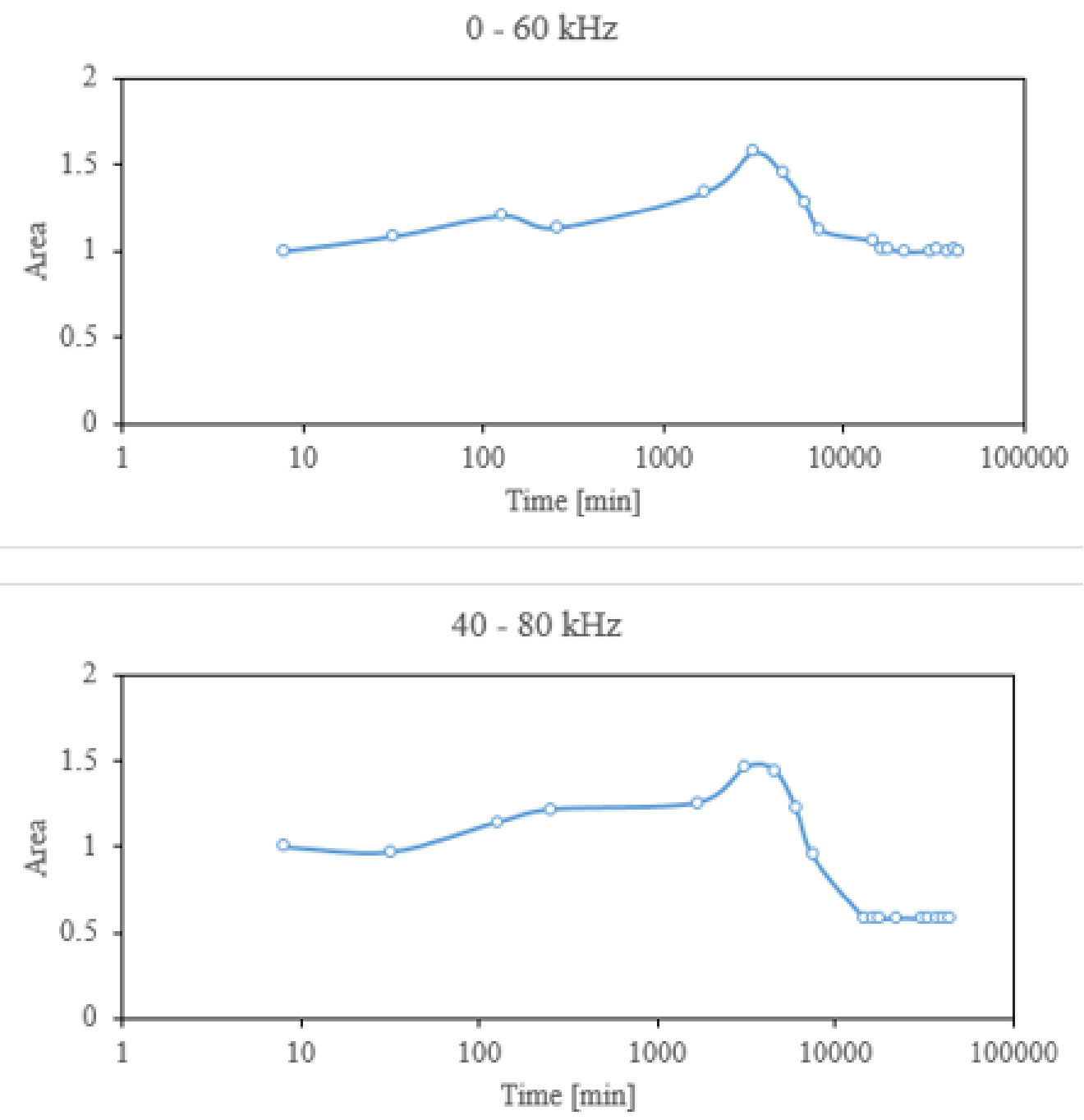

Figure 88: Window 1 (shear transmitter/compressional \#1 receiver): (a) Time signal, (b) FFT, (c) Area under the curve in the function of time. 
(a)

S - wave [Compressional \#1] $54 \mathrm{kHz}$

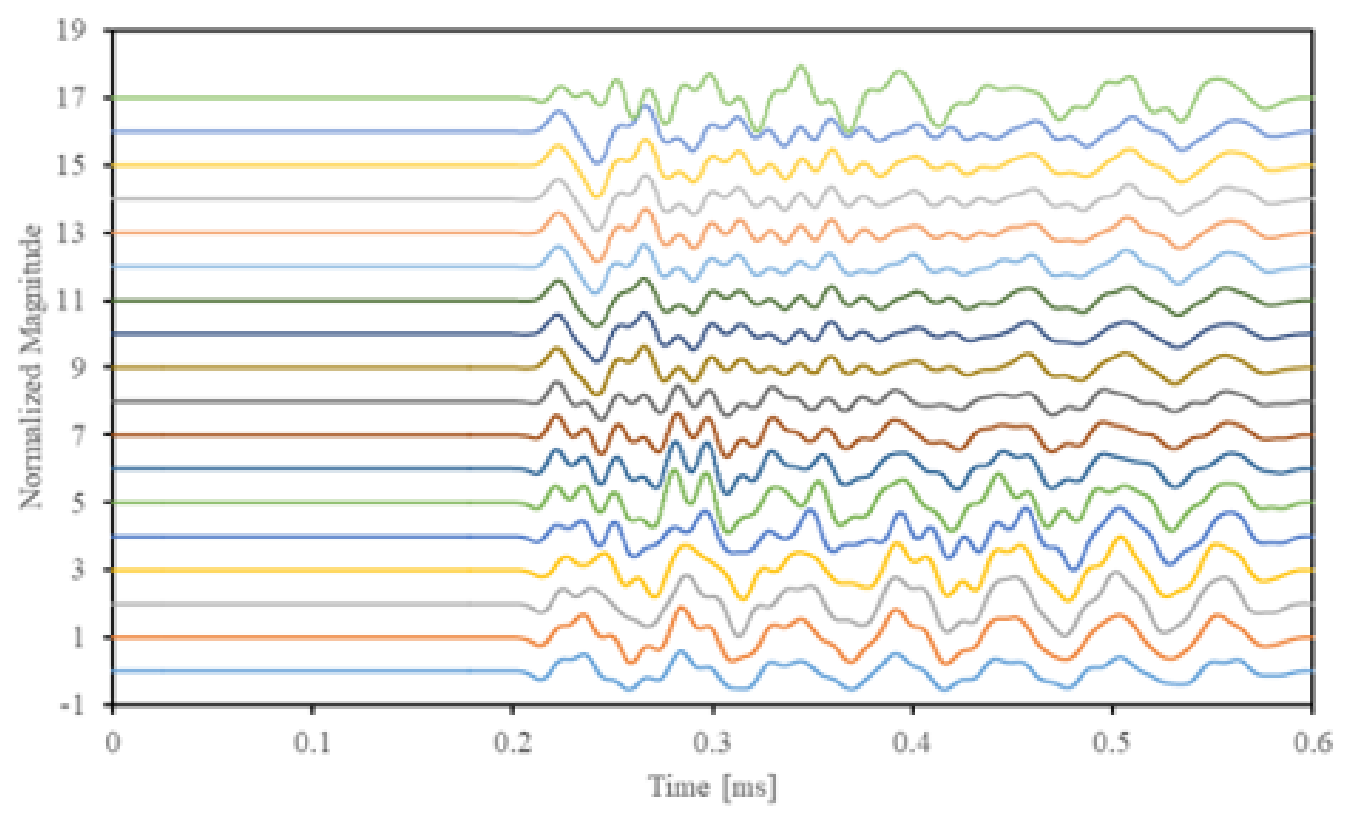

$-1 \mathrm{~min}-32 \mathrm{~min}-128 \mathrm{~min}-256 \mathrm{~min}-$ Day $1-$ Day 2

—Day 3 -Day 4 -Day 5 -Day 10 -Day 11 - Day 12

-Day 15 - Day 21 - Day 23 - Day 26 - Day 28 - Day 30 
(b)

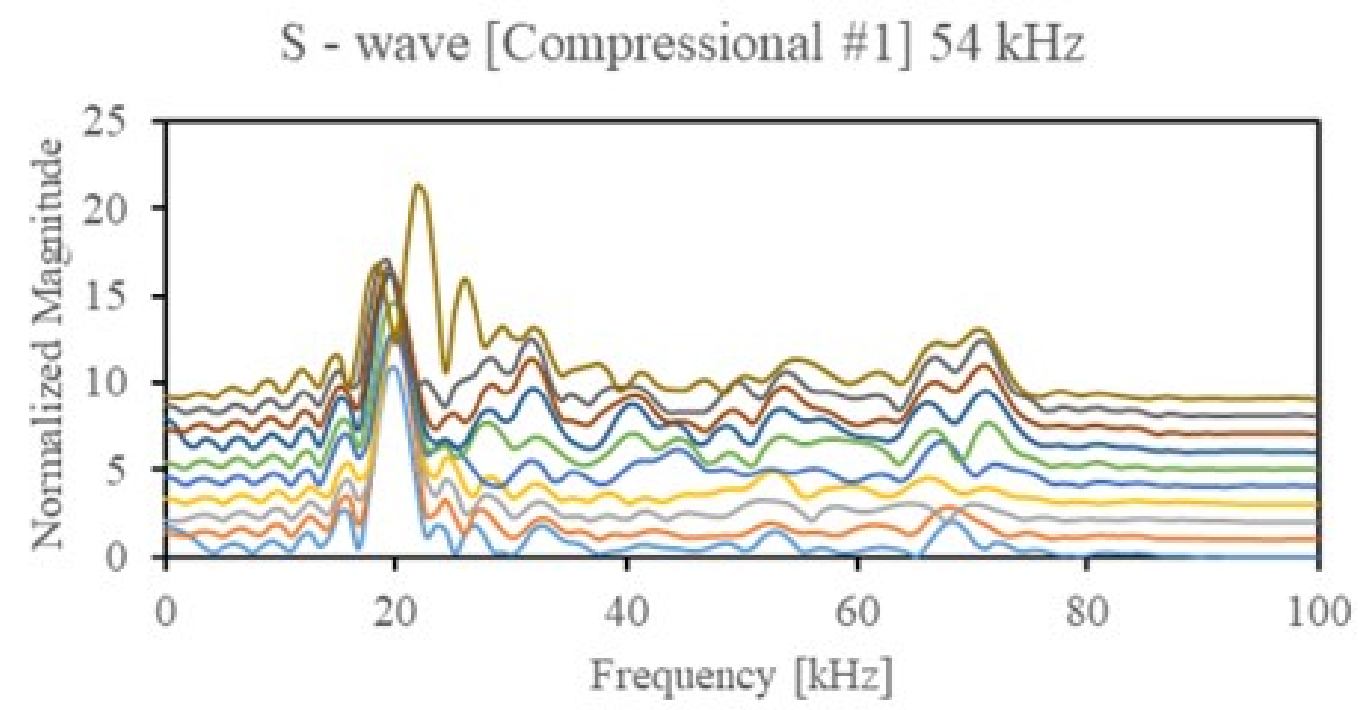

$-1 \mathrm{~min}-32 \mathrm{~min}-128 \mathrm{~min}-256 \mathrm{~min}-$ Day 1

-Day 2 -Day 3 - Day 4 -Day 5 - Day 10

$\mathrm{S}$ - wave [Compressional \#1] $54 \mathrm{kHz}$

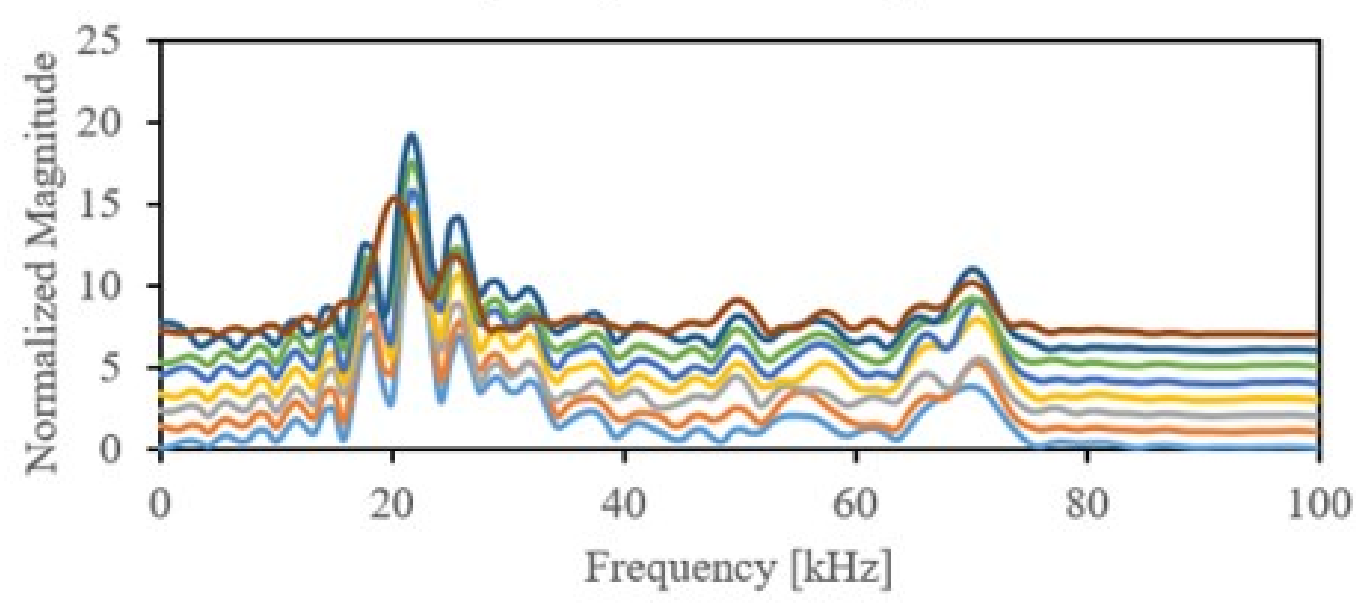

-Day 11 - Day 12 - Day 15 - Day 21

—Day 23 - Day 26 —Day 28 -Day 30 
(c)

\section{$0-40 \mathrm{kHz}$}

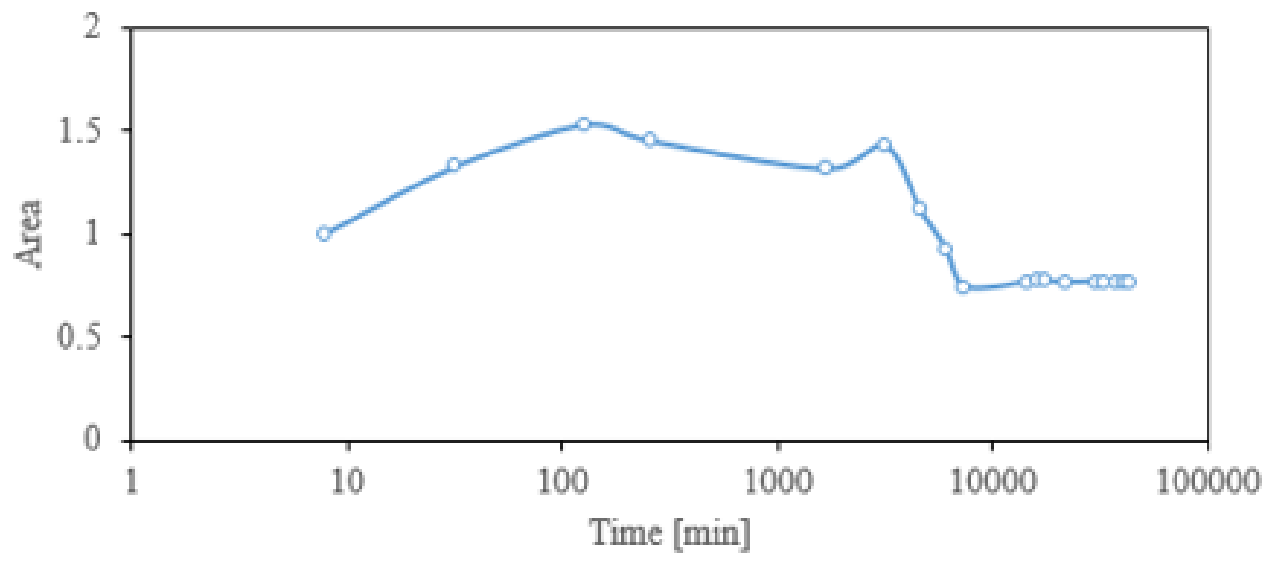

$50-90 \mathrm{kHz}$

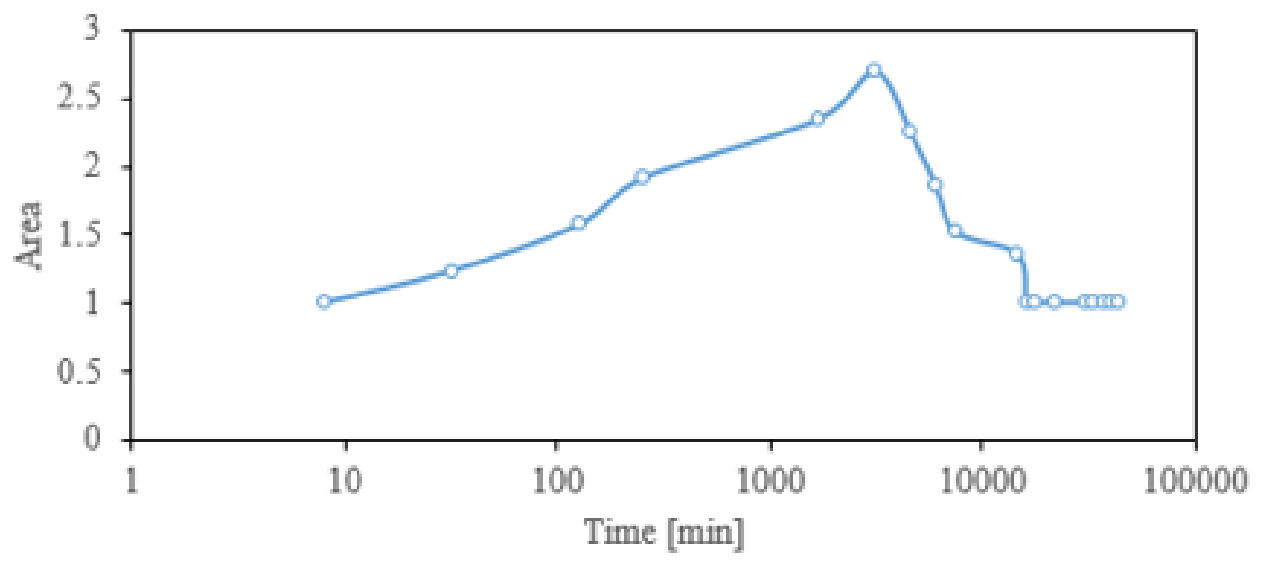

Figure 89: Window 2 (shear transmitter/compressional \#1 receiver): (a) Time signal, (b) FFT, (c) Area under the curve in the function of time. 
(a)

S - wave [Compressional \#2] $54 \mathrm{kHz}$

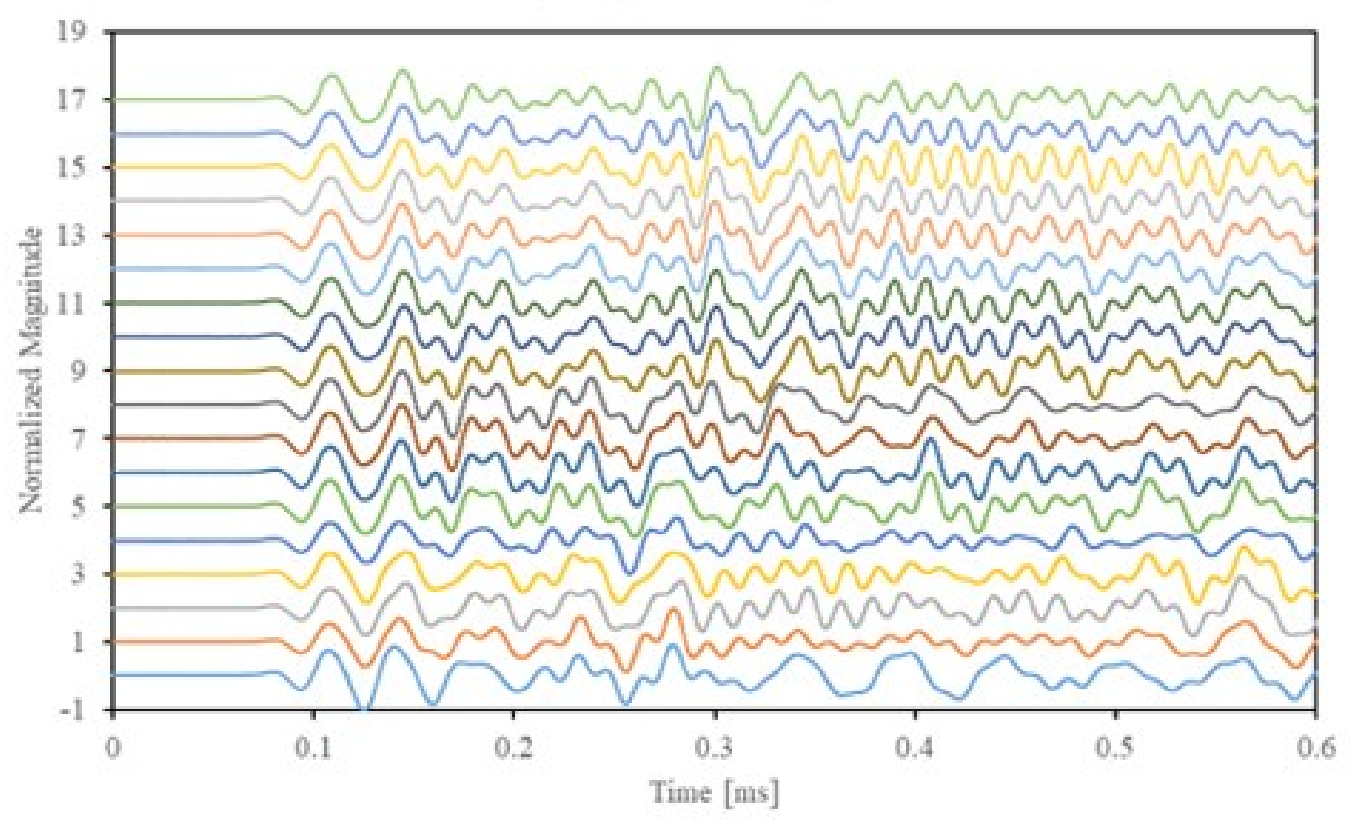

$-1 \mathrm{~min}-32 \mathrm{~min}-128 \mathrm{~min}-256 \mathrm{~min}-$ Day $1-$ Day 2

-Day 3 -Day 4 -Day 5 -Day 10 - Day 11 - Day 12

-Day 15 - Day 21 - Day 23 - Day 26 - Day 28 - Day 30 
(b)

$$
\mathrm{S} \text { - wave [Compressional \#2] } 54 \mathrm{kHz}
$$

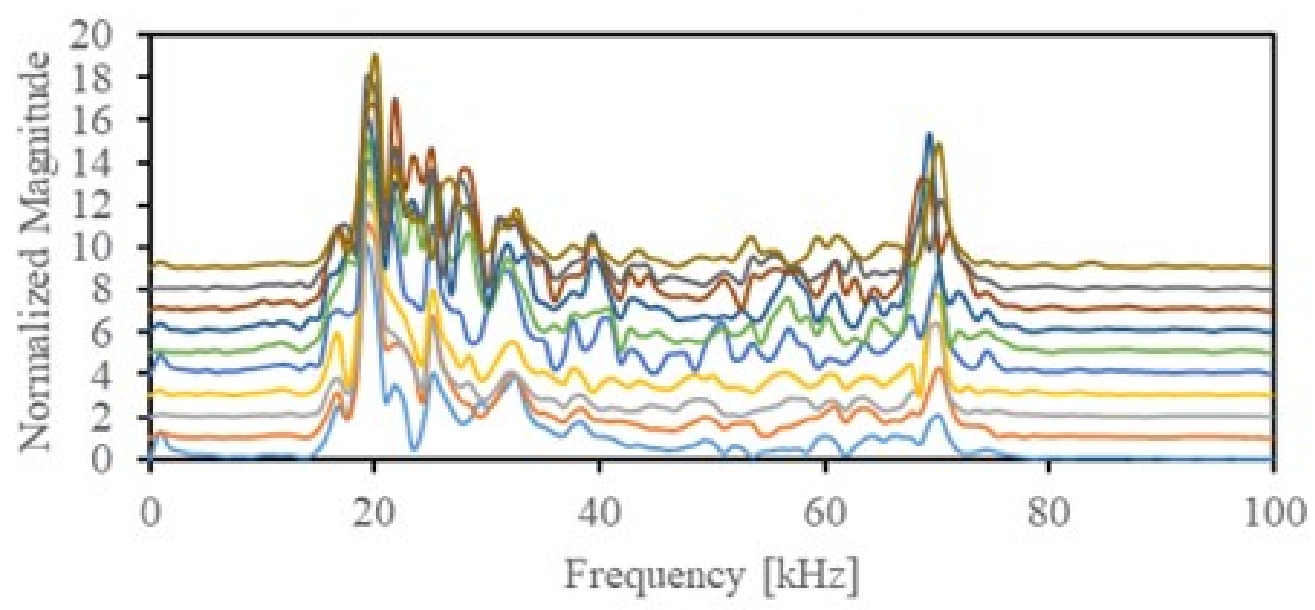

$-1 \mathrm{~min}-32 \mathrm{~min}-128 \mathrm{~min}-256 \mathrm{~min}-$ Day 1

—Day 2 - Day 3 - Day 4 -Day 5 -Day 10

$\mathrm{S}$ - wave [Compressional \#2] $54 \mathrm{kHz}$

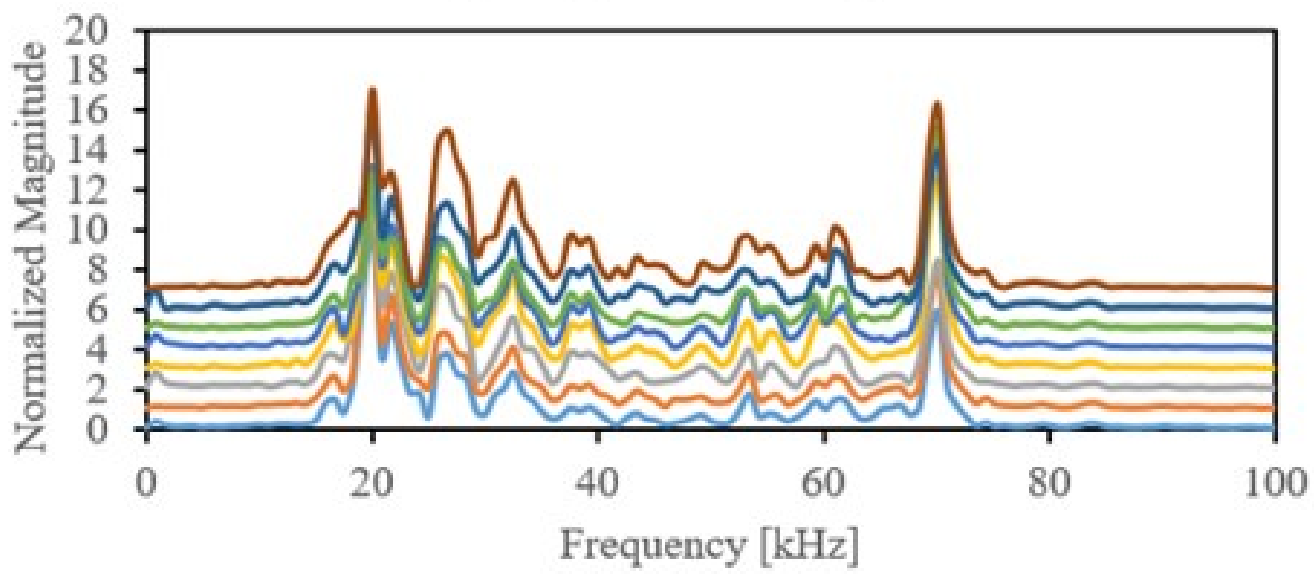

-Day 11 - Day 12 - Day $15-$ Day 21

—Day 23 -Day 26 -Day 28 -Day 30 
(c)
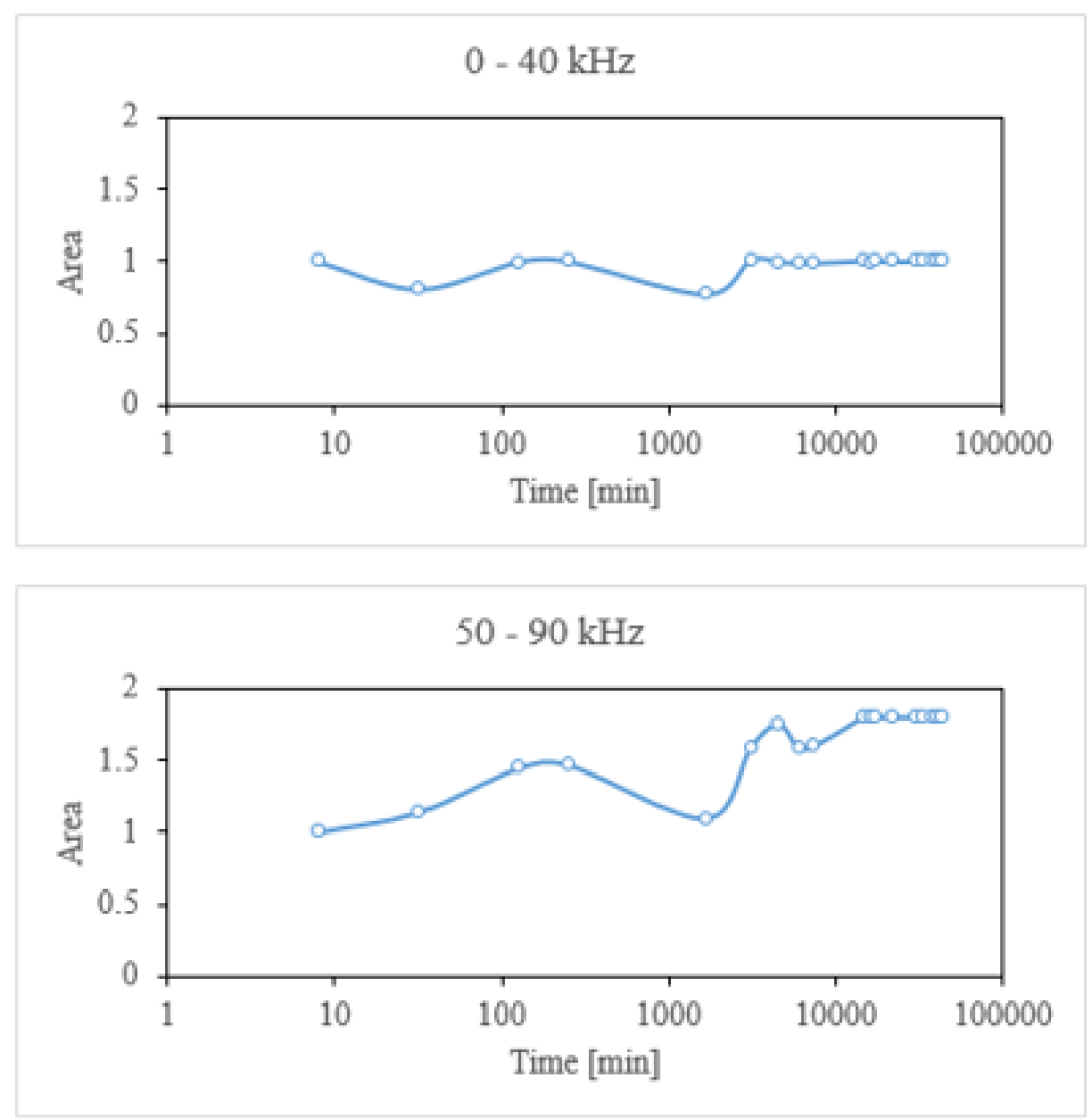

Figure 90: Without window (shear transmitter/compressional \#2 receiver): (a) Time signal, (b) FFT, (c) Area under the curve in the function of time. 
(a)

S - wave [Compressional \#2] $54 \mathrm{kHz}$

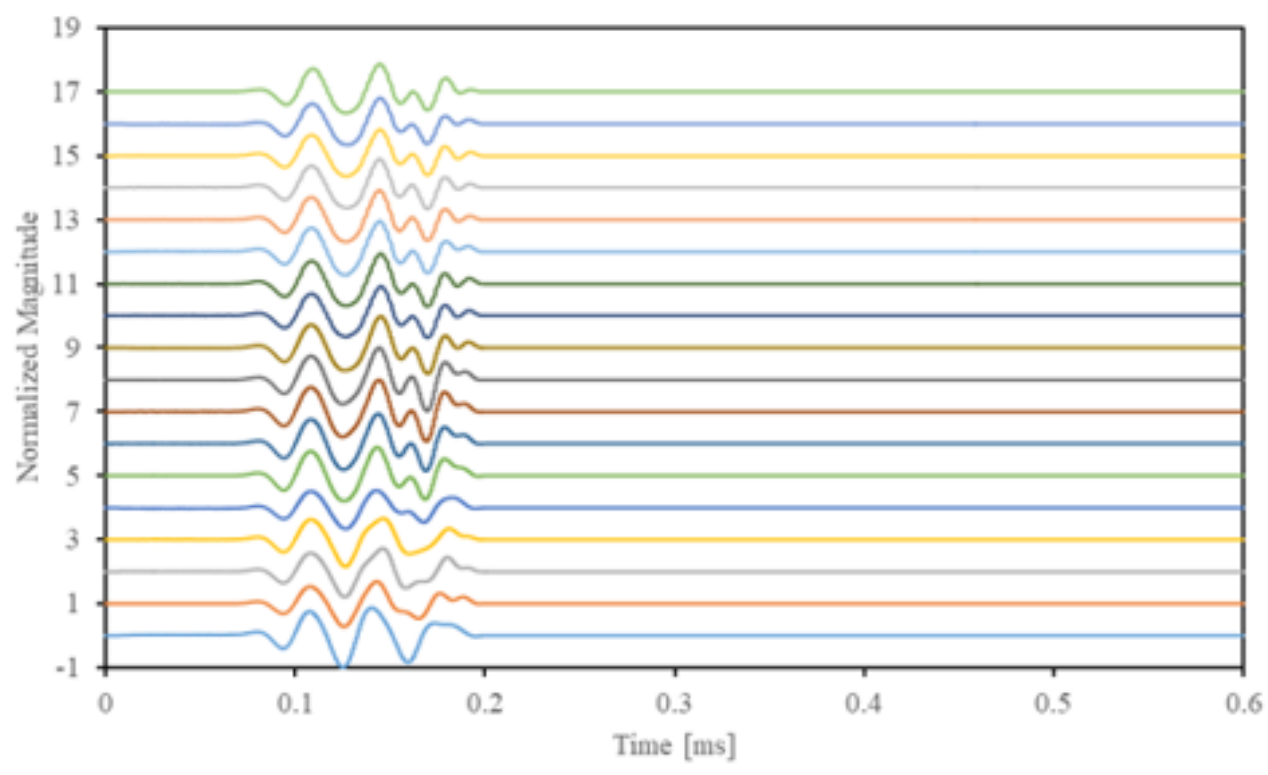

$$
\begin{aligned}
& -1 \mathrm{~min}-32 \mathrm{~min}-128 \mathrm{~min}-256 \mathrm{~min}-\text { Day } 1-\text { Day } 2 \\
& - \text { Day } 3-\text { Day } 4-\text { Day } 5-\text { Day } 10-\text { Day } 11-\text { Day } 12 \\
& - \text { Day } 15-\text { Day } 21-\text { Day } 23-\text { Day } 26-\text { Day } 28-\text { Day } 30
\end{aligned}
$$


(b)

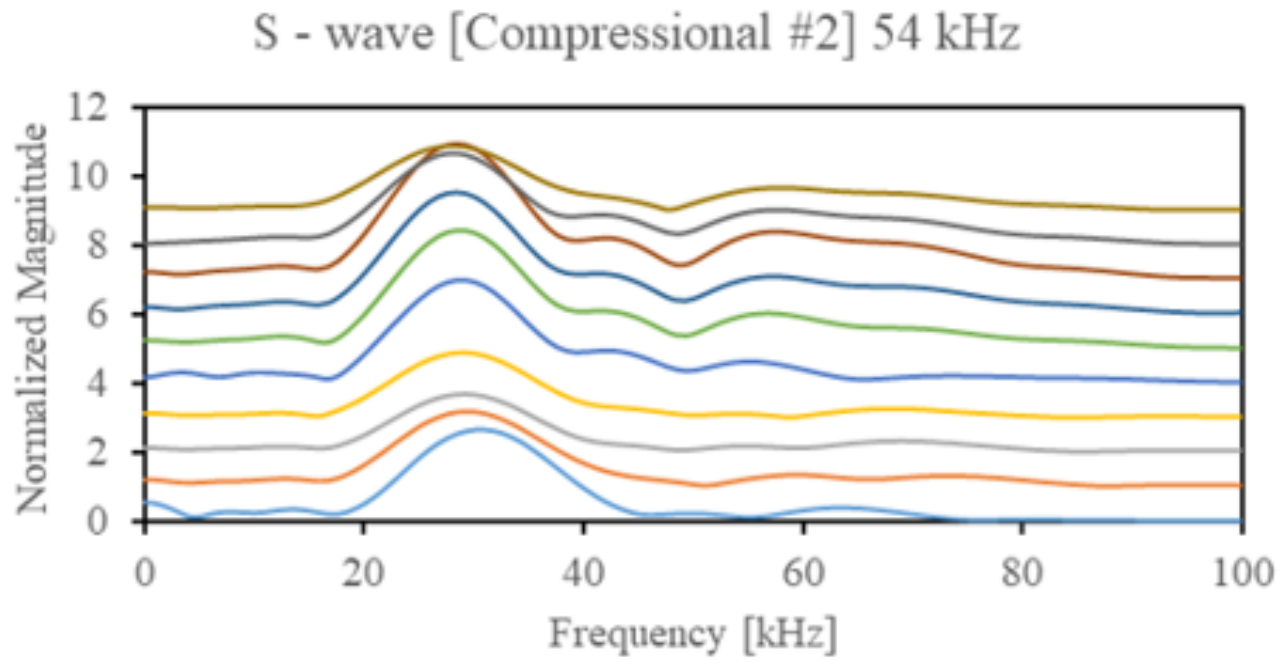

$-1 \mathrm{~min}-32 \mathrm{~min}-128 \mathrm{~min}-256 \mathrm{~min}$-Day 1

—Day 2 - Day 3 -Day 4 -Day 5 - Day 10

$\mathrm{S}$ - wave [Compressional \#2] $54 \mathrm{kHz}$

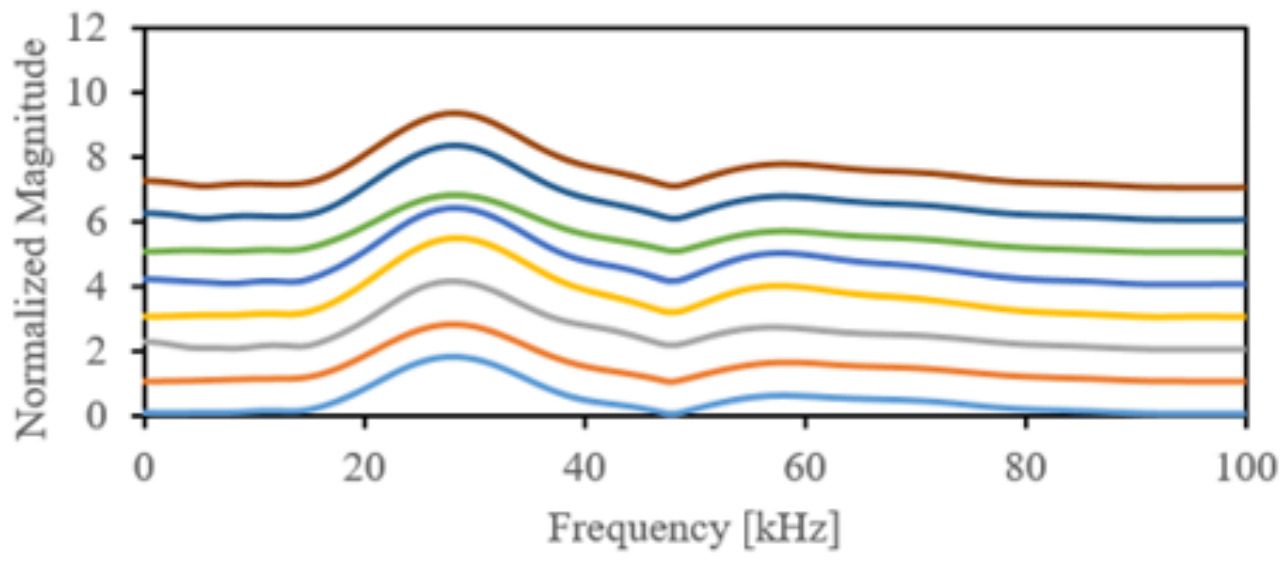

-Day 11 - Day 12 - Day 15 - Day 21

-Day 23 - Day $26-$ Day 28 - Day 30 
(c)
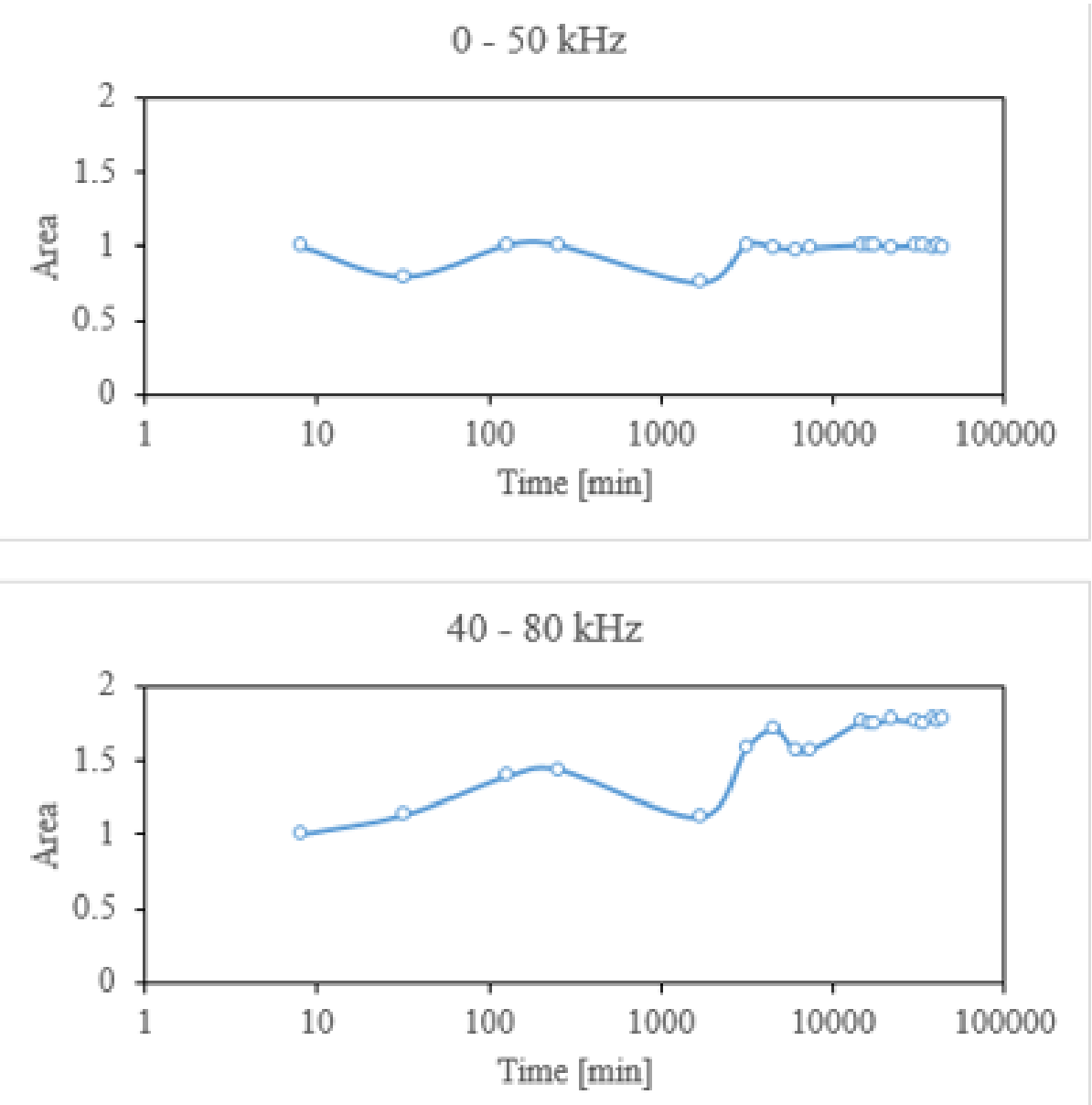

Figure 91: Window 1 (shear transmitter/compressional \#2 receiver): (a) Time signal, (b) FFT, (c) Area under the curve in the function of time. 
(a)

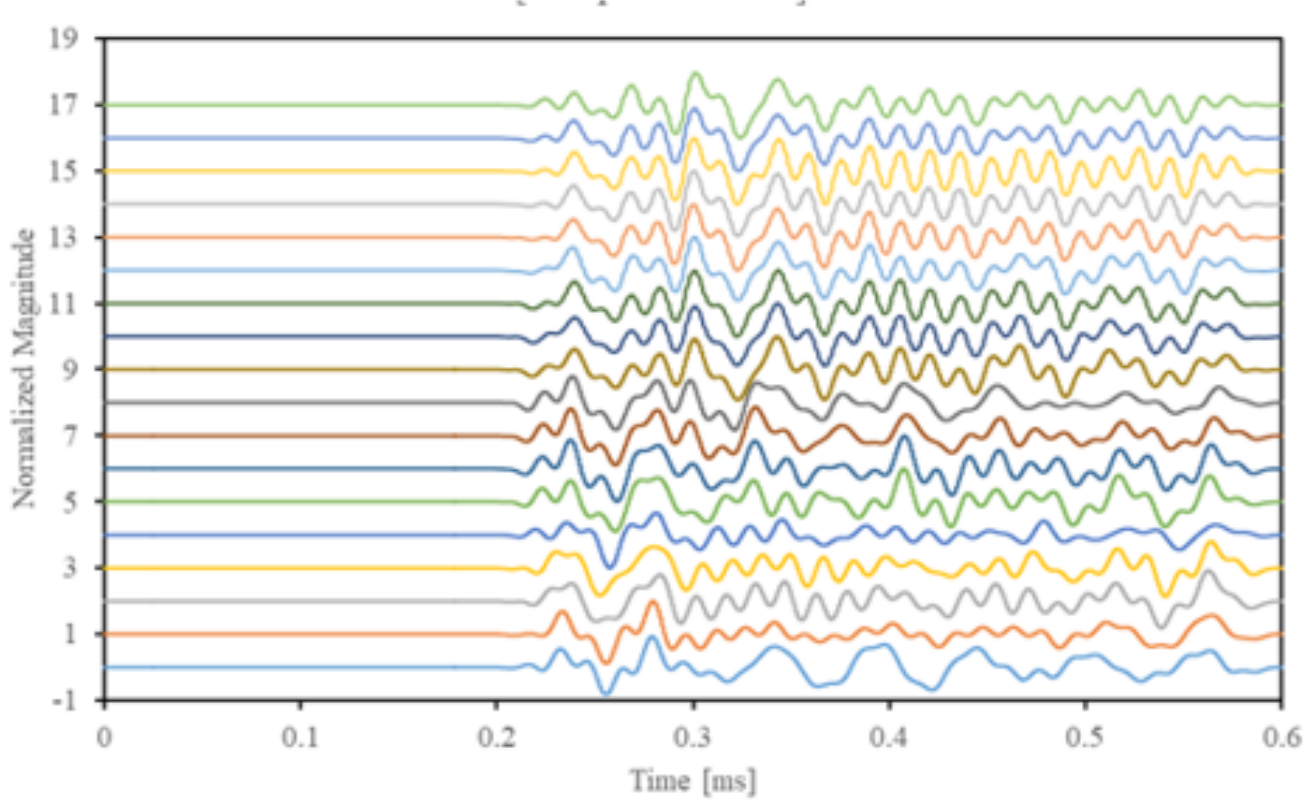

$-1 \mathrm{~min}-32 \mathrm{~min}-128 \mathrm{~min}-256 \mathrm{~min}-$ Day $1-$ Day 2

-Day 3 -Day 4 -Day 5 -Day 10 -Day 11 - Day 12

-Day 15 - Day 21 - Day 23 - Day 26 - Day 28 - Day 30 
(b)

$\mathrm{S}$ - wave [Compressional \#2] $54 \mathrm{kHz}$

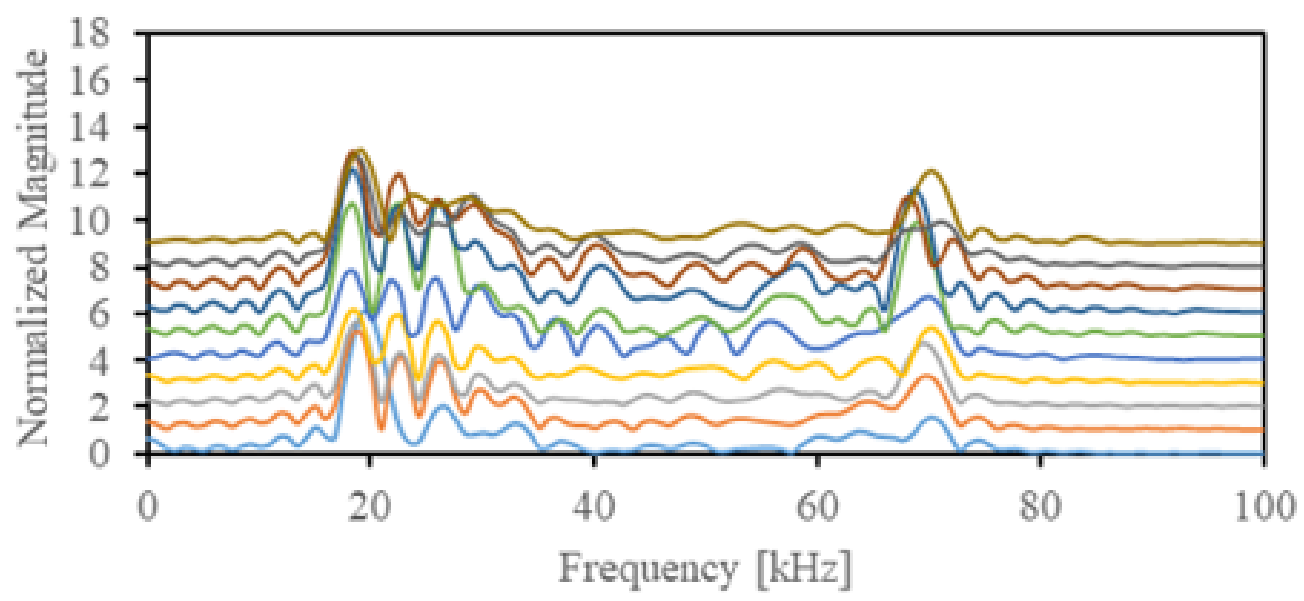

$-1 \mathrm{~min}-32 \mathrm{~min}-128 \mathrm{~min}-256 \mathrm{~min}-$ Day 1

—Day 2 -Day 3 -Day 4 —Day 5 -Day 10

$\mathrm{S}$ - wave [Compressional \#2] $54 \mathrm{kHz}$

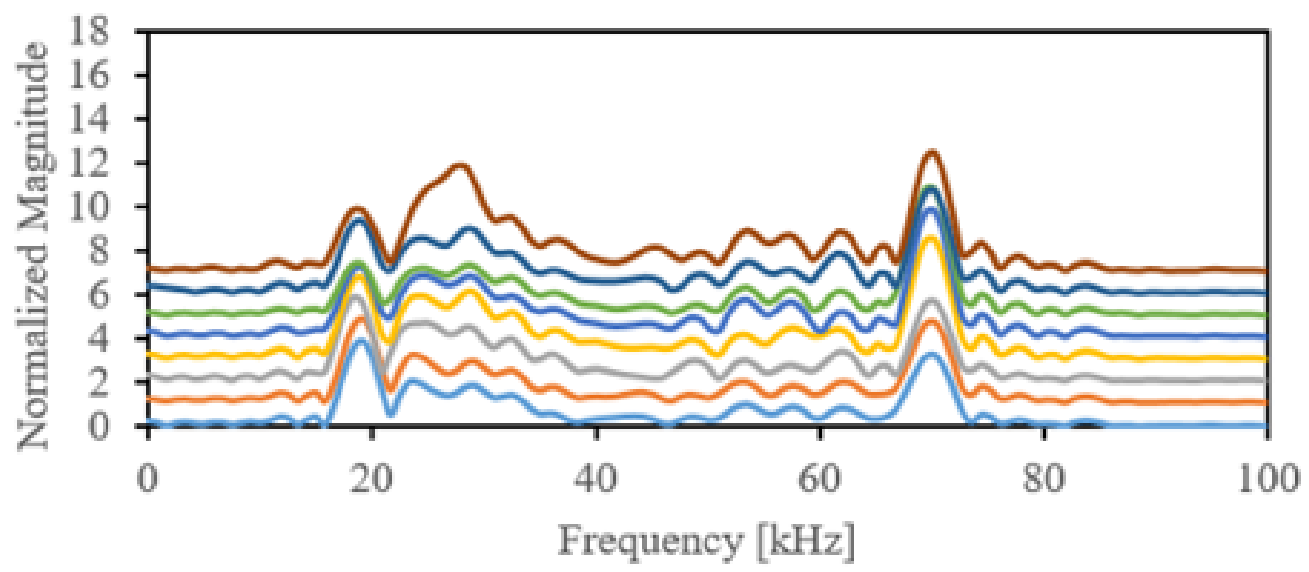

—Day 11 - Day 12 - Day 15 - Day 21

—Day 23 -Day 26 —Day 28 -Day 30 
(c)
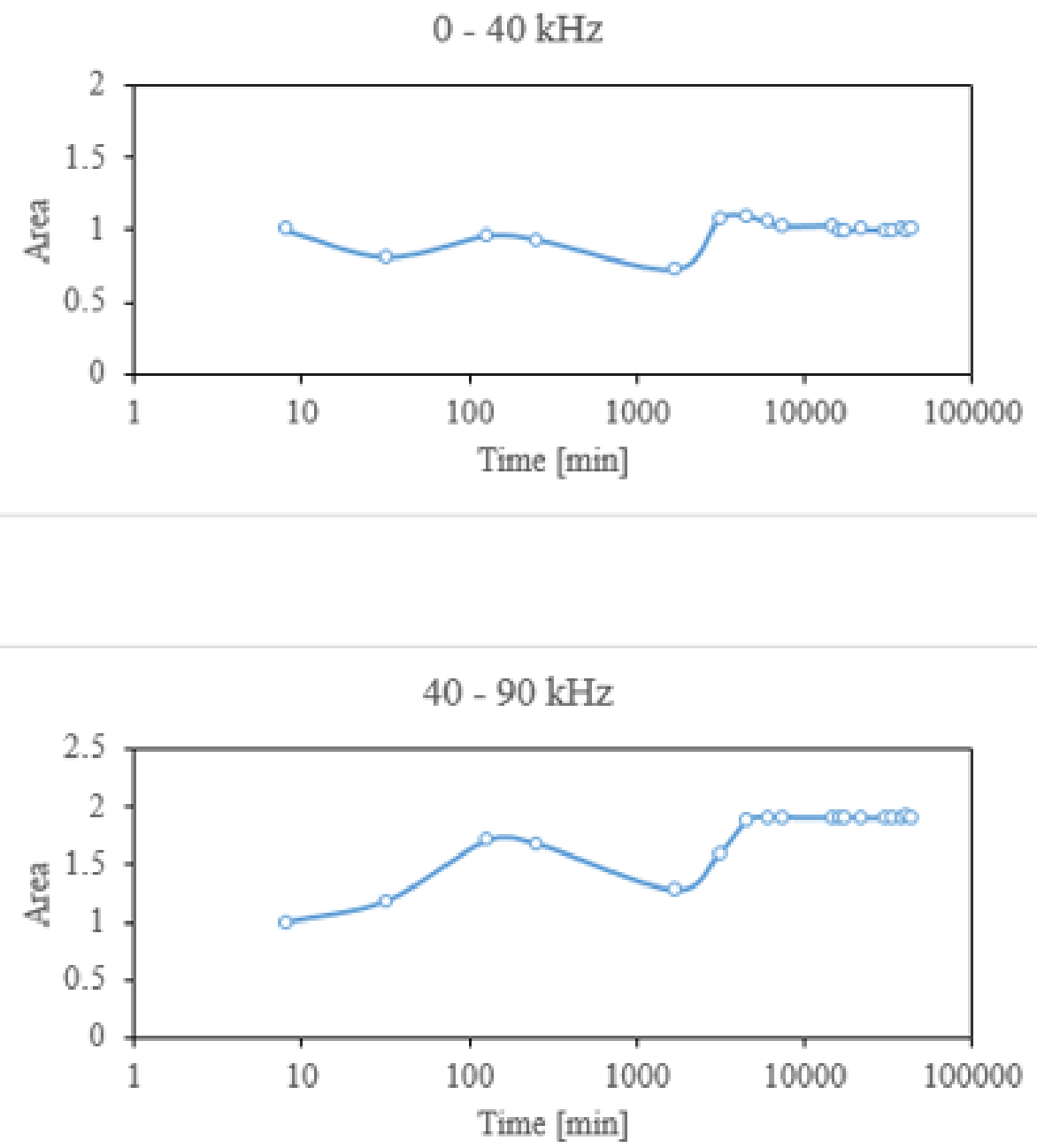

Figure 92: Window 2 (shear transmitter/compressional \#2 receiver): (a) Time signal, (b) FFT, (c) Area under the curve in the function of time. 


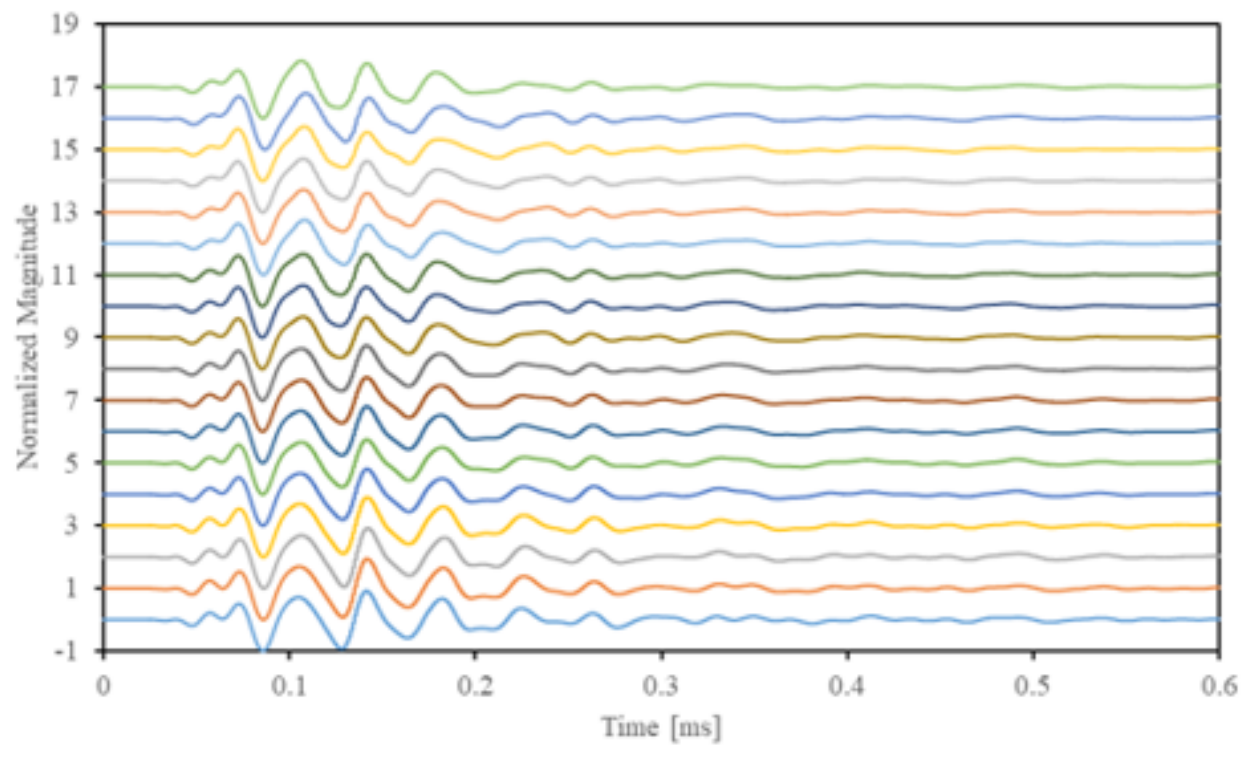

$-1 \mathrm{~min}-32 \mathrm{~min}-128 \mathrm{~min}-256 \mathrm{~min}-$ Day $1-$ Day 2

-Day 3 -Day 4 -Day 5 -Day 10 -Day 11 -Day 12

-Day 15 - Day 21 - Day 23 - Day 26 - Day 28 - Day 30 
(b)

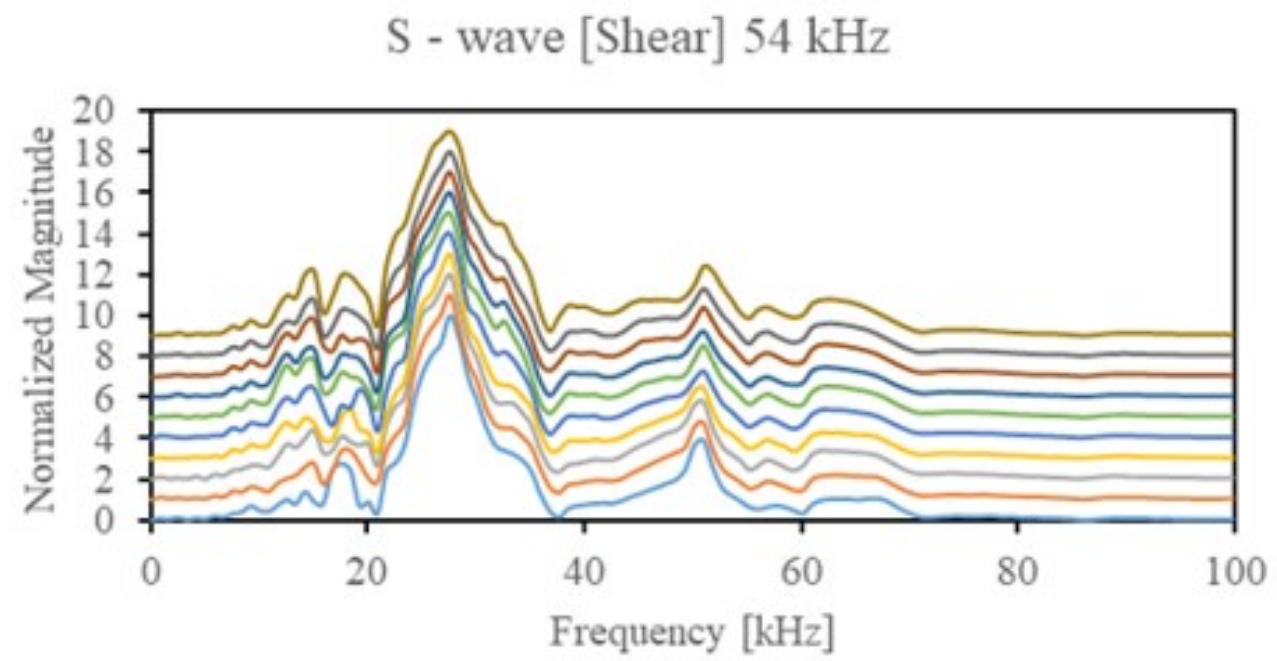

$-1 \mathrm{~min}-32 \mathrm{~min}-128 \mathrm{~min}-256 \mathrm{~min} \longrightarrow$ Day 1

-Day 2 - Day 3 -Day 4 -Day 5 -Day 10

$\mathrm{S}$ - wave [Shear] $54 \mathrm{kHz}$

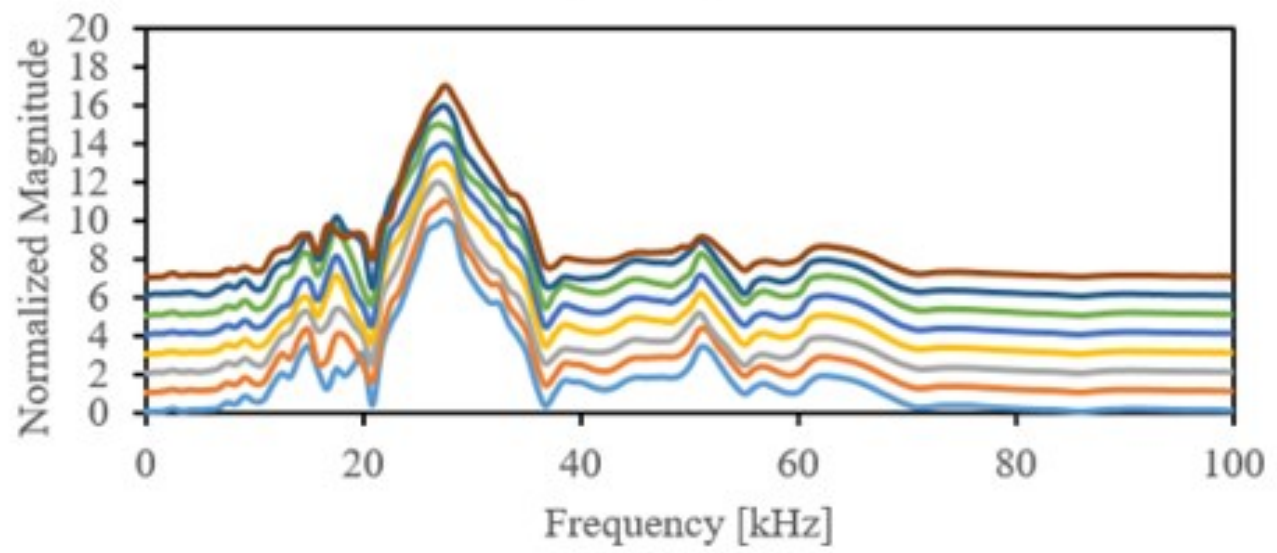

-Day 11 - Day 12 - Day 15 - Day 21

-Day 23 -Day 26 - Day 28 - Day 30 
(c)
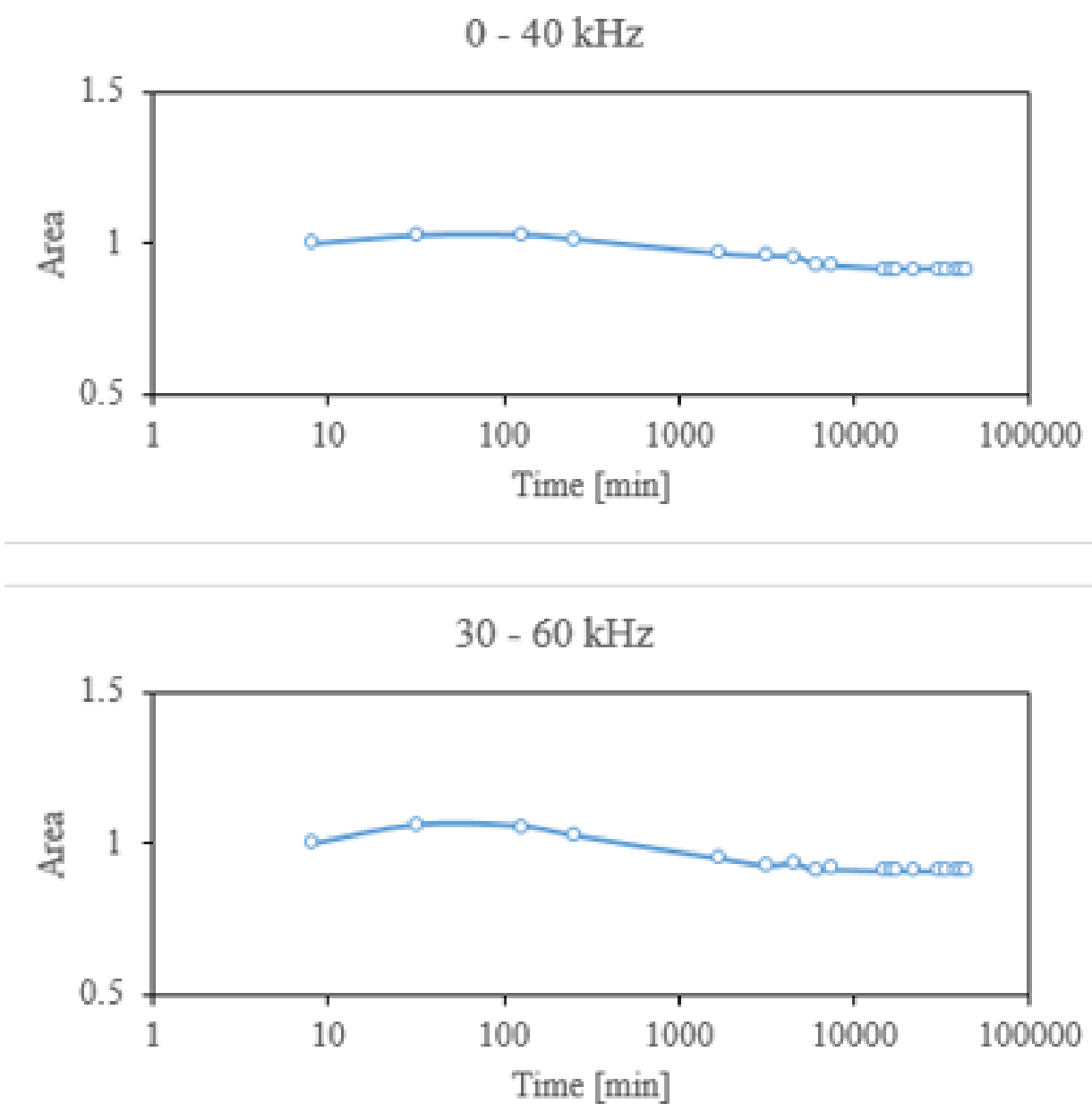

Figure 93: Without window (shear transmitter/receiver): (a) Time signal, (b) FFT, (c) Area under the curve in the function of time. 
(a)

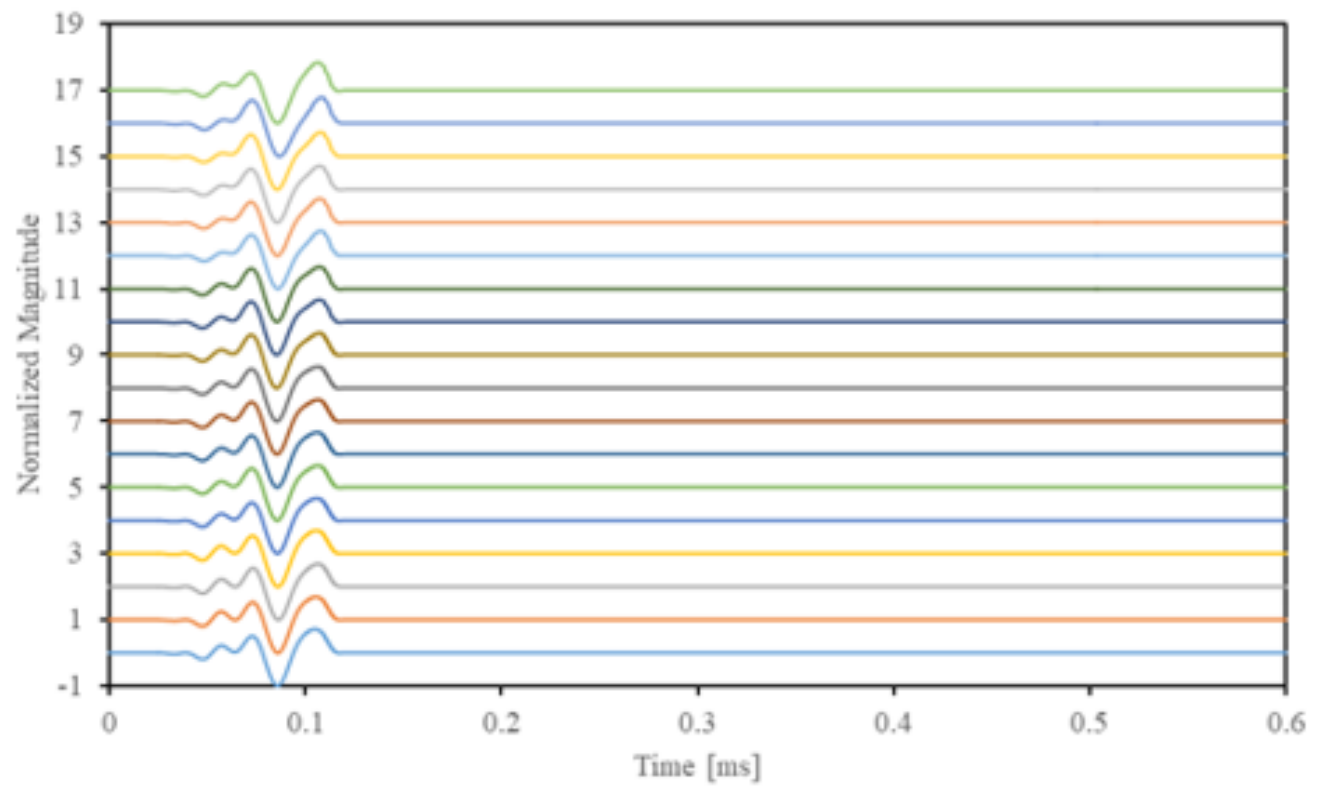

$-1 \mathrm{~min}-32 \mathrm{~min}-128 \mathrm{~min}-256 \mathrm{~min}-$ Day $1-$ Day 2

—Day 3 -Day 4 -Day 5 -Day 10 -Day 11 - Day 12

-Day 15 - Day 21 - Day 23 - Day 26 - Day 28 - Day 30 
(b)

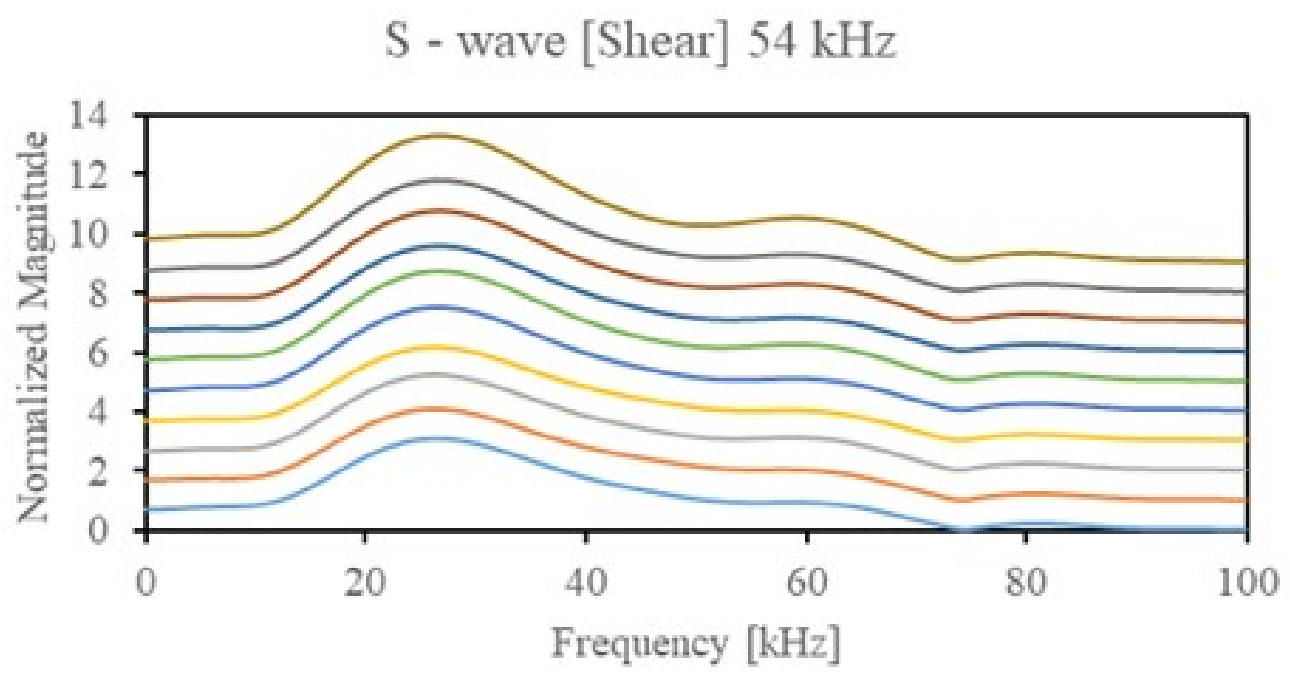

$-1 \mathrm{~min}-32 \mathrm{~min}-128 \mathrm{~min}-256 \mathrm{~min}-$ Day 1

-Day 2 -Day 3 -Day 4 -Day 5 -Day 10

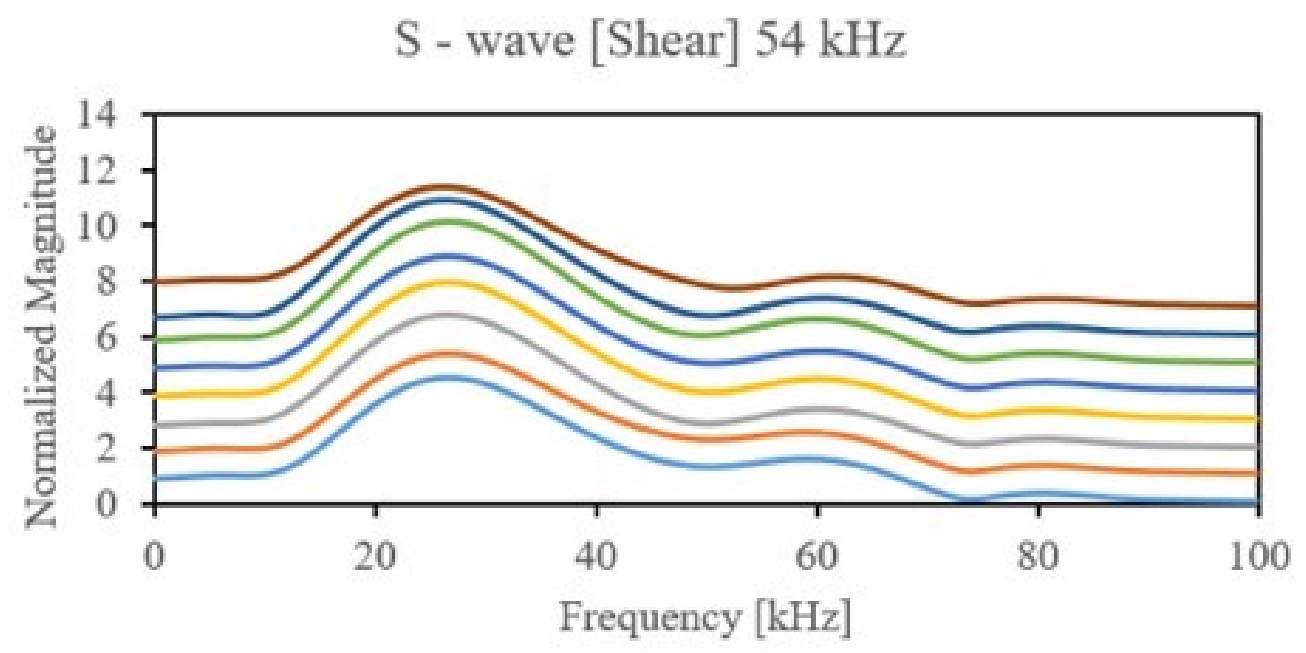

-Day 11 - Day 12 - Day 15 - Day 21

—Day 23 -Day 26 - Day 28 -Day 30 
(c)

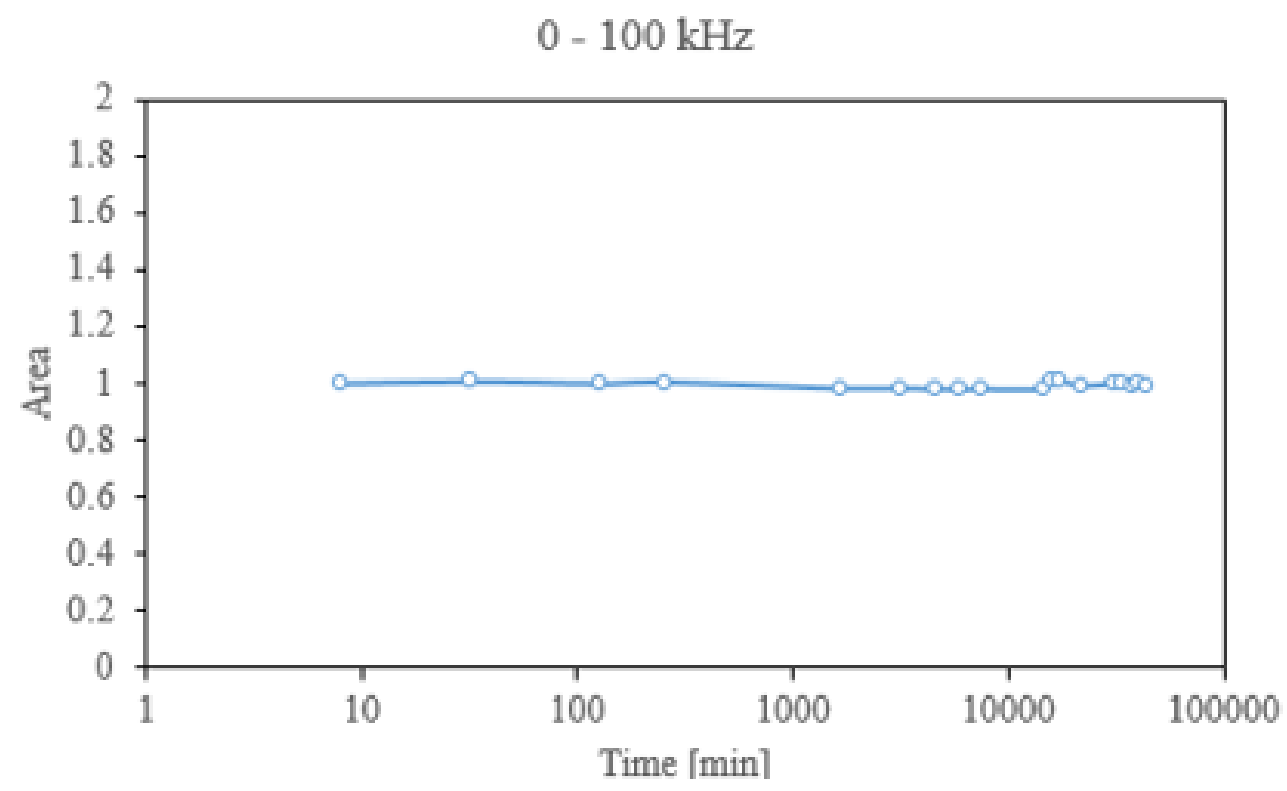

Figure 94: Window 1 (shear transmitter/receiver): (a) Time signal, (b) FFT, (c) Area under the curve in the function of time. 
(a)

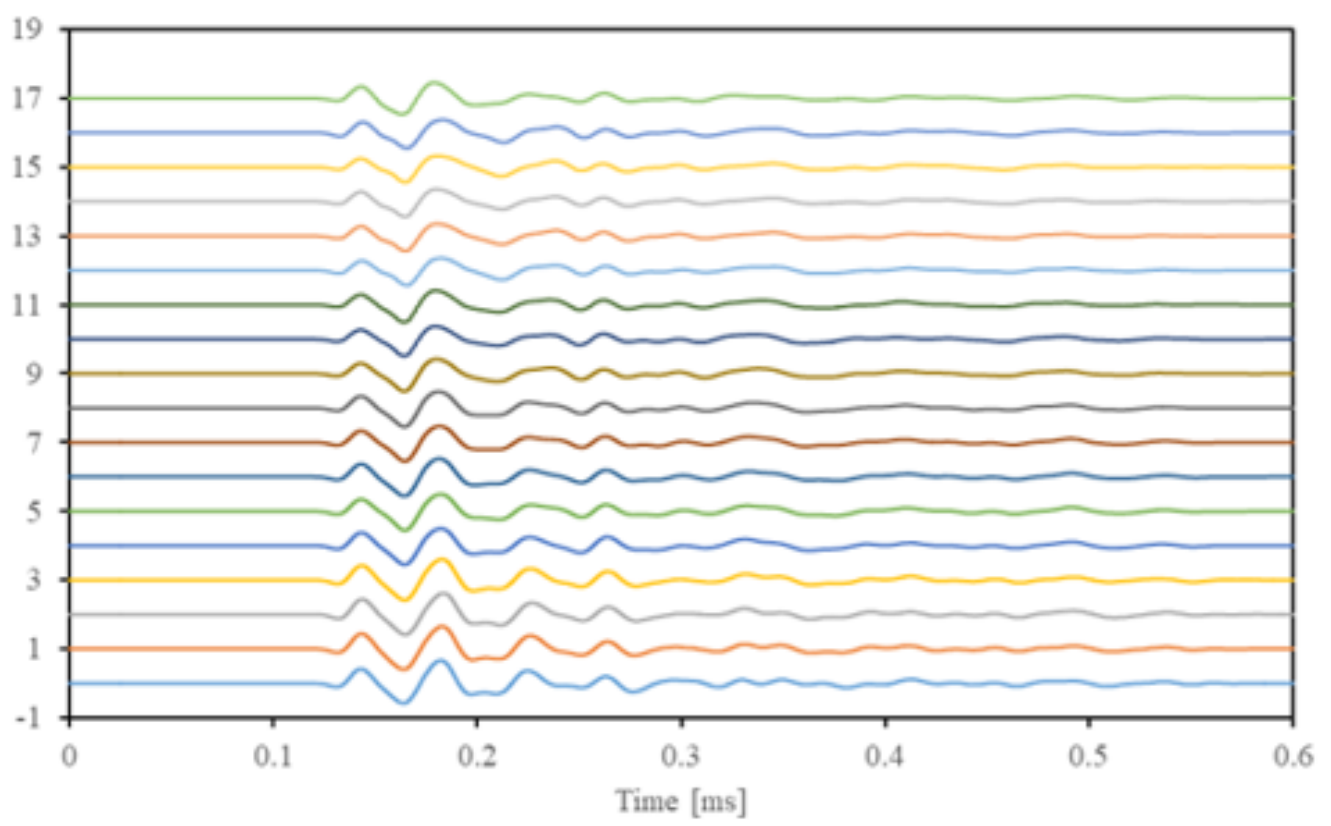

$-1 \mathrm{~min}-32 \mathrm{~min}-128 \mathrm{~min}-256 \mathrm{~min}-$ Day $1-$ Day 2

—Day 3 -Day 4 -Day 5 - Day 10 - Day 11 - Day 12

-Day 15 - Day 21 - Day 23 - Day 26 - Day 28 - Day 30 
(b)

\section{$\mathrm{S}$ - wave [Shear] $54 \mathrm{kHz}$}

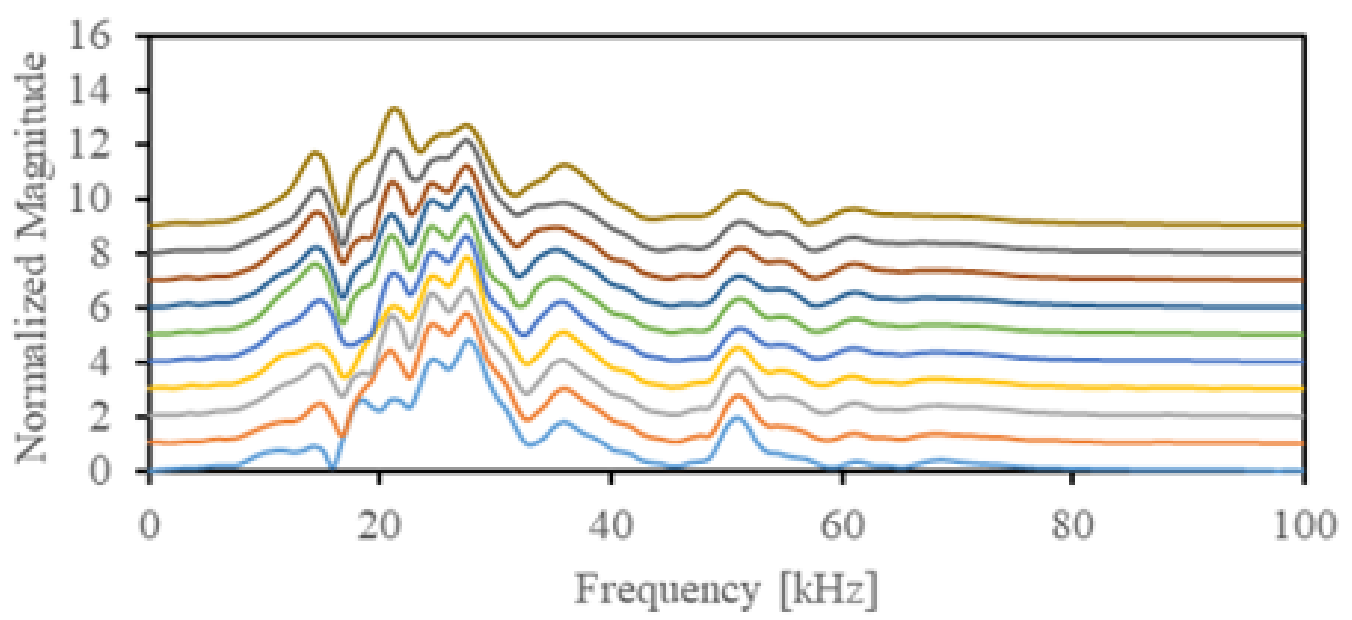

$-1 \mathrm{~min}-32 \mathrm{~min}-128 \mathrm{~min}-256 \mathrm{~min}-$ Day 1

—Day 2 -Day 3 -Day 4 -Day 5 -Day 10

$\mathrm{S}$ - wave [Shear] $54 \mathrm{kHz}$

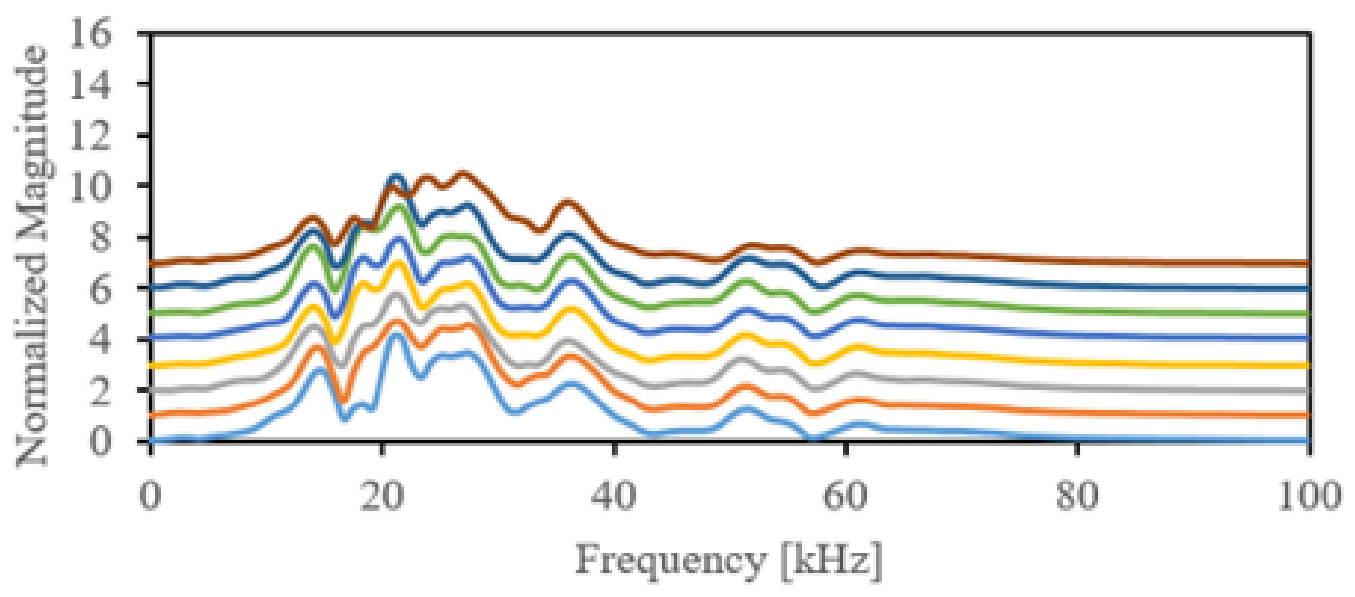

-Day 11 - Day 12 - Day 15 - Day 21

—Day 23 -Day 26 - Day 28 -Day 30 
(c)
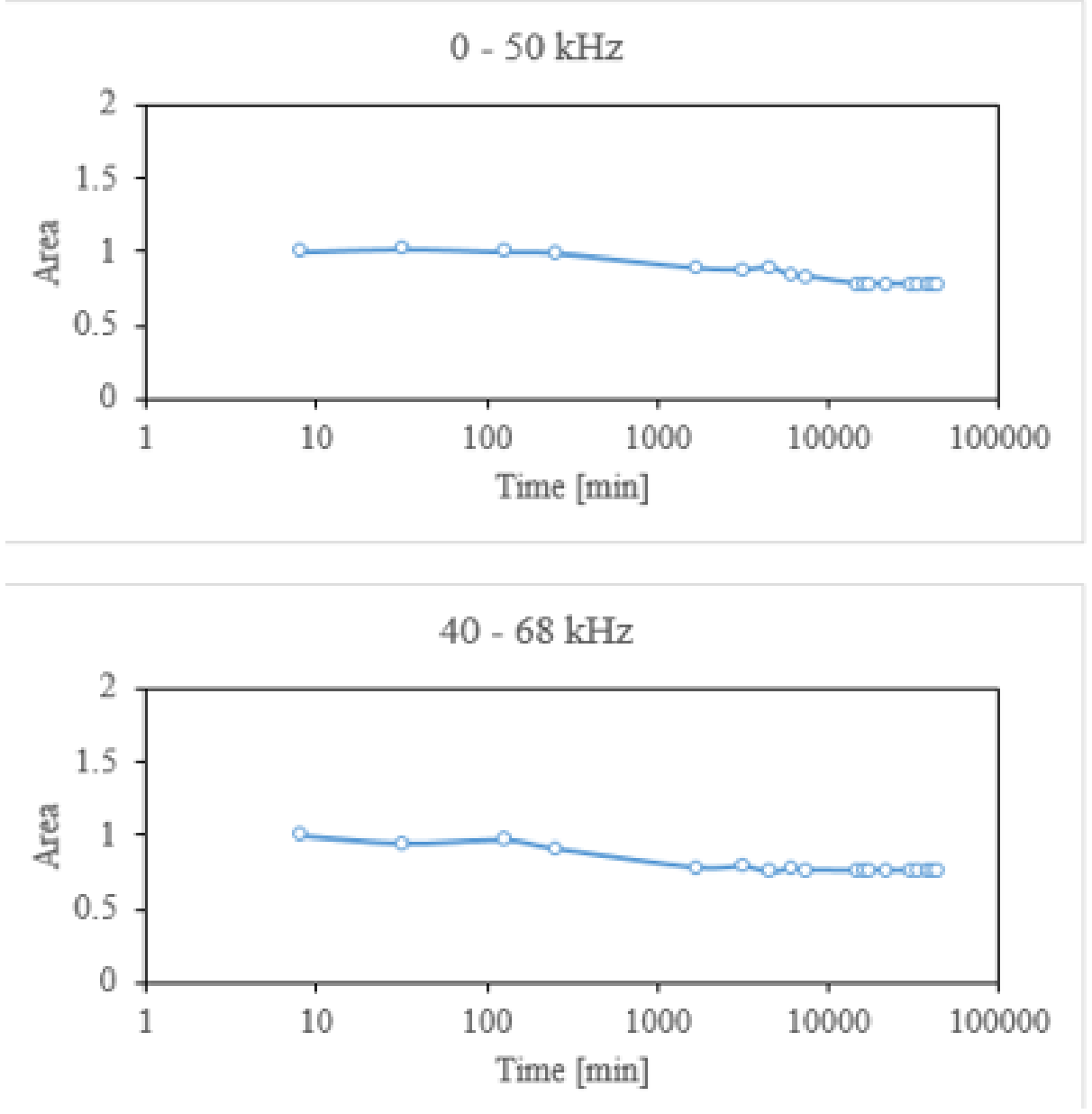

Figure 95: Window 2 (shear transmitter/receiver): (a) Time signal, (b) FFT, (c) Area under the curve in the function of time. 


\section{Appendix C}

\section{C.1 3D - Printed Equipment}

Two 3D - printed equipment were designed using AutoCAD in this study, consisting of the column and transducer holders, illustrated in Figure 94. Three separate columns with a total height of $555 \mathrm{~mm}$ and $110 \mathrm{~mm}$ in diameter as well as the holders are printed using polylactic acid materials. The advantages of using $3 \mathrm{D}$ printing for these equipment is that it allows for flexibility in designing the equipment and it also allows the tailor-made equipment to be quickly fabricated with high precision.

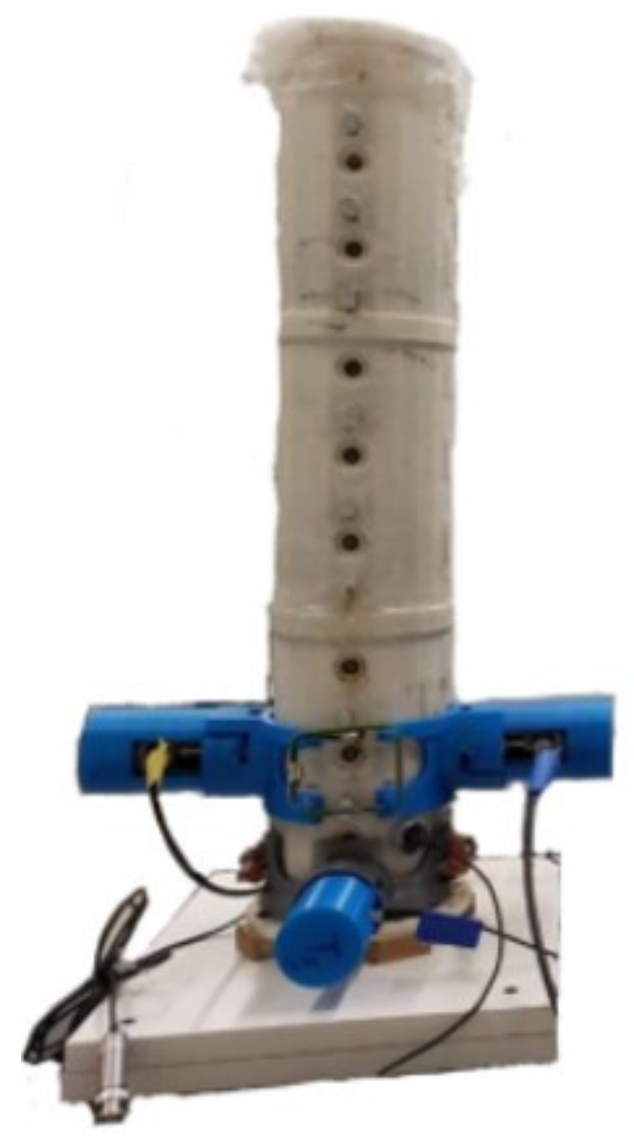

Figure 96: The 3D - holders attached at the bottom of the column. 